\title{
Phosphorus-containing carbons: preparation, properties and utilization
}

\author{
A.M. Puziy ${ }^{1^{*}}$, O.I. Poddubnaya ${ }^{1}$, B. Gawdzik ${ }^{2}$, J.M.D. Tascón ${ }^{3}$ \\ ${ }^{1}$ Institute for Sorption and Problems of Endoecology, National Academy of Sciences of Ukraine, \\ vul. Naumova 13, Kyiv, 03164, Ukraine \\ ${ }^{2}$ Maria Curie-Skłodowska University, ul. Gliniana 33, Lublin, 20-614, Poland \\ ${ }^{3}$ Instituto Nacional del Carbón, INCAR-CSIC, C/Francisco Pintado Fe 26, 33011 Oviedo, Spain
}

\section{Abstract}

Heteroatom doping of carbon materials modifies their chemical and electronic properties. Phosphoruscontaining carbon materials are reviewed by focusing on their preparation, properties and applications. The preparation methods include carbonization of carbon precursors with phosphorus compounds, modification of already prepared carbons and deposition of carbon and phosphorus from the gas phase. Phosphorus in carbons occurs mainly bound to oxygen, even in carbons obtained using oxygen-free compounds. The most common structure is pentavalent tetra-coordinated phosphorus as in phosphates; however, some $\mathrm{P}-\mathrm{O}$ bonds may be replaced with $\mathrm{P}-\mathrm{C}$ bonds. Phosphorus species bind to the active sites of carbon rendering stability to P-containing carbons. This defines the properties of P-containing carbons: hydrophilic acid surface and chemical stability, which are beneficial in a wide range of technologically important applications. P-containing carbons show a high adsorption capacity for metal ions and organic molecules with basic nature. P-species of acidic nature impart carbon a catalytic activity in diverse reactions useful in the production of commodity chemicals and biomass transformation. P-species alter the optical properties of carbons suitable in energy production, protection of the environment or bioimaging. Finally, P-species make carbons suitable for many electrochemical applications like energy storage (EDLC, Li-ion batteries) or in fuel cells.

\section{Content}

PHOSPHORUS-CONTAINING CARBONS: PREPARATION, PROPERTIES AND UTILIZATION. .1

ABSTRACT .............................................................................................................................................................................

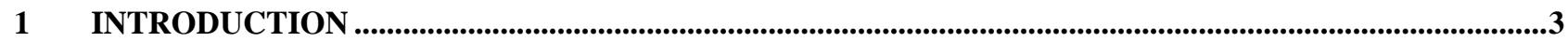

2 PREPARATION OF PHOSPHORUS-CONTAINING CARBONS .................................................................5

2.1 ROUTE 1 - METHODS BASED ON A CARBON-CONTAINING PRECURSOR …….......................................................

2.1.1 Route 1a-Carbonization of a carbon-containing precursor mixed with a phosphorus-containing

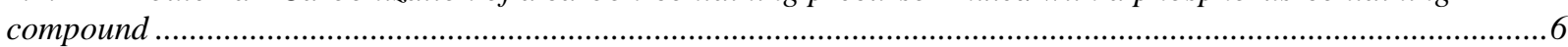

2.1.2 Route $1 b$-Carbonization of a carbon-containing precursor chemically bonded with a phosphorus-

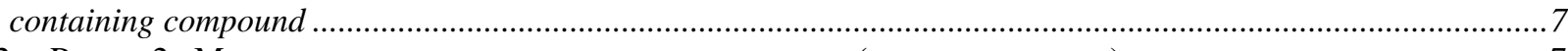

2.2 ROUTE 2 - METHODS BASED ON A PREFABRICATED CARBON (POST-TREATMENT) ……......................................

2.3 ROUTE 3 - CO-DEPOSITION OF CARBON AND PHOSPHORUS FROM THE GAS PHASE ................................................ 8

\footnotetext{
*Corresponding author. E-mail: alexander.puziy@ispe.kiev.ua
} 


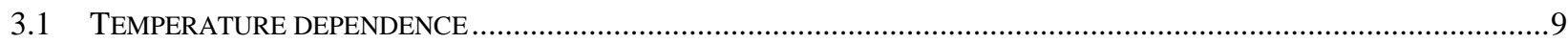

3.1.1 Route 1 - Methods based on a carbon-containing precursor .......................................................... 9

3.1.2 Route 2 - Methods based on a prefabricated carbon (post-treatment)...............................................14

3.1.3 Route 3 - Co-deposition of carbon and phosphorus from the gas phase ................................................ 16

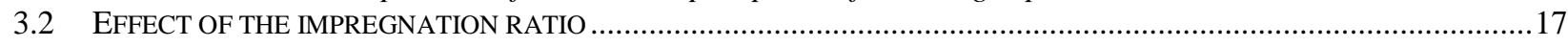

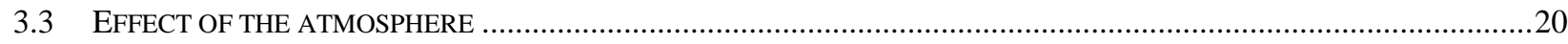

3.4 EFFECT OF CARBON REACTIVITY (CARBONIZATION TEMPERATURE) …...............................................21

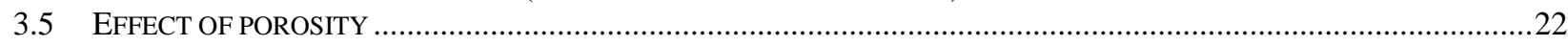

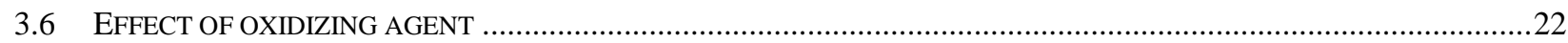

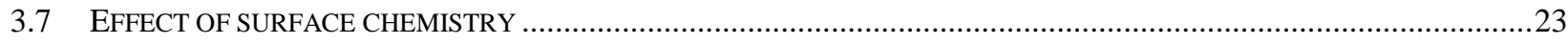

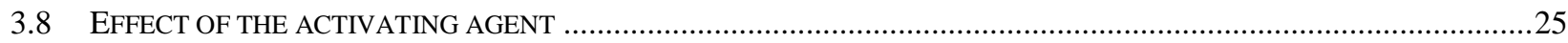

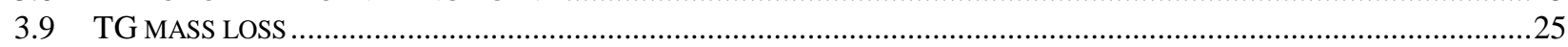

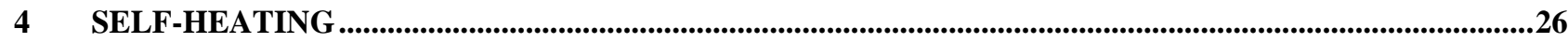

5 CHEMICAL STATE OF PHOSPHORUS IN P-CONTAINING CARBONS ..........................................27

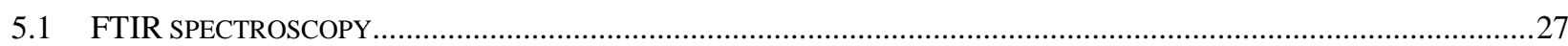

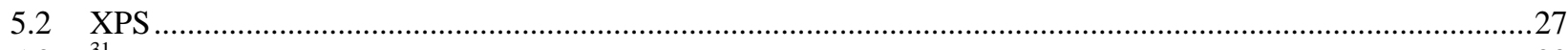

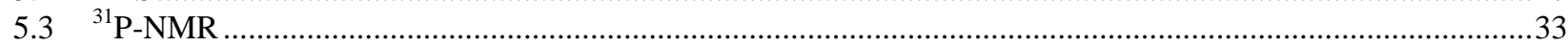

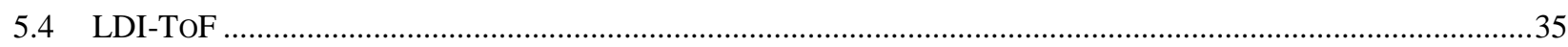

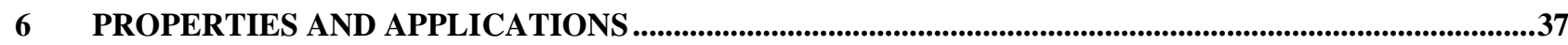

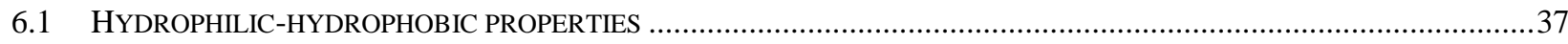

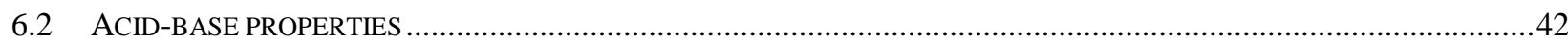

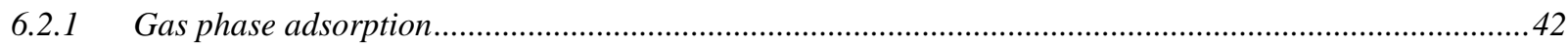

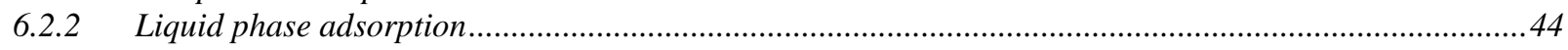

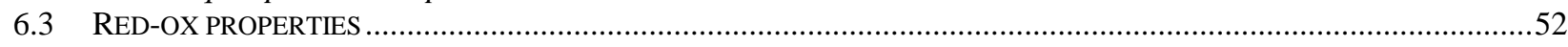

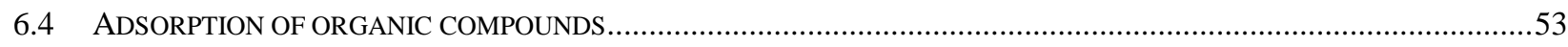

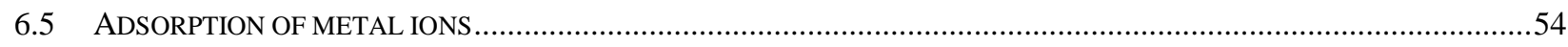

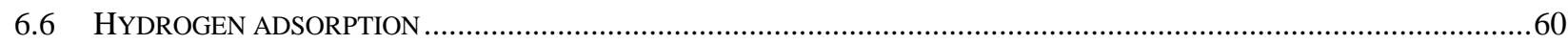

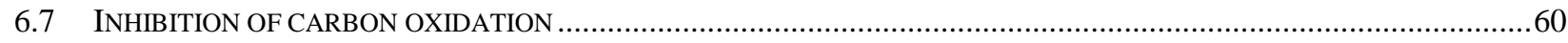

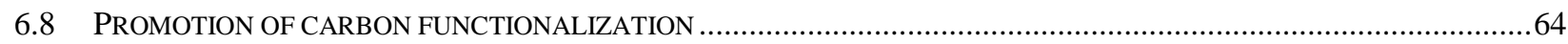

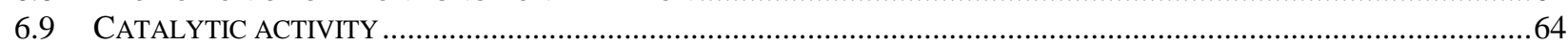

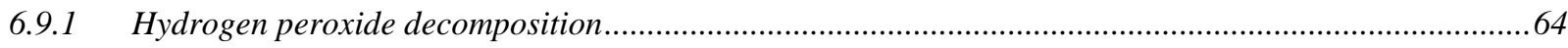

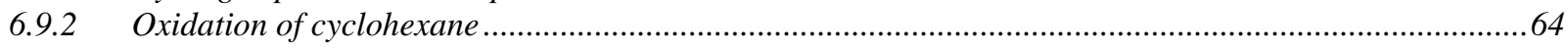

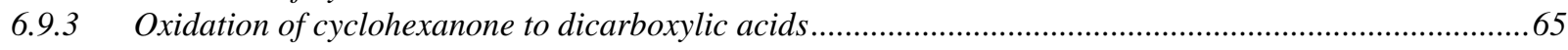

6.9.4 Oxidation of benzyl alcohols to benzaldehydes ..............................................................................65

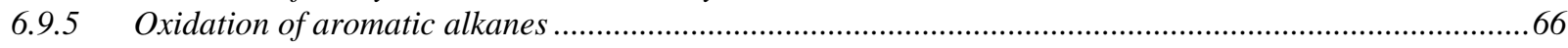

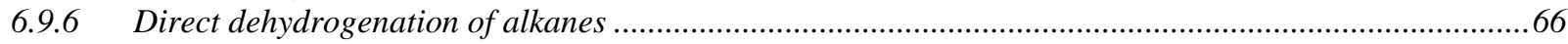

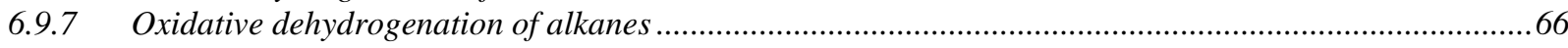

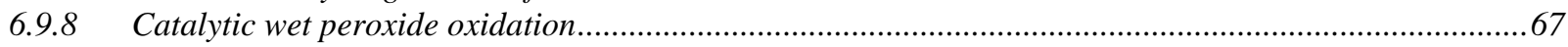

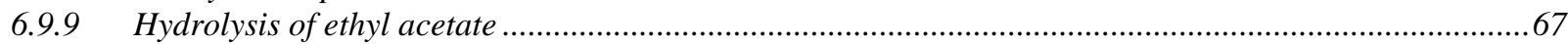

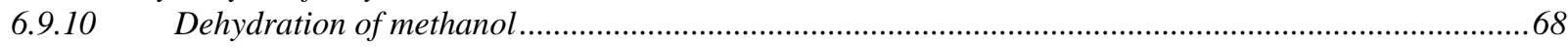

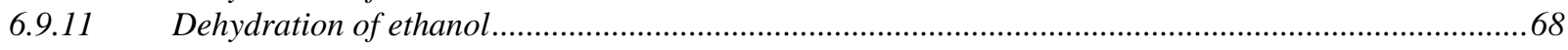

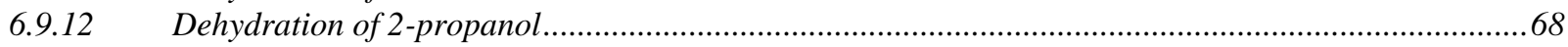

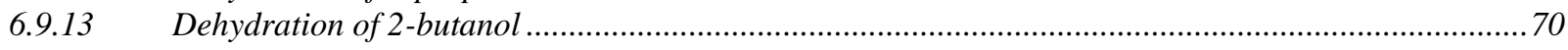

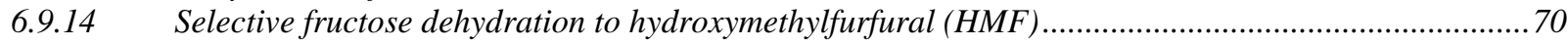

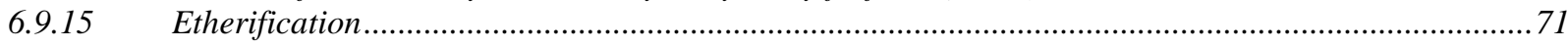

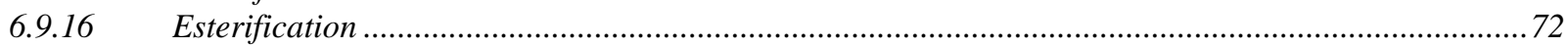

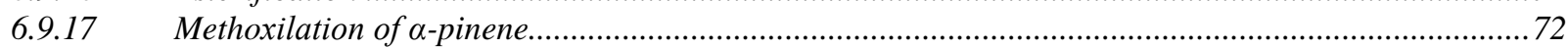

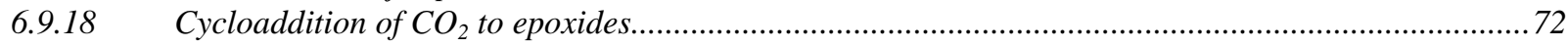

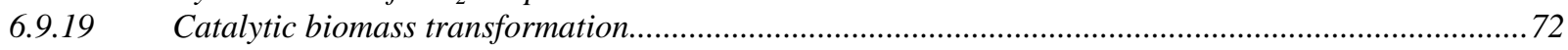

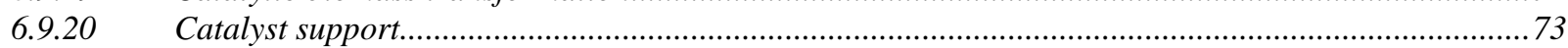

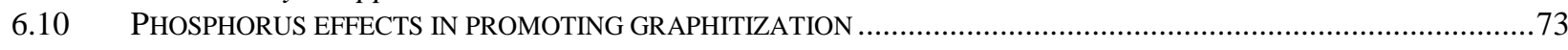

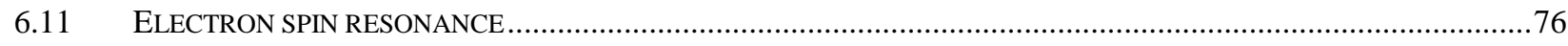

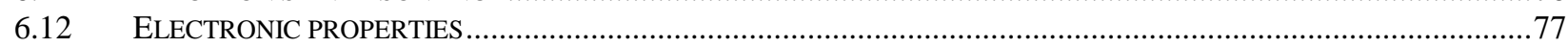

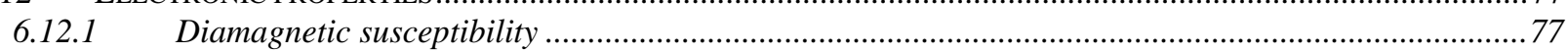

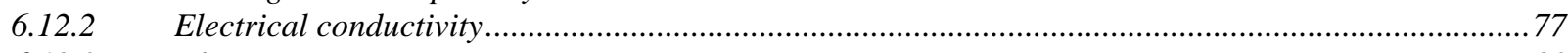

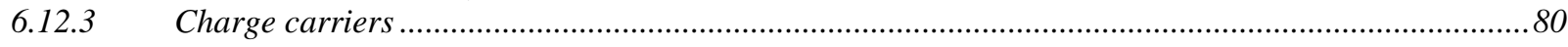

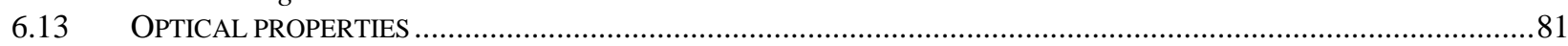

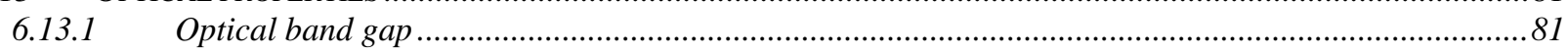

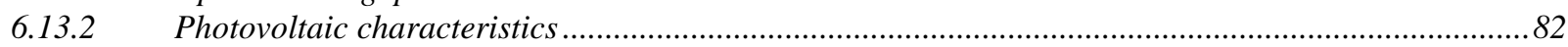

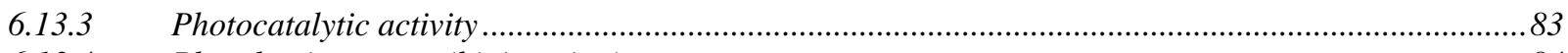

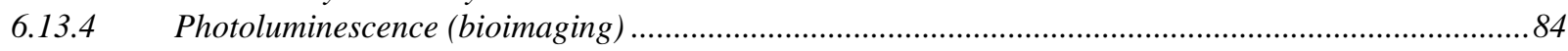




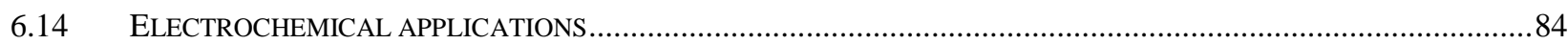

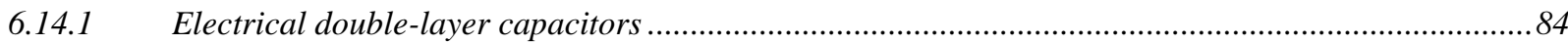

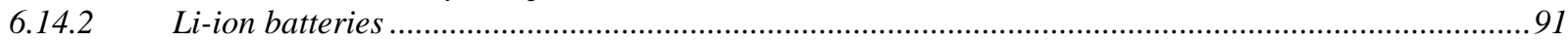

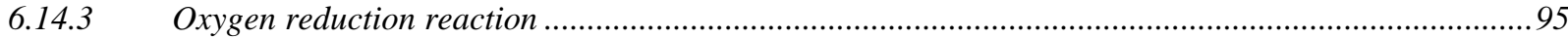

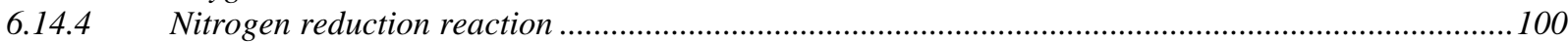

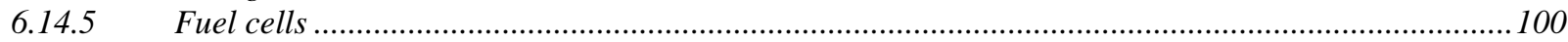

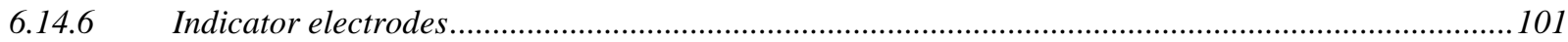

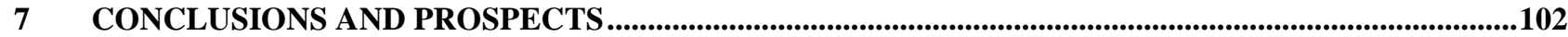

\section{Introduction}

As it is well known, carbon materials practically always contain elements other than carbon, which are collectively referred to as "heteroatoms". These elements are present in carbons for different reasons: they are either derived from the precursor or the preparation method, added purposely to modify the properties of the resulting carbon materials, or incorporated upon simple exposure of the carbon material to the ambient atmosphere (the case of many oxygen- and hydrogen-containing species). The last two elements are by far the most abundant heteroelements present in carbons, followed by nitrogen. Less frequent are boron, sulfur, phosphorus and halogens. These elements can either be alone (i.e., accompanying only carbon), or associated with each other (e.g., $\mathrm{H}, \mathrm{N}, \mathrm{S}$ or $\mathrm{P}$ together with $\mathrm{O}$ in form of oxygenated functional groups).

As concerns their mode of combination, if one focuses on $\mathrm{sp}^{2}$-bonded carbons for the sake of simplicity, heteroatoms can be either incorporated to the basal planes (e.g., quaternary nitrogen), or to their edges in form of a myriad of possible functional groups. In the former case, the incorporated elements will create electron-rich or electron-poor reactive unsaturations, whereas functionalities are known to give rise to a rich carbon surface chemistry.

As indicated above, oxygen is inevitably present in carbon materials and imparts them acidic properties [1-4] and hydrophilicity $[2,3,5]$. This results in enhanced metal ion binding $[6,7]$, adsorption of polar molecules [8] and catalytic activity in acid-catalyzed reactions $[9,10]$. The inclusion of nitrogen in the structure of the carbon increases the amount of basic groups and changes the charge in the graphene layers $[11,12]$. This results in enhanced anion-exchange capacity [6], catalytic activity in oxidation-reduction reactions [13-15] and enhanced electrochemical activity [16]. Boron can replace the carbon atom in the graphite structure influencing the structural, electronic and some other properties $[17,18]$. Also, boron in the carbon structure imparts oxidation inhibition to carbon materials [18-23]. B-doped carbons show an 
enhanced electrochemical behavior in supercapacitors [24-27] and in Li-ion batteries [28-30]. Sulfur in S-doped carbons may exist in different oxidation states and modes of combination (Simpregnated, S-functionalized and S-intercalated) [31-33]. Accordingly, this element confers to carbons a wide variety of properties and applications. Several forms of sulfur (C-S-C, S-O and S-H) improve the performance of carbons for heavy metal adsorption [32], $\mathrm{H}_{2}$ storage and $\mathrm{CO}_{2}$ capture [32], photocatalytic destruction of contaminants [32-35], or in energy related applications [3133], whereas sulfonated carbons (containing $-\mathrm{SO}_{3} \mathrm{H}$ groups) are of particular interest as solid acid catalysts for biodiesel production and biomass conversion [32,36]. $\mathrm{Cl}$ - and $\mathrm{Br}$-doping increases carbon hydrophilicity, resulting in increasing water adsorption at low relative pressures and heat of immersion in water [2]. Cl-doping enhances the acidic properties of carbons $[37,38]$. Bromination increases mercury adsorption by activated carbons $[39,40]$. Contrary to other halogens, fluorination results in a hydrophobic surface which almost does not adsorb water molecules [41,42]. Halogenation ( $\mathrm{F}, \mathrm{Cl}, \mathrm{Br}, \mathrm{I})$ effectively improves the electrochemical behavior of carbon materials in supercapacitors [43] and Li-ion batteries [44-47].

In comparison with oxygen $[2,3,7,48-55]$ and nitrogen $[7,14,15,53,56-66]$ heteroatoms, phosphorus has received much less attention. This is reflected in only some brief mention to phosphorus-containing carbons in reviews on much broader subjects $[17,49,53,67-71]$ and incomplete reviews restricted to the effect of phosphorus on carbon adsorbents $[72,73]$. Only the property of phosphorus heteroatom to inhibit oxidation of carbon materials was investigated in depth due to its practical importance for the aerospace industry [68]. The interaction of organic materials with different phosphorus compounds was also studied for developing flame retardant formulations [74-81]. However, other properties of phosphorus-containing carbons have not received sufficient attention, which restricts their application. The absence of systematic studies on phosphorus-containing carbons is strange considering that phosphoric acid activation is widely used in the industry and also in scientific research for the production of carbon adsorbents $[82,83]$; porous carbons resulting from this preparation method usually contain phosphorus incorporated from phosphoric acid, although its presence has been neglected by many authors.

In a recent review on mesoporous templated carbons [84], phosphorus has been named "the next heteroatom to be explored". According to these authors, "The scarce reports available on phosphorus-doped porous carbon materials call for future research on this heteroatom", and "Even though phosphorus remained somewhat less popular, it has been widely used as co-dopant in order to obtain multifunctional carbon materials". Certainly, this element has a rich chemistry, involving different oxidation states, that deserves being exploited to modify carbons in general (not only mesoporous templated carbons). This survey provides a review of the preparation, the 
chemical structure of phosphorus species, the properties and the applications of phosphoruscontaining carbons. In preparing this review, we tried to answer the following questions: (i) what is the chemical structure of P-species in carbons?; does the chemical structure of P-species depend on the preparation method?; (ii) what are the properties specific to P-carbons and how do they depend on the chemical structure of P-species?; (iii) in what applications could the properties specific to P-carbons be utilized, or where could P-carbons be advantageous over other carbons?

\section{Preparation of phosphorus-containing carbons}

The approaches for introducing phosphorus into the carbon structure may be classed into three main groups depending on the precursor used for preparation (Fig. 1). The first route comprises the heat treatment of a carbon-containing precursor either mixed or chemically bonded with a phosphorus-containing compound. A second route includes the modification of a prefabricated carbon material with a phosphorus-containing compound, usually at high temperature. A third route involves the co-deposition of carbon and phosphorus from the gas phase.

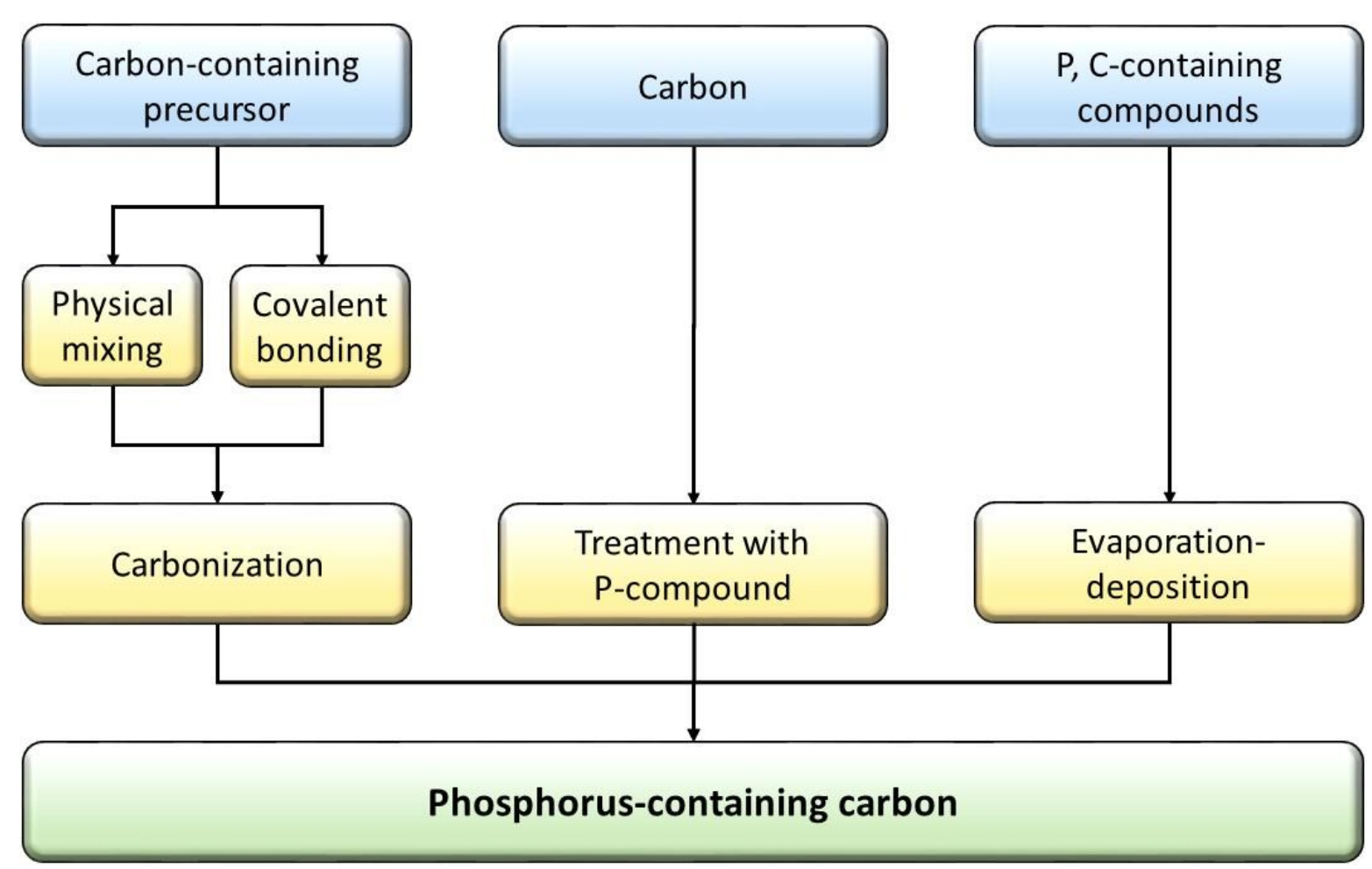

Fig. 1 Diagram of methods used for the preparation of phosphorus-containing carbons. 


\subsection{Route 1 - Methods based on a carbon-containing precursor}

2.1.1 Route 1a - Carbonization of a carbon-containing precursor mixed with a phosphoruscontaining compound

\subsubsection{Carbonization of a carbon-containing precursor mixed with $\mathrm{H}_{3} \mathrm{PO}_{4}$ (phosphoric acid activation)}

A wealth of publications exists on phosphoric acid activation of different precursors including lignocellulosic materials, separate components of biomass (cellulose, lignin), coals, polymers or individual chemicals. Although the majority of the published studies did not take into account the possible introduction of phosphorus, there is a sufficiently large amount of publications that report phosphorus introduction in the carbon structure.

In this review we will discuss only papers where at least an analysis for $\mathrm{P}$ in the corresponding carbons is included (or preferably, where some characterization of $\mathrm{P}$ species has been carried out). Papers on carbons obtained by chemical activation with phosphoric acid (or other methods) where occurrence of $\mathrm{P}$ can only be inferred by comparison with other papers will not be discussed here as it is impossible to correlate the properties of these carbons with the amount of mode of combination of $\mathrm{P}$ therein.

Extensive investigations of the phosphoric acid activation of wood $[85,86]$ allowed to propose a mechanism of activation [82,87], which appears to be valid for the activation of other lignocellulosic materials [88,89] and coals [90-92]. Phosphoric acid functions both as an acid catalyst to promote bond cleavage and the formation of cross-links via cyclization and condensation reactions, and to combine with organic species to form phosphate and polyphosphate bridges that connect and cross-link biopolymer fragments. The addition (or insertion) of phosphate groups drives a process of dilation that, after removal of the acid, leaves the matrix in an expanded state with an accessible pore structure. Essentially, this is the activation process. At temperatures above $450^{\circ} \mathrm{C}$, a secondary contraction of the structure occurs when the phosphate linkages become thermally unstable. The reduction in cross-link density allows the growth and alignment of polyaromatic clusters, producing a more densely packed structure with some reduction in porosity.

Activation with phosphoric acid was applied to introduce phosphorus in carbon using many different precursors such as wood [85-87,93-98], bamboo [99], lignocellulosic wastes like coconut shells [100], olive stones [95,101-103], apricot stones [104,105], date pits [106], peach pits [107], almond shells [108], pecan shells [108-111], peanut shells [112,113], corncob [114], aguaje seeds [115], apple pulp [116,117], arundo donax cane [118], cotton stalks [119,120], hemp [95,121-123], 
rice husks [124-127], jackfruit peels [128], vine shoots [129,130], sisal fibers [131], coffee grounds [132,133], smooth cordgrass [134], agave bagasse [135], artichoke leaves [136], reedy grass leaves [137], lotus stalks [138], water hyacinth [139], hay [140], biomass components like cellulose $[141,142]$ and lignin $[95,141,143-146]$, bituminous coal [91], lignite [147], synthetic polymers like epoxy resin [148], polyacrylonitrile [149,150], poly(styrene-co-divinylbenzene) [151,152], polyimide copolymer [153], polyaramid fibers Nomex [154-158] or Kevlar [159], poly(p-phenylene benzobisoxazole) fibers [160,161], polyvinyl alcohol [162,163], resorcinol-formaldehyde [25,164168], tannin-melamine-hexamine polymer [169], or individual organic compounds like glucose $[170,171]$, sucrose [172-174], aniline [175], 2-cyanoguanidine [176,177], and $\mathrm{N}, \mathrm{N}$-dimethylformamide [178].

\subsubsection{Use of other phosphorus-containing chemicals}

Other activating/modifying agents were also used like pyrophosphoric acid [179-181], polyphosphoric acid [179], $\mathrm{Na}_{2} \mathrm{HPO}_{4}$ [182], $\mathrm{NH}_{4} \mathrm{H}_{2} \mathrm{PO}_{4}$ [183], $\left(\mathrm{NH}_{4}\right)_{2} \mathrm{HPO}_{4}[93,184],\left(\mathrm{NH}_{4}\right)_{3} \mathrm{PO}_{4}$ $[185,186], \mathrm{P}_{2} \mathrm{O}_{5}[187,188]$, phosphate esters (trimetylphosphate, tributylphosphate, triethyl phosphite) $[189,190]$, guanidine phosphate [191,192], triphenylphosphine [193], phytic acid [179,194-200], or phosphorus-containing ionic liquids [201-204].

2.1.2 Route $1 \mathrm{~b}$ - Carbonization of a carbon-containing precursor chemically bonded with a phosphorus-containing compound

Route $1 \mathrm{~b}$ comprises the carbonization of a carbon-containing precursor containing a chemically bound phosphorus compound. The carbon- and phosphorus-containing precursors were prepared by polycondensation reaction [205,206], phosphorylation with $\mathrm{H}_{3} \mathrm{PO}_{4}$ [207-209], $\mathrm{H}_{4} \mathrm{P}_{2} \mathrm{O}_{7}$ [210], $\mathrm{PCl}_{3}[211,212]$, or $\mathrm{POCl}_{3}[213,214]$; also, commercially available phosphoruscontaining ion exchange resin was used $[215,216]$.

\subsection{Route 2 - Methods based on a prefabricated carbon (post-treatment)}

Route 2 involves the modification of a prefabricated carbon with a phosphorus compound, usually at elevated temperatures. For this modification, various compounds were used: phosphoric acid [217-228], $\mathrm{H}_{3} \mathrm{PO}_{4}$ without heating [229], ultrasonic-assisted anodic treatment with $\mathrm{H}_{3} \mathrm{PO}_{4}$ [230], treatment with phosphate and phosphite esters [231], methylphosphonic acid [20,232,233], $\mathrm{PCl}_{3}$ [234-237], $\mathrm{POCl}_{3}$ [20,233,238], triphenylphosphine [239-241], phytic acid [242], ammonium hexafluorophosphate [243], ionic liquids (1-butyl-3-methlyimidazolium hexafluorophosphate) [244], red phosphorus [245,246], or white phosphorus [247]. 


\subsection{Route 3 - Co-deposition of carbon and phosphorus from the gas phase}

Phosphorus-containing carbons were prepared by deposition from gas phase using gas mixtures of $\mathrm{CH}_{4}$ and $\mathrm{PCl}_{3}[17,248,249]$, toluene and triphenylphosphine [250-254], pyridine and triphenylphosphine [255], phosphonitrilic chloride trimer $\left(\mathrm{P}_{3} \mathrm{~N}_{3} \mathrm{Cl}_{6}\right.$, Sigma-Aldrich, CAS 940-71-6) as the $P$ and $N$ sources, and ethanol as the $C$ source [256].

Another technique for the preparation of phosphorus-containing carbons is radio frequency plasma-enhanced deposition using a mixture of $\mathrm{CH}_{4}$ and $\mathrm{PH}_{3}$ [257-259] or a mixture of $\mathrm{CH}_{4}$ and $\mathrm{H}_{2}$ as carbon source and red phosphorus as doping source $[260,261]$.

An alternative procedure for the preparation of phosphorus-containing carbons is laser enhanced evaporation-deposition using a camphor [262,263] or graphite [264-269] target mixed with red phosphorus.

High-frequency furnace method [270] was used for the synthesis of stable phosphorus heterofullerenes [271]. Graphite and black phosphorus were evaporated by an induction furnace at $2400^{\circ} \mathrm{C}$ in flowing helium $(300 \mathrm{hPa}, 1400 \mathrm{~L} / \mathrm{h})$. The obtained fullerenes were purified by sublimation. Laser desorption mass spectra clearly identified phosphorus-containing fullerenes $\mathrm{C}_{59} \mathrm{P}(\mathrm{m} / \mathrm{z}=739.01)$ and $\mathrm{C}_{69} \mathrm{P}(\mathrm{m} / \mathrm{z}=859.11)$. Other phosphorus-containing fullerenes with low intensity were detected $C_{58} P_{2}(m / z=757.84), C_{77} P(m / z=955.06), C_{81} P(m / z=1003.71)$ and $C_{83} P$ $(\mathrm{m} / \mathrm{z}=1027.65)$. Authors [271] stated that the composition of phosphorus-containing fullerenes obeying the formula $C_{2 n-x} P_{x}(x=1,2)$ argues against an external functionalization of pure fullerene cages, as is the fact that phosphorus-containing fullerenes can be sublimated without decomposition at high temperatures. Short air contact led to the formation of the phosphoruscontaining fullerene oxides $\mathrm{C}_{59} \mathrm{PO}$ and $\mathrm{C}_{69} \mathrm{PO}$, which could only be detected in negative mode. Longer air contact led to disappearance of signals from $\mathrm{C}_{59} \mathrm{P}$ and $\mathrm{C}_{69} \mathrm{P}$ in favor of the simultaneously growing signals of $\mathrm{C}_{59} \mathrm{PO}$ and $\mathrm{C}_{69} \mathrm{PO}$. The rapid reaction of $\mathrm{C}_{59} \mathrm{P}$ and $\mathrm{C}_{69} \mathrm{P}$ is close to the behavior of phosphine analogs.

Phosphorus-doped tetrahedral amorphous carbon films (ta-C:P) were deposited by means of a filtered cathodic vacuum arc system (base pressure was $10^{-5} \mathrm{~Pa}$, arc voltage of 32-35 $\mathrm{V}$ ) using high purity graphite (99.999\%) with different amount of red phosphorus (0.2-2 wt\%) [272,273]. Phosphorus was distributed uniformly through the film. Auger electron spectroscopy revealed approximately the same fraction of $\mathrm{P}$ atomic concentration in the films as present in the cathode by mass [272]. The calculated mass concentrations of phosphorus, ignoring the $\mathrm{H}$ content, were $0.51,1.28$ and $2.54 \mathrm{wt} \%$. Based on EELS and radial distribution function it was concluded that 
predominantly tetrahedrally bonded microstructure of the films is maintained for P-doped carbon films $[272,273]$.

Phosphorus-incorporated tetrahedral amorphous carbon (ta-C:P) films were prepared by filtered cathodic vacuum arc technology with phosphine as the dopant [274-277]. It has been shown that increasing the negative substrate bias from -20 to $-80 \mathrm{~V}$ increased the phosphorus content from 5.4 to 6.8 at\%. Further increasing the negative bias up to $-2000 \mathrm{~V}$ gradually decreased the phosphorus content to 3.4 at\% [275]. Increasing the flow rate of phosphine from 0 to $30 \mathrm{~cm}^{3} / \mathrm{min}$ at constant substrate bias $(-80 \mathrm{~V})$ increased the phosphorus content up to 16.8 at\% $[274,277]$. XPS revealed the occurrence of $10-12$ at $\%$ of oxygen, which the authors attributed to contamination upon air exposure. Increasing the phosphorus content increased the amount of $\mathrm{sp}^{2}$ hybridized carbon [277]. The relatively broad P $2 p$ envelope was deconvoluted into two contributions: a carbon-phosphorus species (C-P bonding) at $131.3 \pm 0.2 \mathrm{eV}$ and a phosphorusoxygen species (P-O bonding) at $133.3 \pm 0.2 \mathrm{eV}[274,276]$. The low-energy component was also ascribed to P-P or P-H bonding since not clear evidence for C-P bonding was observed in the $\mathrm{C} 1 \mathrm{~s}$ envelope [277].

\section{Phosphorus content}

The main factors determining the phosphorus content during carbonization with a phosphorus precursor (route 1) and modification of a preexisting carbon (route 2) are temperature and concentration of activating/modifying agent (impregnation ratio). Other factors that affect the phosphorus content are the atmosphere used during activation/modification, carbon reactivity, porosity, surface chemistry and the type of activating agent.

\subsection{Temperature dependence}

\subsubsection{Route 1 - Methods based on a carbon-containing precursor}

3.1.1.1 Route 1a-Carbonization of a carbon-containing precursor mixed with a phosphoruscontaining compound

Different amounts of phosphorus in carbons were obtained depending on the synthesis conditions. The general trend is increasing phosphorus content in carbon with increasing carbonization temperature up to $800^{\circ} \mathrm{C}$. Detailed studies reported that a maximum phosphorus content is introduced at $800{ }^{\circ} \mathrm{C}$ for phosphoric acid activated carbons from precursors of different origin including polymers [151-153,278], apricot stones [104,105] and lignosulfonate [145] (Fig. 2). The increase in phosphorus content with increasing carbonization temperature is attributed to enhancement of the intensity of the reaction with temperature. However, at higher temperatures 
$\left(>800^{\circ} \mathrm{C}\right)$ the phosphorus content decreases due to degradation of the phosphocarbonaceous species and formation of volatile phosphorus-containing compounds (phosphorus pentoxide and elemental phosphorus) as a result of reduction of the phosphates to elemental phosphorus [279]. Formation of elemental phosphorus was also observed during the phosphoric acid activation of Nomex polymer fibers [156], carbonization of alginate with $\mathrm{Na}_{2} \mathrm{HPO}_{4}$ [182] and during pyrolysis of a phosphorus-containing phenol resin [206]. The study on the oxidation protection of carbon materials by phosphorus doping also showed that the phosphorus compounds tend to evaporate from the carbon surface at temperatures higher than $800^{\circ} \mathrm{C}[68,232]$.

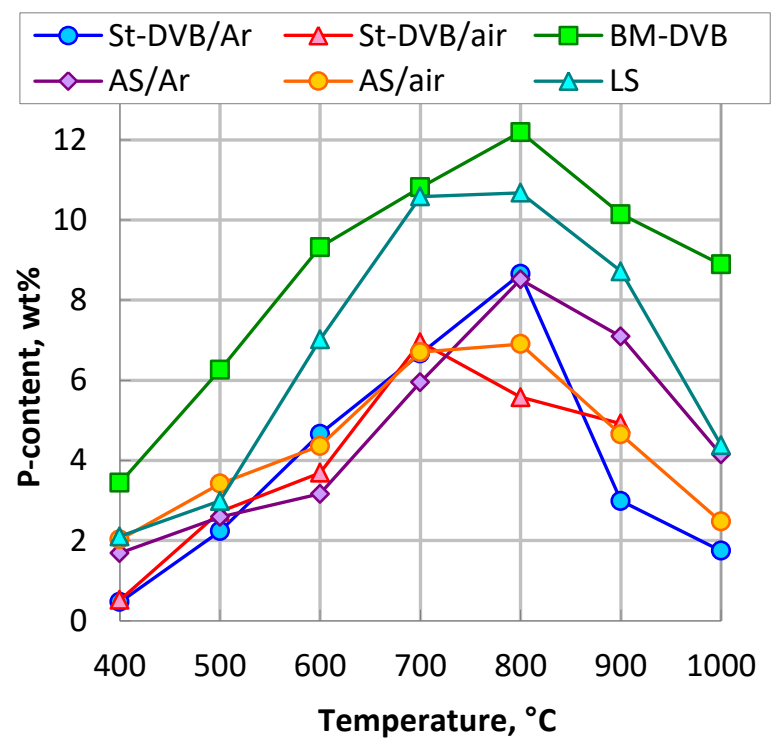

Fig. 2 Phosphorus content in carbons from styrene-divinylbenzene copolymer (St-DVB), polyimidedivinylbenzene copolymer (BM-DVB), apricot stones (AS) and lignosulfonate (LS) obtained in argon and air atmosphere. Adapted with permission from Ref. [104,105,145,151-153,278]. Copyright (2002) (2003) (2005) (2007) (2014) Elsevier, (2013) Springer.

Volatilization of phosphorus compounds may occur by the following reactions:

$$
\begin{aligned}
& 4 \mathrm{H}_{3} \mathrm{PO}_{4}+10 \mathrm{C}=\mathrm{P}_{4}+10 \mathrm{CO}+6 \mathrm{H}_{2} \mathrm{O} \\
& 4 \mathrm{H}_{3} \mathrm{PO}_{4}+10 \mathrm{C}=\mathrm{P}_{4} \mathrm{O}_{10}+6 \mathrm{H}_{2} \mathrm{O} \\
& \mathrm{P}_{4} \mathrm{O}_{10}+10 \mathrm{C}=\mathrm{P}_{4}+10 \mathrm{CO}
\end{aligned}
$$

Thermodynamic analysis showed that the Gibbs free energy for each of the reactions (1)(3) that could take place during phosphoric acid activation is negative at temperatures above $750{ }^{\circ} \mathrm{C}$ (Fig. 3), indicating that their occurrence is favorable (spontaneous) $[72,145]$. It should be noted that the reduction of phosphates by carbon at high temperatures is an industrial method for the production of phosphorus [280]. 


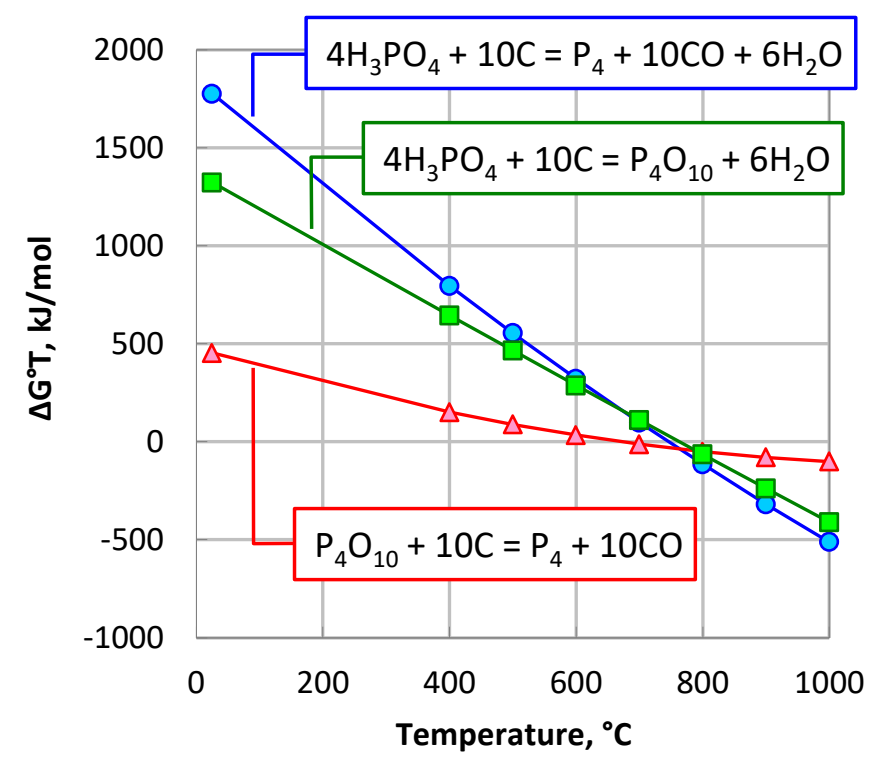

Fig. 3. Temperature dependence of the Gibbs free energy of the reactions that can occur during phosphoric acid activation. Reprinted with permission from Ref. [145]. Copyright (2014) Elsevier.

A similar tendency of increasing phosphorus content with increasing carbonization temperature up to $800{ }^{\circ} \mathrm{C}$ was also reported for carbons obtained by phosphoric acid activation of wood [93], olive stones [102], hemp [121], cellulose and Kraft lignin [141], Nomex fibers [158], sucrose [173], and polyvinyl alcohol [163].

A decreasing phosphorus content in carbons obtained by phosphoric acid activation of an epoxy resin at temperatures in the range $900-1200{ }^{\circ} \mathrm{C}$ was reported [148], which is in line with previous investigations (Fig. 4). However, the decrease tended to diminish with decreasing impregnation ratio. 


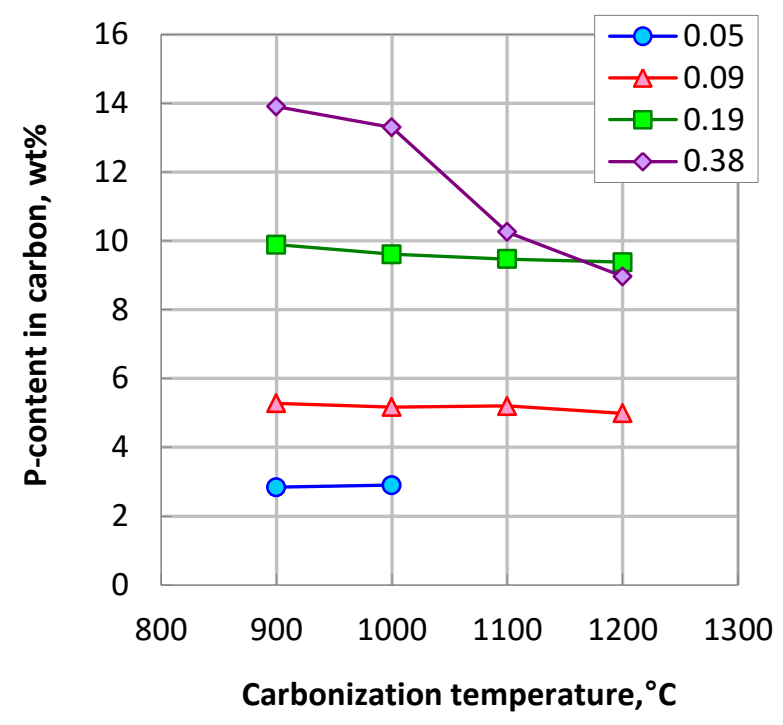

Fig. 4 Temperature dependence of phosphorus content in carbons obtained by phosphoric acid activation of epoxy resin using different impregnation ratios (indicated in the figure). Adapted with permission from Ref. [148]. Copyright (1997) Elsevier.

Phosphorus content showed a maximum at $800^{\circ} \mathrm{C}$ in carbon fibers obtained by phosphoric acid activation of poly(p-phenylene benzobisoxazole) (PBO) fibers (Fig. 5) [161]. The temperature dependence of phosphorus content tended to diminish with increasing impregnation ratio (IR).

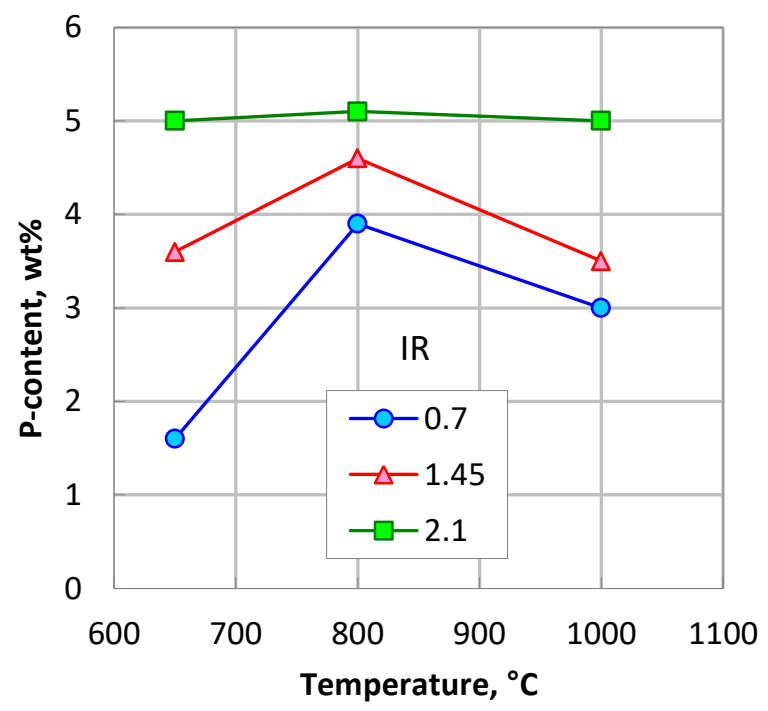

Fig. 5. Phosphorus content in PBO-derived carbon fibers with different impregnation ratio (IR) as a function of carbonization temperature. Adapted with permission from Ref. [160,161]. Copyright (2012) Elsevier, (2012) American Chemical Society.

A maximum phosphorus content was also achieved at $800{ }^{\circ} \mathrm{C}$ for aniline-based carbons obtained by phosphoric acid activation at $700-900{ }^{\circ} \mathrm{C}[175]$.

However, there are some exceptions to the trend of phosphorus content peaking at $800^{\circ} \mathrm{C}$. A decreasing P content from 2.6 to 1.5 wt\% as temperature increased from 350 to $475{ }^{\circ} \mathrm{C}$ for 
phosphoric acid activation of pecan shells was reported [109]. The decrease could be ascribed to a very high air flow of $2.5 \mathrm{~L} / \mathrm{min}$. A decreasing phosphorus content $(1.2,0.8,0.6$ and $0.6 \mathrm{wt} \%)$ with increasing carbonization temperature $\left(450,525,600\right.$ and $\left.650^{\circ} \mathrm{C}\right)$ in carbons obtained by phosphoric acid activation of Kraft lignin in air has been observed [143]. An almost linear decrease in phosphorus content with carbonization temperature between 400 and $800{ }^{\circ} \mathrm{C}$ was reported for carbons obtained by hydrothermal treatment of sucrose in the presence of phosphoric acid followed by carbonization at different temperatures [172] (Fig. 6).

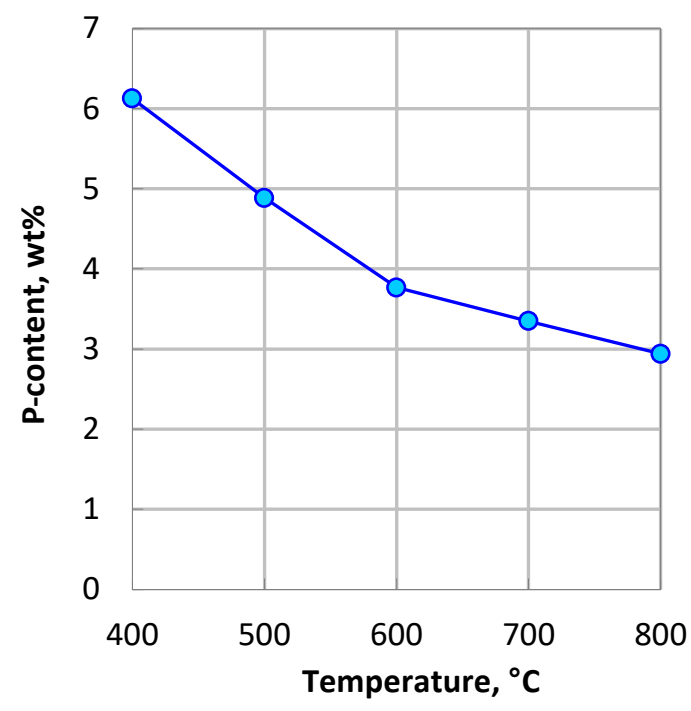

Fig. 6. Temperature dependence of phosphorus content in carbons obtained by hydrothermal treatment of sucrose in the presence of phosphoric acid followed by carbonization at different temperatures. Adapted with permission from Ref. [172]. Copyright (2011) Elsevier.

3.1.1.2 Route 1b-Carbonization of a carbon-containing precursor chemically bonded with a phosphorus-containing compound

A maximum amount of phosphorus was introduced at $800-900{ }^{\circ} \mathrm{C}$ for carbons prepared from phosphorus-containing phenol-formaldehyde resin (Fig. 7) [205,206]. 


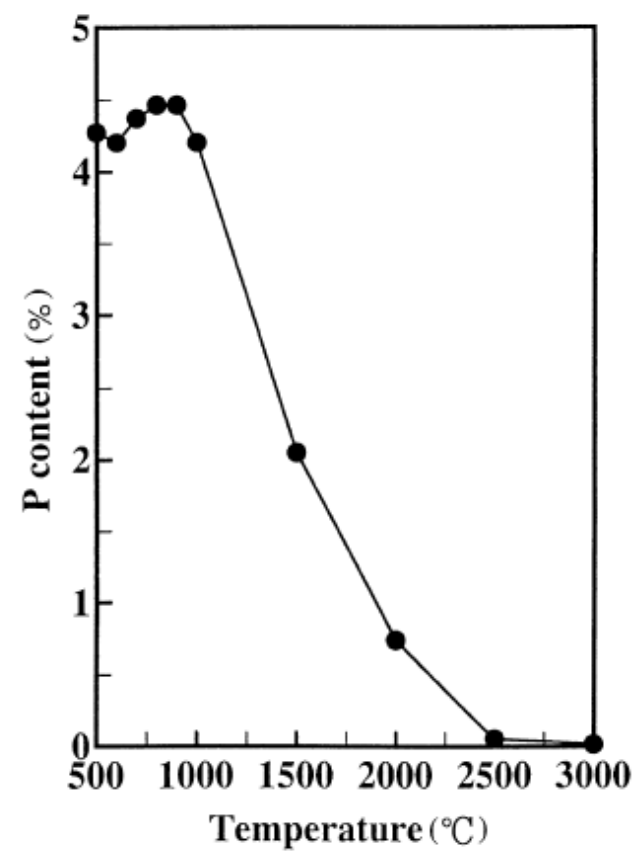

Fig. 7. Phosphorus content in carbon fibers prepared by carbonization of phosphorus-containing -phenolformaldehyde fibers at different temperatures. Reprinted with permission from Ref. [206]. Copyright (1999) Elsevier.

The phosphorus content increased when a phosphorylated phenol-formaldehyde resin was carbonized in the temperature range from 500 to $900{ }^{\circ} \mathrm{C}$ [209]. However, a decreasing phosphorus content from 3.3-3.9 to 0.6-0.8 wt\% with increasing carbonization temperature from 800 to $1500{ }^{\circ} \mathrm{C}$ was reported in carbon fibers prepared from phosphorylated viscose [208].

The highest phosphorus content that was achieved by this method is $14 \mathrm{wt} \%$ for phosphoric acid activated carbon from epoxy resin [148] and $12 \mathrm{wt} \%$ for carbon from polyimide [153].

\subsubsection{Route 2 - Methods based on a prefabricated carbon (post-treatment)}

A maximum amount of phosphorus introduced at $800{ }^{\circ} \mathrm{C}$ was also observed when prefabricated carbons were thermally treated with phosphorus compounds.

Phosphorus content peaked at $800^{\circ} \mathrm{C}$ upon reaction of coconut-based carbon with phosphoric acid at different temperatures [281]. With increasing heat treatment temperature up to $800{ }^{\circ} \mathrm{C}$, the phosphorus content increased up to $6.5 \mathrm{wt} \%$ and decreased at higher temperature (Fig. 8). 


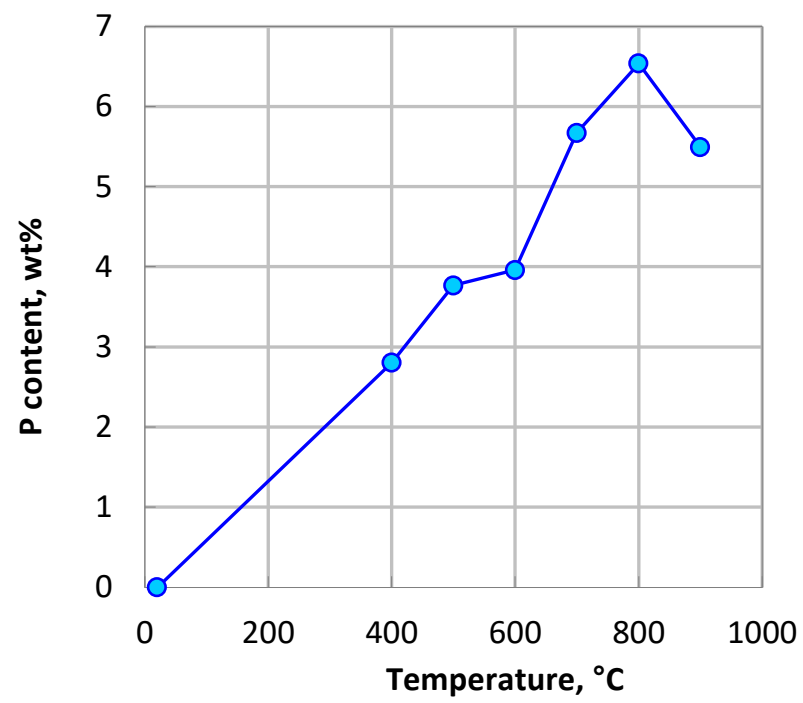

Fig. 8. Phosphorus content in coconut shell activated carbons heat-treated with phosphoric acid at different temperatures.

A maximum amount of phosphorus was introduced at $800{ }^{\circ} \mathrm{C}$ when an activated commercial peat-based carbon SKT was modified with $\mathrm{PCl}_{3}$ for 7 hours (Fig. 9) [234].

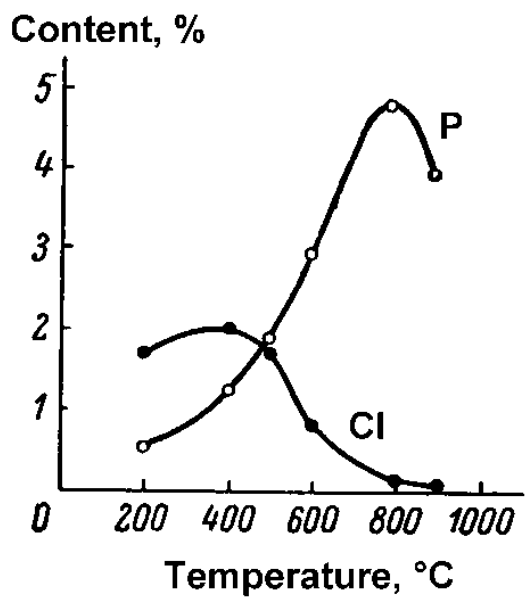

Fig. 9 The effect of temperature of phosphorylation with $\mathrm{PCl}_{3}$ on phosphorus and chlorine content introduced in carbon SKT. Adapted from [234].

The same trend of increasing phosphorus content in carbon from polyfurfuryl alcohol with increasing temperature of modification up to $800{ }^{\circ} \mathrm{C}$ using phosphorus trichloride was reported (Fig. 10) [237]. 


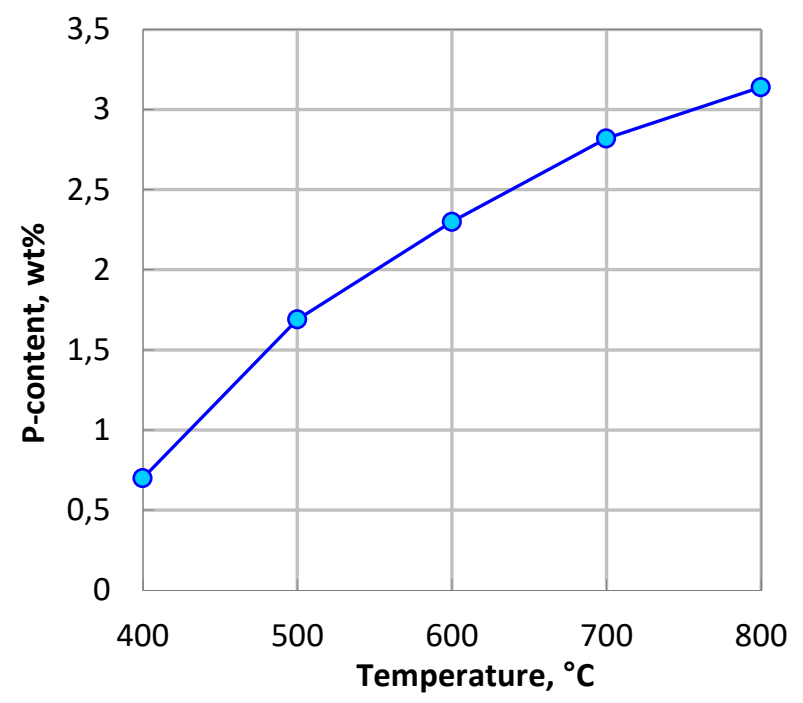

Fig. 10. Phosphorus content in polyfurfuryl-based carbons treated with $\mathrm{PCl}_{3}$ at different temperatures. Adapted from [237].

Modification of fullerene $C_{60}$ with red phosphorus in the temperature range $650-950{ }^{\circ} \mathrm{C}$ resulted in the formation of phosphorus-containing nanocrystalline graphitic structures [245]. A maximum amount of phosphorus (15 wt\%) was introduced at $800^{\circ} \mathrm{C}$.

A few instances of decreasing phosphorus content with increasing temperature up to $800{ }^{\circ} \mathrm{C}$ were reported too. This was found to occur for a $\mathrm{C} / \mathrm{C}$ composite impregnated with methanol solution of methylphosphonic acid [233] or for natural graphite impregnated with $\mathrm{POCl}_{3}$ [238]. The decrease in these cases could be ascribed to the decomposition of methylphosphonic acid and evaporation of phosphorus oxychloride at low temperatures, which decreased the concentration of the modifying agent.

The maximum amounts of phosphorus achieved by this method were $15 \mathrm{wt} \%$ for a carbon obtained by modification of fullerene with red phosphorus [245] and $6.5 \mathrm{wt} \%$ for the modification of a coconut shell activated carbon with phosphoric acid [281].

\subsubsection{Route 3 - Co-deposition of carbon and phosphorus from the gas phase}

Chemical vapor co-deposition of carbon and phosphorus from a gas mixture of $\mathrm{CH}_{4}$ and $\mathrm{PCl}_{3}$ (1 to 15 vol\%) at $1220-1730{ }^{\circ} \mathrm{C}$ showed a decreasing phosphorus content in the obtained pyrocarbons with increasing deposition temperature [248] (Fig. 11). This follows the trend of decrease in P-content above $800{ }^{\circ} \mathrm{C}$ observed for other preparation methods (see subsections 3.1.1 and 3.1.2) $[17,248,249]$. 


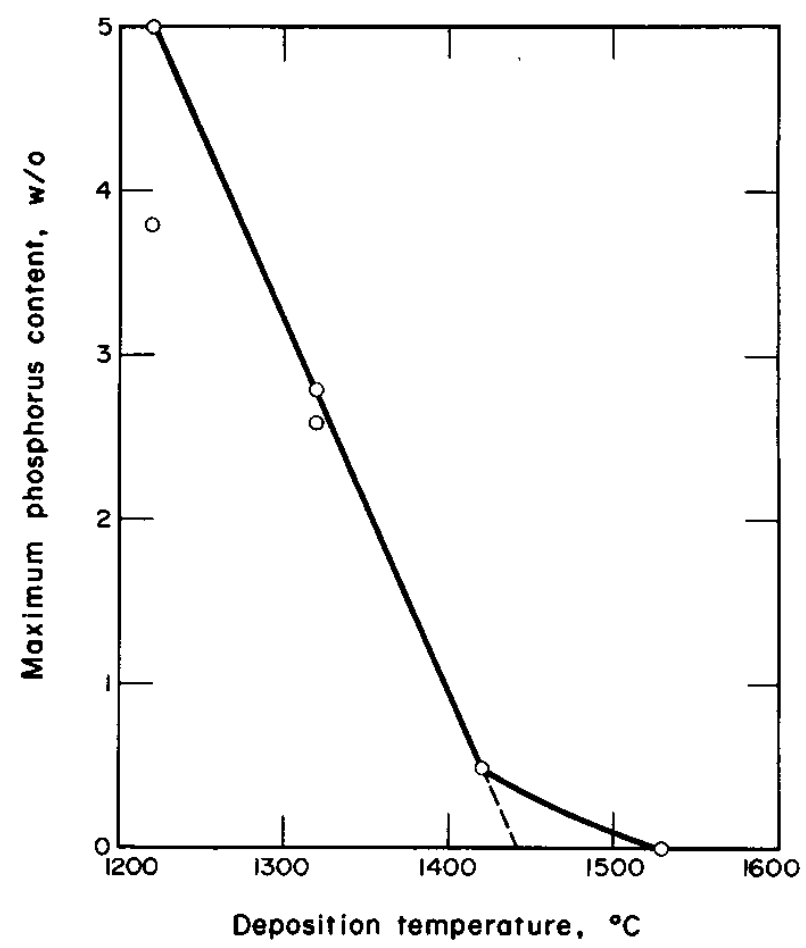

Fig. 11 Maximum phosphorus concentration retained in pyrocarbon vs deposition temperature. Reprinted with permission from Ref. [248]. Copyright (1973) Elsevier.

To summarize the effects of temperature, one can conclude that P content in carbons reaches a maximum at ca. $800{ }^{\circ} \mathrm{C}$, irrespective of the P-carbon preparation method. At lower temperatures, the extent of carbon reaction with phosphorus is low, whereas above $800{ }^{\circ} \mathrm{C}$ phosphorus compounds tend to be lost by reduction and/or volatilization. Some existing exceptions to this general trend can be easily explained by concurrence of the effects of other operation conditions.

\subsection{Effect of the impregnation ratio}

Increasing phosphorus content with increasing impregnation ratio (IR) up to 0.5 with a slight decrease at higher IR=0.75-1 was observed for carbons obtained by the template method using sucrose- $\mathrm{H}_{3} \mathrm{PO}_{4}$ mixture and silica gel as structure directing agent [174].

With increasing impregnation ratio from 0.5 to 1.25 the phosphorus content in corncobbased carbons increased from 3.2 to $4.7 \mathrm{wt} \%$ [114]. As the impregnation ratio increased from 0.5 to 1.5 , the phosphorus content in carbons obtained by phosphoric acid activation of aguaje seeds at $600{ }^{\circ} \mathrm{C}$ increased from 4.1 to $7.6 \mathrm{wt} \%$ [115]. With increasing impregnation ratio from 1 to 2 the content of phosphorus in carbons obtained by phosphoric acid activation of artichoke leaves at $500{ }^{\circ} \mathrm{C}$ increased from 0.71 to $1.16 \mathrm{wt} \%$ and decreased to $0.97 \mathrm{wt} \%$ for an impregnation ratio of 3 [136]. 
The phosphorus content increased (from 4.3-6.9 to 8.9-12.1 wt\%) with increasing impregnation ratio from 0.5 to 2.5 for carbons from cellulose or kraft lignin [141]. For carbons obtained by phosphoric acid activation of Kraft lignin at $450{ }^{\circ} \mathrm{C}$ the phosphorus content increased from 0.9 to $2.3 \mathrm{wt} \%$ as the impregnation ratio increased from 1 to 1.75 [143].

With increasing impregnation ratio from 0 to 0.74 the content of phosphorus in Kevlarbased carbon fibers increased from 0 to $5.5 \mathrm{wt} \%$ and slightly decreased to $4.5 \mathrm{wt} \%$ with further increasing the impregnation ratio to 1.97 [159]. With an impregnation ratio increasing up to 2 , the phosphorus content in PBO-derived carbon fibers increased, the effect being stronger at low concentrations of phosphoric acid (Fig. 12) [160,161].

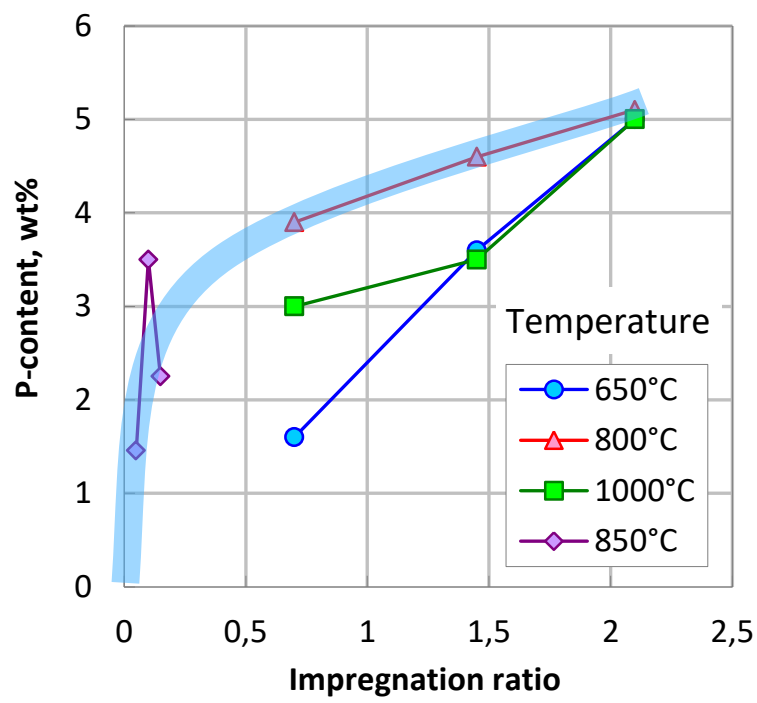

Fig. 12. Phosphorus content in PBO-derived carbon fibers as a function of the impregnation ratio (right). Adapted with permission from Ref. [160,161]. Copyright (2012) Elsevier, (2012) American Chemical Society.

The phosphorus content increased from 4.6 to $7.1 \mathrm{wt} \%$ with increasing impregnation ratio from 0.2 to 6.4 for carbons obtained by carbonization of sodium alginate impregnated with $\mathrm{Na}_{2} \mathrm{HPO}_{4}$ up to $900{ }^{\circ} \mathrm{C}$ in argon atmosphere [182]. In the case of phosphoric acid-activated carbons from sucrose, the phosphorus content increased with increasing both carbonization temperature (from 400 to $800^{\circ} \mathrm{C}$ ) and impregnation ratio (from 0.6 to 0.9) (Table 1) [173]. Further increasing the impregnation ratio to 1.2 slightly decreased the amount of phosphorus.

Table 1. Characteristics of carbons obtained by phosphoric acid activation of sucrose. Adapted by permission from Springer from Ref. [173], Copyright 2012.

\begin{tabular}{|l|l|l|}
\hline Temperature, ${ }^{\circ} \mathrm{C}$ & $\mathrm{P}, \mathrm{wt} \%$ \\
\hline \multicolumn{2}{|l|}{ Carbons obtained by treatment of sucrose with $\mathrm{H}_{3} \mathrm{PO}_{4}$} & \\
\hline
\end{tabular}




\begin{tabular}{|l|l|l|}
\hline 400 & 0.6 & 9.05 \\
\hline 800 & 0.6 & 10.57 \\
\hline 400 & 0.9 & 12.63 \\
\hline 800 & 0.9 & 15.24 \\
\hline 400 & 1.2 & 11.78 \\
\hline 800 & 1.2 & 8.82 \\
\hline Sucrose-based carbon treated with $\mathrm{H}_{3} \mathrm{PO}_{4}$ & 2.58 \\
\hline 400 & 0.9 & 2.03 \\
\hline 800 & 0.9 & \multicolumn{2}{|l|}{} \\
\hline
\end{tabular}

Increasing the amount of phosphoric acid impregnated in an epoxy resin (IR $=0-0.38)$ increased the phosphorus content in carbons obtained at temperatures in the $900-1000{ }^{\circ} \mathrm{C}$ range, while for carbons obtained at higher temperatures $\left(1100-1200^{\circ} \mathrm{C}\right)$ the increase was observed only up to an impregnation ratio of 0.2 [148]. With impregnation ratio increasing up to 0.2 , the phosphorus content increased up to 2.3 at\% in carbons prepared from dicyandiamide [176]. The Pcontent in carbons from coffee grounds sharply increased with increasing IR up to 1 and levelled off at a higher amount of phosphoric acid (2-3) [133].

A decrease of phosphorus content with increasing impregnation ratio was observed in certain cases. Thus, with increasing impregnation ratio from 0.3 to 1.8 , the content of phosphorus decreased from 1.5 to 1 wt\% in carbons from coffee grounds [132]. An increase in the impregnation ratio from 1 to 2 decreased the amount of phosphorus from 11.1 to 4.6 wt\% in carbons from hemp cane [121]. This fact was attributed to the narrow microporous structure in the monolithic activated carbon, with a very low mesopore contribution that reduced the extraction of phosphoric acid residues during the washing process.

As concerns the use of activating agents different from $\mathrm{H}_{3} \mathrm{PO}_{4}$, an increase of phosphorus content with increasing impregnation ratio was observed for activation of alginate with $\mathrm{NaH}_{2} \mathrm{PO}_{4}$ [182].

In summary: as in the case of temperature, $\mathrm{P}$ content in carbons tends to go through a maximum at intermediate values of the impregnation ratio. Thus, increasing the amount of $\mathrm{P}$ containing reagent relative to carbon precursor increases the amount of $P$ remaining in the resulting carbon material up to a certain limit, to decrease thereafter. However, in some cases, a 
continuous decrease in P content was observed with increasing IR, which could be justified based on porous texture characteristics.

\subsection{Effect of the atmosphere}

The atmosphere used during activation affects the phosphorus content; the most dramatic effect was observed for steam atmosphere. Thus, the amount of phosphorus retained in a carbon obtained by chemical activation of wood with $\left(\mathrm{NH}_{4}\right)_{2} \mathrm{HPO}_{4}$ or $\mathrm{H}_{3} \mathrm{PO}_{4}$ at $480{ }^{\circ} \mathrm{C}$ was 4.5 wt\% for nitrogen, $3.7 \mathrm{wt} \%$ for carbon dioxide, $1.5 \mathrm{wt} \%$ for air and only $0.8 \mathrm{wt} \%$ for steam atmosphere $[85,93]$. Chemical activation of wood in a steam atmosphere resulted in only $0.07 \mathrm{wt} \%$ of phosphorus in the carbon as compared to $2.2 \mathrm{wt} \%$ for nitrogen [94]. Heat treatment of woodbased carbon in steam atmosphere at $600{ }^{\circ} \mathrm{C}$ for $1 \mathrm{~h}$ decreased the phosphorus content from 2.2 to 0.14 wt\%.

The stagnant self-generated atmosphere during phosphoric acid activation resulted in a lower phosphorus content as compared to activation carried out under a nitrogen flow $[96,118]$. The difference was ascribed to an enhanced removal of water in flowing atmosphere, which facilitates the formation of polyphosphates and/or phosphate esters by the reactions:

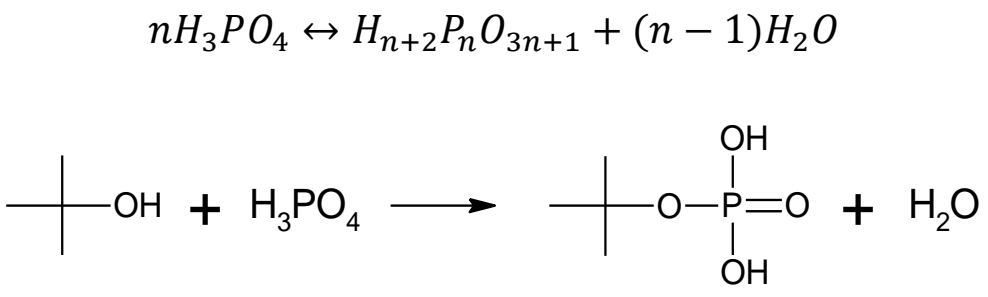

This explanation seems to hold true since an optimum flow rate of air for phosphorus introduction was reported for carbons obtained by phosphoric acid activation of pecan shells [111]. The phosphorus content increased from 0.73 to $0.87 \mathrm{wt} \%$ as the rate of airflow increased from 100 to $400 \mathrm{~mL} / \mathrm{min}$; it decreased to $0.79 \mathrm{wt} \%$ with a further increase in the flow rate to $2000 \mathrm{~mL} / \mathrm{min}$.

The phosphorus content in carbons obtained in air flow $[105,152]$ was the same as for nitrogen flow $[104,151]$ for phosphoric acid activation of both polymer and fruit stones up to $700{ }^{\circ} \mathrm{C}$; it was lower at higher temperatures.

Therefore, the most significant effect of the atmosphere during activation is that of water, which clearly reduces the amount of $\mathrm{P}$ incorporated to the resulting solid carbons. 
Introduction of phosphorus into the structure of an already prepared carbon depends on the temperature at which the carbon was prepared. Modification of a polymer-based carbon with phosphoric acid at $800{ }^{\circ} \mathrm{C}$ resulted in a higher amount of phosphorus (3.4 wt\%) for a carbon obtained at lower temperature $\left(500{ }^{\circ} \mathrm{C}\right)$ than for a carbon obtained at $800^{\circ} \mathrm{C}(1.9 \mathrm{wt} \%)$ [222]. The higher phosphorus content was ascribed to the higher reactivity of the carbon due to its low degree of carbonization.

High surface area rayon-derived activated carbon cloth obtained at temperatures lower than $1000^{\circ} \mathrm{C}$ was more prone to introduction of phosphorus by high temperature modification with methylphosphonic acid at $900{ }^{\circ} \mathrm{C}$ (phosphorus content $5.2 \mathrm{wt} \%$ ) or $\mathrm{POCl}_{3}(6.7 \mathrm{wt} \%$ of phosphorus) [20] in comparison with corresponding carbon felt obtained at $1500{ }^{\circ} \mathrm{C}(<0.05 \mathrm{wt} \%)$.

The amount of phosphorus introduced into cellulose-derived carbon fibers depended on both the carbonization temperature of the carbon fiber and the temperature of phosphorylation with $\mathrm{PCl}_{3}$ (Fig. 13) [236]. With increasing phosphorylation temperature, the amount of phosphorus in the carbon fiber increased while increasing the carbonization temperature of carbon fibers decreased the amount of phosphorus introduced at the same temperature. Phosphorylation at $400{ }^{\circ} \mathrm{C}$ resulted in 8-10 wt\% of phosphorus in carbon fibers obtained at $400-500{ }^{\circ} \mathrm{C}$ while only 23 wt\% of phosphorus was introduced into carbon fibers carbonized at $600-700^{\circ} \mathrm{C}$. The difference in susceptibility of carbon fibers to $P$ introduction was ascribed to a decreasing amount of reactive groups in the carbon fiber with increasing carbonization temperature.

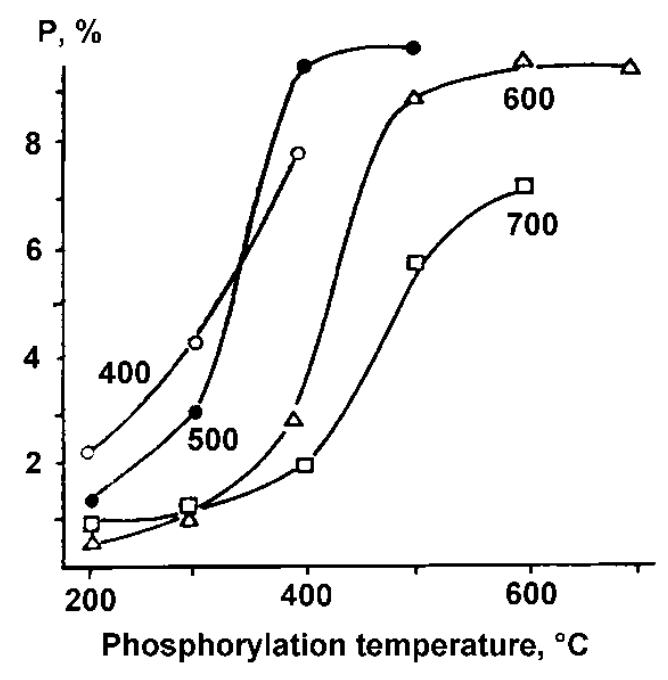

Fig. 13 The effect of temperature of phosphorylation with $\mathrm{PCl}_{3}$ on phosphorus content introduced in carbon fibers pyrolyzed at different temperatures indicated in the figure. Adapted from [236]. 
Contrary to the above trend, the phosphorus content was higher for carbons obtained by phosphoric acid activation of hay after pre-pyrolysis at $500{ }^{\circ} \mathrm{C}(6.3-6.4 \mathrm{wt} \%)$ than for direct activation (2.2-4.7 wt\%) [140].

In summary: the trends for $\mathrm{P}$ incorporation to carbons follow usual reactivity trends. Thus, more $\mathrm{P}$ is incorporated into more reactive carbons (i.e., those that have been treated at lower temperatures). On the other hand, for a given phosphorylation treatment, the higher the temperature, the higher the extent of the reaction.

\subsection{Effect of porosity}

Increasing the porosity of phenol-formaldehyde-based carbons led to an increasing phosphorus content from 2.3 to 3.5 wt\% after modification with $\mathrm{PCl}_{3}$, which was explained by increasing the available surface area of the carbon where modification took place [235].

\subsection{Effect of oxidizing agent}

Addition of an oxidizing agent, ammonium persulfate $\left(\left(\mathrm{NH}_{4}\right)_{2} \mathrm{~S}_{2} \mathrm{O}_{8}\right)$ during phosphoric acid activation of wood and lignin affected the yield, phosphorus content, porous structure and amount of surface groups of carbons [282]. It has been shown that with increasing concentration of oxidizing agent to $10 \mathrm{wt} \%$ the phosphorus content increased to 3.6-4.2 wt\% and decreased at a higher concentration of $\left(\mathrm{NH}_{4}\right)_{2} \mathrm{~S}_{2} \mathrm{O}_{8}$. Maximum conversion of carbon, porosity and amount of surface groups were also observed at $10 \mathrm{wt} \%$ of $\left(\mathrm{NH}_{4}\right)_{2} \mathrm{~S}_{2} \mathrm{O}_{8}$. The effect was explained by oxidation of the precursor, which facilitated the formation of phosphoric acid esters (Fig. 14, reactions 1-2). At concentrations greater than 10 wt\% over-oxidation occurs (Fig. 14, reaction 3), which eliminates carbon as gaseous oxides and decreases phosphorus content, as well as conversion of carbon, porosity and amount of surface groups.

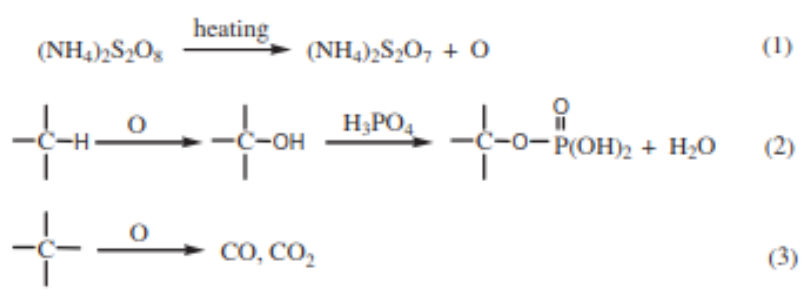

Fig. 14. Schematic of the oxidation reactions between active oxygen from $\left(\mathrm{NH}_{4}\right)_{2} \mathrm{~S}_{2} \mathrm{O}_{8}$ and the matrix during phosphoric acid activation of wood and lignin. Reprinted with permission from Ref. [282]. Copyright (2014) Elsevier.

Functionalization with an $\mathrm{H}_{3} \mathrm{PO}_{4}-\mathrm{HNO}_{3}$ mixture at $150{ }^{\circ} \mathrm{C}$ led to a higher amount of phosphorus (1.19 at\%) for graphitic carbon nanofibers obtained at $3000^{\circ} \mathrm{C}$ as compared to carbon 
nanofibers obtained at lower temperatures, 700 and $1500{ }^{\circ} \mathrm{C}(0.23-0.24$ at\%) [283]. The effect was ascribed to acidic oxidation, which resulted in the opening of the numerous closed loop ends in graphitic CNFs and in the subsequent formation of free edges, which are more prone to surface functionalization.

\subsection{Effect of surface chemistry}

The surface chemistry of carbon materials has an impact on the extent of phosphorus doping and the forms of surface phosphorus species. The reactivity of natural graphite towards modification with $\mathrm{POCl}_{3}$ was improved by pre-oxidation with $\mathrm{NaClO}$ [238]. This enhanced reactivity was ascribed to the formation, upon oxidation of the carbon surface, of polar groups, which are known to react with $\mathrm{POCl}_{3}$ to give phosphoryl derivatives and phosphate esters (Fig. 15).

SURFACE TREATMENT OF GRAPHITE

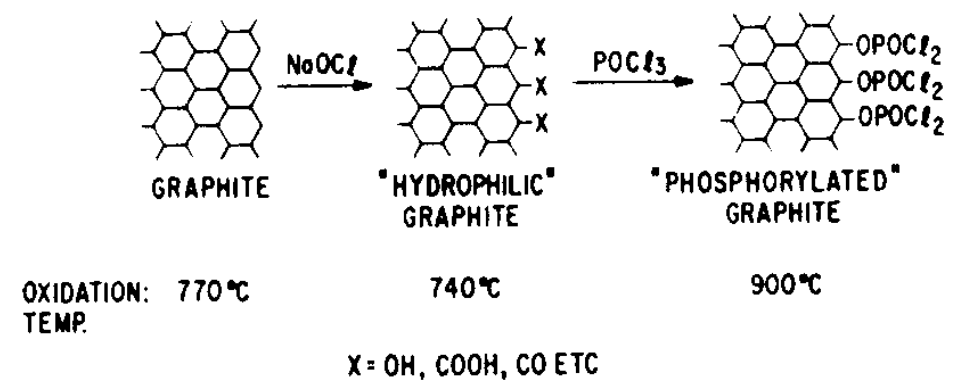

Fig. 15. Schematic representation of the surface treatment of graphite with $\mathbf{P O C l}_{3}$. Reprinted with permission from Ref. [238]. Copyright (1972) Elsevier.

A slight increase in the amount of phosphorus from 0.05 to 0.08 wt\% was reported for a low surface area carbon felt that was activated with nitric acid before treatment with $\mathrm{POCl}_{3}[20]$.

Phosphorus was introduced in an ordered mesoporous carbon (OMC) even at room temperature by stirring in $85 \mathrm{wt} \%$ phosphoric acid overnight followed by washing to neutral $\mathrm{pH}$ [229]. Even such a mild treatment at ambient temperature resulted in the incorporation of $1 \mathrm{wt} \%$ of phosphorus (as determined by XPS) in a porous carbon previously heat-treated to $850{ }^{\circ} \mathrm{C}$. It was assumed that phosphorus attachment occurred via reaction with surface functional groups such as hydroxyls, ethers and hydrides, while quinones, and to a lesser extent, carboxylic acids should be unreactive at room temperature (Fig. 16). Certainly, ring opening of ethers may occur under acidic conditions resulting in $\mathrm{C}_{-} \mathrm{OPO}_{3}$ groups, similarly to the attachment via surface hydroxyls. The amount of acid phosphate-like surface groups was estimated by the $\mathrm{NH}_{3}$-TPD technique to be $0.132 \mathrm{mmol} / \mathrm{g}$. 


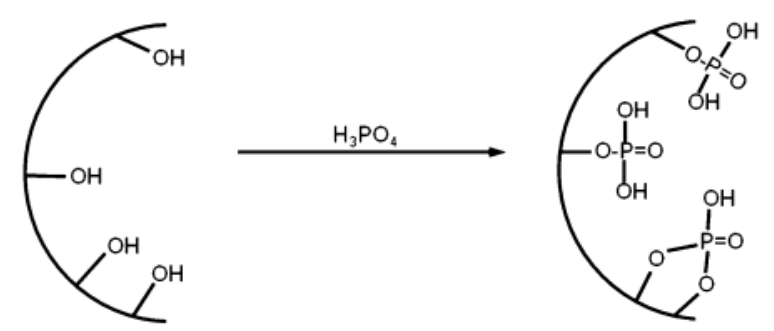

Fig. 16. Phosphorylation via attachment to surface hydroxyls. Reproduced from Ref. [229] with permission from the PCCP Owner Societies.

The carbonization temperature of the parent carbon affected the type of phosphorus species as well as phosphorus content in carbons obtained by direct modification of OMCs with phosphoric acid at room temperature [284]. With increasing carbonization temperature, the amount of surface hydroxyl groups, which are potential active sites for functionalization, decreases leading to a decrease in the phosphorus doping level and to the formation of $\mathrm{C}-\mathrm{PO}_{3}$ species rather than C-O-P species.

A phosphorus-containing carbon was obtained by ultrasonic-assisted anodic treatment of $\mathrm{C} / \mathrm{C}$ composites in an aqueous solution of $\mathrm{H}_{3} \mathrm{PO}_{4}$ [230]. About 4 at\% of phosphorus and 25 at $\%$ of oxygen was introduced in the $\mathrm{C} / \mathrm{C}$ composite. The enhanced formation of surface groups was attributed to the energy input of the ultrasound and electric field according to the scheme shown on Fig. 17.

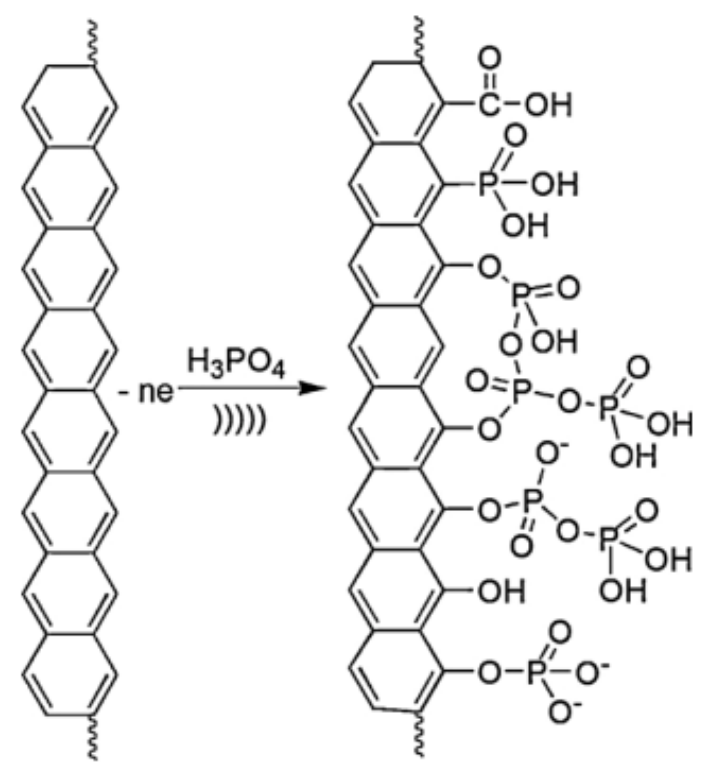

Fig. 17. Schematic representation of phosphorus groups formed on $\mathrm{C} / \mathrm{C}$ composites during ultrasonic-assisted anodic treatment. Reprinted with permission from Ref. [230]. Copyright (2012) Elsevier. 
Similarly to Section 3.4, one can conclude that the increase in reactivity brought about by occurrence of reactive functional groups produces an increase in P retention in carbons. In particular, oxidative treatments produce carbons that are simultaneously rich in $\mathrm{P}$ and $\mathrm{O}$.

\subsection{Effect of the activating agent}

Phosphoric acid was more active in phosphorus introduction into carbon (4.2 wt\%) than $\left(\mathrm{NH}_{4}\right)_{2} \mathrm{HPO}_{4}(2.6 \mathrm{wt} \%)$ during chemical activation of wood at $400{ }^{\circ} \mathrm{C}$ [93]. Phosphoric acid was also a more active agent as compared to phosphate esters for phosphorus doping in carbons obtained by carbonization of lotus stalks [190]. The phosphorus content was 1, 0.4 and 0.5 at\% for carbons activated with phosphoric acid, trimetylphosphate and tributylphosphate respectively.

\subsection{TG mass loss}

Based on the proportionality existing between mass loss at $850-1000^{\circ} \mathrm{C}$ and phosphorus content in carbons modified with $\mathrm{PCl}_{3}$ it was suggested that breaking of phosphorus-carbon bonds occurs in this temperature range [237]. This fact is supported by the appearance of an exothermal effect with maximum at about $850^{\circ} \mathrm{C}$, which is absent for non-modified carbon with only oxygencontaining surface groups [237].

Investigation of the oxidation inhibition of graphite with methylphosphonic acid showed that at $830^{\circ} \mathrm{C}$ phosphorus additives leave "zigzag" faces making them vulnerable to attack of oxygen [232]. However, at higher temperatures phosphorus species appear to remain bonded to the "arm-chair" faces up to $1050^{\circ} \mathrm{C}$.

Thermogravimetric analysis of a carbonaceous material treated with $\mathrm{H}_{3} \mathrm{PO}_{4}$ suggested that the desorption and elimination of phosphorus radicals bonded to the carbon surface occurs at $950{ }^{\circ} \mathrm{C}[218]$.

DTG curves of phosphorus-containing carbons from a polyimide copolymer exhibited a significant mass loss in the temperature range of $800-900^{\circ} \mathrm{C}$ that was linearly proportional to the phosphorus content (Fig. 18) [153]. The mass loss was ascribed to thermal breakdown of C-O-P bonding and elimination of phosphorus compounds. Mass loss in the same temperature range was also observed by other researchers and has been assigned to the rupture of C-O-P bonds and volatilization of phosphorus compounds in the form of elemental phosphorus $[140,145,155,156,159,161,285]$. 


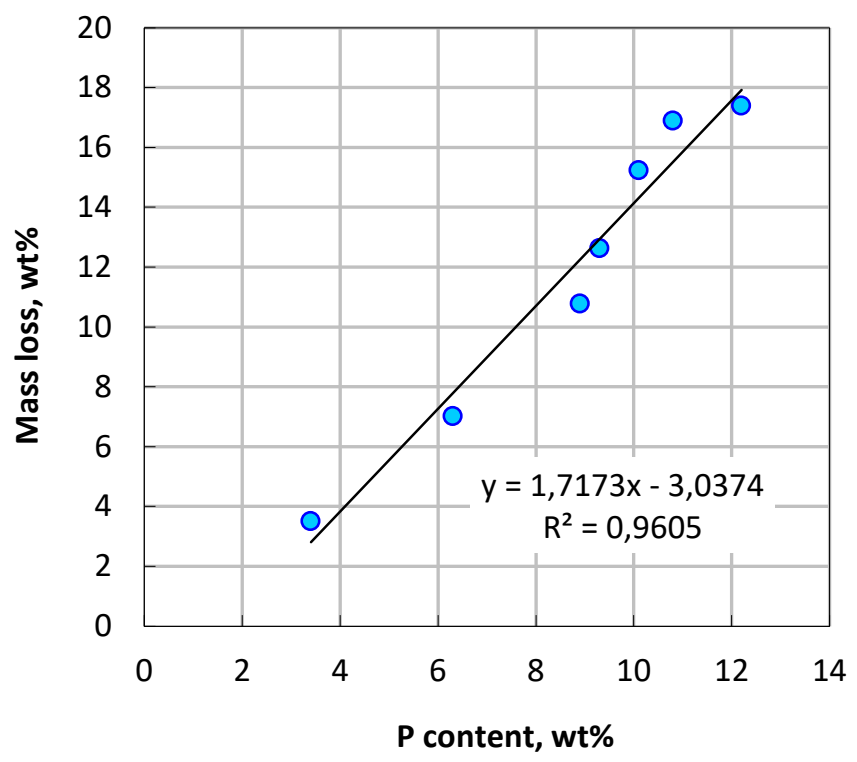

Fig. 18. Dependence of mass loss in the range of 800-900 ${ }^{\circ} \mathrm{C}$ on the phosphorus content in polyimide-derived carbons. Adapted by permission from Springer, Ref [153]. Copyright (2013).

\section{Self-heating}

An interesting self-heating phenomenon was observed for phosphorus-containing carbons from both a styrene-divinylbenzene polymer [151] and apricot stones [104]: when the carbon after phosphoric acid activation and cooling down to room temperature in an argon atmosphere was exposed to air, it was spontaneously heated. The self-heating effect was substantial - the temperature of the sample raised to $80-90^{\circ} \mathrm{C}$. This effect may be attributed to the oxidation of reduced forms of phosphorus by atmospheric oxygen or to the strongly exothermal reaction of $\mathrm{P}_{2} \mathrm{O}_{5}$ with water from the ambient atmosphere.

The same spontaneous exothermic reaction was observed when wood-based carbons just activated with $\mathrm{H}_{3} \mathrm{PO}_{4}$ and cooled in a desiccator were exposed to water or moist air [97]. The selfheating was ascribed to the exothermic reaction of $\mathrm{P}_{2} \mathrm{O}_{5}$ generated during carbonization with water or moist air.

Heating of a phosphorus-containing carbon from olive stones upon contact with air at $25^{\circ} \mathrm{C}$ just after heat treatment up to $900{ }^{\circ} \mathrm{C}$ in $\mathrm{N}_{2}$ atmosphere followed by cooling down to $25^{\circ} \mathrm{C}$ was reported [286]. The temperature increase was $6^{\circ} \mathrm{C}$ accompanied with $3 \%$ weight gain. The effect was explained by reduction of phosphorus species at high temperature in inert atmosphere to reduced species that are very reactive and could be (re)oxidized upon contact with air, even at room temperature, forming again C-O-P type groups. 


\section{Chemical state of phosphorus in P-containing carbons}

\subsection{FTIR spectroscopy}

Infrared spectroscopy provides valuable information on the chemical structure of carbon materials. Phosphorus-containing carbons usually show an absorption band between 1300 and $900 \mathrm{~cm}^{-1}$. Due to the overlap of absorption bands from many oxygen and phosphorus compounds in this region, an unambiguous assignment is difficult.

The aforementioned broad band between 1300 and $900 \mathrm{~cm}^{-1}$ typical of phosphoruscontaining carbons has a maximum at $1220-1180 \mathrm{~cm}^{-1}$ and shoulders at $1080-1060 \mathrm{~cm}^{-1}$ and $1000-$ $980 \mathrm{~cm}^{-1}[94,102-105,114,117,126,127,136,140,145,147,151,152,155,156,173]$. The intensity of this band is proportional to phosphorus content in the carbon. The shoulders may be more evident as peaks on difference spectra between a P-containing and an equivalent oxidized P-free carbon [151]. The peak at $1220-1180 \mathrm{~cm}^{-1}$ was assigned to the stretching mode of hydrogenbonded $\mathrm{P}=\mathrm{O}$ [287-289], to $\mathrm{O}-\mathrm{C}$ stretching vibrations in $\mathrm{P}-\mathrm{O}-\mathrm{C}$ (aromatic) linkage $[287,290]$ and to $\mathrm{P}=\mathrm{OOH}$ [290]. The shoulder at $1080-1060 \mathrm{~cm}^{-1}$ was ascribed to an ionized linkage $\mathrm{P}^{+}-\mathrm{O}^{-}$in acid phosphate esters $[287,288]$ and to symmetrical vibration in a chain of $\mathrm{P}-\mathrm{O}-\mathrm{P}$ (polyphosphate) [76,291]. The shoulder at 1000-990 $\mathrm{cm}^{-1}$ may be due to $\mathrm{P}-\mathrm{O}-\mathrm{C}$ (aliphatic) stretching [287-289], $\mathrm{P}-\mathrm{O}-\mathrm{C}$ (aromatic) asymmetric stretching [289], $\mathrm{P}-\mathrm{O}$ stretching in $>\mathrm{P}=\mathrm{OOH}$ [289], $\mathrm{P}-\mathrm{OH}$ bending [288], P-O-P asymmetric stretching in polyphosphates $[287,289]$ and symmetrical stretching of $\mathrm{PO}_{2}$ and $\mathrm{PO}_{3}$ in phosphate-carbon complexes [76].

In summary, FTIR spectroscopy is useful to differentiate several oxygenated species from each other (phosphates, polyphosphates, phosphate-carbon complexes), although the multiplicity of species makes band assignment somewhat ambiguous.

\section{$5.2 \quad X P S$}

XPS is a suitable method to study the elemental composition and chemical state of phosphorus in carbons. However, there is some controversy as to the interpretation of peak-fitting results connected with peak shape (taking account of spin-orbit splitting $0.84 \mathrm{eV}$ resulting in doublet peak $2 p_{1 / 2}$ and $2 p_{3 / 2}$ [292]; Gauss-Lorentz mixing function) and the standard spectra database used for assignment [292,293].

There is a great deal of evidence that phosphorus in phosphorus-containing carbons exists in pentavalent tetra-coordinated phosphorus form (phosphate-like structure). This is no surprise since the most common phosphorus source is phosphoric acid. The phosphorus atom has a great difficulty to break all the $\mathrm{P}-\mathrm{O}$ bonds present in the activating (modifying) agent like $\mathrm{H}_{3} \mathrm{PO}_{4}$ and so 
cannot be substitutionally incorporated into the carbon backbone. Another reason may be the theoretically demonstrated ability of the phosphorus atoms in a substitutional position to chemisorb oxygen, which leads to the formation of P-O bonds [294]. This explanation is supported by the experimentally observed formation of phosphate structures in phosphorus-containing carbons obtained from oxygen-free sources like graphite and black phosphorus [271], fullerene $\mathrm{C}_{60}$ and red phosphorus [245], carbon monolith and red phosphorus [246] or by chemical vapor deposition of triphenylphosphine [295].

Only one type of phosphorus was reported for wood-based carbon (obtained at $480^{\circ} \mathrm{C}$ ) with a binding energy ( $B E)$ of $134.3 \mathrm{eV}\left(\mathrm{P} 2 \mathrm{p}_{3 / 2}\right)$, which was attributed to phosphorus bound to an aromatic network via C-O-P linkage [85].

The XPS P 2p signal of a P-containing carbon obtained by phosphoric acid activation of peanut shells at $550^{\circ} \mathrm{C}$ was deconvoluted into two main peaks: one at $134.0-134.6 \mathrm{eV}$ corresponding to metaphosphate and a second peak at 133.6-134.7 eV ascribed to $(\mathrm{PhO})_{3} \mathrm{PO}$ compounds [112]. In both cases, the $\mathrm{P}$ atom is bonded to four $\mathrm{O}$ atoms by one double bond and three single bonds.

Based on a fitting scheme consisting of adding new peaks until no improvement of the goodness of fit was achieved, the temperature transformation of the chemical state of phosphorus was studied $[279,296]$. It has been shown that the major phosphorus moiety in phosphoruscontaining carbons from styrene- divinylbenzene copolymer obtained at $400-1000^{\circ} \mathrm{C}$ is pentavalent tetra-coordinated phosphorus (phosphate-like structure) with a BE of $132.90 \pm 0.4 \mathrm{eV}$. The position of the P 2p peak slightly decreases form $133.9 \mathrm{eV}$ to $133.0 \mathrm{eV}$ with increasing carbonization temperature from 400 to $500{ }^{\circ} \mathrm{C}$. The decrease in binding energy was ascribed to a transformation of phosphate esters to polyphosphates and/or to a change of the nature of the atoms surrounding the phosphorus atom [292]. A similar trend was reported for phosphoric acid activated carbon fibers from sisal [131]. For carbons obtained up to $800{ }^{\circ} \mathrm{C}$ phosphate/polyphosphate was the only phosphorus species; at $900{ }^{\circ} \mathrm{C}, 5 \%$ of phosphorus pentoxide appeared (BE $136.0 \mathrm{eV}$ ), which disappeared at $1000^{\circ} \mathrm{C}$; instead, $5 \%$ of red phosphorus (BE $129.6 \mathrm{eV}$ ) came into existence [279].

A similar structure of phosphorus species was revealed by XPS in phosphorus-containing carbons from fruit stones $[279,297]$. Phosphates were present in a small amount in carbons obtained at $400-500^{\circ} \mathrm{C}$ and disappeared at higher temperatures. Pyrophosphates and metaphosphates were the main components (91-96\%) for carbons obtained at all temperatures 
(400-1000 $\left.{ }^{\circ} \mathrm{C}\right)$. A minor content of phosphorus pentoxide (6-9\%) was observed in carbons obtained at $600-1000{ }^{\circ} \mathrm{C}$.

The temperature evolution of phosphorus species in phosphorus and nitrogen co-doped carbons from polyimide-divinylbenzene copolymer was studied [298]. It has been shown that the main component, phosphates, decreases from $44 \%$ to zero as the temperature increased from 400 to $800{ }^{\circ} \mathrm{C}$. The relative amount of pyrophosphates increased from $41 \%$ to $58 \%$ with temperature rising to $800{ }^{\circ} \mathrm{C}$ and decreased to $46 \%$ at $1000^{\circ} \mathrm{C}$. The relative content of metaphosphates progressively increased with increasing temperature from $15 \%$ to $47 \%$. A minor amount of phosphorus pentoxide (6-8\%) was observed at $700-1000{ }^{\circ} \mathrm{C}$.

The P 2p peak from P-containing carbon fibers from Kevlar [159] was deconvoluted into three components, which were attributed to the formation of phosphates and polyphosphates (likely pyrophosphates) (131.9-132.7 eV), metaphosphates (133.3-134.9 eV) and phosphorus oxide, $\mathrm{P}_{2} \mathrm{O}_{5}(133.9-134.9 \mathrm{eV})$. The amount of phosphates and polyphosphates present on the fibers increased until IR $=1.0$ and at the same time the amount of metaphosphates decreased. This tendency reversed for higher impregnation ratios.

The XPS spectra of P-containing carbon monoliths from formaldehyde and resorcinol [204] showed a binding energy of $\mathrm{P} 2 \mathrm{p}$ core-level signal at $133.5 \mathrm{eV}$ that was assigned to tetracoordinated pentavalent phosphorus as in phosphates. XPS spectra of $\mathrm{P}, \mathrm{B}$-containing carbon from resorcinol-formaldehyde showed that the main phosphorus species is a phosphate with $\mathrm{BE}$ centered at $134.5 \mathrm{eV}$ [166].

Soft-templated phosphorus-containing mesoporous carbons were prepared by one-pot self-assembly of resorcinol and formaldehyde in the presence of triblock copolymer Pluronic F127 and phosphoric acid alone or in mixture with nitric or hydrochloric acids $[164,165]$. The presence of phosphorus was evidenced by a $\mathrm{P} 2 \mathrm{p}$ signal at $133.3-133.7 \mathrm{eV}$, which was ascribed to $\mathrm{C}-\mathrm{O}-\mathrm{PO}_{3}$ type species.

XPS P 2p of carbon from a tannin-melamine-hexamine polymer [169] showed a signal with a BE of $132.9 \mathrm{eV}$ (79.1\%), which was assigned to P-O species, while another component with a BE of $136.3 \mathrm{eV}$ should be attributed to phosphorus pentoxide [292]. The O/P atomic ratio was 3.6, which falls within the region between phosphates (4) and polyphosphates (3).

Deconvolution of the P $2 p$ envelope for P-containing carbon from coffee grounds revealed three components with binding energies of $132.9,134.1$ and $136.0 \mathrm{eV}$, which were assigned to pyrophosphate, metaphosphates and phosphorus pentoxide [133]. It should be noted that the above assignment of phosphorus is not supported by the O/P atomic ratio - it is about $1.0 \pm 0.13$, 
which is much less than for pyrophosphates (3.5), phosphates (3) or phosphorus pentoxide (2.5). This fact suggests that some $\mathrm{P}-\mathrm{O}$ bonds may be replaced with $\mathrm{P}-\mathrm{C}$ bonds.

The XPS P 2p envelope of an aniline-based carbon [175] was deconvoluted into single components with binding energies $132.9-133.1 \mathrm{eV}$ for carbons obtained at $700-800{ }^{\circ} \mathrm{C}$, which were assigned to phosphate and/or pyrophosphate groups. A slight increase of the binding energy when increasing the carbonization temperature from 700 to $800{ }^{\circ} \mathrm{C}$ was attributed to dehydration and condensation of phosphates or interaction of phosphorus functionalities with enlarged aromatic ring system upon heating. A peak at $135.2 \mathrm{eV}$ for the carbon obtained at $900{ }^{\circ} \mathrm{C}$ was ascribed to metaphosphate functionalities, which were formed by the condensation of phosphates (or pyrophosphates).

XPS showed three types of phosphorus species present in carbon obtained by $\mathrm{H}_{3} \mathrm{PO}_{4}$ activation of reedy grass leaves at $500{ }^{\circ} \mathrm{C}$. The peak at $131.9-132.7 \mathrm{eV}$ was attributed to phosphates and polyphosphates, the peak at 133.3-134.9 eV was ascribed to metaphosphates and the peak at $129.6 \mathrm{eV}$ was assigned to elemental phosphorus [137].

The XPS P 2p envelope located at $133.3 \mathrm{eV}$ showed that phosphorus in glucose-derived carbons was present in form of phosphates [171].

Another fitting scheme was suggested for the analysis of the chemical structure of phosphorus in hemp stems-derived carbons [299]. By fitting the P $2 p$ envelope to four components with fixed binding energies, the following phosphorus species were proposed, from the most oxidized to the most reduced: (i) $\mathrm{C}-\mathrm{O}-\mathrm{PO}_{3}$ at $134.1 \mathrm{eV}$ (ii) $\mathrm{C}-\mathrm{PO}_{3}$ at $133.1 \mathrm{eV}$, (iii) $\mathrm{C}_{3} \mathrm{PO}$ with $\mathrm{BE}$ at $132 \mathrm{eV}$ and (iv) $\mathrm{C}_{3} \mathrm{P}$ at $131.0 \mathrm{eV}$.

The P $2 p$ spectrum of phosphorus in hemp-derived P-containing carbons showed a band with a main peak at a BE of about $133.7 \mathrm{eV}$, which was ascribed to pentavalent tetra-coordinated phosphorus $\left(\mathrm{PO}_{4}\right)$ as in polyphosphates and/or phosphates. An increase of the $\mathrm{H}_{3} \mathrm{PO}_{4}$ activation temperature from 350 to $500{ }^{\circ} \mathrm{C}$ slightly increased the binding energy of the main peak to a value close to $134.0 \mathrm{eV}$, which was assigned to $\mathrm{C}-\mathrm{O}-\mathrm{PO}_{3}$ groups [121,122]. A further increase of the activation temperature to $550^{\circ} \mathrm{C}$ resulted in decreasing the intensity of the peak at a binding energy of $133.4 \mathrm{eV}$, which was ascribed to a $\mathrm{P}$ atom bonded to one $\mathrm{C}$ atom and three $\mathrm{O}$ atoms, as in $\mathrm{C}-\mathrm{PO}_{3}$ groups. A small band at around $132.1 \mathrm{eV}$ that appeared in carbon fibers obtained at the highest activation temperature of $550^{\circ} \mathrm{C}$ was ascribed to a reduced phosphorus compound as C-P.

The XPS P 2p envelope of phosphorus-containing carbons from different lignocellulosic precursors (lignin, olive stones, plywood waste and hemp canes) was deconvoluted into two components: one with $\mathrm{BE} 134.0 \mathrm{eV}$ representing $82 \%$ of the total phosphorus and a remaining 
component with $\mathrm{BE} 133.4 \mathrm{eV}$ [95]. The first component was assigned to C-O- $\mathrm{PO}_{3}$ groups while the second peak was ascribed to a $\mathrm{P}$ atom bonded to one $\mathrm{C}$ atom and three $\mathrm{O}$ atoms, as in $\mathrm{C}-\mathrm{PO}_{3}$ groups.

XPS spectra showed two bands in a phosphorus-containing carbon obtained by $\mathrm{H}_{3} \mathrm{PO}_{4}$ activation of olive stones at $500{ }^{\circ} \mathrm{C}$. The bands were assigned to $\mathrm{C}-\mathrm{O}-\mathrm{PO}_{3}(134.0 \mathrm{eV})$ and $\mathrm{C}-\mathrm{PO}_{3}$ (133.4 eV) groups with a higher contribution of the former groups on the carbon surface [101].

Four types of phosphorus surface groups were suggested to exist in carbons obtained by phosphoric acid activation of olive stones at $400-800{ }^{\circ} \mathrm{C}$ [102]. The main XPS P $2 p$ peak at $134.0 \mathrm{eV}$ was assigned to phosphorus bound to carbon through an $\mathrm{O}$ atom like $\mathrm{C}-\mathrm{O}-\mathrm{PO}_{3}$ or $(\mathrm{C}-\mathrm{O})_{3} \mathrm{PO}$ groups. The peak at around $133.1 \mathrm{eV}$ was ascribed to $\mathrm{C}-\mathrm{P}$ bonding as in $\mathrm{C}-\mathrm{PO}_{3}$ and $\mathrm{C}_{2} \mathrm{PO}_{2}$ groups. Lower intensity peaks at 132.0 and $131.0 \mathrm{eV}$ were attributed to $C_{3} P O$ and $C_{3} P$ groups, respectively. The increase of the activation temperature resulted in a shift of the maximum of the $P 2 p$ band to lower binding energies, which was explained by a decrease in the proportion of more oxidized phosphorus groups and an increase in the amount of $\mathrm{C}_{3} \mathrm{PO}$ and $\mathrm{C}_{3} \mathrm{P}$ groups.

The XPS P $2 p$ spectrum of a lignin-derived carbon obtained by $\mathrm{H}_{3} \mathrm{PO}_{4}$ activation at $500{ }^{\circ} \mathrm{C}$ contained peaks attributable to mainly $\mathrm{C}_{2}-\mathrm{PO}_{2} / \mathrm{C}-\mathrm{PO}_{3}$ and $\mathrm{C}-\mathrm{O}-\mathrm{PO}_{3}$ groups [144]. Upon thermal treatment up to $900{ }^{\circ} \mathrm{C}$, the $\mathrm{C}-\mathrm{O}-\mathrm{PO}_{3}$ groups seemed to be transformed into $\mathrm{C}_{3}-\mathrm{PO}$ groups; when heated in the presence of oxygen, the latter are reoxidized to $\mathrm{C}-\mathrm{O}-\mathrm{PO}_{3}$, delaying carbon gasification.

Three types of phosphorus species were reported for lignin-derived carbon fibers obtained by carbonization of lignin precursor fibers with $\mathrm{H}_{3} \mathrm{PO}_{4}$ at $900{ }^{\circ} \mathrm{C}$ in nitrogen containing 3 vol\% of oxygen [146]. The XPS P $2 p$ envelope was deconvoluted into components for polyphosphates and/or phosphates (-C-O-P-species: $(\mathrm{CO})_{3} \mathrm{PO},(\mathrm{CO})_{2} \mathrm{PO}_{2}$ and $\left.(\mathrm{CO}) \mathrm{PO}_{3}\right)$ at $134.0 \mathrm{eV}$; -C-P-O- species (C- $\mathrm{PO}_{3}$ and/or $\mathrm{C}_{2}-\mathrm{PO}_{2}$ groups) at $133.2 \mathrm{eV}$; and $-\mathrm{C}_{3} \mathrm{PO}$ groups, at $132.0 \mathrm{eV}$. It is notable that the major contribution was from the most reduced phosphorus form, $-\mathrm{C}_{3} \mathrm{PO}$ even though carbon fibers were obtained in an oxidizing atmosphere.

The XPS P 2p signal of P-containing carbons obtained by phosphoric acid activation of rice husk at $400-700{ }^{\circ} \mathrm{C}$ showed peaks at $134.0-134.6 \mathrm{eV}$ and around $133.6 \mathrm{eV}$, that were assigned to phosphorus bound to oxygen atoms and to phosphorus bonded to one carbon and oxygen atoms respectively [127].

Nitrogen/phosphorus co-doped nonporous carbon nanofibers were prepared by electrospinning of a mixture of polyacrylonitrile (PAN) and phosphoric acid followed by stabilization and carbonization at $800{ }^{\circ} \mathrm{C}$ [150]. With increasing amount of phosphoric acid, the 
phosphorus content in the carbon nanofibers increased up to $10.2 \mathrm{wt} \%$. XPS showed the presence of three major phosphorus groups differentiated by their binding energies: C-O-P type groups $(134.2 \mathrm{eV})$, such as $(\mathrm{CO})_{3} \mathrm{PO},(\mathrm{CO})_{2} \mathrm{PO}_{2}$ and $(\mathrm{CO}) \mathrm{PO}_{3} ; \mathrm{P}$ atom bonded to one or two $\mathrm{C}$ atoms and three or two $\mathrm{O}$ atoms as in $\mathrm{C}-\mathrm{PO}_{3}$ or $\mathrm{C}_{2}-\mathrm{PO}_{2}$ groups (133.1 eV); and reduced phosphorus compound as $C_{3}-\mathrm{P}$ groups $(132.2 \mathrm{eV})$.

The XPS P 2p spectrum of a carbon obtained by carbonizing a mixture of resol resin and phosphoric acid at $500{ }^{\circ} \mathrm{C}$ [167] was deconvoluted into three peaks with 132.8, 133.6 and $134.3 \mathrm{eV}$ binding energies, which were ascribed to $\mathrm{P}-\mathrm{C}, \mathrm{C}-\mathrm{P}=\mathrm{O}$, and $\mathrm{P}-\mathrm{O}-\mathrm{C}$, respectively.

The XPS P 2p envelope of a phosphorus-containing carbon obtained by carbonization at $850{ }^{\circ} \mathrm{C}$ of a styrene-divinylbenzene copolymer phosphorylated with $\mathrm{PCl}_{3}$ was deconvoluted into two components with binding energies of $132.8 \mathrm{eV}$ and $133.9 \mathrm{eV}$ [212]. The first component (45\%) was attributed to phenylphosphinic acid, like in the starting resin, and the remaining phosphorus species was identified as phosphorus bonded to $-\mathrm{OPh},-\mathrm{Ph},=\mathrm{O}$, or $-\mathrm{OH}$ (for example, $\mathrm{Ph}_{3} \mathrm{PO}$ : $\left.132.5 \mathrm{eV} ;(\mathrm{PhO})_{3} \mathrm{PO}: 133.6 \mathrm{eV} ; \mathrm{Ph}_{2} \mathrm{PO}(\mathrm{OH}): 133.3 \mathrm{eV}\right)$.

A carbon obtained by direct modification of OMCs with phosphoric acid at room temperature showed two peaks with binding energies around 134.6 and $133.4 \mathrm{eV}$, which were assigned to C-O-P and C-P structures, respectively [284]. With increasing carbonization temperature of the parent $\mathrm{OMC}$, the intensity of the C-O-P component decreased, whereas the C-P component increased. It was concluded that the low-temperature carbon contains more -OH groups that form C-O-P linkage while the high temperature carbon leads to formation of direct C-P bonds.

The evolution of the phosphorus-containing groups in two series of carbons prepared by $\mathrm{H}_{3} \mathrm{PO}_{4}$ activation of lignocellulose and by $\mathrm{H}_{3} \mathrm{PO}_{4}$ modification of activated carbon on heat treatment up to $900{ }^{\circ} \mathrm{C}$ in inert $\left(\mathrm{N}_{2}\right)$ and reducing $\left(\mathrm{H}_{2}\right)$ atmospheres was studied [300]. It has been shown that heat treatment in $\mathrm{H}_{2}$ resulted in the removal of much more phosphorus than in $\mathrm{N}_{2}$ atmosphere. During the heat-treatment, C-O-P linkages in phosphorus-containing carbons were progressively transformed into C-P-O, $\mathrm{C}_{3}-\mathrm{P}-\mathrm{O}, \mathrm{C}_{3}-\mathrm{P}$, and even elemental phosphorus. In an $\mathrm{N}_{2}$ atmosphere, this evolution occurs extensively at up to $800^{\circ} \mathrm{C}$, leading to considerable formation of $\mathrm{C}_{3}-\mathrm{P}-\mathrm{O}$, whereas $\mathrm{C}_{3}-\mathrm{P}$ linkages were not formed even at $900{ }^{\circ} \mathrm{C}$. In an $\mathrm{H}_{2}$ atmosphere, this evolution occurred extensively at much lower temperatures starting from $500^{\circ} \mathrm{C}$, producing $\mathrm{C}_{3}-\mathrm{P}$ linkages and eventually elemental phosphorus. Moreover, the two activated carbons exhibited different evolution trends, suggesting that phosphate-like groups located at the edges of graphite-like 
crystallites (in modified carbon) are more easily transformed, irrespective of the atmosphere used, than those in the lattice of the graphite-like crystallites $\left(\mathrm{H}_{3} \mathrm{PO}_{4}\right.$-activated carbon).

Thus, XPS is a powerful tool to reveal the nature of phosphorus species and their transformations in phosphorus-containing carbons though some controversy exists in the interpretation of the results. Pentavalent tetra-coordinated phosphorus (phosphate-like structure) is, by far, the most common species identified in P-containing carbons by this technique. As the heat treatment temperature of the carbons is increased, this species was shown by XPS to transform into pyrophosphate, metaphosphate, phosphorus pentoxide and even elemental phosphorus. Another interpretation scheme shows gradual substitution of oxygen atoms surrounding phosphorus by carbon atoms and even formation of thee-valent phosphorus species with increasing heat treatment temperature.

\section{$5.3 \quad{ }^{31} \mathrm{P}-\mathrm{NMR}$}

${ }^{31} \mathrm{P}-\mathrm{NMR}$ spectroscopy was used to study the chemical state of phosphorus in carbons obtained by phosphoric acid activation of pecan shells at $450{ }^{\circ} \mathrm{C}$ under different rates of air flow [111]. The ${ }^{31} \mathrm{P}-\mathrm{NMR}$ spectra showed only one large peak at around $0 \mathrm{ppm}$, which was deconvoluted into two components - sharp and broad. The sharp component was ascribed to free unreacted phosphoric acid, and the broad component was assigned to alkyl and dialkyl phosphate esters formed due to the condensation between phosphoric acid and phenolic $\mathrm{OH}$. The relative amount of bound phosphorus decreased from 78.0 to $69.9 \%$ with increasing rate of airflow from 100 to $400 \mathrm{~mL} / \mathrm{min}$ and increased to $85 \%$ with further increasing airflow rate to $2000 \mathrm{~mL} / \mathrm{min}$. The increase in relative amount of bound phosphorus in carbon obtained at $2000 \mathrm{~mL} / \mathrm{min}$ flow rate was in line with ${ }^{13} \mathrm{C}-\mathrm{NMR}$ results, which showed a maximum amount of carboxylic and phenolic groups (responsible for the formation of phosphate esters) for this sample. It was suggested that perhaps small amounts of polyphosphates were present, but no phosphonic acid and phosphonates were found in the carbon structure.

${ }^{31}$ P-NMR spectra of phosphorus-containing carbon fibers obtained by phosphoric acid activation of natural sisal fibers at $250-830^{\circ} \mathrm{C}$ revealed two peaks with chemical shifts ranging from -3.3 to $-7.0 \mathrm{ppm}$ and from -14.5 to $-17.4 \mathrm{ppm}$ [131]. These peaks were assigned to metaphosphosric acid (or polyphosphates) and to elemental phosphorus, respectively. However, the assignment of the small peak at -14.5--17.4 ppm to elemental phosphorus contradicts a reported value $-450 \mathrm{ppm}$ [301]. Moreover, the presence of elemental phosphorus is doubtful in samples obtained at very low temperatures $\left(250-500^{\circ} \mathrm{C}\right)$ since reduction of phosphoric acid to elemental phosphorus occurs at temperatures higher than $750-800{ }^{\circ} \mathrm{C}$ (see Fig. 3 and refs 
$[145,280])$. The presence of elemental phosphorus was not confirmed by XPS (BE around $130 \mathrm{eV}$ [292]) [131]. The reported peaks may be assigned to end groups and middle groups in polyphosphates [302-304].

${ }^{31} \mathrm{P}$ NMR spectra of P-containing carbons from a bituminous coal showed a peak at -10 ppm and a second peak ranging from -40 to -54 ppm, which were assigned to phosphates and polyphosphates with $\mathrm{OP}(\mathrm{O}-)_{3}$ as building units respectively [91].

The solid-state ${ }^{31} \mathrm{P}-\mathrm{NMR}$ spectra of polymer-based phosphorus-containing carbon showed two peaks, one around 0 ppm and a second at 7-14 ppm [279]. The peak at ca. 0 ppm was attributed to a phosphate-like structure [76]. The phosphate peak is shifted to a higher magnetic field (from 0.4 to $-4.9 \mathrm{ppm}$ ) with increasing carbonization temperature, which was attributed to an increasing positive shielding from $\pi$-electrons of enlarging graphene layers. The second peak at 7-14 ppm appeared at $500{ }^{\circ} \mathrm{C}$, gradually decreased with increasing temperature and vanished at $800^{\circ} \mathrm{C}$. This peak was tentatively ascribed to phosphonates, i.e. compounds with C-P bonding. It follows that phosphorus in the carbon exists mainly in phosphate-like form bound to carbon via CO-P linkage.

The occurrence of the phosphate structure revealed by the XPS P 2p signal (BE $133.5 \mathrm{eV}$ ) was corroborated by the appearance of a dominant signal at $-4.7 \mathrm{ppm}$ in the solid-state ${ }^{31} \mathrm{P}$ NMR spectrum of phosphorus-containing carbon monoliths [204]. The upfield shift was attributed to the enhanced positive shielding coming from the $\pi$-electrons of extended graphene domains.

The solid state ${ }^{31} \mathrm{P}-\mathrm{NMR}$ spectrum of phosphorus-containing graphene showed two peaks at -4 and 21 ppm, which were assigned to two types of phosphorus and match well with the expected values for triphenylphosphine and triphenylphosphine oxide that appear at -6 and 23 ppm, respectively [182].

A carbon obtained by direct modification of OMCs with phosphoric acid at room temperature showed two peaks in its ${ }^{31} \mathrm{P}-\mathrm{NMR}$ spectrum in the range from -0.4 to $-6 \mathrm{ppm}$, which were assigned to phosphates and phosphonates respectively [284]. With increasing carbonization temperature of the starting carbon the intensity of the C-P peak ( $-6 \mathrm{ppm})$ increased, which was explained by the progressive decrease in the concentration of oxygen-containing groups capable of reacting with phosphoric acid during carbonization.

Graphitic amorphous phosphorus-containing carbons obtained by heat treatment of fullerene $C_{60}$ with red phosphorus were investigated by ${ }^{31}$ P-NMR spectrometry [245]. It has been shown that carbon materials obtained at high temperatures $\left(800-950^{\circ} \mathrm{C}\right.$ ) contain phosphate (from -11.9 to $3.2 \mathrm{ppm}$ ), alkyl phosphate ( $35 \mathrm{ppm}$ ) and phosphorane (from -53 to $-25 \mathrm{ppm}$ ) structural 
elements, besides elemental phosphorus (from -530 to $-536 \mathrm{ppm}$ ) in considerable amounts. Carbons obtained at lower temperatures $\left(650-700^{\circ} \mathrm{C}\right)$ contain nearly exclusively $\mathrm{P}-\mathrm{O}$ and $\mathrm{P}-\mathrm{C}$ bonds.

Thus, solid-state ${ }^{31} \mathrm{P}-\mathrm{NMR}$ spectroscopy is a suitable method for investigating the chemical state of phosphorus in P-containing carbons. Most investigations revealed the occurrence of a phosphate-like structure though phosphonates with C-P bonding were also reported.

\section{$5.4 \quad$ LDI-ToF}

Direct evidence of polyphosphates in phosphorus-containing carbons was obtained by laser desorption/ionization method and time-of-flight mass spectrometry (LDI-ToF) [305]. Phosphoruscontaining carbons were obtained by phosphoric acid activation of polymer or fruit stone precursors at different temperatures. LDI-ToF spectra showed phosphate and polyphosphate fragments, which may be classified into four groups containing fragments of mono-, di-, tri- and tetra-phosphates (Fig. 19,Table 2). Polyphosphates with a degree of polymerization higher than four were not detected in discernible amounts. Smaller phosphate fragments in each group may be obtained by sequential loss of water and oxygen from the parent phosphoric acid molecule (M) (Fig. 20, Table 2). The most intense peaks correspond to fragments generated by loss of one water molecule ([M - $\left.\mathrm{H}_{2} \mathrm{O}-\mathrm{H}\right]^{-}$anion) in mono, di and triphosphate groups and by loss of two water molecules $\left(\left[\mathrm{M}-2 \mathrm{H}_{2} \mathrm{O}-\mathrm{H}\right]^{-}\right.$anion) in a tetra-phosphate group. The observed phosphate/polyphosphate fragments appeared as singly charged species, which suggests that phosphorus species in phosphorus-containing carbons exist as monoesters of polyphosphoric acid and hence the largest fragment appears in the LDI-ToF experiment by breaking a $\mathrm{C}-\mathrm{O}$ bond in an ester group C-O-P due to laser irradiation. 


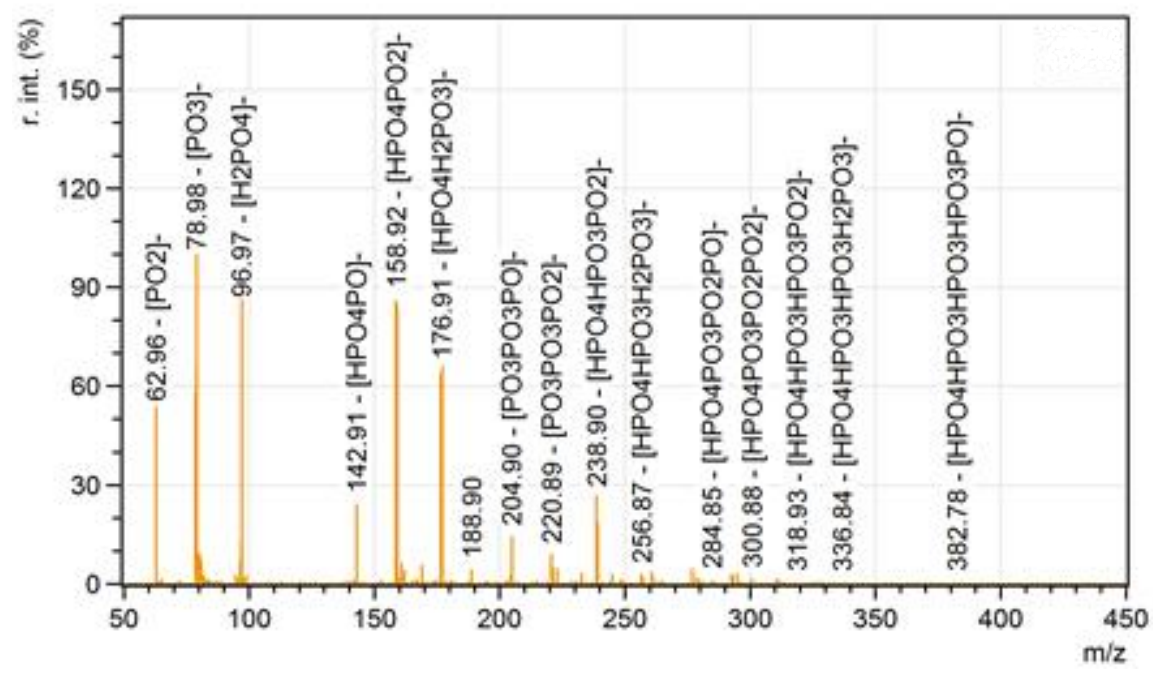

Fig. 19. Negative mode LDI-ToF mass spectra of phosphorus-containing carbon SP800 obtained from St-DVB copolymer at $800{ }^{\circ} \mathrm{C}$. Adapted with permission from Ref. [305]. Copyright (2013) Elsevier.

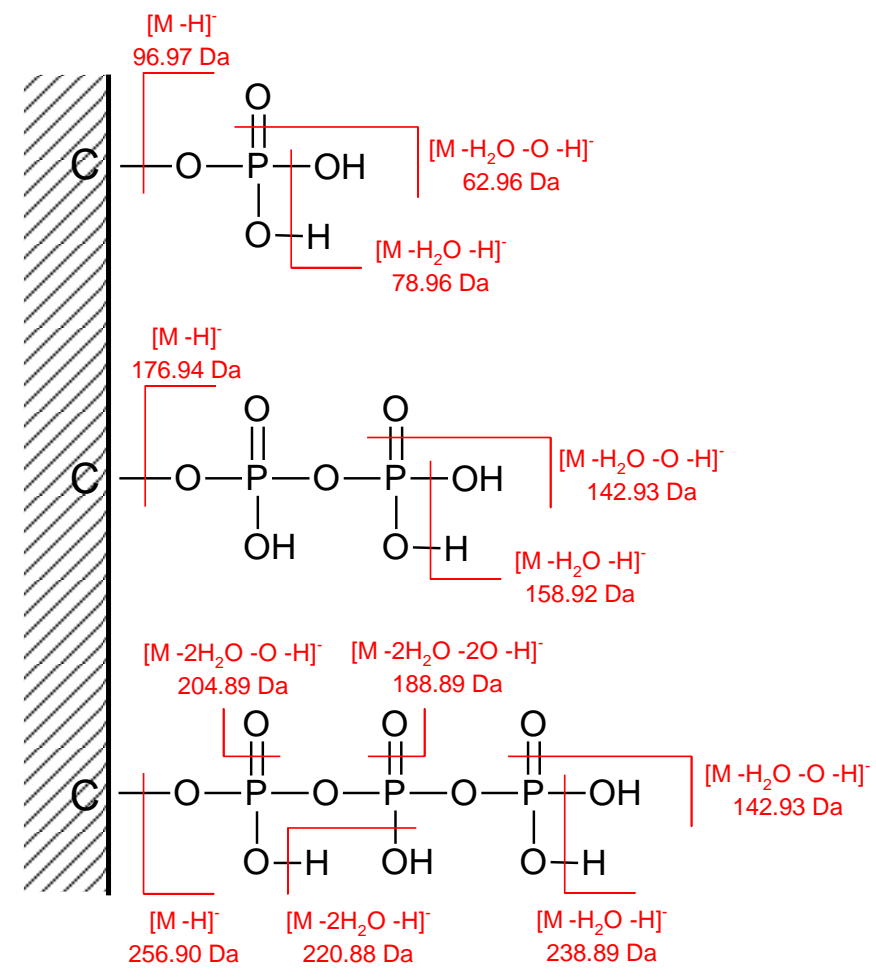

Fig. 20. Fragmentation scheme of phosphorus species in phosphorus-containing carbons. $M$ is a neutral molecule of phosphoric or polyphosphoric acids. Reprinted with permission from Ref. [305]. Copyright (2013) Elsevier.

Table 2. Phosphate fragments in LDI ToF spectra of phosphorus-containing carbons. Reprinted with permission from Ref. [305]. Copyright (2013) Elsevier.

\begin{tabular}{llll}
\hline Group & Ion & Description & $\mathrm{m} / \mathrm{z}$ \\
\hline monophosphate & {$\left[\mathrm{PO}_{2}\right]^{-}$} & {$\left[\mathrm{M}-\mathrm{H}_{2} \mathrm{O}-\mathrm{O}-\mathrm{H}\right]^{-}$} & 62.96 \\
& {$\left[\mathrm{PO}_{3}\right]^{-}$} & {$\left[\mathrm{M}-\mathrm{H}_{2} \mathrm{O}-\mathrm{H}\right]^{-}$} & 78.96
\end{tabular}




\begin{tabular}{|c|c|c|c|}
\hline & {$\left[\mathrm{H}_{2} \mathrm{PO}_{4}\right]^{-}$} & {$[\mathrm{M}-\mathrm{H}]^{-}$} & 96.97 \\
\hline \multirow[t]{3}{*}{ Diphosphate } & {$\left[\mathrm{HPO}_{4} \mathrm{PO}^{-}\right.$} & {$\left[\mathrm{M}-\mathrm{H}_{2} \mathrm{O}-\mathrm{O}-\mathrm{H}\right]^{-}$} & 142.93 \\
\hline & {$\left[\mathrm{HPO}_{4} \mathrm{PO}_{2}\right]^{-}$} & {$\left[\mathrm{M}-\mathrm{H}_{2} \mathrm{O}-\mathrm{H}\right]^{-}$} & 158.92 \\
\hline & {$\left[\mathrm{HPO}_{4} \mathrm{H}_{2} \mathrm{PO}_{3}\right]^{-}$} & {$[\mathrm{M}-\mathrm{H}]^{-}$} & 176.94 \\
\hline \multirow[t]{5}{*}{ Triphosphate } & {$\left[\mathrm{PO}_{2} \mathrm{PO}_{3} \mathrm{PO}^{-}\right.$} & {$\left[\mathrm{M}-2 \mathrm{H}_{2} \mathrm{O}-2 \mathrm{O}-\mathrm{H}\right]^{-}$} & 188.89 \\
\hline & {$\left[\mathrm{PO}_{3} \mathrm{PO}_{3} \mathrm{PO}\right]^{-}$} & {$\left[\mathrm{M}-2 \mathrm{H}_{2} \mathrm{O}-\mathrm{O}-\mathrm{H}\right]^{-}$} & 204.89 \\
\hline & {$\left[\mathrm{PO}_{3} \mathrm{PO}_{3} \mathrm{PO}_{2}\right]^{-}$} & {$\left[\mathrm{M}-2 \mathrm{H}_{2} \mathrm{O}-\mathrm{H}\right]^{-}$} & 220.88 \\
\hline & {$\left[\mathrm{HPO}_{4} \mathrm{HPO}_{3} \mathrm{PO}_{2}\right]^{-}$} & {$\left[\mathrm{M}-\mathrm{H}_{2} \mathrm{O}-\mathrm{H}\right]^{-}$} & 238.89 \\
\hline & {$\left[\mathrm{HPO}_{4} \mathrm{HPO}_{3} \mathrm{H}_{2} \mathrm{PO}_{3}\right]^{-}$} & {$[\mathrm{M}-\mathrm{H}]^{-}$} & 256.90 \\
\hline \multirow[t]{5}{*}{ tetraphosphate } & {$\left[\mathrm{HPO}_{4} \mathrm{PO}_{3} \mathrm{PO}_{2} \mathrm{PO}\right]^{-}$} & {$\left[\mathrm{M}-2 \mathrm{H}_{2} \mathrm{O}-\mathrm{O}-\mathrm{H}\right]^{-}$} & 284.85 \\
\hline & {$\left[\mathrm{HPO}_{4} \mathrm{PO}_{3} \mathrm{PO}_{2} \mathrm{PO}_{2}\right]^{-}$} & {$\left[\mathrm{M}-2 \mathrm{H}_{2} \mathrm{O}-\mathrm{H}\right]^{-}$} & 300.85 \\
\hline & {$\left[\mathrm{HPO}_{4} \mathrm{HPO}_{3} \mathrm{HPO}_{3} \mathrm{PO}\right]^{-}$} & {$\left[\mathrm{M}-\mathrm{H}_{2} \mathrm{O}-\mathrm{O}-\mathrm{H}\right]^{-}$} & 302.86 \\
\hline & {$\left[\mathrm{HPO}_{4} \mathrm{HPO}_{3} \mathrm{HPO}_{3} \mathrm{PO}_{2}\right]^{-}$} & {$\left[\mathrm{M}-\mathrm{H}_{2} \mathrm{O}-\mathrm{H}\right]^{-}$} & 318.86 \\
\hline & {$\left[\mathrm{HPO}_{4} \mathrm{HPO}_{3} \mathrm{HPO}_{3} \mathrm{H}_{2} \mathrm{PO}_{3}\right]^{-}$} & {$[\mathrm{M}-\mathrm{H}]^{-}$} & 336.87 \\
\hline
\end{tabular}

From the above results one can conclude that the most useful feature of mass spectrometry is to directly show the presence of polyphosphates on the carbon surface.

\section{Properties and applications}

\subsection{Hydrophilic-hydrophobic properties}

Introduction of phosphorus in the structure of carbon materials results in enhancing their hydrophilic properties.

$\mathrm{A} \mathrm{PCl}_{3}$-treated carbon from novolac phenol-formaldehyde resin showed a significantly increased adsorption of water while adsorption of benzene and $\mathrm{CO}_{2}$ remained intact regarding the untreated carbon [235]. The most pronounced increase was observed at low relative pressures $\mathrm{p} / \mathrm{p}^{0}<0.5$ (Table 3 ). The amount of primary adsorption centers calculated from the initial part of the water adsorption isotherm for carbons exposed to different treatments was the highest for the oxidized carbon while the number of primary centers per modifying atom was the highest for the $\mathrm{PCl}_{3}$-treated carbon (Table 3). 
Table 3 Adsorption of water at $20^{\circ} \mathrm{C}$ on phenol-formaldehyde-based carbons treated with $\mathrm{PCl}_{3}$, oxidized, chlorinated and ammonia-activated. Adapted from [235].

\begin{tabular}{|c|c|c|c|c|c|c|}
\hline Carbon & $\begin{array}{l}\text { Content of } \\
\text { modifying } \\
\text { element, } \\
\text { wt\% }\end{array}$ & $\begin{array}{l}\text { Number of } \\
\text { primary } \\
\text { adsorption } \\
\text { centers, } \\
\mathrm{mmol} / \mathrm{g}\end{array}$ & $\begin{array}{l}\text { Number of } \\
\text { primary } \\
\text { adsorption } \\
\text { centers per } \\
\text { atom of } \\
\text { modifying } \\
\text { element }\end{array}$ & $\begin{array}{l}a_{0.5} \\
\left(\mathrm{~cm}^{3} / \mathrm{g}\right)\end{array}$ & $\begin{array}{l}a_{1.0} \\
\left(\mathrm{~cm}^{3} / \mathrm{g}\right)\end{array}$ & $a_{0.5} / a_{1.0}$ \\
\hline Parent & $\begin{array}{l}1.9 \\
\text { (oxygen) }\end{array}$ & 0.109 & - & 0.013 & 0.353 & 0.04 \\
\hline $\begin{array}{l}\mathrm{PCl}_{3^{-}} \\
\text {treated }\end{array}$ & 3.5 & 4.71 & 4.17 & 0.171 & 0.350 & 0.49 \\
\hline Oxidized & 9.5 & 6.15 & 1.04 & 0.220 & 0.306 & 0.73 \\
\hline Chlorinated & 7.0 & 0.645 & 0.32 & 0.034 & 0.312 & 0.11 \\
\hline $\begin{array}{l}\text { Ammonia- } \\
\text { activated }\end{array}$ & 2.0 & 2.18 & 1.50 & 0.090 & 0.256 & 0.35 \\
\hline
\end{tabular}

A derivatographic investigation showed that modification with $\mathrm{PCl}_{3}$ at $500-800{ }^{\circ} \mathrm{C}$ of a carbon from polyfurfuryl alcohol results in five times increase in water adsorption (estimated as mass loss in the temperature range $20-200{ }^{\circ} \mathrm{C}$ accompanied by a highly endothermic effect) showing a higher hydrophilicity for the phosphorus-containing carbon [237].

Further investigation [306] showed that the shape of water adsorption isotherms on $\mathrm{PCl}_{3}$ modified carbons is the same as on oxidized carbons. Difference adsorption isotherms, which show the increase of water adsorption by modified carbons as compared to non-modified ones, revealed a pronounced increase of adsorption at low relative pressures with maximum at $p / p^{0}=0.3-0.4$ (Fig. 21). The increase of water adsorption was proportional to phosphorus content (Fig. 22). 


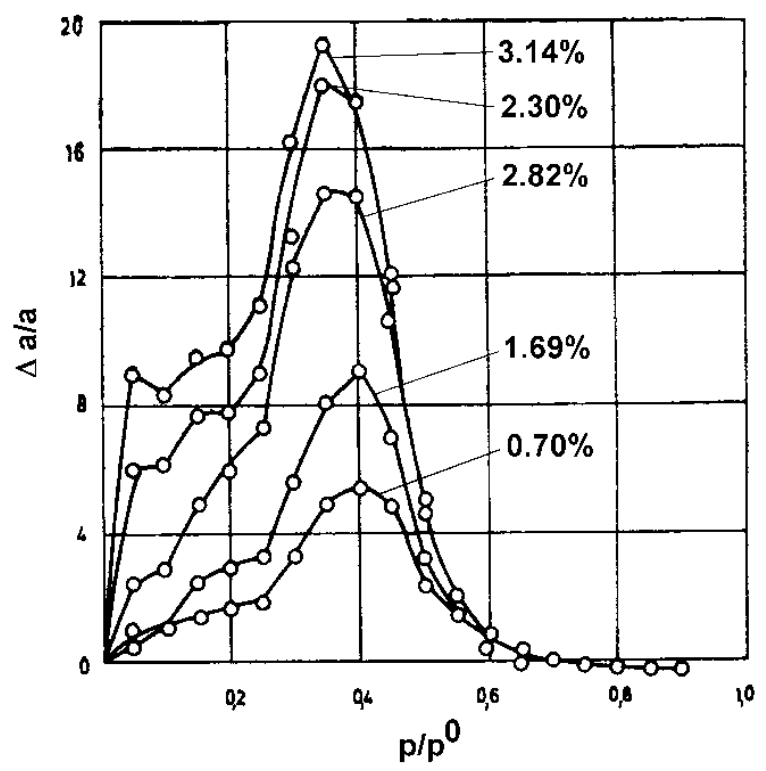

Fig. 21 Difference water adsorption isotherms at $25^{\circ} \mathrm{C}$ by $\mathrm{PCl}_{3}$-modified carbons from polyfurfuryl alcohol with P-content indicated on the graph. Adapted from [306].

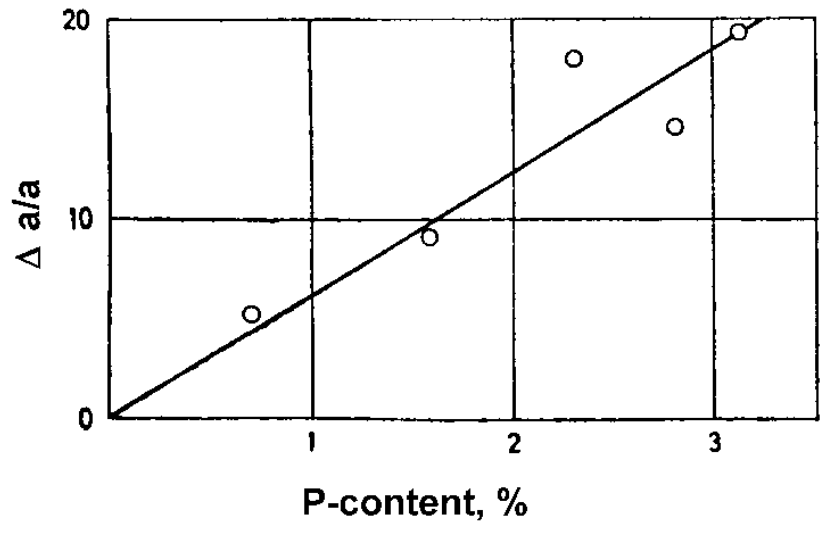

Fig. 22 Dependence of relative maximum increase of water adsorption at $25{ }^{\circ} \mathrm{C}$ on phosphorus content of $\mathrm{PCl}_{3^{-}}$ modified carbons from polyfurfuryl alcohol. Adapted from [306].

It was also observed that following impregnation with organo-phosphorus esters and subsequent heat-treatment, graphite became strongly hydrophilic [231]. The amount of water adsorbed increased with increasing amount of residual phosphorus compound (with decreasing heat-treatment temperature) (Fig. 23). The effect was ascribed to decomposition of the organic part of the ester that left a strongly adsorbed residue, most probably in the form of phosphate $\left(-\mathrm{OPO}_{3}\right)$ or phosphite $\left(-\mathrm{OPO}_{2}\right)$ groups with high affinity to water molecules. 


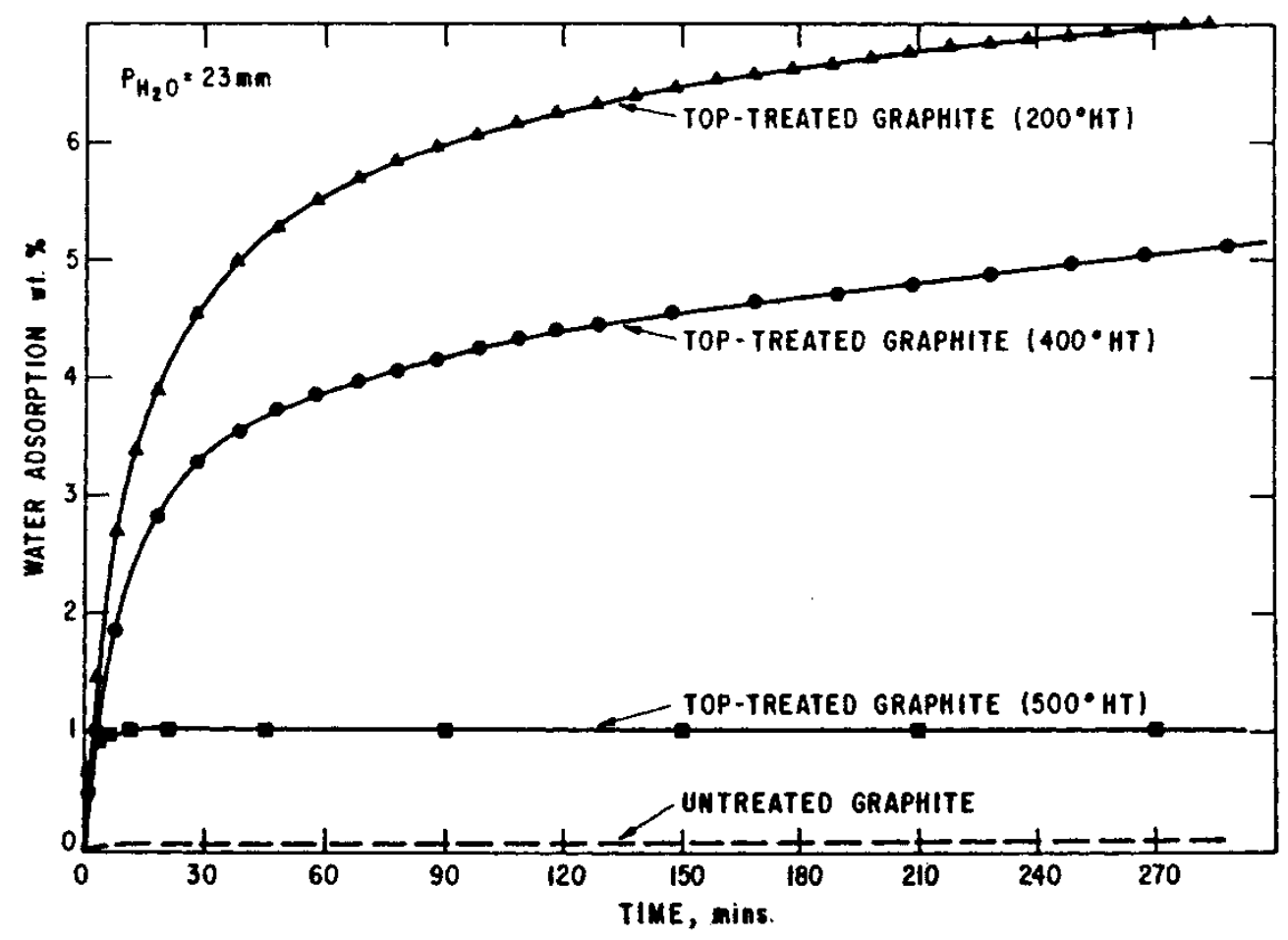

Fig. 23 Kinetics of water adsorption at $25{ }^{\circ} \mathrm{C}\left(\mathbf{P}_{\mathrm{H} 2 \mathrm{O}}=23 \mathrm{~mm}\right)$ on graphite treated with trioctyl-phosphate (TOP) for 2 hours at different temperatures. Reprinted with permission from Ref. [231]. Copyright (1984) Elsevier.

A phosphorus and nitrogen-containing carbon NPC obtained by carbonization of a commercial phosphorylated resin showed a high adsorption capacity for water vapor at low relative pressures $[215,216]$. The water adsorption isotherm belongs to type IV of IUPAC classification indicating a highly hydrophilic surface of the carbon (Fig. 24). On the contrary, adsorption of water on an almost pure carbonaceous adsorbent SCS prepared from the same copolymer shows a type III isotherm characteristic of a weak interaction of carbon surface with water molecules. The amount of hydrophilic sites calculated by means of the Langmuir equation was very high, $11.7 \mathrm{mmol} / \mathrm{g}$, which is 2.5 times higher as compared to a carbon obtained from styrene-divinylbenzene copolymer followed by oxidation with nitric acid; however, the amount of ionizable acid groups (measured by $\mathrm{NaOH}$ adsorption) was only 1.2 higher. From these data it was concluded that hydrophilicity is due not only to acid surface groups but to non-ionizable oxygen, phosphorus and nitrogen-containing groups as well. 


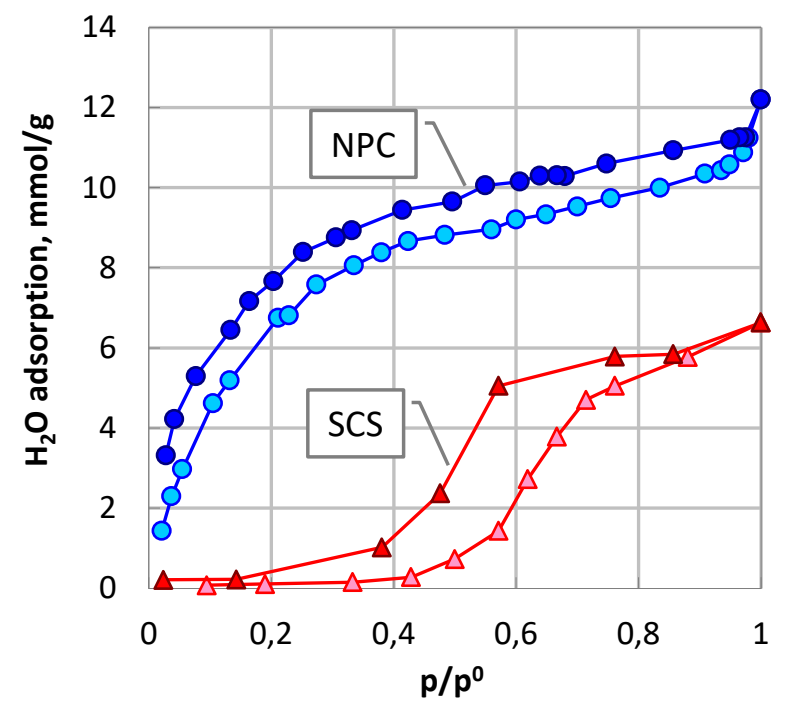

Fig. 24. Water vapor adsorption isotherm at $20^{\circ} \mathrm{C}$ on N,P-containing carbon NPC and a purely carbonaceous adsorbent prepared from the same copolymer SCS. Adapted by permission from Springer from Ref. [216]. Copyright (2000).

The distribution of the hydrophilic surface sites calculated form the water adsorption isotherm using the Frumkin-Fowler-Guggenheim model showed multiple adsorption sites with maxima at 42, 43, 45 and $49 \mathrm{~kJ} / \mathrm{mol}$ (Fig. 25) [216]. On the contrary, the distribution for the purely carbonaceous adsorbent SCS obtained from the same copolymer is dominated by a large peak at $40.5 \mathrm{~kJ} / \mathrm{mol}$ corresponding to micropore filling with water molecules.

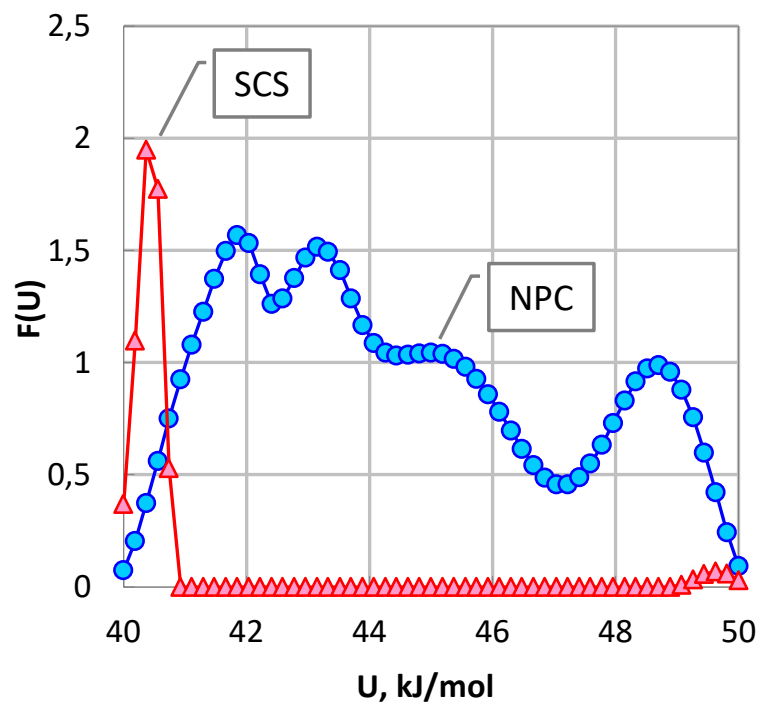

Fig. 25 Distribution of hydrophilic surface sites calculated form water adsorption isotherm using the FrumkinFowler-Guggenheim model in N,P-containing carbon NPC and purely carbonaceous adsorbent prepared from the same copolymer SCS. Adapted by permission from Springer from Ref. [216]. Copyright (2000).

Introduction of phosphorus into a carbon monolith significantly increased water adsorption at low relative pressures $\left(p / p^{0}<0.5\right)[121]$. Water adsorption on this phosphorus-containing 
carbon at low relative pressures $\left(\mathrm{p} / \mathrm{p}^{0}<0.5\right)$ was comparable to that on silica gel, being significantly higher at high relative pressures $\left(p / p^{0}>0.5\right)$.

Thus, introduction of phosphorus results in hydrophilic properties of carbon materials.

\subsection{Acid-base properties}

Introduction of phosphorus imparts acid properties to carbon materials, which are manifested as adsorption of basic compounds from gas or liquid phase.

\subsubsection{Gas phase adsorption}

Chemisorption of basic molecules such as ammonia, pyridine or 2,6-dimethylpyridine is often used to probe the acidity of the solids.

It has been shown that treatment of phenol-formaldehyde-based carbon with $\mathrm{PCl}_{3}$ at $800^{\circ} \mathrm{C}$ significantly (2-3 times) increased adsorption of ammonia (Fig. 26) [235]. The adsorption of ammonia on a carbon containing $3.5 \mathrm{wt} \%$ of phosphorus was almost the same as on oxidized carbon. Since the porous structure of carbons remained intact during modification, the increase regarding the parent carbon was ascribed exclusively to the enhanced acidic properties of the modified carbons.

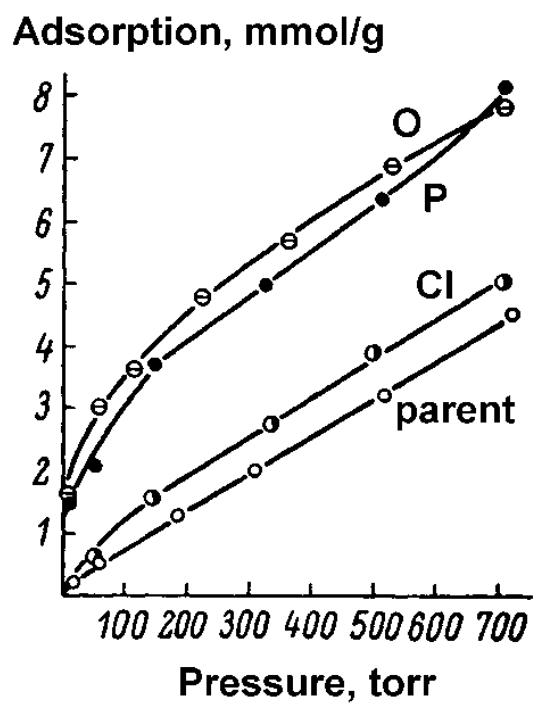

Fig. 26 Ammonia adsorption isotherms at $20{ }^{\circ} \mathrm{C}$ on phenol-formaldehyde-based carbons, parent and treated with $\mathrm{PCl}_{3}$, oxidized and chlorinated. Adapted from [235].

The $\mathrm{NH}_{3}$-TPD method was used to assess the acid properties of phosphorus-containing carbons $[95,101]$. $\mathrm{NH}_{3}$-TPD curves were deconvoluted into three Gaussian components corresponding to weak $\left(<220^{\circ} \mathrm{C}\right)$, moderate $\left(220-275^{\circ} \mathrm{C}\right)$ and strong $\left(>275^{\circ} \mathrm{C}\right)$ acid groups. The 
total amount of acid surface groups probed by the $\mathrm{NH}_{3}$-TPD method was in the range of 0.86 $1.8 \mathrm{mmol} / \mathrm{g}$.

Quasi-equilibrium thermodesorption of ammonia showed a decreasing total amount of acid sites with increasing heat treatment temperature of phosphorus-containing carbon catalysts [307]. Modeling of ammonia desorption using the adsorption integral equation [308] showed the presence of five types of surface groups on carbon catalysts, which were assigned to very weak (62 $\mathrm{kJ} / \mathrm{mol})$, weak $(82 \mathrm{~kJ} / \mathrm{mol})$, medium $(107 \mathrm{~kJ} / \mathrm{mol})$, strong $(136 \mathrm{~kJ} / \mathrm{mol})$ and very strong $(165 \mathrm{~kJ} / \mathrm{mol})$ surface sites. The distributions were dominated by very weak and weak surface sites whose contribution to the total amount of surface sites decreased from $100 \%$ to $55 \%$ with increasing heat treatment temperature from 200 to $600{ }^{\circ} \mathrm{C}$ [307]. The decreasing adsorption of ammonia from the gas phase is in line with the decreasing total amount of acid surface groups revealed by potentiometric titration.

The total amount of acid sites, obtained by integrating $\mathrm{NH}_{3}$-TPD profiles, increased with increasing phosphorus content in soft-templated phosphorus-containing mesoporous carbons $[164,165]$. The same correlation between phosphorus content and amount of acid groups was obtained using TPD of pyridine, however, the total concentration of acid groups was slightly lower as compared to ammonia [165]. The difference was ascribed to the larger size of the pyridine molecule. The total amount of acid sites was in the range of $0.20-1.52 \mathrm{mmol} / \mathrm{g}$ depending on the method of preparation.

$\mathrm{NH}_{3}$-TPD profiles of phosphorus-containing carbons obtained by direct modification of an ordered mesoporous carbon at room temperature with phosphoric acid were broad with a maximum at $220^{\circ} \mathrm{C}$ [284]. The amount of acid surface sites estimated by total amount of desorbed $\mathrm{NH}_{3}$ was proportional to the phosphorus content.

Comparing the amounts of pyridine, which reacts with Brønsted acid sites and Lewis acid sites, and 2,6-dimethylpyridine, which titrates only Brønsted acid sites, retained after the desorption process it was shown that phosphorus-containing carbon obtained by phosphoric acid activation of hemp stem contains only Brønsted acid sites [299]. The absence of Lewis acid sites was further confirmed by FTIR of adsorbed pyridine and 2,6-dimethylpyridine.

The study of acidity by adsorption of pyridine revealed that deactivation of a phosphoruscontaining carbon catalyst during ethanol dehydration in an oxygen-free atmosphere occurs due to decreasing acidity from 1 to $0.45 \mathrm{mmol} / \mathrm{g}$ caused by coke deposition on acid sites [102]. Addition of oxygen prevented this decrease in acidity and hence coke deposition during ethanol dehydration. 
Therefore, the general trend for acid-base properties as deduced from gas adsorption points to an almost linear dependence of ammonia adsorption on phosphorus content. However, the slope of ammonia adsorption vs phosphorus content is different for different series of carbons. This most probably due to the fact that ammonia can be adsorbed on other acid groups (those containing only oxygen) as well as in micropores.

\subsubsection{Liquid phase adsorption}

\subsubsection{Boehm titration}

In liquid phase, the acid-base properties of phosphorus-containing carbons are most often estimated from the uptake of bases with different strength as proposed by Boehm $[1,309]$. In addition to the acid groups determined by the Boehm titration method a total amount of basic groups is also estimated by adsorption of $\mathrm{HCl}$.

Phosphorus-containing carbons obtained by phosphoric acid activation of different precursors showed a high content of acid surface groups as revealed by Boehm titration $[94,109,110,115,126,128,141,163]$. However, no clear correlation between phosphorus content and the amount of surface groups was observed. On the contrary, the amount of strongly acidic groups obtained by Boehm titration was proportional to P-content for carbons from coffee grounds [132].

A high value of the cation exchange capacity (CEC) obtained from $\mathrm{NaOH}$ adsorption up to $5.9 \mathrm{mmol} / \mathrm{g}$ for phosphoric acid activated carbons from sucrose was reported [173]. In contrast to phosphoric acid activation of sucrose, modification of sucrose-based carbons with phosphoric acid at high temperature resulted in a much lower content of acid groups $(0.8-0.9 \mathrm{mmol} / \mathrm{g})$ due to a very low concentration of reactive surface groups in the already prepared carbon. The CEC value was linearly dependent on phosphorus content in carbons obtained by both phosphoric acid activation of sucrose and by phosphorylation of sucrose-based carbons independently from the carbonization temperature and impregnation ratio (Fig. 27). 


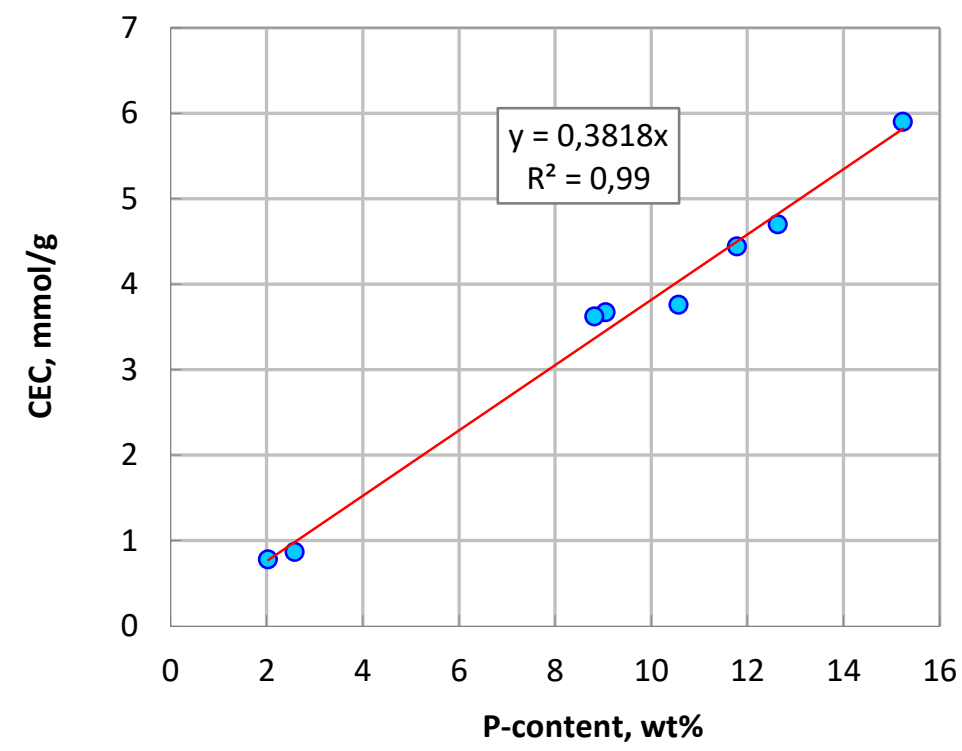

Fig. 27. Dependence of CEC on phosphorus content in phosphorus-containing carbons from sucrose. Adapted by permission from Springer from Ref. [173]. Copyright (2012).

A linear relationship between $\mathrm{NaOH}$ uptake and phosphorus content was observed for phenol-formaldehyde-based carbons treated with $\mathrm{PCl}_{3}$ at $800{ }^{\circ} \mathrm{C}[234]$. Calculations showed that each phosphorus atom is combined with one hydrogen atom capable of reacting with the $\mathrm{NaOH}$ molecule (Fig. 28).

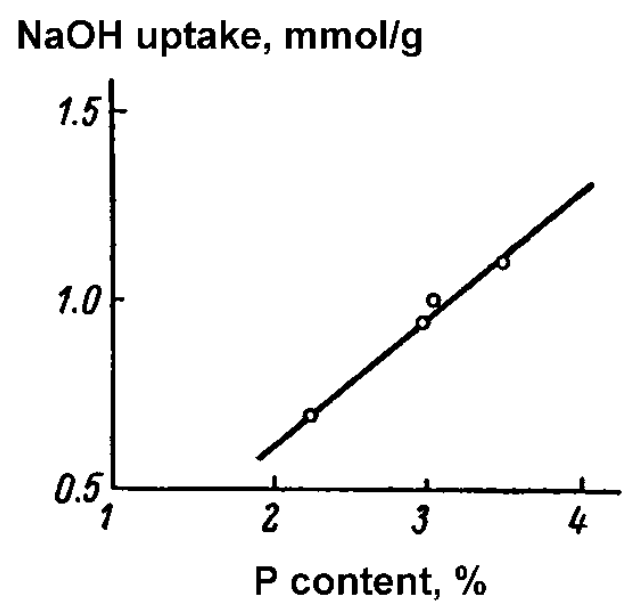

Fig. 28 Relationship between phosphorus content and $\mathrm{NaOH}$ uptake for phenol-formaldehyde-based carbons with different burn-offs treated with $\mathrm{PCl}_{3}$ at $800{ }^{\circ} \mathrm{C}$. Adapted from [234].

The proportional increase of $\mathrm{NaOH}$ uptake with increasing $\mathrm{P}$ content was observed only at low phosphorus contents (<4 wt\%) for phosphorus-containing cellulose-based carbon fibers treated with $\mathrm{PCl}_{3}$ at $400{ }^{\circ} \mathrm{C}$ (Fig. 29) [236]. At higher phosphorus content the $\mathrm{NaOH}$ uptake leveled off, which was ascribed to the fact that only a part of phosphorus exists in form of monoprotic acid. 


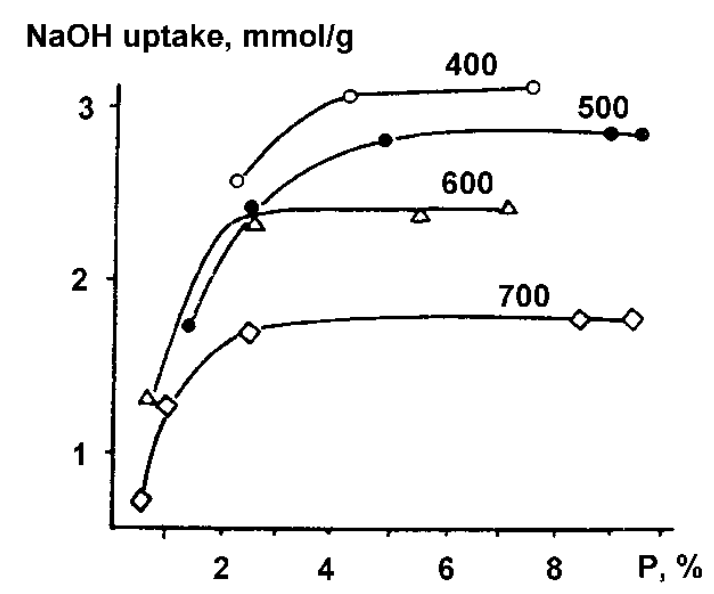

Fig. 29 Relationship between phosphorus content and $\mathrm{NaOH}$ uptake for $\mathrm{PCl}_{3}$-treated cellulose-based carbon fibers obtained at different temperatures (indicated in the figure). Adapted from [236].

A linear increase in $\mathrm{NaOH}$ adsorption with phosphorus content was also observed for $\mathrm{PCl}_{3}-$ modified polyfurfuryl alcohol-based carbons (Fig. 30) [237]. Contrary to this, adsorption of $\mathrm{HCl}$ reduced to zero with increased phosphorus content.

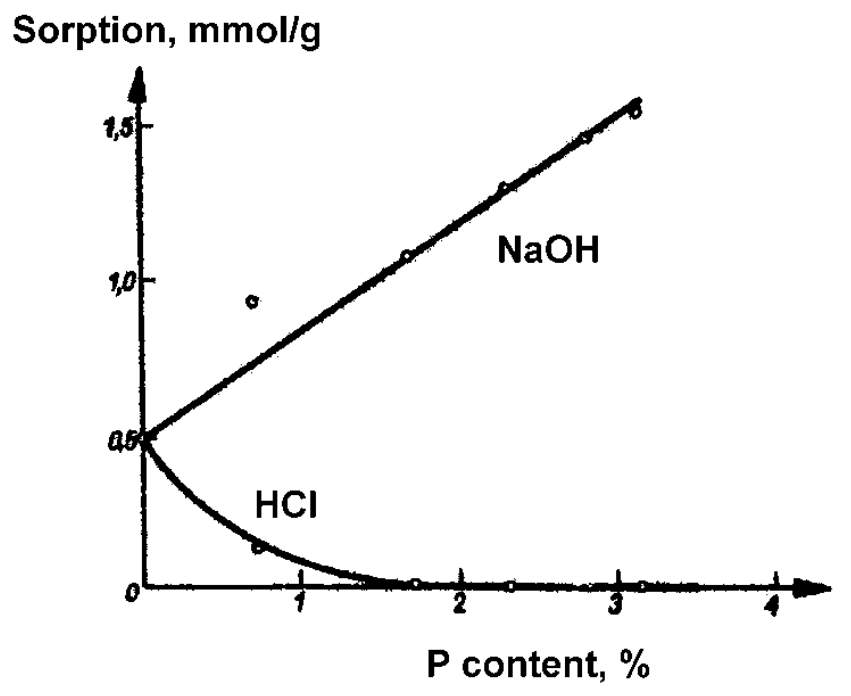

Fig. 30 Dependence of $\mathrm{NaOH}$ and $\mathrm{HCl}$ adsorption on phosphorus content of $\mathrm{PCl}_{3}$-modified carbons from polyfurfuryl alcohol. Adapted from [237].

Thus, the general trend shows an almost linear dependence of $\mathrm{NaOH}$ uptake on phosphorus content. However, the slope of the $\mathrm{NaOH}$ uptake vs phosphorus content line is different for different series of carbons. This is most probably due to the fact that $\mathrm{NaOH}$ can neutralize other acid groups (oxygen-containing only) as well. 
The point of zero charge (PZC), i.e. the $\mathrm{pH}$ at which both surface negative and positive charges are equal to each other, is a suitable characteristic to assess the acid-base behavior of a solid [310]. Usually ash-free activated carbons obtained at a high temperature $\left(>700{ }^{\circ} \mathrm{C}\right)$ possess a relatively hydrophobic surface and show a slightly basic character in aqueous electrolyte solutions [2]. Oxygen-containing surface groups impart acid properties to the carbon and change the PZC from slightly basic or neutral to acid pHs [311-313].

Introduction of phosphorus into the carbon structure imparts acidic properties, which is reflected in a shift of the PZC to the acid region. The point of zero charge of phosphoruscontaining carbon from pecan shells with a phosphorus content of $2.1 \mathrm{wt} \%$ was determined to be 1.77 [109] using a pH drift method [314,315]. The point of zero charge of phosphorus-containing carbons as obtained by the $\mathrm{pH}$ drift method attained values in the ranges of 1.9-2.0 [128] (carbons from jackfruit peels), 3.4-3.5 [99] (carbons from bamboo with phosphorus content $1.46 \mathrm{wt} \%$ ) and 1.94-2.24 [135] (carbons from agave bagasse containing 2.2-3.2 wt\% of phosphorus). Thus, phosphorus-containing carbons show an acid PZC indicating the presence of acidic surface groups.

Potentiometric titration is a more advanced technique than Boehm titration, as it allows one to determine the proton affinity distribution, i.e. the distribution of the amount of surface groups in respect to their dissociation constants.

Potentiometric titration of a phosphorus and nitrogen-containing carbon NPC obtained by carbonization of a commercial resin showed only proton dissociation in the $\mathrm{pH}$ range of 3-9 with $0.3 \mathrm{mmol} / \mathrm{g}$ of fully dissociated groups at $\mathrm{pH} 3$ [215]. The proton affinity distribution calculated by a condensation approximation showed a broad peak in the pK range of 3-8 and a second peak with pK at about 9, which were attributed to carboxylic and phosphoric acids, and to phenolic groups respectively.

The $\mathrm{pH}$-titration of a phosphorus-containing carbon obtained by carbonization of a phosphorylated phenol-formaldehyde resin did not show any discernible inflection point, which is characteristic of polyfunctional ion exchangers [213]. The PZC of this phosphorus-containing carbon estimated by extrapolation was 1.75 . The calculated proton affinity distribution exhibited four types of surface groups with pK's of 2.5 (0.69 mmol/g), $4.6(0.22 \mathrm{mmol} / \mathrm{g}), 6.8(0.89 \mathrm{mmol} / \mathrm{g})$ and $9.9(0.80 \mathrm{mmol} / \mathrm{g})$, which were attributed either to polyphosphates, phosphonic acids, phosphonous acids or phosphines [214]. An electrophoretic measurement showed that the surface of the phosphorus-containing carbon is negatively charged in the 1.5-9.5 pH range 
$[213,214]$. The negative surface charge was attributed to the dissociated acidic phosphoruscontaining groups on the surface.

Potentiometric titration revealed the acidic surface of polymer-based phosphoruscontaining carbons $[151,152,316]$. The calculated proton affinity distributions showed very acidic surface groups with pK 1.4-1.8, which were assigned to phosphate/polyphosphate groups. The amount of P-containing surface groups was proportional to phosphorus content in the carbon.

Potentiometric titration of phosphorus-containing carbon deposits on silica gel showed a progressive shift of the surface charge densities to negative values with increasing phosphorus content [170].

In the case of phosphorus-containing carbon obtained by the template method (sucrosephosphoric acid mixture as carbon and phosphorus sources and silica gel as structure directing agent) potentiometric titration revealed a very large amount of acid surface groups (4.1-4.7 $\mathrm{mmol} / \mathrm{g})$, a significant fraction of which ( $46 \pm 3 \%$ ) corresponds to phosphate groups $(p K=2.3 \pm 0.1)($ Fig. 31) [174].

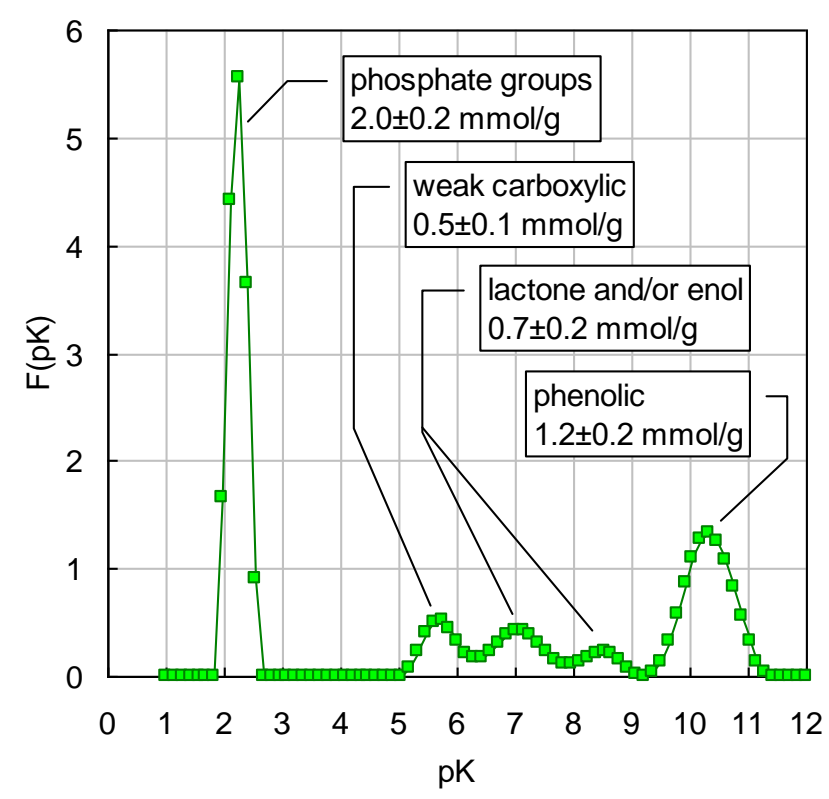

Fig. 31. Proton affinity distribution of a phosphorus-containing carbon obtained by the template method. Adapted with permission from Ref. [174]. Copyright (2011) Elsevier.

Potentiometric titration of phosphorus-containing carbons from corncob showed a progressive shift of PZC values from neutral (7.3) to acid values (1.9-2.4) with increasing phosphorus content (Fig. 32 left) [114]. The proton affinity distributions revealed that these phosphorus-containing carbons feature several types of surface groups which may be assigned to 
the first $(\mathrm{pK}=2.0-2.6)$ and second $(\mathrm{pK}=6.7-7.4)$ dissociation constants of phosphates, weakly acidic carboxylic groups ( $\mathrm{pK}=4.7-5.0$ ) and enol and phenol groups ( $\mathrm{pK}=8-11$ ) (Fig. 32 right).
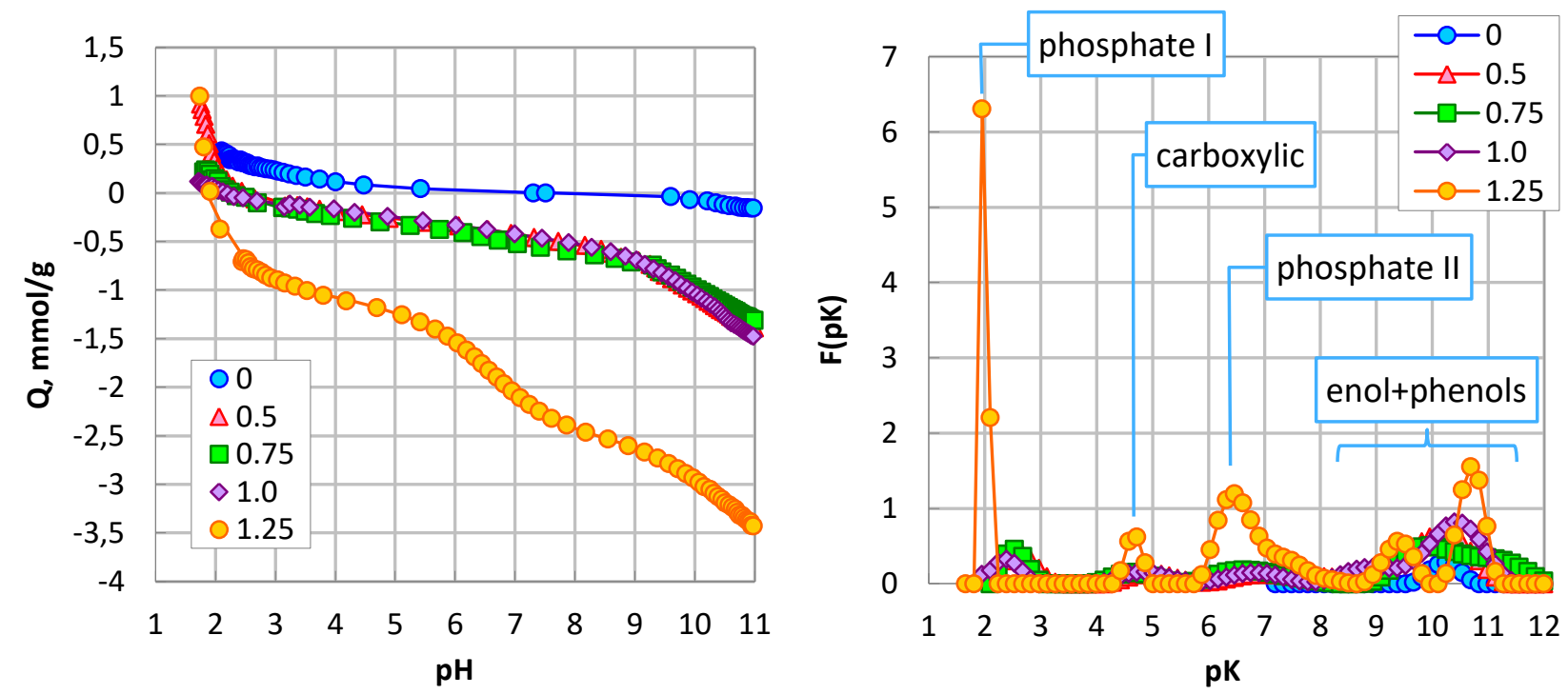

Fig. 32. Proton binding isotherms (left) and proton affinity distributions (right) for phosphorus-containing carbons from corncob obtained with different impregnation ratios. Adapted with permission from Ref. [114]. Copyright (2012) Elsevier.

Potentiometric titration of phosphorus-containing carbons from polyimide copolymer (BMDVB) showed a progressive shift of the proton binding isotherms to negative values with increasing phosphorus content (Fig. 33, left), indicating an increasing amount of acid surface groups [153]. The proton affinity distributions calculated by CONTIN method [317] show peaks corresponding to the first $(\mathrm{pK}=2.0-2.4)$ and second $(\mathrm{pK}=6.6-7.0)$ dissociation constants of phosphate groups together with carboxylic ( $\mathrm{pK}=4.4-5.4)$, enols and phenol groups $(\mathrm{pK}=8-11)$ (Fig. 33, right). The amount of phosphate groups almost linearly increased with increasing phosphorus content (Fig. 34, left). The point of zero charge shifted to a more acid region with increasing phosphorus content indicating increasing acidity of the carbon (Fig. 34, right). 

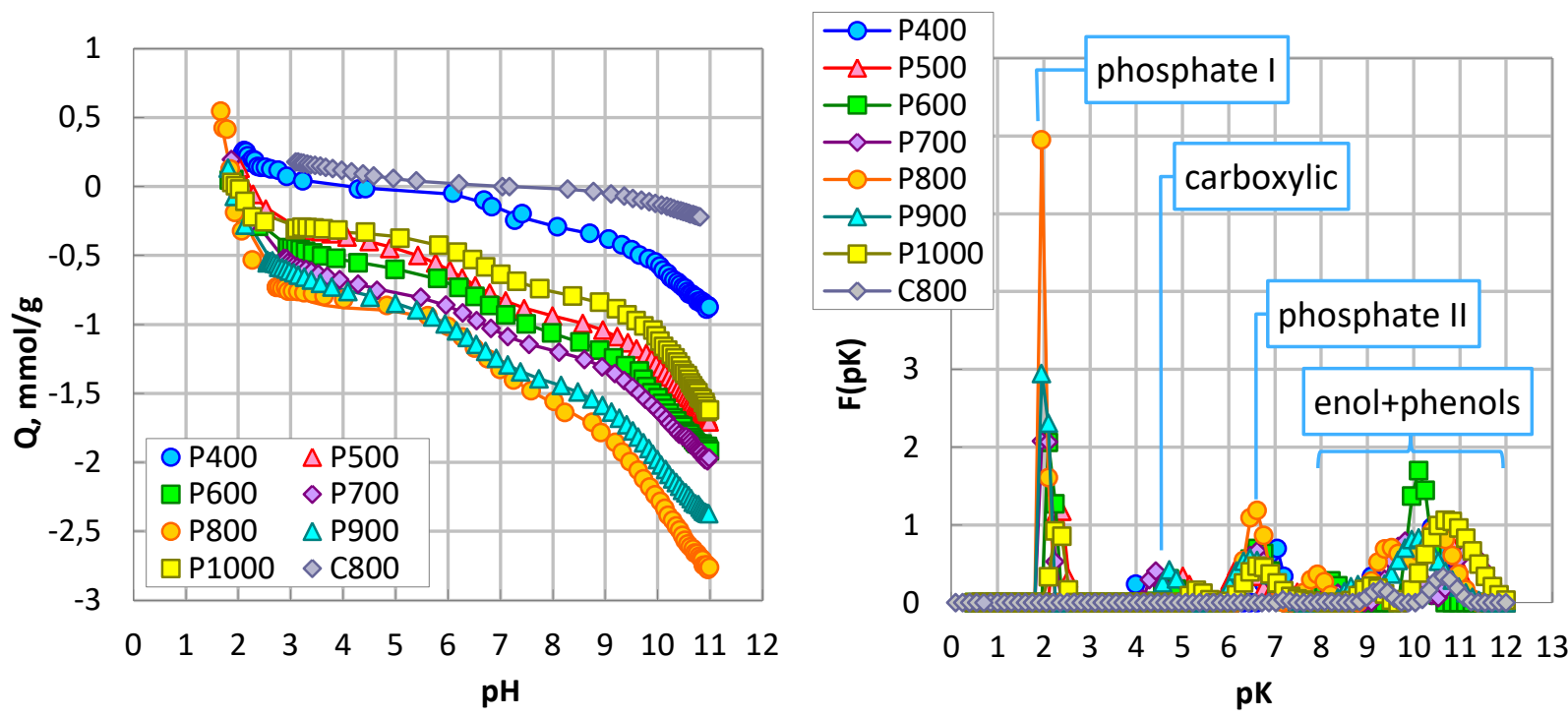

Fig. 33. Proton binding isotherms (left) and proton affinity distributions (right) for phosphorus-containing carbons from polyimide copolymer. P400-P1000 are P-containing carbons obtained at $400-1000{ }^{\circ} \mathrm{C}$. For comparison, data for $P$-free carbon obtained at $800{ }^{\circ} \mathrm{C}(\mathrm{C800})$ are included. Adapted by permission from Springer, Ref. [153]. Copyright (2013).
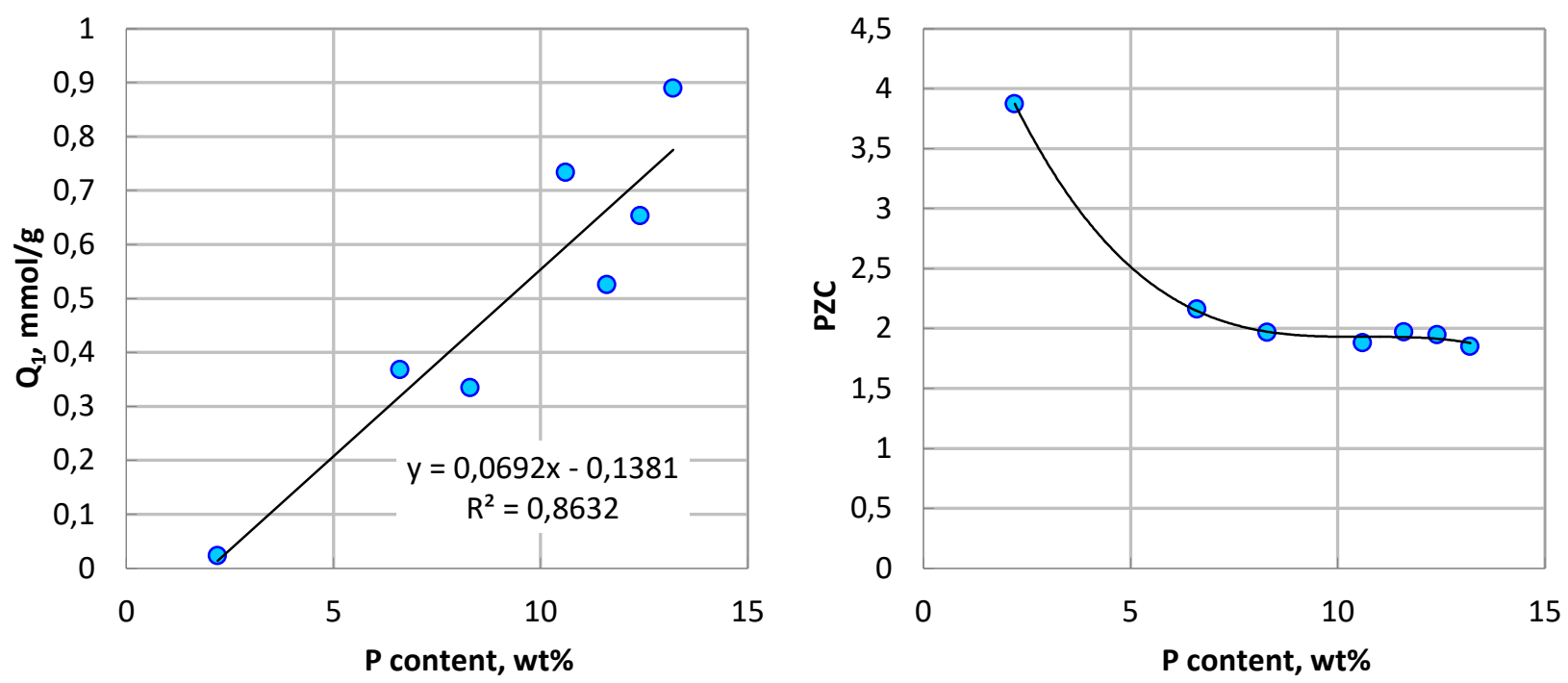

Fig. 34. Dependence of the amount of phosphate groups (left) and PZC (right) on phosphorus content in phosphorus-containing carbons from polyimide copolymer. Adapted by permission from Springer, Ref. [153]. Copyright (2013).

The potentiometric titration of an activated carbon from coconut shell modified with phosphoric acid at different temperatures showed a drastic shift of the proton-binding isotherms to negative values indicating the formation of acid surface groups with increasing temperature (Fig. 35, left) [221]. Proton affinity distributions revealed the occurrence of surface groups with a pK close to the first and second dissociation constants of phosphates (Fig. 35, right). 

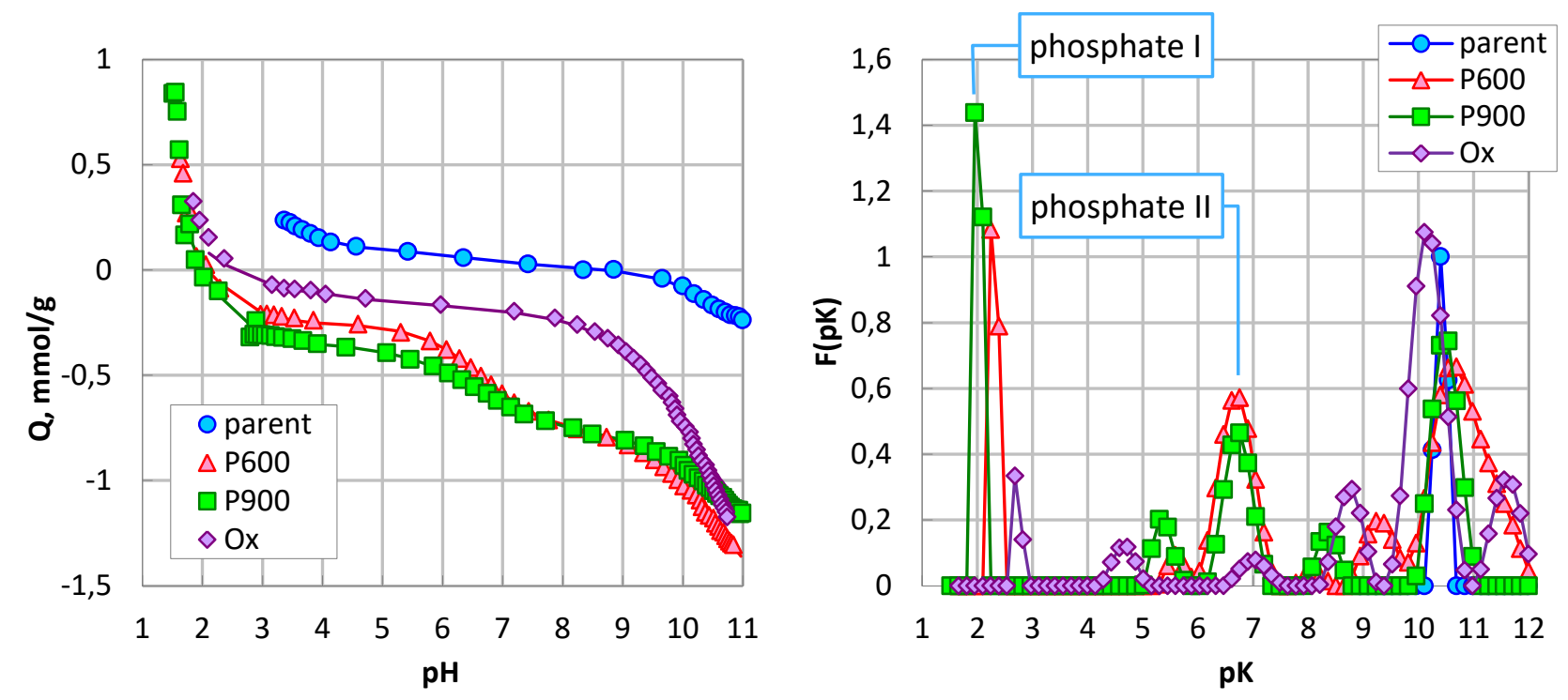

Fig. 35. Proton binding isotherms (left) and proton affinity distributions (right) for phosphorus-containing carbons from coconut shell modified with phosphoric acid at different temperatures. $\mathrm{P600}$ and $\mathrm{P900}$ are P-containing carbons modified at $600{ }^{\circ} \mathrm{C}$ and $900{ }^{\circ} \mathrm{C}$. For comparison, data for a carbon oxidized with $\mathrm{HNO}_{3}(\mathrm{Ox})$ are included. Adapted by permission from Springer, Ref. [221]. Copyright (2012).

The potentiometric titration showed three types of surface groups with pK values of 1.86 (3.64 mmol/g), $4.15(0.21 \mathrm{mmol} / \mathrm{g})$ and $5.12(0.19 \mathrm{mmol} / \mathrm{g})$ in a phosphorus-containing carbon obtained by phosphoric acid activation of agave bagasse [135]. In the case of phosphoruscontaining carbons from sucrose, the potentiometric titration showed surface groups of one type with pK = 1.7-1.9 [173]. Such acid groups were attributed to residual of phosphate $\mathrm{H}_{3} \mathrm{PO}_{4}$ ( $\left.\mathrm{pK}_{1}=1.96\right)$, pyrophosphate $\mathrm{H}_{4} \mathrm{P}_{2} \mathrm{O}_{7}\left(\mathrm{pK}_{2}=1.95\right)$, phosphorous $\mathrm{H}_{3} \mathrm{PO}_{3}\left(\mathrm{pK}_{1}=1.8\right)$ and metaphosphoric $(\mathrm{pK}<2)$ acids.

Potentiometric titration of lignosulfonate-based phosphorus-containing carbons (Fig. 36, left) revealed the occurrence of up to 7 different types of acid surface groups (Fig. 36, right), which could be assigned to phosphate/polyphosphate groups, carboxylic, enols, lactones, and phenolic groups [145]. The amount of very acidic groups was proportional to phosphorus content. 

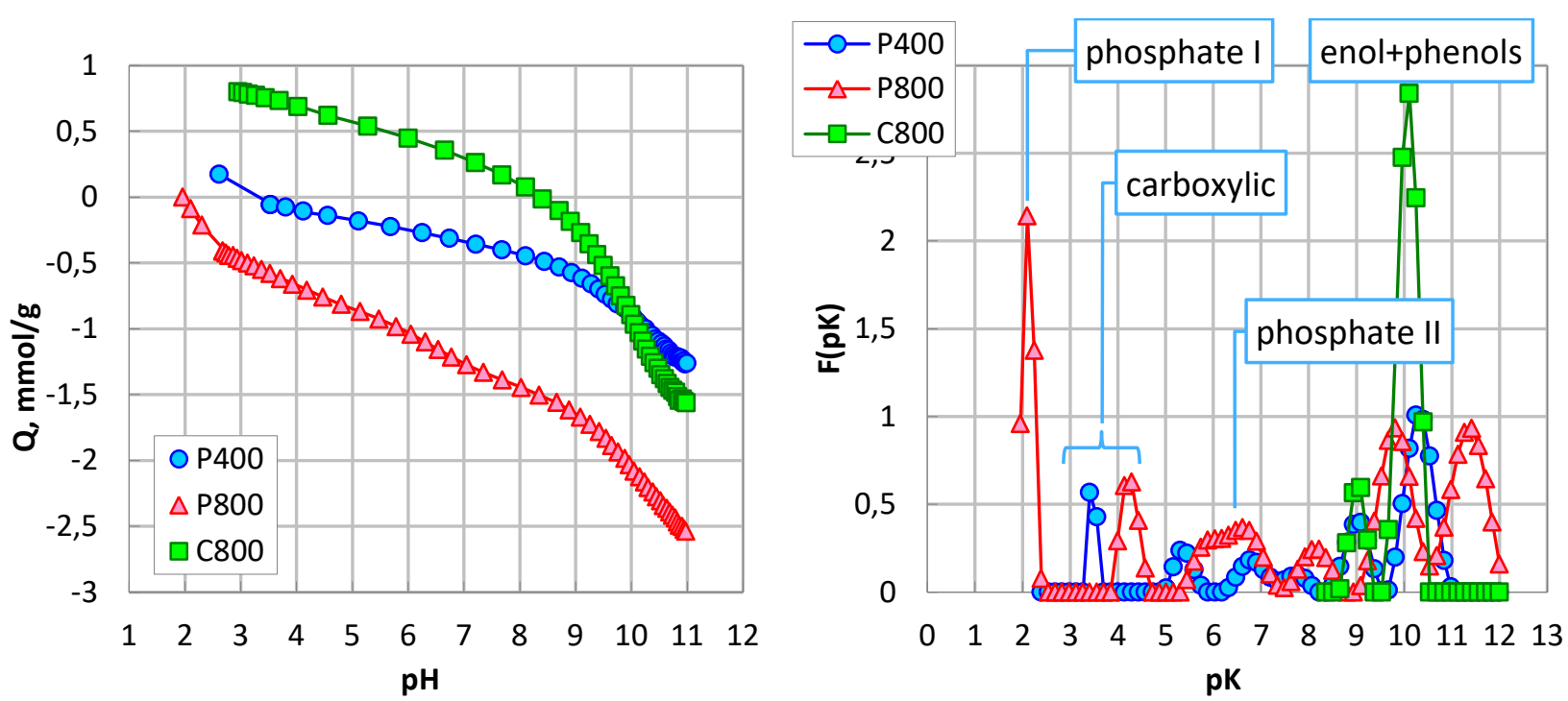

Fig. 36. Proton binding isotherms (left) and proton affinity distributions (right) for phosphorus-containing carbons obtained by phosphoric acid activation of lignosulfonate at $400{ }^{\circ} \mathrm{C}(\mathrm{P400})$ and $800{ }^{\circ} \mathrm{C}(\mathrm{P800})$. For comparison, data for a P-free carbon obtained at $800{ }^{\circ} \mathrm{C}(\mathrm{C800})$ are included. Adapted with permission from Ref. [145]. Copyright (2014) Elsevier.

Overall, one can conclude that potentiometric titration as an advanced technique is able to reveal the presence in carbons of phosphate-like surface groups with at least two dissociation constants. The amount of the most acidic groups with pK around 2-2.5 is linearly dependent on phosphorus content.

\subsection{Red-ox properties}

Phosphorus combined with the carbon surface can significantly influence the red-ox properties of $\mathrm{P}$-containing carbons. The reducing ability to $\mathrm{Fe}^{3+}$ (estimated as $\mathrm{Fe}^{3+}$ uptake from $1 \mathrm{M}$ $\mathrm{HCl}$ ) decreased drastically with increasing phosphorus content for $\mathrm{PCl}_{3}$-modified carbons from polyfurfuryl alcohol (Fig. 37) [237]. A concomitant increase in oxidizing ability to KI in N,Ndimethylformamide was observed. Increasing phosphorus content decreased the amount of bound bromine (from an aqueous solution of $\mathrm{KBr}$ and $\mathrm{Br}_{2}$ ), which was attributed to reaction of $\mathrm{PCl}_{3}$ with the carbon surface in the sites with non-saturated bonds. 


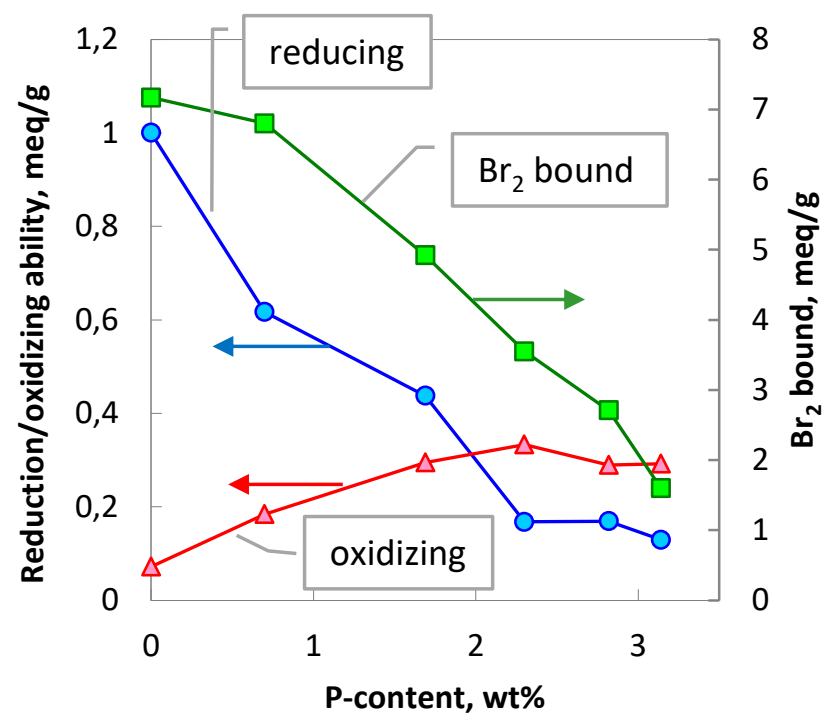

Fig. 37. Reducing ability to $\mathrm{Fe}^{3+}$, oxidizing ability to $\mathrm{KI}$ and amount of bound bromine as a function of phosphorus content in $\mathbf{P C l}_{3}$-modified carbons from polyfurfuryl alcohol. Adapted from [237].

Activated carbon fibers obtained by phosphoric acid activation of sisal fiber at $850{ }^{\circ} \mathrm{C}$ showed an enhanced reduction-adsorption capacity to $\mathrm{Ag}\left(\mathrm{NH}_{3}\right)_{2}{ }^{+}$as compared to carbon fibers produced by other methods $\left(\mathrm{ZnCl}_{2}\right.$ activation, steam activation followed by oxidation with $\mathrm{H}_{2} \mathrm{O}_{2}$, $\mathrm{KMnO}_{4}$ or $\mathrm{HNO}_{3}$ ) [318]. The enhanced amount of silver particles on the surface of phosphoric acid activated carbon fiber was evidenced by electron microscopy. Thus, $\mathrm{H}_{3} \mathrm{PO}_{4}$ activated carbon fiber might be used for the recovery of noble metals as well as in the preparation of catalysts. Silvercontaining activated carbon fibers also showed a strong antibacterial activity against Escherichia coli and Staphylococcus aureus [319].

\subsection{Adsorption of organic compounds}

The adsorption of organic molecules on phosphorus-containing carbons was extensively studied, however, without revealing the role of phosphorus-containing surface groups $[108,320]$. Generally, oxygen-containing surface groups hinder the interaction of organic molecules with the carbon surface $[55,321-323]$. The same effect was reported for phosphorus-containing surface groups. The adsorption of benzene, toluene, ethyl benzene and p-xylene mixture (BTEX) on phosphorus-containing carbons from agricultural wastes was inferior to that on commercial P-free carbon [324]. The difference was attributed to an increased polarity of the carbon surface (phosphorus and oxygen-containing surface groups), which reduces the adsorption of the hydrophobic BTEX, despite the highly developed porosity of phosphoric acid-activated carbons.

By contrast, a high adsorption of paracetamol by phosphorus-containing carbons from sucrose was reported [172]. As it might be expected, the adsorption capacity decreased with 
increasing phosphorus content and concomitant increasing total amount of acid surface groups. The reversibility of paracetamol adsorption (adsorbed amount ratio between second and first runs) increased linearly with increasing phosphorus content, revealing the key role of phosphorus in paracetamol adsorption. It was concluded that phosphorus-containing surface acidic groups are responsible for high adsorption capacities precluding chemisorption of the paracetamol.

An important role of surface acid groups in adsorption of dibenzothiophene from n-octane and a commercial hydro-treated diesel fuel using phosphoric acid-activated carbon from rice hulls was reported [325]. The beneficial role of the surface groups was ascribed to the formation of donor-acceptor complexes between the surface acidic groups and dibenzothiophene.

The presence of phosphorus, especially in the form of pyrophosphates and phosphorus pentoxide, increased the capacity and selectivity of adsorption of dibenzothiophenes on phosphorus-containing polymer-based carbons due to induced acidity to the surface [222]. Phosphorus doping of carbon also suppressed the oxidation of dibenzothiophenes.

Finally, surface acidity induced by phosphorus compounds and microporosity were the major factors contributing to the adsorption of $\mathrm{N}, \mathrm{N}$-dimethylamine from aqueous solution by phosphorus-containing carbons [115].

\subsection{Adsorption of metal ions}

The presence on acidic surface groups confers phosphorus-containing carbons the ability to adsorb metal ions from aqueous solutions. Although the adsorption of metal ions by phosphoric acid-activated carbons was patented long ago [326], this phenomenon has received only occasional attention in the literature until the end of the 20th century.

The adsorption of metal ions by phosphorus-containing carbons from pecan shells was investigated [109,327,328]. Copper adsorption increased with increasing pH in the range 2.1-4.8. At low concentrations of copper $(<1 \mathrm{mmol} / \mathrm{L})$, the ratio of copper adsorbed to released protons was close to unity suggesting an ion exchange mechanism of adsorption. At higher concentrations, the calculated ratio became considerably greater than unity, and increased with an increase in solution concentration. From this fact, it was inferred [109] that, in addition to the ion-exchange mechanism, surface complexation with oxygen- and phosphorus-containing functional groups can be considered as well. Desorption studies showed that copper could not be desorbed by deionized water but easily removed by $10 \mathrm{wt} \% \mathrm{HCl}$, which suggests that copper species were adsorbed chemically. Energy dispersive X-ray spectroscopy revealed a high concentration of phosphorus in 
the studied carbons, which allowed authors to conclude that phosphorus provides acidic sites required for copper and strontium adsorption by carbon from pecan shells [329].

Copper adsorption by phosphorus-containing carbons from polymers [151,152,330,331] and apricot stones [105] was studied as well. The adsorption of copper increased with increasing $\mathrm{pH}$ due to competition between hydrogen and copper ions for the exchange sites. Phosphoruscontaining carbon showed a higher copper uptake than oxidized carbon from the same polymer. Additional oxidation of phosphorus-containing carbon further enhanced copper adsorption. The uptake of copper also increased with increasing phosphorus content. Modeling of copper binding by means of the surface complexation model showed that phosphorus-containing groups are the most important ones for the adsorption of copper from acidic solutions.

Adsorption of heavy metal ions was investigated on a phosphorus-containing carbon obtained from a phosphorylated phenol-formaldehyde resin $[213,214]$. The capacity to adsorb lead was higher $(0.76 \mathrm{mmol} / \mathrm{g})$ than for copper $(0.61 \mathrm{mmol} / \mathrm{g})$. Breakthrough experiments showed that the affinity decreased in the order of $\mathrm{Pb}>\mathrm{Cu}>\mathrm{Cd} \geq \mathrm{Ni}$. The ability to adsorb heavy metal ions was attributed to surface acidic groups containing oxygen and phosphorus. Because the solubility of metal phosphates follows the same sequence, metal ion binding was attributed to the formation of insoluble surface metal-phosphate species. Contrary to the case of oxidized carbon, phosphorus-containing carbon exhibited a high selectivity towards lead in mixed $\mathrm{Cu}+\mathrm{Pb}$ solution [214]. Column experiments showed breakthrough of lead at 400 bed volumes while copper breakthrough appeared immediately. Lead uptake at $10 \%$ breakthrough was $0.27 \mathrm{mmol} / \mathrm{g}$ whereas copper adsorption was only $0.04 \mathrm{mmol} / \mathrm{g}$. The high selectivity towards lead was attributed to phosphonic surface groups that generally prefer larger, more polarizable $\left(\mathrm{Pb}^{2+}\right.$ is more polarizable than $\mathrm{Cu}^{2+}$ ) and strongly hydrated cations.

The adsorption of heavy metal ions $(\mathrm{Cu}, \mathrm{Cd}, \mathrm{Co}$ and $\mathrm{Pb}$ ) onto oxidized phosphoruscontaining carbon SP800-Ox has been investigated [332]. It has been shown that metal ion adsorption depends on solution $\mathrm{pH}$ and the amount of metal ions in the adsorption system. At $\mathrm{pH}$ 2 the adsorption decreases in the order: $\mathrm{Pb}>\mathrm{Cu}>\mathrm{Cd}>\mathrm{Co}\left(\mathrm{C}_{0}=0.001 \mathrm{M}\right)$ and $\mathrm{Pb}>\mathrm{Cd}>\mathrm{Cu}>\mathrm{Co}$ $\left(\mathrm{C}_{0}=0.01 \mathrm{M}\right)$. At pH 4 the adsorption decreases in the order: $\mathrm{Cu} \approx \mathrm{Co}>\mathrm{Cd}>\mathrm{Pb}\left(\mathrm{C}_{0}=0.001 \mathrm{M}\right)$ and $\mathrm{Pb}>\mathrm{Cu} \approx \mathrm{Cd}>\mathrm{Co}\left(\mathrm{C}_{0}=0.01 \mathrm{M}\right)$. At pH 6 the adsorption decreases in the following order: $\mathrm{Cu}>\mathrm{Cd} \approx \mathrm{Co}>\left(\mathrm{C}_{0}=0.01 \mathrm{M}\right)$. Heavy metal ion binding was modeled by means of the surface complexation model using a diffuse double layer to account for electrostatic effects [333,334]. The calculated metal ion binding constants (Table 4) suggest the formation of only monodentate charged complex with composition $\equiv \mathrm{SOMe}^{+}$, where $\mathrm{SO}^{-}$is a deprotonated phosphoric, carboxylic 
or phenolic surface group. No other surface complexes were found to be significant. The binding constants together with calculated species distributions showed the significant role of the most acidic phosphate and carboxylic surface groups for heavy metal ion binding.

Table 4. Calculated constants $(\log \mathrm{K})$ of formation of charged monodentate surface complex $\left(\equiv \mathrm{SOMe}^{+}\right)$with surface groups of oxidized phosphorus-containing carbon SP800-Ox. Reprinted with permission from Ref. [332]. Copyright (2004) Elsevier.

\begin{tabular}{|l|l|l|l|l|}
\hline Surface group & $\mathrm{Cu}$ & $\mathrm{Cd}$ & $\mathrm{Co}$ & $\mathrm{Pb}$ \\
\hline Phosphorus-containing & -1.86 & -1.08 & -1.26 & -0.36 \\
\hline Carboxylic & -0.21 & -0.93 & -2.71 & -0.36 \\
\hline Phenolic & -4.15 & -5.17 & -6.84 & -1.34 \\
\hline
\end{tabular}

Copper binding by phosphorus-containing carbons from corncob obtained with different impregnation ratios has been reported [114]. Copper adsorption increased with increasing pH due to the gradual dissociation of surface groups (Fig. 38). Addition of phosphoric acid to corncob during pyrolysis significantly increased the copper uptake by carbon at the same $\mathrm{pH}$. With increasing impregnation ratio, the phosphorus content increased and so did the removal efficiency. The carbons obtained with the highest impregnation ratio (1-1.25) showed a significant adsorption of copper (20-30\%) even at a pH as low as 1.5 which is lower than their corresponding PZC (1.9-2.4), i.e. under conditions where the surface of carbon is positively charged and hence cation adsorption should be hindered. This phenomenon has been ascribed to an ion exchange reaction between the delocalized protonated $\pi$-electrons of the graphene layer of carbon $\left(-\mathrm{C} \pi-\mathrm{H}_{3} \mathrm{O}^{+}\right)$and the metal ion [335]. The results also show that carbons obtained with $\mathrm{IR}=1.0-1.25$ remove more copper at $\mathrm{pH}=2.7-4.7$ than ion exchange resins with carboxylic (KB-4) and sulfonic (KU-23) groups. 


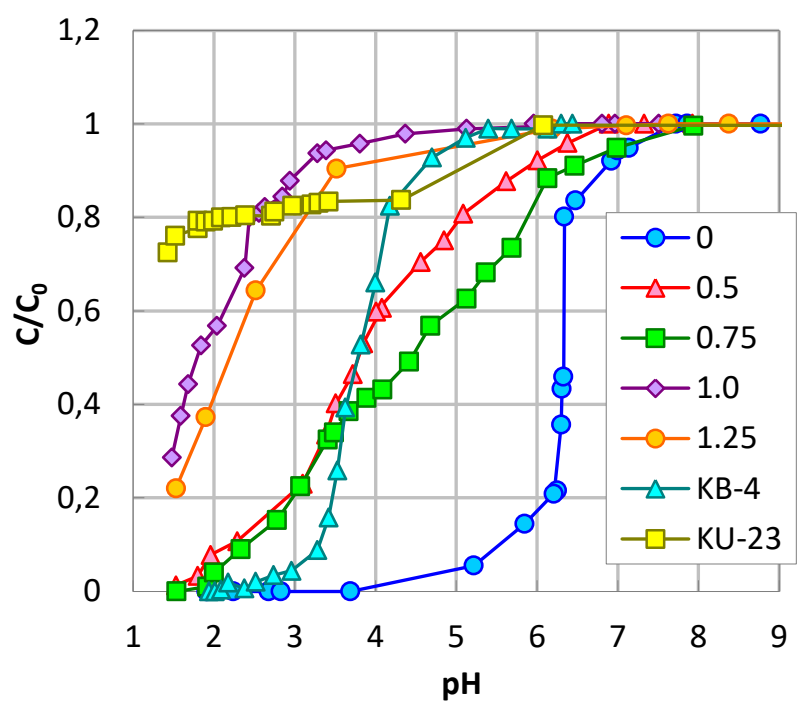

Fig. 38. Copper adsorption on phosphorus-carbons obtained from corncob and ion exchange resins with carboxylic (KB-4) and sulfonic (KU-23) groups. Impregnation ratio indicated in the inset. Reprinted with permission from Ref. [114]. Copyright (2012) Elsevier

A high copper and lead adsorption capacity of phosphorus-containing carbons obtained by phosphoric acid modification of carbon from coconut shell has been reported [221]. These phosphorus-containing carbons showed a higher adsorption of both metal ions as compared to an oxidized carbon prepared from the same activated coconut shell-based carbon (Fig. 39). The difference in adsorptive behavior was ascribed to the presence of phosphate surface groups.
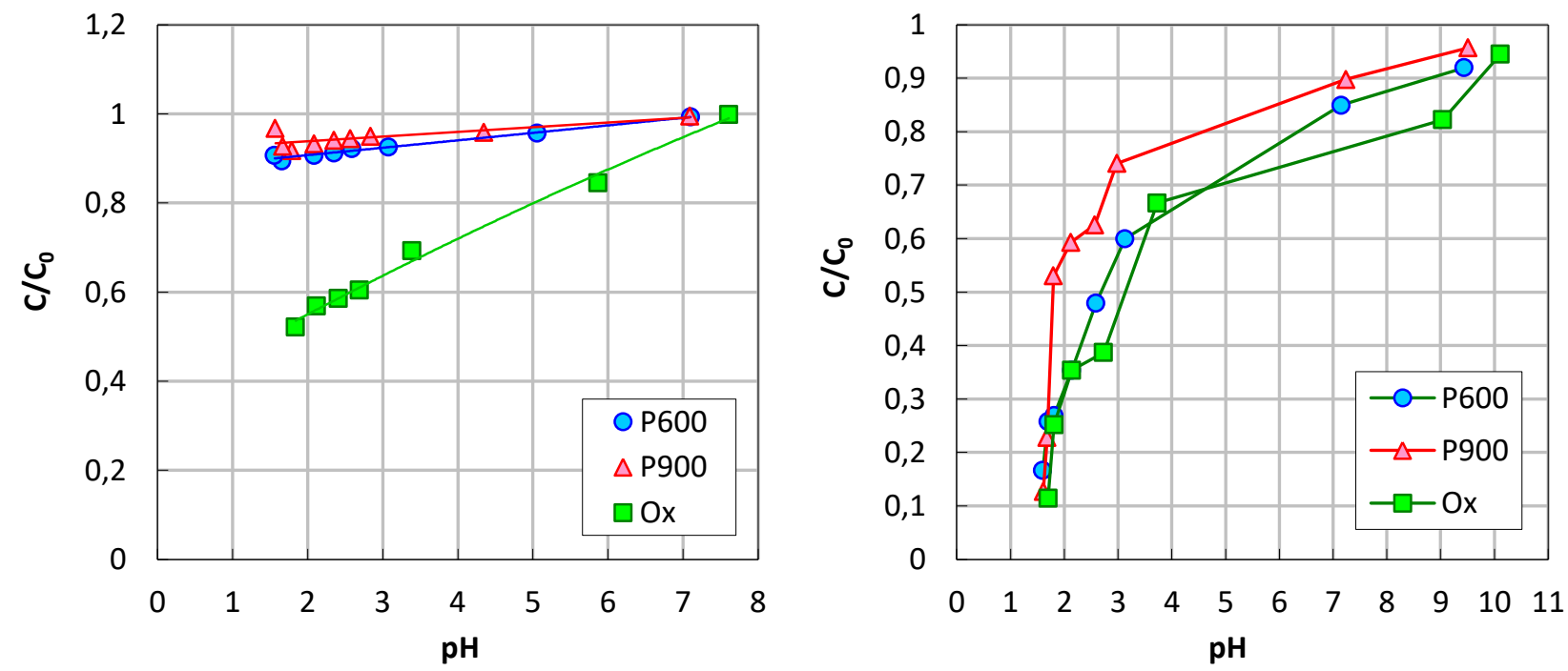

Fig. 39. Copper (left) and lead (right) adsorption by phosphorus-containing carbons (P600 and P900) and oxidized carbon $(\mathrm{Ox})$ prepared from coconut shell-activated carbon. Reprinted by permission from Springer, Ref. [221]. Copyright (2012).

$\mathrm{Pb}$ binding by phosphorus-containing carbons obtained by chemical activation of lotus stalks with phosphoric acid, trimetylphosphate and tributylphosphate has been investigated [190]. 
The maximum adsorption capacities were 139.0, 229.1 and $240.6 \mathrm{mg} / \mathrm{g}$ for carbons activated with phosphoric acid, trimetylphosphate and tributylphosphate respectively. These values are 1.4-2.3 times higher than for other phosphoric acid-activated carbons. The adsorption was attributed to a large amount of oxygen-containing functional groups.

$\mathrm{Pb}$ binding by phosphoric acid activated carbons from sucrose was reported [173]. Adsorption capacities were $220-390 \mathrm{mg} / \mathrm{g}$ for initial concentration $0.002 \mathrm{M}$ and $30-110 \mathrm{mg} / \mathrm{g}$ for initial concentration $0.0002 \mathrm{M}$. The degree of lead removal was about $90 \%$. This high adsorption capacity for $\mathrm{Pb}$ ions was attributed to a high concentration of phosphorus-containing surface groups.

$\mathrm{Pb}$ adsorption on P-containing carbon from water hyacinth fitted the Langmuir equation with a maximum capacity of $119 \mathrm{mg} / \mathrm{g}$ [139]. Under the optimized conditions, $1.0 \mathrm{~g} / \mathrm{L}$ of carbon could remove as much as $90 \%$ of $\mathrm{Pb}(\mathrm{II})(50 \mathrm{mg} / \mathrm{L})$ in $20 \mathrm{~min}$ at $\mathrm{pH}=6.0$ and temperature of $298 \mathrm{~K}$. The desorption study demonstrated that the P-containing carbon could be readily regenerated using $0.1 \mathrm{M} \mathrm{HCl}$ and reused at least six times without a significant adsorption capacity reduction. The proposed mechanism of $\mathrm{Pb}$ adsorption includes ion exchange with phosphate groups among other phenomena.

A high adsorption capacity towards copper was reported for phosphorus-containing carbons from lignosulfonate [145]. With increasing $\mathrm{pH}$ copper binding increased and approached $100 \%$, which was ascribed to progressive dissociation of surface groups followed by surface complexation (Fig. 40). With increasing phosphorus content in carbon the copper adsorption increased. All carbons exhibited a pronounced adsorption of copper at $\mathrm{pH}$ values lower than the PZC, where copper adsorption should be hindered by a repulsive force between the copper cation and the positively charged carbon surface. The phenomenon was ascribed to an ion-exchange reaction between the delocalized protonated $\pi$-electrons of the graphene layer $\left(-\mathrm{C} \pi-\mathrm{H}_{3} \mathrm{O}^{+}\right)$and the metal ion, as it occurred for other metal ions [335,336]. An additional support to the important role of the interaction with protonated $\pi$-electrons is the highest adsorption capacity exhibited by the carbon obtained at $900{ }^{\circ} \mathrm{C}$, which has a lower amount of acid surface groups than the equivalent carbon obtained at $800^{\circ} \mathrm{C}$. 


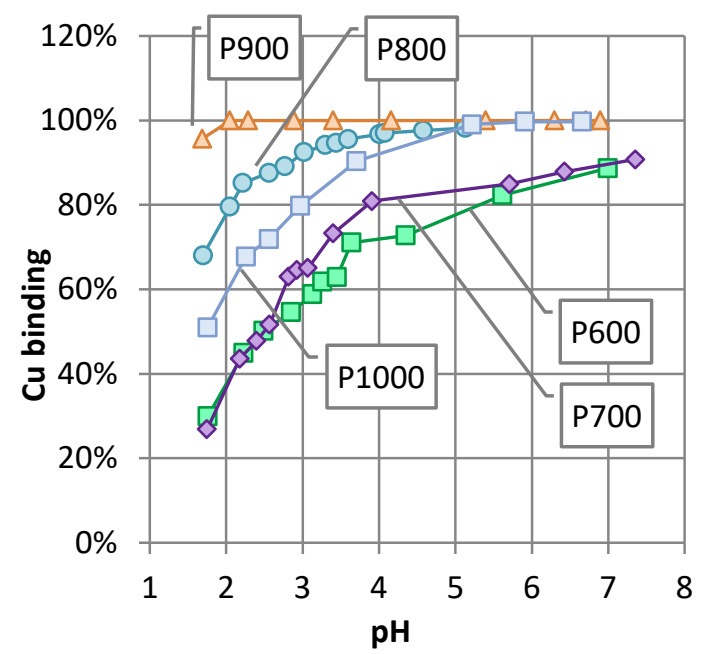

Fig. 40. Copper binding by phosphorus-containing carbons from lignosulfonate. P600-P1000 are P-containing carbons obtained at $600-1000{ }^{\circ} \mathrm{C}$. Reprinted with permission from Ref. [145]. Copyright (2014) Elsevier.

The adsorption edge for cadmium was shifted from 8-10 to more acid values, 5.5-8 with introduction of phosphorus in carbon deposits on silica gel [170]. The calculated distribution of $\mathrm{Cd}^{2+}$ binding constants showed that the strongest binding corresponded to a complex of cadmium with phosphate surface groups formed at $\mathrm{pH}<4$.

Modification of a biochar with phosphoric acid enhanced the adsorption of copper and cadmium [337]. The improvement of adsorption was ascribed to formation of surface complexes with phosphorus-containing surface groups together with other carboxyl and hydroxyl groups.

A carbon obtained by phosphoric acid activation of Cassava peel was efficient for removing $\mathrm{Cr}(\mathrm{VI})$ (99.8\%), $\mathrm{Hg}(\mathrm{II})(86.4 \%)$ and $\mathrm{Fe}(\mathrm{II})$ (92.9\%) [338]. This chemically activated carbon was more efficient than that prepared by physical activation due to the introduction of phosphate groups. A phosphorus-containing carbon obtained by $\mathrm{H}_{3} \mathrm{PO}_{4}$ activation of birch wood showed a good adsorption of mercury from aqueous solution (160 mg/g) [94].

A phosphorus-containing lignin-derived carbon showed a very high capacity for neodymium (356 mg/g) and dysprosium (345 mg/g), while the adsorption of iron was an order of magnitude lower. This suggests a possible method for the separation of these rare earth elements from Fe(III) [241]. The XPS study revealed a crucial role of surface phosphate groups in Nd(III) and Dy(III) binding, with a minor contribution of carboxylic groups. The study showed the potential of lignin-derived phosphorus-functionalized nanoporous carbon for the enrichment and separation of $\mathrm{Nd}(\mathrm{III})$ and $\mathrm{Dy}(\mathrm{III})$.

A phosphorus-containing carbon from glucose showed a high adsorption capacity towards $\mathrm{U}(\mathrm{VI})$ [339]. The adsorption capacity was 3.5 times higher than on P-free carbon. The phosphorus- 
containing carbon showed a high selectivity towards $\mathrm{U}(\mathrm{VI})$ over $\mathrm{Na}(\mathrm{I}), \mathrm{Mg}(\mathrm{II}), \mathrm{Zn}(\mathrm{II}), \mathrm{Mn}(\mathrm{II}), \mathrm{Ni}(\mathrm{II})$ and $\mathrm{Sr}(\mathrm{II})$ with selectivity coefficients of $14-51$. Almost complete removal (100 \%) of U(VI) from wastewater containing $15 \mathrm{mg} / \mathrm{L}$ was achieved with $12 \mathrm{~g} / \mathrm{L}$ loading of phosphorus-containing carbon.

Thus, one can conclude that the introduction of phosphorus in carbons leads to the formation of acidic surface groups that are able to bind metal ions. An important feature of phosphorus-containing carbons is their high adsorption capacity for metal ions at low pHs, which could be useful for the treatment of acid solutions. The high selectivity of phosphorus-containing carbons towards rare-earth metal ions and uranium deserves further investigations.

\subsection{Hydrogen adsorption}

Theoretical calculations have shown that substitution of carbon atom with phosphorus in graphene structure has a positive effect on the adsorption of hydrogen due to the possible increase in the local attractive forces of the surface by substituted atoms [340] and decrease in the activation energy of hydrogen adsorption [341]. The introduction of phosphorus increased hydrogen uptake by $50-55 \%$ at both ambient and cryogenic temperatures [340].

Introduction of phosphorus heteroatom into carbons enhanced the hydrogen physisorption capacities and hydrogen binding energies relative to pristine carbon and common carbonaceous materials [189]. The hydrogen uptake at $77 \mathrm{~K}$ and 2 bar increased from $1.8 \mathrm{wt} \%$ per $1000 \mathrm{~m}^{2} / \mathrm{g}$ to $2.4 \%$ per $1000 \mathrm{~m}^{2} / \mathrm{g}$.

Phosphorus introduction into a carbon significantly increased hydrogen adsorption from $0.18 \%$ to $1.2 \%$ at 100 bar at room temperature [342].

Finally, introduction of phosphorus into graphene material significantly increased hydrogen adsorption from $0.2-0.3 \%$ to $2.2 \%$ at 100 bar at room temperature [220].

In summary: both theoretical and experimental studies suggest that $\mathrm{P}$ atoms in carbons can enhance hydrogen adsorption (storage) therein. However, the number of works is limited to produce definitive conclusions about the possible advantages of P-containing carbons over the corresponding heteroatom-free carbons.

\subsection{Inhibition of carbon oxidation}

To tackle the weak oxidation stability of carbon materials, which impedes their wider use, many investigations have been undertaken, including doping of carbons with phosphorus [68]. 
It has been shown that $\mathrm{POCl}_{3}$ treatment of graphite decreased the rate of oxidation in dry oxygen [238]. At $850^{\circ} \mathrm{C}$ the oxidation rate for a $\mathrm{POCl}_{3}$-treated sample was an order of magnitude lower than that of the untreated sample. The apparent activation energy increased in the presence of the inhibitor from 49 to $72 \mathrm{kcal} / \mathrm{mol}$. Visual observation of graphite oxidation showed that $\mathrm{POCl}_{3}$ affects not only the overall rate of oxidation but also the kinetic anisotropy of the reaction by increasing the ratio of oxidation rates along the $a$ - and $c$-axes.

Later on, it was found that impregnation of graphite with organic phosphate and phosphite esters resulted in an increased resistance to air oxidation at elevated temperatures [231]. The oxidation rate of graphite impregnated with trichloroethyl phosphate followed by heat-treatment at $400{ }^{\circ} \mathrm{C}$ for 2 hours was approximately an order of magnitude lower than that of pure graphite. However, the apparent activation energy was the same for both materials (48 kcal $/ \mathrm{mol}$ ), suggesting that the phosphorus additive blocked the active sites rather than changing the basic oxidation mechanism. All other phosphorus additives showed a similar constant value of the apparent activation energy at $209 \pm 21 \mathrm{~kJ} / \mathrm{mol}$.

Even simple washing in phosphoric acid for 2 hours followed by drying for 1 hour in a vacuum oven reduced the oxidation rate of carbon [343]. The temperatures needed for reaching the same burn-offs were increased by about $200{ }^{\circ} \mathrm{C}$ after carbon treatment with phosphoric acid. It was inferred that phosphoric acid treatment blocks the active sites in the carbon material by forming a less reactive complex at edge sites, presumably at both zigzag and armchair sites $[343,344]$.

Introduction of phosphorus into a glassy carbon obtained by carbonizing a mixture of phenolic resin with $\mathrm{P}_{2} \mathrm{O}_{5}$ resulted in an increase of the oxidation resistance in air by about $200{ }^{\circ} \mathrm{C}$ as compared to non-doped carbon [187].

On the contrary, phosphoric acid treatment ( 2 vol\% $\mathrm{H}_{3} \mathrm{PO}_{4}$ in methanol for $6 \mathrm{~h}$, followed by drying at $100^{\circ} \mathrm{C}$ for $2 \mathrm{~h}$ ) of pitch-based carbon fibers was reported to decrease their oxidation stability [345]. However, aluminum acid phosphate impregnation, with ozone pre-treatment, improved the oxidation resistance of carbon materials (polycrystalline graphite and pitch-based carbon fibers), as shown by weight measurements in air up to $1500^{\circ} \mathrm{C}$ [345].

Reducing the oxidation tendency due to active site blockage of carbonaceous materials by impregnation with $\mathrm{H}_{3} \mathrm{PO}_{4}$ followed by heat treatment at $600{ }^{\circ} \mathrm{C}$ was reported [218]. The modification results in the formation of C-O-P bonds at the surface on the zigzag faces of the carbonaceous material. The oxidation time to reach $10 \%$ burn-off at $650{ }^{\circ} \mathrm{C}$ was 5 to 50 times longer for the phosphorus-modified carbonaceous materials. Moreover, phosphate groups at the 
surface of the carbonaceous material neutralize the catalytic effect of impurities, which are one of the principal causes of the oxidation. The efficiency of oxidation inhibition was limited to temperatures lower than $950^{\circ} \mathrm{C}$ since desorption and elimination of phosphorus radicals bonded to the carbon surface take place at higher temperatures.

It has been shown that the oxidation resistance of graphite was improved as the phosphorus loading (methylphosphonic acid) increased; a $20 \mathrm{wt} \%$ phosphorus addition to graphite resulted in increasing the oxidation temperature by about $150{ }^{\circ} \mathrm{C}$ for the same degree of burn-off [232].

It was demonstrated that P-doped activated carbon cloth samples exhibited oxidation inhibition and retained as much as $20 \%$ residual mass after reaction in air at $1000^{\circ} \mathrm{C}[20]$. Oxidation inhibition increased with increasing heat treatment temperature. P-doped carbon felt samples also exhibited oxidation inhibition, however the effect was less pronounced (the samples burned out at $\left.820^{\circ} \mathrm{C}\right)$, most probably due to low phosphorus loading $(<0.05 \mathrm{wt} \% \mathrm{P})$. Activation of carbon felt in nitric acid prior to P-doping slightly increased phosphorus loading (0.07-0.08 wt\%) and also oxidation inhibition (these samples burned out at $850^{\circ} \mathrm{C}$ ).

It has been shown that treatment with methylphosphonic acid and $\mathrm{POCl}_{3}$ increased the resistance of $C / C$ composites to oxidation [233]. The temperature of beginning of oxidation was increased from $780 \mathrm{~K}$ for untreated $\mathrm{C} / \mathrm{C}$ composite to $890 \mathrm{~K}$ for samples treated with methylphosphonic acid at $400-800{ }^{\circ} \mathrm{C}$. A C/C composite sample treated with $\mathrm{POCl}_{3}$ at $600{ }^{\circ} \mathrm{C}$ showed the same strong inhibition effect as a sample treated with methylphosphonic acid at the same temperature even though the P-content was much lower. However, the effect became very slight when the sample was pretreated at $1000^{\circ} \mathrm{C}$ in nitrogen before the oxidation experiment. The loss of inhibition effect at $1000^{\circ} \mathrm{C}$ was explained by a change in the chemical state of phosphorus (C-O-P bonding at $400-800^{\circ} \mathrm{C}$ and $\mathrm{C}-\mathrm{P}-\mathrm{O}$ bonding at $1000^{\circ} \mathrm{C}$ ). The inhibition effect of the phosphorus deposit was suggested to be due to active site blockage.

Introduction of phosphorus in carbons increased their oxidation resistance, due to the presence of phosphorus compounds on the carbon surface $[122,144,146]$. It has been suggested that the oxidation resistance is due to phosphorus-containing groups, mainly $\mathrm{C}-\mathrm{O}-\mathrm{PO}_{3}$, that acted as inhibitors of carbon gasification, first by stabilizing the carbon active sites and later acting as a physical barrier to oxygen. Upon thermal treatment up to $900{ }^{\circ} \mathrm{C}$, the $\mathrm{C}-\mathrm{O}-\mathrm{PO}_{3}$ species was transformed into $\mathrm{C}_{3}-\mathrm{PO}$, which in the presence of oxygen was reoxidized back to $\mathrm{C}-\mathrm{O}-\mathrm{PO}_{3}$, delaying carbon gasification. 
The oxidation resistance of phosphorus-containing carbons obtained by phosphoric acid activation of olive stones was investigated [286]. TPD and XPS results indicated that P-containing surface groups preferentially react with molecular oxygen, prior to carbon gasification, through the oxidation of C-P bond to form C-O-P ones, which are thermally stable at temperatures lower than $700^{\circ} \mathrm{C}$. At higher temperatures, these C-O-P type surface groups decompose to less oxygenated $\mathrm{P}$ groups on the carbon surface (of C-P type) generating $\mathrm{CO}$ (and $\mathrm{CO}_{2}$ ) in the gas phase. These C-P type surface groups seem to be very reactive and are (re)oxidized upon contact with air, even at room temperature, forming again C-O-P type groups. Thus, the presence of these oxygencontaining $\mathrm{P}$ surface groups with an interesting redox functionality of high chemical and thermal stability seems to be responsible for the high oxidation resistance and high oxygen content (once exposed to ambient air) of this type of porous carbons.

Phosphorus compounds can inhibit the oxidation of carbonaceous materials in the presence of catalytic additives. A significant suppression of the catalytic activity of cobalt by phosphorus (added as methylphosphonic acid) in the graphite-oxygen reaction was reported [232]. Neutralization of catalytic impurities by phosphate groups in $\mathrm{H}_{3} \mathrm{PO}_{4}$-treated carbon fiber preforms and C/C composite was observed [218].

It was found that the catalytic effect of Ca was almost completely suppressed by impregnation of a $\mathrm{C} / \mathrm{C}$ composite with methylphosphonic acid or $\mathrm{POCl}_{3}$ followed by heat treatment at $600{ }^{\circ} \mathrm{C}$ [233]. However, the catalytic effect of $\mathrm{K}$ was only partially suppressed due to the superior wetting ability and mobility of the potassium species. Phosphoric acid neutralized the catalytic activity of alkali metals in the oxidation of HOPG up to $800^{\circ} \mathrm{C}$ [346].

However, the absence of satisfactory protection of phosphorus (introduced as $\mathrm{P}\left(\mathrm{OC}_{6} \mathrm{H}_{5}\right)_{3}$ in 15 wt\% ethanol solution) in the case of a carbon supported $\mathrm{Cu}-\mathrm{Cr}$ catalyst towards oxygen was reported [347].

One can thus conclude that as a rule, phosphorus protects carbons against oxidation, although in a few cases the opposite effect was detected. The most widely accepted explanation to this inhibition of carbon oxidation is that the phosphorus species blocks the active sites at the carbon material surface by forming a less reactive complex at edge sites. This would involve the formation of bonds such as C-O-P and C-P-O bonds. P compounds can also inhibit the catalytic activity of impurities present in carbon, which would catalyze the reactions of carbon with oxygen. 
Phosphoric acid-activated carbon can graft more surface nitrogen during oxidation with $\mathrm{HNO}_{3}$ than a carbon prepared by $\mathrm{CO}_{2}$ activation [348,349]. The surface nitrogen is mainly in form of nitro groups on the surface of $\mathrm{P}$-containing carbons, while the $\mathrm{N}$ species in $\mathrm{P}$-free carbons are mainly in lower oxidation states. The difference was attributed to the participation of phosphorus species during treatment with $\mathrm{HNO}_{3}$ through protonation of nitric acid with formation of nitronium ion or by detachment from the carbon surface leaving active sites for attaching nitro groups.

\subsection{Catalytic activity}

Phosphorus-containing carbons have proven to be an active catalyst in various reactions including oxidation, dehydrogenation, dehydration, hydrolysis and etherification or esterification, cycloaddition and biomass transformation.

\subsubsection{Hydrogen peroxide decomposition}

The catalytic activity of $\mathrm{PCl}_{3}$-modified carbons from polyfurfuryl alcohol in hydrogen peroxide decomposition was reported [306]. It was found that incorporation of phosphorus in carbon considerably decreased the rate of $\mathrm{H}_{2} \mathrm{O}_{2}$ decomposition (Fig. 41). Noteworthy there is an analogy with oxidized carbon because increasing oxygen content as well as phosphorus content caused a decrease of basic surface groups (Fig. 30), which are catalytic centers for hydrogen peroxide decomposition.

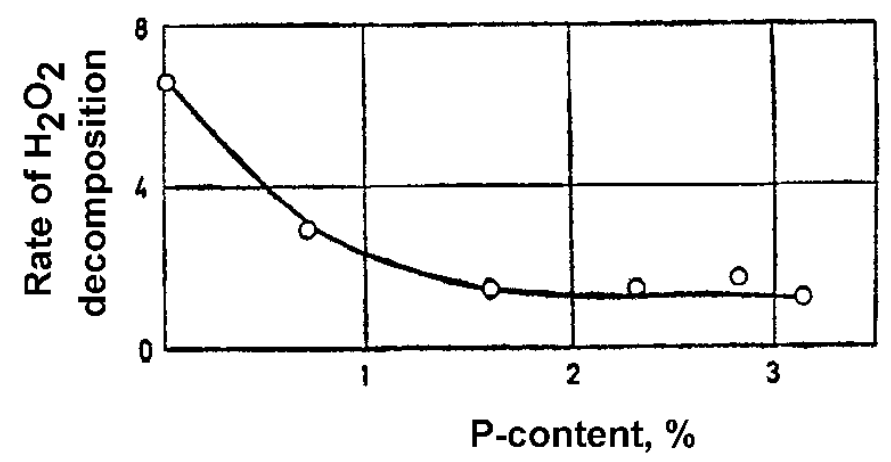

Fig. 41. Dependence of the rate constant for $\mathrm{H}_{2} \mathrm{O}_{2}$ decomposition on $\mathrm{P}$-content in $\mathrm{PCl}_{3}$-modified carbons from polyfurfuryl alcohol. Adapted from [306].

\subsubsection{Oxidation of cyclohexane}

Phosphorus-doped carbon nanotubes were active in the industrially important liquid phase oxidation of cyclohexane with molecular oxygen to produce cyclohexanol and cyclohexanone 
[350]. The enhanced catalytic activity in this oxidation reaction was attributed to an increasing electron donation ability of CNT due to doping with n-type dopants like phosphorus or nitrogen.

\subsubsection{Oxidation of cyclohexanone to dicarboxylic acids}

The catalytic properties of synthetic phosphorus-containing carbons in oxidation with air of cyclohexanone to dicarboxylic acids were investigated [351]. It was shown that addition of phosphorus to carbons increased the selectivity to adipic acid. It was argued that the selectivity improvement was due to a higher number of oxygenated functional groups able to catalyze the oxidative bond breaking of cyclic ketone.

\subsubsection{Oxidation of benzyl alcohols to benzaldehydes}

A P-doped carbon obtained by microwave treatment of phytic acid showed catalytic activity in the aerobic oxidation of benzylic alcohols with $>98 \%$ selectivity to benzaldehydes $[197,352]$. Based on extensive studies, a unique catalytic mechanism was proposed (Fig. 42), which is different from those for both $\mathrm{N}$-doped and O-doped carbon materials. The reaction mechanism includes the formation of benzyl alcoholate intermediate with $\mathrm{O}=\mathrm{P}(\mathrm{V})$ moieties, production of benzaldehyde leaving a reduced $\mathrm{P}(\mathrm{III})$ species and oxidation with oxygen of the $\mathrm{P}(\mathrm{III})$ species to regenerate the $\mathrm{O}=\mathrm{P}(\mathrm{V})$ centers to complete the catalytic cycle. Dual $\mathrm{P}, \mathrm{S}$-doping of porous carbon significantly improved the catalytic activity with excellent selectivity in aerobic alcohol oxidation reactions [353].

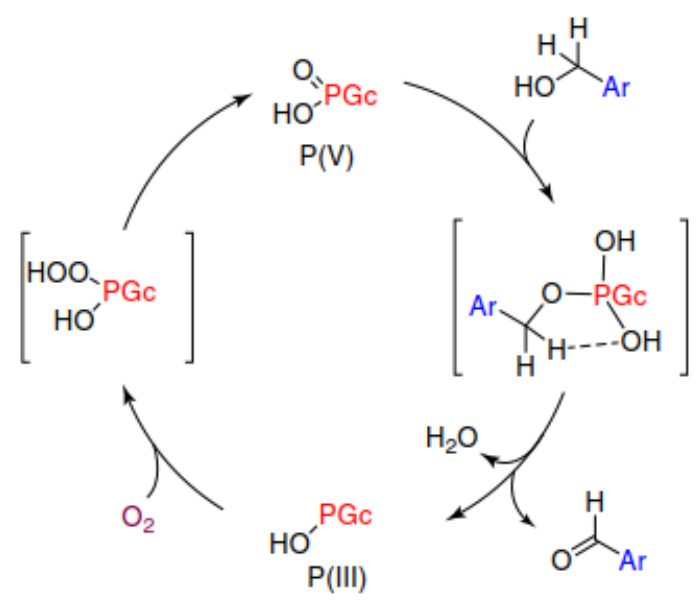

Fig. 42. Proposed mechanism of benzyl alcohol oxidation over P-doped carbon materials (PGc) using oxygen as an oxidant. Reprinted with permission from [197]. Copyright (2016) American Chemical Society.

Later on, the above mechanism was confirmed for a phosphorus-containing carbon prepared by phosphoric acid activation of microcrystalline cellulose in the selective oxidation by air of benzyl alcohol to benzaldehyde (99.7\% yield) in the presence of water [142]. The catalyst 
exhibited a high turnover frequency, which was ascribed to $C_{3} P O$ species identified by XPS experiments and DFT calculations.

\subsubsection{Oxidation of aromatic alkanes}

A high catalytic activity of phosphorus, nitrogen and sulfur co-doped carbon in the selective oxidation of aromatic alkanes was reported [354]. The excellent activity, selectivity and good recyclability of these metal-free carbon catalysts were ascribed to modulation of the electronic structure of carbon by dopants like phosphorus, nitrogen and sulfur.

\subsubsection{Direct dehydrogenation of alkanes}

Modification of an ordered mesoporous carbon with phosphorus increased the activity and selectivity in the direct dehydrogenation of propane to propylene [355]. The improved activity and selectivity were ascribed to the formation of $\mathrm{P}=\mathrm{O}$ groups created on the catalyst surface after modification. The $\mathrm{P}=\mathrm{O}$ groups are believed to be electron donors for $\mathrm{C}=\mathrm{O}$ active centers, or independent active centers for the direct dehydrogenation of propane. Doping with phosphorus was more advantageous than with boron for the direct dehydrogenation of propane, while nitrogen-doping was inferior to undoped mesoporous carbon [356]. The difference in catalytic activity was attributed to a different effect on the amount of carbonyl and/or quinone groups of the carbon, which play a pivotal role in the direct dehydrogenation of propane.

\subsubsection{Oxidative dehydrogenation of alkanes}

Phosphorus doping of carbon can improve the catalytic behavior in oxidative dehydrogenation reactions on carbon catalysts, as it was highlighted in recent reviews [357-359].

Carbon nanofibers (CNF) showed a high catalytic activity in the oxidative dehydrogenation of propane [360]. Modification of CNF with phosphorus (impregnation with $\left(\mathrm{NH}_{4}\right)_{2} \mathrm{HPO}_{4}$ followed by calcination in argon at $800^{\circ} \mathrm{C}$ for $2 \mathrm{~h}$ and then in air at $600^{\circ} \mathrm{C}$ for $2 \mathrm{~h}$ ) improved the thermal stability of the catalyst in an oxygen environment by blocking active sites $[20,68]$. P-modified CNF can operate at $500{ }^{\circ} \mathrm{C}$ without gasification and a $40 \%$ propene selectivity could be reached at a $42 \%$ propane conversion.

Oxidized carbon nanotubes were used as catalyst in the oxidative dehydrogenation of propane [361] and n-butane [362]. Doping of oxidized CNT with 0.5 wt\% of phosphorus (impregnation with $\left(\mathrm{NH}_{4}\right)_{3} \mathrm{PO}_{4}$ followed by calcination for $30 \mathrm{~min}$ ) significantly enhanced the yield of alkenes to $13.8 \%$. Phosphorus doping of carbon nanotubes increased the selectivity to alkenes by suppressing the combustion rate of butane, rather than enhancing the formation rate of alkenes, and inhibited the oxidation of the carbon catalyst. 
CNT also catalyzed the oxidative dehydrogenation of ethane to ethylene. P-doping of oxidized CNT drastically enhanced the oxidation resistance and thus the alkene selectivity was increased due to the suppression of electrophilic oxygen intermediates on the carbon surface [363]. However, the conversion was low due to a decreasing reactivity of alkanes with decreasing chain length.

A promotion mechanism of phosphate modification of nanodiamond in the oxidative dehydrogenation of propane was reported [364]. The results revealed that phosphate preferentially reacts with the phenol groups initially present on the nanodiamond surface, and then it selectively blocks the defect sites that lead to COx formation from deep oxidation resulting in an increased propene selectivity. During this process, the catalyst active sites (ketonic carbonyl groups) were not affected. Such effects originated from the formation of covalent C-O-P bonds on the carbon surface, which was estimated as $15 \%$ loading.

Modification of a graphitic mesoporous carbon with phosphorus heteroatom improved the selectivity in the oxidative dehydrogenation reaction of isobutane to isobutene [365]. The improvement in selectivity was not proportional to the amount of phosphorus added - a small phosphorus content improved the selectivity by suppressing the combustion of isobutane. However, a higher amount of phosphorus groups resulted in coverage of selective quinone sites and/or creation of active sites favorable to total oxidation.

Thus, one can summarize these results as follows: doping of carbons with phosphorus enhances oxidation stability in an oxygen environment during the oxidative dehydrogenation by blocking defect sites, and enhances the activity and selectivity to alkenes.

\subsubsection{Catalytic wet peroxide oxidation}

A phosphorus and nitrogen-containing carbon xerogel showed a high activity in the catalytic wet peroxide oxidation of 4-nitrophenol [168]. It was shown that the increase of phosphoric acid concentration during activation resulted in a higher removal rate for 4nitrophenol in catalytic wet peroxide oxidation. The carbon catalyst with a highest amount of phosphorus (3.5 wt\%) achieved a complete decomposition of 4-nitrophenol within $60 \mathrm{~min}$.

\subsubsection{Hydrolysis of ethyl acetate}

Modification of a coconut shell carbon with phosphoric acid at high temperature significantly increased its catalytic activity in the hydrolysis of ethyl acetate [366]. With increasing modification temperature, the amount of incorporated phosphate groups increased in parallel with catalytic activity for ethyl acetate hydrolysis. The high catalytic activity in this reaction was 
ascribed to the formation of thermally stable strongly acidic phosphorus-containing surface groups, an increase in the number of surface acid groups and their dissociation constants. The catalytic activity of carbons modified by phosphoric acid was higher than that of oxidized carbon due to the presence of strongly acidic phosphate groups.

\subsubsection{Dehydration of methanol}

A phosphorus-containing carbon obtained by phosphoric acid activation of olive stones showed a high selectivity in methanol dehydration to dimethyl ether [367]. The reaction in helium atmosphere resulted in a gradual deactivation of the catalyst due to coke deposition on acid sites and reduction of surface C-O-P sites to C-P sites. Deactivation of the catalyst was avoided in air atmosphere due to the re-oxidation of reduced surface phosphorus-containing groups without gasification of the carbon catalyst.

\subsubsection{Dehydration of ethanol}

The catalytic decomposition of ethanol over phosphorus-containing acid carbon catalysts obtained by phosphoric acid activation of olive stones has been studied as well [102]. The reaction proceeded to mainly dehydration products, with a very high selectivity to ethylene. In the absence of $\mathrm{O}_{2}$ the catalysts suffered a progressive deactivation by coke deposition on the acid active sites. However, the presence of oxygen produced a significant increase of the ethanol conversion without any significant change in the selectivity of the reaction and avoided deactivation of the catalysts under the operation conditions studied.

\subsubsection{Dehydration of 2-propanol}

The influence of phosphorus on the decomposition of 2-propanol at $200{ }^{\circ} \mathrm{C}$ was studied for $\mathrm{PCl}_{3}$-modified carbons [306]. Comparing the changes of selectivity during 2-propanol decomposition towards dehydration (Fig. 43, line 1) and dehydrogenation (Fig. 43, line 2) with phosphorus content revealed the great impact of phosphorus on the course of the reaction. The increase of phosphorus content, which increased the acidic character of the carbon surface, caused as well an increase in the selectivity to dehydration and significant decrease in the selectivity to dehydrogenation. Based on the known crucial role of aromatic graphene layers in dehydrogenation, it was concluded that introduction of phosphorus, aside from creation of new catalytic centers active for dehydration, produces a shield effect that hinders the centers of dehydrogenation. This fact is supported by the fast drop of the selectivity of dehydrogenation to di-isopropyl ether with increasing phosphorus content (Fig. 43, line 3). 


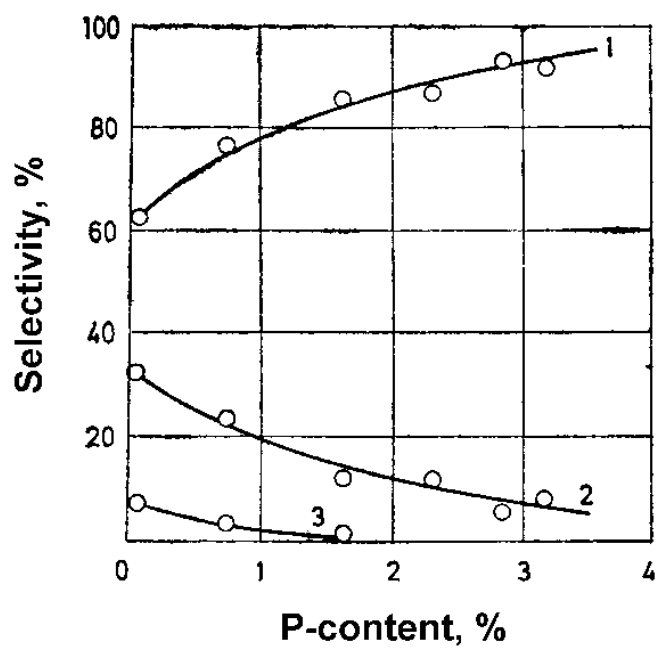

Fig. 43. Dependence of selectivity of 2-propanol decomposition on $\mathrm{P}$-content of $\mathrm{PCl}_{3}$-modified carbons from polyfurfuryl alcohol: 1 - dehydration to propylene, 2 - dehydrogenation to acetone, 3 - dehydration to di-isopropyl ether. Adapted from [306].

Phosphorus-containing carbons from lignocellulosic waste or lignin showed a high catalytic activity in the decomposition of 2-propanol $[95,146,299,368]$. For all the studied phosphoruscontaining carbon catalysts the decomposition products were mainly propylene and a very small amount of di-isopropyl ether, i.e., only dehydration reaction occurred. It was concluded that dehydration of 2-propanol to propylene proceeds over strong Brønsted acid sites of phosphoruscontaining carbon catalysts formed during the phosphoric acid activation step. The increase in the amount and strength of acid sites increased the catalytic activity, but did not affect significantly the value of the apparent activation energy of the dehydration reaction. The presence of water vapor (up to 10 vol\%) in the inlet gas stream did not affect significantly neither the conversion level nor the product distribution. Phosphorus-containing carbon catalysts showed a stable catalytic performance in long-time experiments (up to $10 \mathrm{~h}$ ). On the contrary, acetone was the main product of 2-propanol decomposition when P-free carbon catalyst was used, which is indicative of the presence of basic sites.

A phosphorus-containing ordered mesoporous carbon with 1 wt\% of phosphorus showed a high conversion of 2-propanol with near $100 \%$ selectivity to propene [229]. The point of $50 \%$ conversion of 2-propanol was observed at $245^{\circ} \mathrm{C}$, which is similar to a previous report [95] despite the low phosphorus content. It was argued that the relatively high catalytic activity and selectivity may result from the large and uniform mesopores of the ordered mesoporous carbon material.

Soft-templated phosphorus-containing mesoporous carbons showed a high catalytic activity in the conversion of 2-propanol to propene [164]. The activity of these carbon catalysts 
correlated with the number of acid groups obtained by the $\mathrm{NH}_{3}$-TPD method. Increasing the phosphorus content increased the number of acid sites and decreased the temperatures for $25 \%$ and $50 \%$ conversion by $60-70{ }^{\circ} \mathrm{C}$.

\subsubsection{Dehydration of 2-butanol}

The catalytic conversion of 2-butanol on a carbon-based acid catalyst prepared by phosphoric acid activation of olive stones $[95,121]$ has been investigated [101]. It has been shown that 2-butanol over phosphorus-containing carbon yields mainly dehydration products, mostly cis2-butene and trans-2-butene with lower amounts of 1-butene, as well as a very small amount of methyl ethyl ketone as dehydrogenation product. Theoretical calculations demonstrated that the dehydration reaction process follows an E2 mechanism (one-step reaction) with a strong character of E1 mechanism (two-step reaction) [369].

\subsubsection{Selective fructose dehydration to hydroxymethylfurfural (HMF)}

The activity of phosphorylated mesoporous carbons (PMCs) in the dehydration of fructose to HMF was investigated [165]. Acidic PMCs containing 0.9-2.6 at\% of phosphorus showed a better selectivity to HMF compared to a sulfonated carbon catalyst despite exhibiting a lower activity. The concentration of P-containing groups on the PMC correlated with the activity/selectivity of the catalysts - the higher the phosphorus concentration, the higher the activity. However, increasing the P-content decreased the selectivity to HMF. Indeed, a lower concentration of $\mathrm{P}-\mathrm{O}$ groups minimized the degradation of HMF to levulinic acid and the formation of by-products, such as humines.

A linear dependence of the catalytic activity on phosphorus content for phosphorylated carbon nanofibers in fructose dehydration was reported (Fig. 44) [283]. The selectivity to HMF was significantly improved from $48-54 \%$ to $81-87 \%$ by heat treatment of phosphorylated carbon nanofiber at $400{ }^{\circ} \mathrm{C}$ in air. The increase was ascribed to a transformation of C-O-P bonds to C-P bonds less prone to leaching, which causes formation of a homogeneous catalyst like phosphoric acid with low selectivity. 


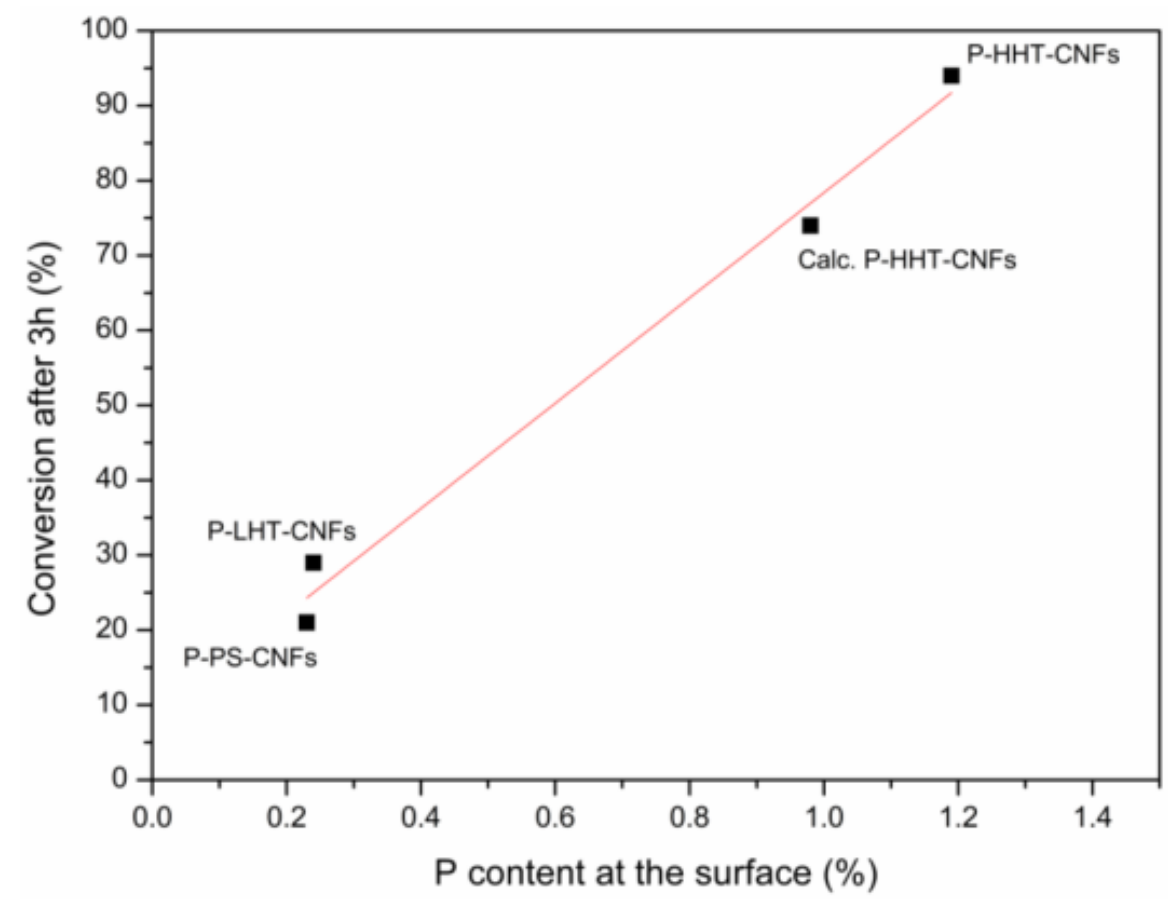

Fig. 44. Correlation between catalyst activity in fructose dehydration and surface phosphorus content in carbon nanofibers. Reprinted from Ref. [283].

Increasing the amount of acid groups (from 0.64 to $3.36 \mathrm{mmol} / \mathrm{g}$ ) in a carbon catalyst obtained by hydrothermal treatment of glucose with phosphoric acid increased the catalytic activity in fructose conversion (from 77\% to 96\%) [370]. However, the highest selectivity to HMF, $73.8 \%$, was observed for a carbon catalyst with a moderate amount of acidity. A carbon prepared without phosphoric acid showed no catalytic activity for the fructose dehydration reaction. Some loss of catalytic activity of the P-containing carbon catalyst appeared in the second cycle, while the catalytic performances were maintained well in the latter three cycles. The loss of activity in the second cycle was attributed to an acid site leakage from phosphorus-containing surface groups. Thus, the acid density and the phosphorus content of the reused catalyst decreased from 0.81 to $0.15 \mathrm{mmol} / \mathrm{g}$ and from 2.5 to 0.08 at\% respectively during four cycles.

\subsubsection{Etherification}

Phosphorus-containing carbons prepared by phosphoric acid activation of St-DVB copolymer followed by oxidation with $\mathrm{HNO}_{3}$ showed a high catalytic activity in ethyl-tert-butyl ether (ETBE) synthesis from isobutene and ethanol [307]. A maximum isobutene conversion of $63 \%$ was achieved at $100{ }^{\circ} \mathrm{C}$ with a selectivity of $67 \%$.

A crucial role of phosphate groups of carbon catalysts in ETBE synthesis was reported as well $[371,372]$. Modeling the catalytic activity showed that the turnover frequency of phosphate groups $\left(0.0102 \mathrm{~s}^{-1}\right)$ was almost an order of magnitude higher than that of sulfonic groups 
$\left(0.00116 \mathrm{~s}^{-1}\right)$. The study revealed a key role in ETBE synthesis of relatively weak phosphate groups as compared to sulfonic groups.

The catalytic activity of phosphorus-containing carbon from ash wood in tert-amyl methyl ether synthesis from 2-methylbut-2-ene and methanol was studied [373]. A carbon catalyst obtained by activated carbon modification with phosphoric acid at $800{ }^{\circ} \mathrm{C}$ contained $7.9 \mathrm{wt} \%$ of phosphorus and showed a moderate catalytic activity, lower than that of sulfonated carbons.

\subsubsection{Esterification}

Phosphorus-containing carbons obtained by direct modification of ordered mesoporous carbons with phosphoric acid at room temperature showed a good catalytic activity and good reusability in the esterification of oleic acid with methanol [284]. The activity of these carbon catalysts increased with increasing both phosphorus content and the amount of acid groups.

\subsubsection{Methoxilation of $\alpha$-pinene}

An oxidized phosphorus-containing carbon (1.4 at\% P) obtained by phosphoric acid activation of olive stones showed a high catalytic activity in methoxilation of $\alpha$-pinene to $\alpha$-terpinyl methyl ether with good selectivity [374]. An oxidized phosphorus-containing carbon exhibited a higher catalytic activity than an oxidized carbon xerogel and oxidized commercial carbon Norit, which was ascribed to the phosphorus-containing surface groups.

\subsubsection{Cycloaddition of $\mathrm{CO}_{2}$ to epoxides}

Phosphorus-modified graphitic carbon nitride $\left(\mathrm{P}-\mathrm{C}_{3} \mathrm{~N}_{4}\right)$ was used as catalyst for cycloaddition of $\mathrm{CO}_{2}$ to propylene oxide to produce propylene carbonate [375]. The catalytic activity of $\mathrm{P}-\mathrm{C}_{3} \mathrm{~N}_{4}$ increased with the rise of $\mathrm{P}$ content as a result of the enrichment of acid sites. $\mathrm{P}$ $\mathrm{C}_{3} \mathrm{~N}_{4}$ can be easily separated and reused for at least five times without showing significant loss of activity.

\subsubsection{Catalytic biomass transformation}

Phosphorus-containing carbon was found to be active in catalytic fast pyrolysis of cellulose and biomass to selectively produce levoglucosenone - a key intermediate of biologically active products [376]. The activity of this phosphorus-containing carbon was higher than that of liquid strong acids $\left(\mathrm{H}_{3} \mathrm{PO}_{4}, \mathrm{H}_{2} \mathrm{SO}_{4}\right)$, solid super acid $\mathrm{SO}_{4}{ }^{2-} / \mathrm{TiO}_{2}$ and solid phosphoric acid. The superior catalytic activity of the phosphorus-containing carbon catalyst was attributed to certain chemical forms of phosphorus species including $\mathrm{C}-\mathrm{O}-\mathrm{PO}_{3}$ and $\mathrm{C}-\mathrm{PO}_{3}$ which were absent in other catalysts. A granular phosphorus-containing carbon catalyst exhibited a good reusability and stability in the 
recycling experiments - the yield of levoglucosenone was stable during six consecutive runs without any regeneration of the recycled granular carbon catalyst.

Solid catalysts based on carbon xerogels (CXs) containing various heteroatoms $(S, P, N, O)$ were tested in hydrolysis of cellobiose to glucose [377]. CXs containing 3.4 wt\% of phosphorus showed the best catalytic performance, reaching $90 \%$ conversion of cellobiose with $72 \%$ selectivity to glucose, under oxidative atmosphere and in a short reaction time of only $4 \mathrm{~h}$. The presence of phosphonates (-P-C-) was found to increase the selectivity to glucose up to an unprecedented $87 \%$.

\subsubsection{Catalyst support}

A phosphorus-containing carbon obtained by phosphoric acid activation of kraft lignin was used as support for Pd catalyst [378]. The presence of phosphorus-containing groups C-O-P, C-P-O and especially $\mathrm{C}_{3}-\mathrm{P}$ avoided the necessity to use triphenylphosphine as ligand in the SuzukiMiyaura cross-coupling reaction reactions.

Phosphorus-containing carbons with deposited Pd showed a high oxidation resistance in oxidation of toluene [379]. It has been shown that phosphorus-containing groups function as a physical barrier, increasing the oxidation resistance of the carbon support and thus avoiding the burn-off of the carbon part of the catalyst during the oxidation of the organics.

The use of phosphorus-containing carbon with acid surface groups allowed preparation of bifunctional Pt-Pd catalyst for hydrodeoxygenation of tire oil [380,381] or bio-oil [382,383]. The presence of acid phosphorus-containing acid sites lead to synergetic effect with metallic Pt and Pd sites, which favors the hydrogenation of the oxygenated compounds of bio-oil and the unsaturated hydrocarbons of tire oil.

Inhibition of carbon oxidation by phosphorus-doping was utilized in the fabrication of oxidation-resistant carbon-supported VPO catalyst for partial oxidation of propane or propylene $[103,384]$. A carbon support with strong acid sites and high oxidation resistance due to the presence of stable surface phosphorus groups was obtained by phosphoric acid activation of biomass waste (orange skin or olive stones). The subsequent impregnation with $\mathrm{NH}_{4} \mathrm{VO}_{3}$ followed by calcination at $250^{\circ} \mathrm{C}$ yielded surface VPO active phases, selective for the partial oxidation of propane and propylene.

\subsection{Phosphorus effects in promoting graphitization}

A partial change from hard carbon (nongraphitizable) to soft carbon (graphitizable) by phosphorus introduction was reported [148]. The addition of phosphoric acid to a carbonaceous 
precursor (epoxy resin) had a strong effect on carbon structure. The strain probability distribution function calculated from the (002) peak in XRD showed the typical bimodal character of the nanostructure of P-doped carbons. The volume fraction of highly strained, non-parallel layers of carbon, 1-g, decreased with increasing carbonization temperature and with increasing amount of phosphorus in the carbon up to $10 \mathrm{wt} \%$ and increased for carbons with a higher content of phosphorus. With the increase of phosphorus content in the carbon (with increasing amount of $\mathrm{H}_{3} \mathrm{PO}_{4}$ added to the precursor) the interlayer spacing, $d_{002}$, decreased and the lateral crystallite size, $L_{a}$, increased indicating an increase in the degree of structural order. Increasing the carbonization temperature increased the lateral crystallite size, $L_{a}$, while the temperature dependence of the interlayer spacing, $d_{002}$, was much less pronounced. The pore size, $R_{g}$, of the carbon doubled with increasing amount of phosphorus in the carbon from 0 to $10 \mathrm{wt} \%$. However, the BET surface area of the carbons was in the range of $1.5-2.4 \mathrm{~m}^{2} / \mathrm{g}$, which indicates the occurrence of closed porosity not accessible to $\mathrm{N}_{2}$ molecules.

Phosphorus in the carbon structure was reported to enhance the graphitization degree of carbon fibers [206]. The (002) diffraction peak of phosphorus-containing carbon fiber suddenly sharpened at $3000^{\circ} \mathrm{C}$ (Fig. 45). The calculated interlayer spacing for this carbon fiber was $0.3378 \mathrm{~nm}$, which is close to the ideal value of graphite, $0.3354 \mathrm{~nm}$. Based on the asymmetry of the (002) peak it was concluded that phosphorus-containing carbon fiber is an inhomogeneous mixture of graphitic and turbostratic structures. The crystallite dimension $L_{c}$ of that phosphoruscontaining carbon fiber was larger than that of the same carbon fiber without phosphorus (Fig. 46). The difference in $L_{c}$ becomes larger with increasing HTT and became seven-fold at $3000^{\circ} \mathrm{C}$. 


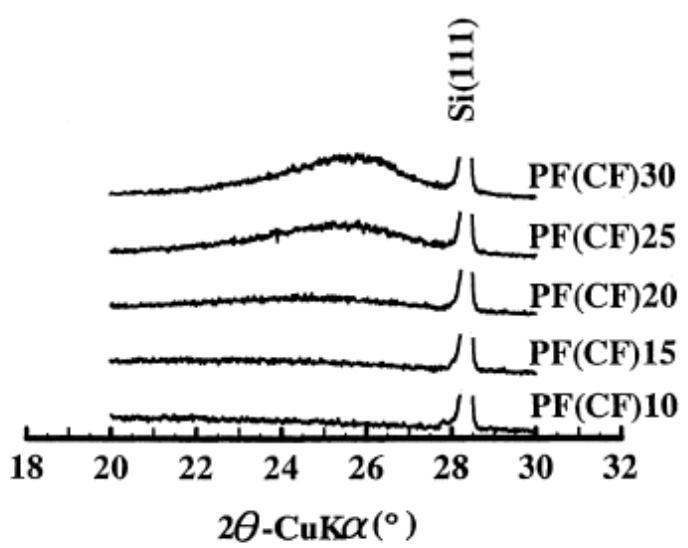

(a) $\mathrm{PF}$ (CF) series

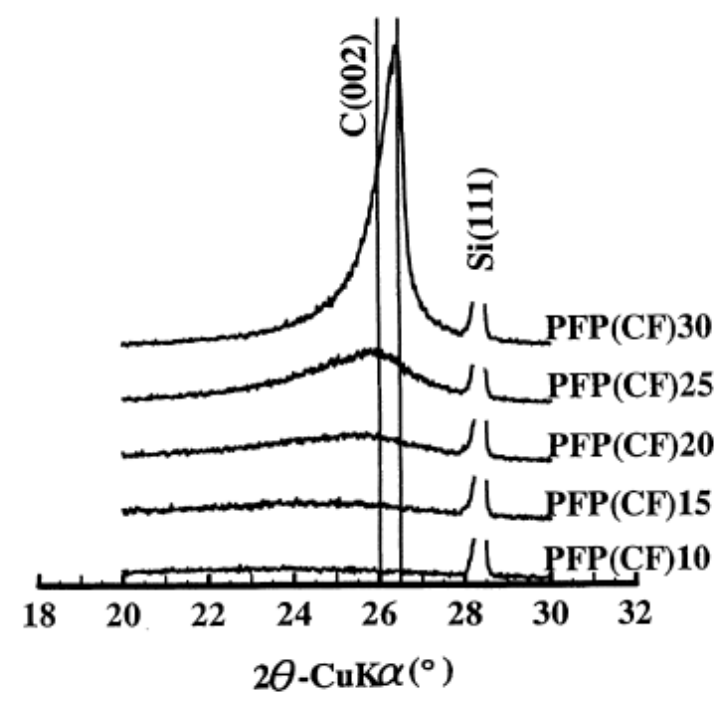

(b) $\operatorname{PFP}(\mathrm{CF})$ series

Fig. 45. XRD patterns of the (002) region of (a) phenol-formaldehyde-based carbon fibers (PF(CF) series) and (b) phosphorus-containing carbon fibers $\left(\mathrm{PFP}(\mathrm{CF})\right.$ series) obtained at $1000-3000{ }^{\circ} \mathrm{C}$ (first two digits of the heat treatment temperature included in the abbreviation). Reprinted with permission from Ref. [206]. Copyright (1999) Elsevier.

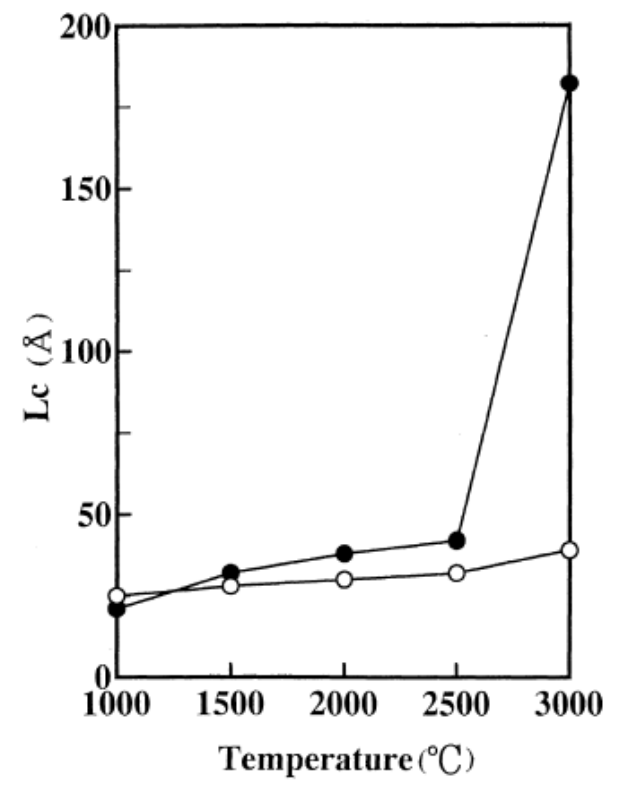

Fig. 46. Variation of $L_{c}$ as a function of HTT. Open symbols - carbon fiber without phosphorus, closed symbols - phosphorus-containing carbon fiber. Reprinted with permission from Ref. [206]. Copyright (1999) Elsevier.

Addition of phosphoric acid to polyacrylonitrile (PAN) increased the interlayer distance in PAN-derived carbons from 0.3510 to $0.3363 \mathrm{~nm}$ [149]. The 002 peak became narrower and the graphite crystallite size, $L_{c}$, increased from 0.962 to $1.030-1.112 \mathrm{~nm}$. The increased interlayer spacing was ascribed to the larger size of the phosphorus atom, while the increased crystalline size was due to the reaction of phosphoric acid with side $-\mathrm{CN}$ groups of PAN to form a cross-linked 
structure, which favors the carbonization process. Scanning electron micrographs of these carbons showed that a layer-like structure appeared after addition of phosphoric acid in contrast to the turbostratic structure present in the carbon obtained without $\mathrm{H}_{3} \mathrm{PO}_{4}$. It was concluded that phosphoric acid was bonded with - $\mathrm{CN}$ groups of the PAN molecules during carbonization, so that the graphite crystallites formed were more ordered.

The growth of graphite microcrystals was significantly promoted by phosphoric acid treatment of a biomass-derived carbon [385]. The coherent domain sizes, $L_{c}$, for carbons heattreated at $2800{ }^{\circ} \mathrm{C}$ increased from 8.58 to $12.3 \mathrm{~nm}$ due to a promotion in the growth of graphitic microcrystals brought about by phosphorus.

\subsection{Electron spin resonance}

Various defects that are related to the electronic disorder, created due to different bonding configurations and which give rise to gap states around the Fermi level, $E_{F}$, can be either paramagnetic or diamagnetic. The paramagnetic defects can be measured by electron spin resonance (ESR).

Phosphorus-doped diamond-like carbon (DLC) films obtained by the pulsed laser deposition technique showed a decrease of spin density with increasing phosphorus content in the carbon (Fig. 47) [262,265]. The decrease of spin density is sharper at low concentrations of phosphorus, being followed by a gradual decrease at a higher P concentration. The ESR linewidth increases with increasing phosphorus content up to $4 \mathrm{wt} \%$ and decreases for the DLC film with the highest phosphorus content.

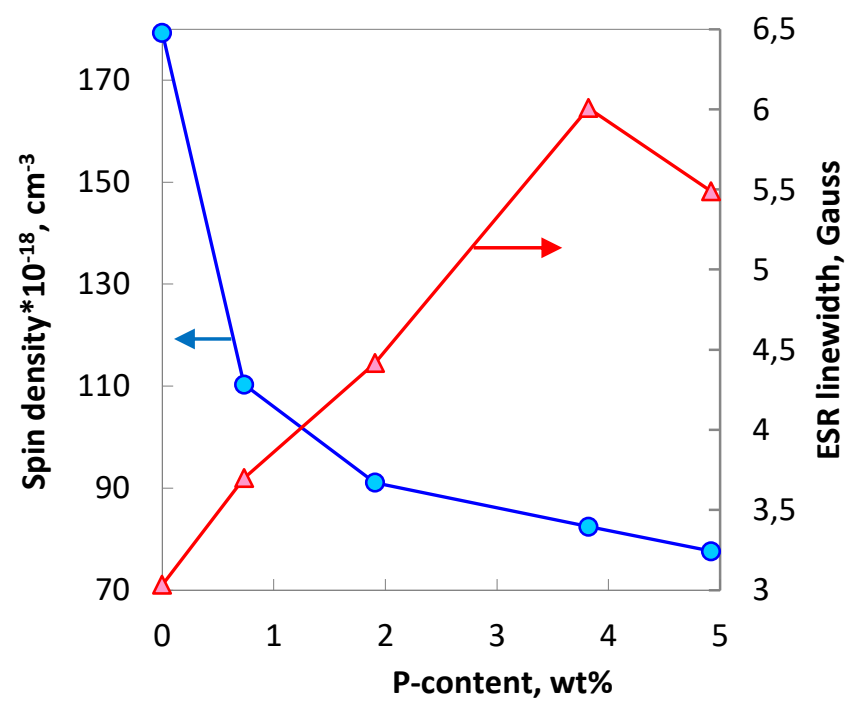

Fig. 47. Variation of the ESR spin density and ESR linewidth of carbon films as a function of $P$ content in the carbon film. Adapted with permission from Ref. [262]. Copyright (2001) Elsevier. 


\subsection{Electronic properties}

\subsubsection{Diamagnetic susceptibility}

The electronic properties reported for phosphorus-containing pyrocarbons refer to the anisotropy of diamagnetic susceptibility, $\Delta x$, measured at $-196^{\circ} \mathrm{C}$ and $20^{\circ} \mathrm{C}$, and the longitudinal component of the susceptibility, $\chi_{\|}$, measured at room temperature [17]. It was shown that the anisotropy of diamagnetic susceptibility, $\Delta \chi$, decreases with increasing phosphorus content. The total susceptibility, $\chi_{T}$, calculated from $\Delta \chi$ and $\chi_{||}$values $\left(\chi_{T}=3 \chi_{\mid l}+\Delta \chi\right)$ decreases with increasing phosphorus content, which is in agreement with changes in anisotropy of diamagnetic susceptibility. Taking into account the fact that the pyrocarbon becomes considerably more disordered with increasing phosphorus content [248], the observed decrease of susceptibility indicates an increased trapping of electrons owing to an increasing number of structural defects.

\subsubsection{Electrical conductivity}

Increasing the phosphorus content in ta-C:P film obtained by cathodic vacuum arc deposition increased their electrical conductivity (Fig. 48) [272,273]. From the exponential dependency of the electrical conductivity on $1 / \mathrm{T}$ above $-23^{\circ} \mathrm{C}$ for all levels of $\mathrm{P}$-content, it was suggested that the conduction occurs via extended states. With increasing phosphorus content in the ta-C:P film, the room temperature conductivity first sharply increases to level off at a Pcontent higher than 1.23 wt\% (Fig. 48). The activation energy systematically decreases; the most dramatic drop is observed for the lowest doping level.

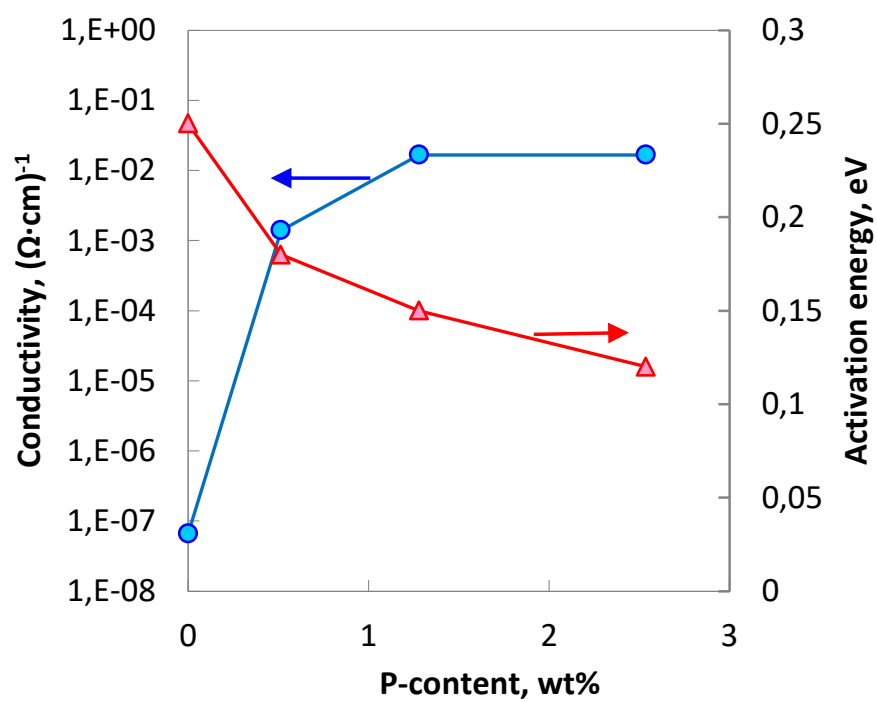

Fig. 48. Variation of the room temperature conductivity and activation energy of a ta-C:P films obtained by cathodic vacuum arc deposition as a function of $P$ content in the carbons. Adapted with permission from Ref. [272]. Copyright (1993) Elsevier. 
The temperature dependence of the electrical conductivity was investigated for phosphorus-doped DLC films [262]. The conductivity decreases initially with addition of a small amount of phosphorus ( $0.73 \mathrm{wt} \%$ in the DLC film) and then increases sharply and gradually thereafter as the P-content increases to 4.9 wt\% (Fig. 49, Fig. 50). Above room temperature, the conduction mechanism is suggested to be in the extended states as the logarithm of the electrical conductivity vs $1 / T$ plot is linear and the temperature at which the activation starts is observed to shift to a lower value with increasing P-content (Fig. 50). These results are similar to those reported for tetrahedral amorphous carbon (ta-C) films [273].

Below room temperature, the slope of the logarithm of the electrical conductivity vs $1 / T$ plot changes and as the temperature is further lowered, the increase of conductivity with increasing temperature becomes very low. The conduction mechanism for the below room temperature and lower temperature regions can be attributed to conduction in band tail states and variable range hopping via deep states, respectively [386].

The activation energy, determined from the slope of the logarithm of electrical conductivity vs $1 / T$ plot for the above room temperature region, increases for the film with 0.73 wt\% phosphorus and decreases for films having higher P-content (Fig. 49) [262]. The activation energy follows the opposite trend observed for room temperature conductivity. The dependence of activation energy and electrical conductivity on P-doping is different from that reported for amorphous carbon films [272], where it was found only a systematic decrease in activation energy and increase in electrical conductivity with increasing P-content in ta-C films.

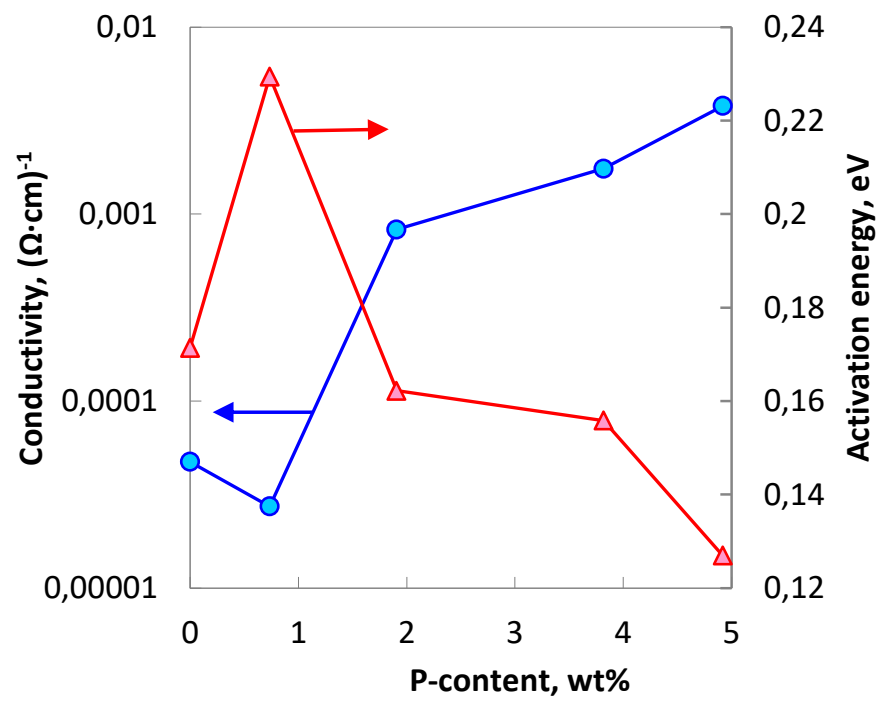

Fig. 49. Variation of the room temperature conductivity and activation energy of DLC films as a function of $P$ content in the carbon. Adapted with permission from Ref. [262]. Copyright (2001) Elsevier. 


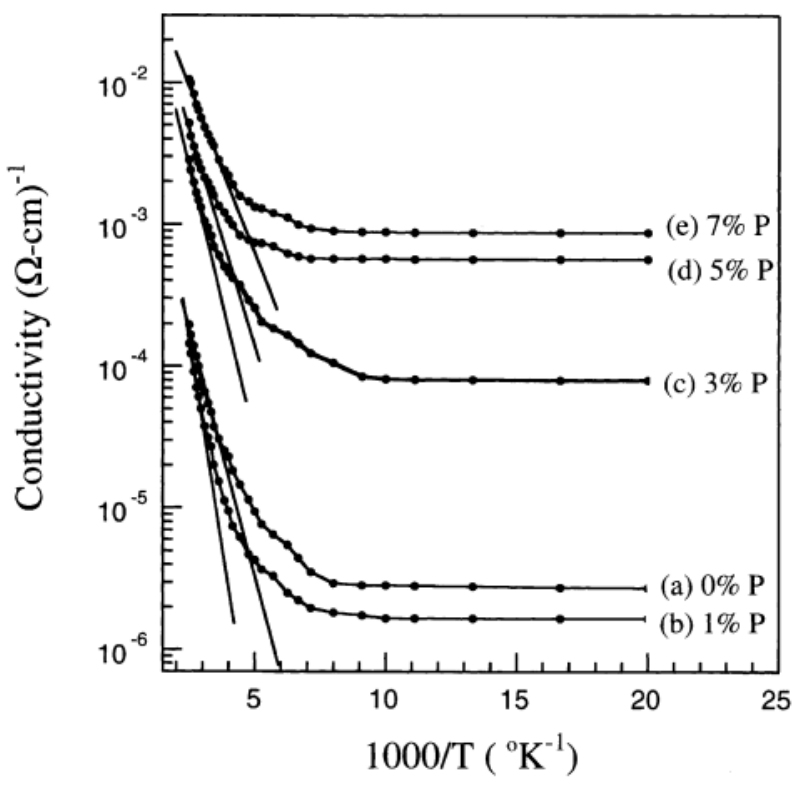

Fig. 50. The temperature dependent conductivity of carbon films obtained from camphoric carbon soot targets with (a) 0 wt \% P, (b) 1 wt\% P (c) 3 wt \% P (d) 5 wt\% P and (e) 7 wt \% P. Reprinted with permission from Ref. [262]. Copyright (2001) Elsevier.

An investigation of the electrical properties of an amorphous carbon film deposited by pulsed laser deposition showed that P-doping decreased the room temperature conductivity from $1.4 \cdot 10^{-4}(\mathrm{Ohm} \cdot \mathrm{cm})^{-1}$ for an un-doped sample to $2 \cdot 10^{-5}(\mathrm{Ohm} \cdot \mathrm{cm})^{-1}$ for a carbon film with $0.6 \mathrm{wt} \%$ of phosphorus $[264,265,387]$. Further increase of phosphorus content to $4.9 \mathrm{wt} \%$ in the deposited film increased the room temperature conductivity to $1 \cdot 10^{-2}(\mathrm{Ohm} \cdot \mathrm{cm})^{-1}$. The behavior of the activation energy of conductivity was opposite: a first decrease from $0.22 \mathrm{eV}$ for the un-doped sample, increase to $0.24 \mathrm{eV}$ for a carbon film with $0.6 \mathrm{wt} \%$ of phosphorus and further decrease to $0.13 \mathrm{eV}$ for a sample with $4.9 \mathrm{wt} \% \mathrm{P}$. The decrease of the room temperature conductivity for the P-doped carbon film as compared to the un-doped sample was ascribed to lattice vibrations leading to the scattering of charge carriers by $\mathrm{P}$ atoms and to a more amorphous nature of carbon films. The increase in room temperature conductivity for the samples with a higher concentration of phosphorus was explained by an increase in graphitization degree and substitutional doping, though the authors did not show any evidence of crystallinity in the P-doped carbon films.

Phosphorus-doping of g- $\mathrm{C}_{3} \mathrm{~N}_{4}$ significantly increased the electric conductivity by 4 orders of magnitude (Fig. 51), which was ascribed to a higher charge-carrier density [201]. The increase in conductivity was not proportional to the phosphorus content, which was attributed to an increasing distortion of the planar graphitic conduction pathways by the bulky phosphorus and deviation of the $\mathrm{P}-\mathrm{N}$ bonding angle from $120^{\circ}$. 


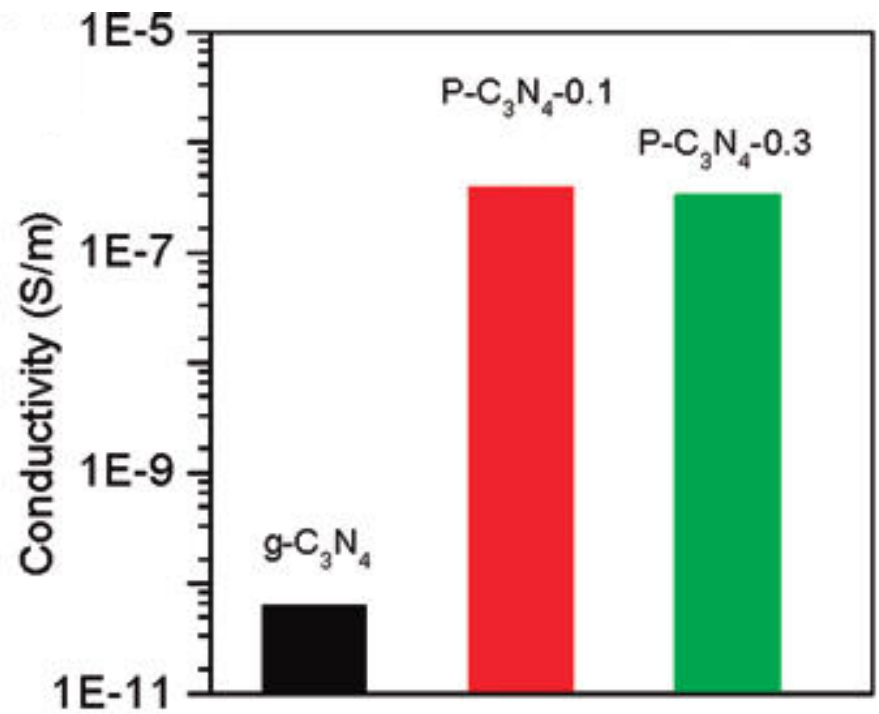

Fig. 51. Electrical conductivity of pristine graphitic carbon nitride $\left(\mathrm{g}-\mathrm{C}_{3} \mathrm{~N}_{4}\right)$ and P-doped samples containing 0.6 $\left(\mathrm{P}-\mathrm{C}_{3} \mathrm{~N}_{4}-\mathbf{0 . 1}\right)$ and 3.8 at \% $\left(\mathrm{P}-\mathrm{C}_{3} \mathrm{~N}_{4}-\mathbf{0 . 3}\right)$ of phosphorus. Reprinted with permission from [201]. Copyright (2010) American Chemical Society.

In summary: P-doping first decreases and then increases the electrical conductivity of the studied carbon materials. However, the increase in electrical conductivity is not proportional to phosphorus content, which was ascribed to a distortion of planar graphitic conduction pathways due to the bulky phosphorus atom.

\subsubsection{Charge carriers}

The P-doping of amorphous carbon films changes the p-type conduction nature of undoped sample to $\mathrm{n}$-type for P-incorporated carbon films [264,272]. It has been suggested that $\mathrm{n}$ type conduction with P-doping is due to activation into extended $\pi^{*}$ states [272].

Hall effect measurements on semiconducting tetrahedral amorphous carbon (ta-C) films deposited by cathodic vacuum arc using 1 wt\% P cathode gave a Hall voltage consistent with conduction by electrons [273].

A P-doped graphene obtained by chemical vapor deposition showed a much stronger ntype behavior than an N-doped graphene [388]. The phosphorus-doped $n$-type graphene showed a high air-stability even under a pure oxygen atmosphere. It is assumed that the strong electrondonating ability of the electron lone pairs of phosphorus can protect graphene against a reduction in n-type properties even under an oxygen atmosphere.

A P,N-co-doped graphene obtained by CVD from ethanol and phosphonitrilic chloride trimer showed a remarkably stable $\mathrm{n}$-type behavior at ambient conditions and a reasonable charge carrier mobility [256]. Based on the fact that most nitrogen-doped graphene materials cannot 
exhibit $n$-type behavior in air it was inferred a key role of doped $\mathrm{P}$ atoms in significantly enhancing the doping efficiency compared to nitrogen-doping.

\subsection{Optical properties}

Photocatalysis has attracted a considerable attention during the past decades because of its potential for environment purification and conversion of photon energy into chemical energy. Although the studies on the photoactivity of carbons are still in their infancy [389], there are some indications on the effect of phosphorus on the optical properties of carbon materials.

\subsubsection{Optical band gap}

The optical band gap of a P-doped DLC film deposited by radio frequency plasma increased from 2.5 to $3.3 \mathrm{eV}$ with increasing phosphorus content up to a $\mathrm{P} / \mathrm{C}$ ratio of 0.79 with a slight decrease of the band gap to $2.9 \mathrm{eV}$ with further increasing the $\mathrm{P} / \mathrm{C}$ ratio to 0.89 [257]. The increase in the band gap was explained by a decrease in the concentration of $\mathrm{sp}^{2}$-bonded carbon within the film, which is consistent with the idea that the films become more amorphous at a high P-content.

The optical properties of DLC films doped with phosphorus were investigated using UV/Vis absorption [258]. The Tauc plot was curved, which was ascribed to the existence of many midband gap states showing the amorphous, defective nature of the obtained films. The estimated band gap decreased from 2.7 to $2.1 \mathrm{eV}$ with increasing $\mathrm{P} / \mathrm{C}$ ratio from 0 to 3 . This fact contradicted previous findings [257], which was ascribed to a highly air sensitive nature of the DLC films with a high P-content [258]. Increasing the ion energy during radio frequency plasma deposition led to decreasing the $\mathrm{P} / \mathrm{C}$ atomic ratio from 1.6 to 0.9 and reducing the optical band gap from 2.6 to $2.3 \mathrm{eV}[259]$.

The optical properties of phosphorus-doped DLC films obtained by pulsed laser deposition [262] have been estimated using the Tauc plot [390]. The optical gap was $0.85 \mathrm{eV}$ for doping levels of 0-3.8 wt\% of phosphorus and decreased to $0.75 \mathrm{eV}$ in DLC films containing $4.9 \mathrm{wt} \%$ of phosphorus. The decrease in optical gap for the carbon film containing $4.9 \mathrm{wt} \%$ of phosphorus was ascribed to an increase of the $\mathrm{sp}^{2}$ cluster size due to graphitization of the DLC film, which is probably induced by a high P content [263].

Contrary to other investigations, no optical band gap changes were reported for ta-C:P films deposited by the cathodic arc method [272]. For a P content of up to $2.5 \mathrm{wt} \%$ the optical band-gap (1.9-2.0 eV) and $\mathrm{sp}^{3}$-bonded C content (deduced from EELS) were reported to be the same as for the un-doped film. The optical band gaps of the ta-C films also remained unchanged at 1.9-2.0 eV with the inclusion of about $1 \mathrm{wt} \%$ phosphorus in the films [273]. 
The optical properties of P-doped amorphous carbon films deposited by pulsed laser deposition were investigated by UV/Vis/NIR spectroscopy measurements for films deposited on quartz substrates in the wavelength range of 200 to $2500 \mathrm{~nm}[264,387]$. Doping with phosphorus increased the optical band gap from $0.65 \mathrm{eV}$ for an un-doped sample to 0.82-0.85 eV for carbon films containing $0.22-1.58$ at $\%$ of phosphorus. Further increasing the amount of doped phosphorus to 1.94 at\% caused a decrease in the optical band gap up to $0.65 \mathrm{eV}$. The authors pointed out that optical band gaps are smaller than the optimum value of about $1.5 \mathrm{eV}$ for a solar cell. The increase of the optical band gap for the samples with a low phosphorus content was explained by compensation of dangling bonds in the structure of the amorphous carbon film and increase of the tetrahedral $\left(\mathrm{sp}^{3}\right)$ fraction of carbon, similarly to the effect of nitrogen incorporation in carbon films, which increased the $\mathrm{sp}^{3}$-carbon content [391].

The optical properties of an amorphous carbon film obtained by the radio frequency plasma enhanced chemical vapor deposition technique [261] showed a slight increase of the optical band gap from 1.9 to $2.0 \mathrm{eV}$ with increasing radio frequency power to $200 \mathrm{~W}$, and a steep decrease to $0.8 \mathrm{eV}$ as the radiofrequency power was increased to $300 \mathrm{~W}$. The changes were ascribed to a decreasing fraction of $\mathrm{sp}^{3}$ sites.

The optical band gap energy was shifted gradually from $2.73 \mathrm{eV}$ to lower energies for a Pdoped g- $\mathrm{C}_{3} \mathrm{~N}_{4}$ with increasing P-content $[201,202]$. The phenomenon was explained by the electronic integration of the P-heteroatoms in the lattice of $g-C_{3} N_{4}$.

In the case of graphene, a large increase in band gap from $0 \mathrm{eV}$ for undoped graphene to $2.85 \mathrm{eV}$ for P-doped graphene containing 7 at\% of phosphorus was reported [182].

A P,N-doped carbon obtained by microwave carbonization of a condensation polymer in the presence of phosphoric acid showed a broad range of absorption in the UV-Vis spectrum with a maximum at $314 \mathrm{~nm}$ [169]. The band gap obtained by means of the Tauc equation was found to be $2.68 \mathrm{eV}$.

In summary, phosphorus introduction definitely affects the optical properties of carbon materials. However, the literature reviewed does not allow drawing a certain trend for the direction of changes induced by P-doping. More investigations with a focus on the chemical state of phosphorus are needed.

\subsubsection{Photovoltaic characteristics}

The photovoltaic characteristics of solar cells constructed from P-doped amorphous carbon films were improved with increasing phosphorus content in the carbon up to 4 wt\% and 
deteriorated thereupon $[264,265]$. The quantum efficiency was improved with increasing Pcontent in the carbon film up to $4 \mathrm{wt} \%$ and decreased for higher amounts of phosphorus. The following characteristics of the cell were achieved: maximum power $0.456 \mathrm{~mW}$, energy coefficient efficiency $1.14 \%$ and fill factor $41 \%$. It was pointed out that although the maximum achieved energy coefficient efficiency was low there is still possibility of improving the photovoltaic cell characteristics by optimizing the deposition conditions [264].

The photovoltaic characteristics of solar cells fabricated from radio frequency plasma enhanced CVD P-doped carbon films were the best for a film grown at $100 \mathrm{~W}$, for which the lowest amount of phosphorus was measured by Auger electron spectroscopy [260]. The maxima of open circuit voltage and short circuit current density for the cells were observed to be approximately $236 \mathrm{~V}$ and $7.34 \mathrm{~mA} / \mathrm{cm}^{2}$. The highest energy conversion efficiency and fill factor were found to be approximately $0.84 \%$ and $49 \%$, respectively.

Phosphorus-containing graphitic carbon nitride $\mathrm{P}-\mathrm{C}_{3} \mathrm{~N}_{4}$ showed more efficient light harvesting, increased electric conductivity (by a factor of 4) and remarkably higher photocurrent (by a factor of 5) as compared to pristine $\mathrm{g}-\mathrm{C}_{3} \mathrm{~N}_{4}$ [201]. The negative photocurrent indicated the dominance of holes in charge transport. Differential pulse voltammetry plots showed that the reduction peak currents are proportional to the phosphorus concentration.

\subsubsection{Photocatalytic activity}

Both, a polymer-derived, sulfur- and phosphorus-doped activated carbon and a commercial phosphorus-containing carbon showed a strong photooxidation activity in UV and visible light for dibenzothiophene and 4,6-dimethyldibenzothiophene from a model diesel fuel [392]. It was suggested that the incorporation of sulfur and phosphorus-containing groups to the carbon matrix decreased the energy band gap. It was assumed that photoinduced holes, electrons and oxygen from surface groups are involved in the involved oxidation reactions.

An increase in the photocatalytic activity of carbon nitride upon doping with phosphorus to decompose Rhodamine B and Methyl orange in aqueous solution was reported [202]. The increase was attributed to favorable textural, optical and electronic properties caused by doping with phosphorus heteroatoms into the carbon nitride matrix.

An enhanced visible light photocatalytic degradation of Rhodamine B over phosphorusdoped graphitic carbon nitride was reported [393]. The enhanced photoactivity was attributed to a favorable texture, optical property and effective separation of photogenerated charge carriers (inhibiting the recombination of electrons and holes) brought about by phosphorus doping. 
Doping graphene with phosphorus increased by one order of magnitude the photocatalytic activity of hydrogen generation in aqueous methanol solution (30 wt\%) and in triethanolamine under UV/Vis irradiation [182]. The photocatalytic activity of P-doped graphene increased with increasing amounts of phosphorus. The activity of P-graphene under visible light was much lower than under UV/Vis light. The photocatalytic activity was attributed to an increasing bandgap from $0 \mathrm{eV}$ for graphene to $2.85 \mathrm{eV}$ for P-doped graphene containing 7 at\% of phosphorus.

P-doping significantly changed the electronic properties of $\mathrm{g}_{-} \mathrm{C}_{3} \mathrm{~N}_{4}$, causing not only a redshifted light absorption, but also improving the electronic conductivity [394]. This resulted in an excellent photocatalytic water reduction performance under visible light irradiation.

\subsubsection{Photoluminescence (bioimaging)}

Photoluminescence spectra of P-doped carbon nitride showed a broad band centered at approximately $470 \mathrm{~nm}$, which was attributed to the band-band photoluminescence phenomenon with the energy of light approximately equal to the band gap energy [202]. Doping with phosphorus of g- $\mathrm{C}_{3} \mathrm{~N}_{4}$ led to quenching of photoluminescence, which was attributed to a decrease in the recombination of electron-hole pairs, which would be favorable for the photocatalytic process.

$\mathrm{P}, \mathrm{N}$-doped carbon nanodots showed blue fluorescence under UV irradiation [178]. The maximum emission wavelength increased from 424 to $463 \mathrm{~nm}$ as the excitation wavelength increased from 210 to $230 \mathrm{~nm}$. The maximum emission intensity around $453.4 \mathrm{~nm}$ (a bright blue emission) was observed for excitation at $225 \mathrm{~nm}$. The 5-10 nm P,N-doped carbon nanodots showed no cytotoxic effect and were successfully used for bioimaging applications.

\subsection{Electrochemical applications}

Doping of carbon materials with different heteroatoms alters their electronic properties. The effect of phosphorus doping was studied by theoretical quantum chemical calculations [294,341,395-398] and by experimental investigations of P-doped carbons in electrochemical applications like electric double-layer capacitor (EDLC), Li-ion batteries, oxygen reduction reaction, fuel cells and other uses [31].

\subsubsection{Electrical double-layer capacitors}

An extraordinary performance in electrical double-layer capacitors (EDLC) of phosphoruscontaining microporous carbons prepared by a simple $\mathrm{H}_{3} \mathrm{PO}_{4}$ activation method has been reported $[297,298,399]$. All the investigated phosphorus-containing carbons of different origin (polymerbased and fruit-stone-based) showed a high electrical capacitance of 190-220 F/g, much higher 
than that of commercial carbon Norit RB3 (140 F/g). Factor analysis showed that the strongest influence on the capacitance corresponded to phosphorus content; a less strong effect was exerted by the surface area of $0.65-0.83 \mathrm{~nm}$ micropores (determined by $\mathrm{CO}_{2}$ adsorption). This high impact of phosphorus content on the capacitance could be connected with an increase in the surface conductivity through Grotthuss mechanism $[400,401]$ as in phosphoric acid $[402,403]$ and acid zirconium phosphates [404]. The high electrical capacity of P-doped carbons was attributed also to pseudocapacitance due to fast Faradic reactions. The most interesting and extraordinary feature of phosphorus-containing carbons is that they could operate in $\mathrm{H}_{2} \mathrm{SO}_{4}$ at potentials up to $1.5 \mathrm{~V}$ without electrolyte decomposition, which is larger than the theoretical potential of water decomposition (1.23 V). This is an important feature since the widening of the cell voltage has a great impact on the energy density of the supercapacitor, as it is proportional to the square of the cell voltage [405]. Moreover, phosphorus-containing carbons show a stable performance during 15000 cycles. The durability and capability of operating at high potentials without oxidation is explained by blockage of active sites by phosphorus compounds.

A very stable electrochemical performance of phosphorus-containing carbon from coffee grounds at potentials (up to $1.5 \mathrm{~V}$ ) larger than the thermodynamic potential for water decomposition was also reported [133]. Only $18 \%$ degradation was observed after 10000 cycles at a current density of $5 \mathrm{~A} / \mathrm{g}$. Due to the wide electrochemical window, a supercapacitor with Pcontaining carbon showed a high energy density of $15 \mathrm{~W} \cdot \mathrm{h} / \mathrm{kg}$ at a power density of $75 \mathrm{~W} / \mathrm{kg}$. The possibility of widening the potential window above the theoretical potential for the decomposition of water was ascribed to reversible electrochemical hydrogen storage in narrow micropores and to the positive effect of phosphorus-rich functional groups, particularly polyphosphates, on the stability of carbon surface.

The effect of phosphorus compounds on the electrochemical behavior of a commercial phosphorus-containing carbon BAX-1500 (MeadWestvaco) of wood origin was reported [406]. The phosphorus environment was altered by modification of the carbon by oxidation and treatment with melamine or urea. It has been shown that with an increase in the heterogeneity of phosphorus-containing species and with a decrease in the content of pyrophosphates, the electrical capacitance increased and the retention ratio of the capacitor was improved.

Phosphorus- and/or boron-doped ordered mesoporous carbons exhibited superior electrochemical performances as compared to their heteroatom-free counterparts when used as electrodes of supercapacitors [25]. With increasing phosphorus content, the electrical capacitance increased indicating a positive impact of phosphorus doping. Phosphorus and phosphorus-boron- 
containing carbons showed a higher capacitance retention with increasing potential scan rate as compared to the corresponding heteroatom-free carbons.

An increase in the electrical capacitance from 31.2 to $124.1 \mathrm{~F} / \mathrm{g}$ at $50 \mathrm{~mA} / \mathrm{g}$ in $1 \mathrm{M} \mathrm{H}_{2} \mathrm{SO}_{4}$ by introduction of phosphorus (using guanidine phosphate) into a starch-based carbon was reported [191]. Addition of phosphoric acid instead of guanidine phosphate resulted in a slightly lower capacitance of $116.1 \mathrm{~F} / \mathrm{g}$.

Increasing the phosphorus content from 2.15 to $3.30 \mathrm{wt} \%$ in ordered P- and B-doped mesoporous carbons increased the gravimetric capacitance of the electrode from 158 to $177 \mathrm{~F} / \mathrm{g}$ in $6 \mathrm{M} \mathrm{KOH}$ electrolyte [166]. The improvement of the capacitance was attributed to the introduction of oxidized $B$ and $P$ species.

Phosphorus-containing carbon monoliths showed voltammograms with a rectangular shape that was maintained for a wide potential window of up to $1.4 \mathrm{~V}$. However, unfuctionalized carbon monoliths exhibited a clear deformation of the rectangular shape of the voltammogram at much lower voltages (e.g., 1 V) [204]. Phosphorus-containing carbon monoliths showed a better retention of the capacitance at high current densities due to a lower equivalent series resistance (2.6 $\Omega$ for P-containing carbon and $4.7 \Omega$ for carbon without phosphorus). P-containing carbon monoliths showed a stable performance during 10000 charge-discharge cycles at $1.4 \mathrm{~V}$ with a capacitance retention of $90 \%$. Moreover, P-containing carbon monoliths showed a higher (both gravimetric and volumetric) energy density than the equivalent carbon monoliths without phosphorus.

The electrochemical properties of $\mathrm{P}, \mathrm{N}$-containing carbons were investigated using cyclic voltammograms $(\mathrm{CV})$ in deaerated $1 \mathrm{M} \mathrm{HClO}_{4}$ [176]. With increasing phosphorus content up to $3 \mathrm{wt} \%$ the CV area, which is closely related to the capacitance, increased and levelled off with a higher concentration of phosphorus. The increase in capacitance was ascribed to an increasing surface area with increasing phosphorus content up to 3 wt\%. However, XRD, XPS and Raman spectra showed that additional P-doping induced defect sites and destroyed the $\mathrm{sp}^{2}$-carbon network in the carbon structure, which reduced the electrical conductivity of the carbon. Therefore, it was concluded that further increasing the capacitance was not achieved due to the diminished electrical conductivity, despite the fact that the surface area of the catalysts was enlarged.

Cyclic voltammetry and galvanostatic charge-discharge tests showed a high specific capacitance (154.4 F/g) and excellent stability of P/N co-doped porous carbons in $6 \mathrm{M} \mathrm{KOH} \mathrm{[175].}$ 
The improved electrochemical performance was attributed to the combination of the co-doping of heteroatoms ( $\mathrm{P}$ and $\mathrm{N}$ ) and to micropores generated by phosphoric acid activation.

Phosphorus-containing graphene from reduced graphene sheets showed an enhanced capacitive performance in an aqueous electrolyte $\left(1 \mathrm{M} \mathrm{H}_{2} \mathrm{SO}_{4}\right)$ due to an increased pseudocapacitance and good electrical conducting network in the electrode structure [226]. The specific capacitance was found to be very stable at the level of $430 \mathrm{~F} / \mathrm{g}$ during 5000 cycles of charge-discharge galvanostatic measurements. These samples exhibited a high power density of $9 \mathrm{~kW} / \mathrm{kg}$ and energy density of $59 \mathrm{~W} \cdot \mathrm{h} / \mathrm{kg}$, which is much higher than that of other graphenebased supercapacitors. The phosphorus-doped graphene showed a high potential for use in lowcost energy storage devices.

Phosphorus- and nitrogen-co-doped porous carbons obtained by carbonization of a mixture of glucose and $\left(\mathrm{NH}_{4}\right)_{3} \mathrm{PO}_{4}$ were investigated as electrode material for supercapacitors [185]. These phosphorus- and nitrogen-co-doped porous carbons exhibited a specific capacitance of $183.8 \mathrm{~F} / \mathrm{g}$, a capacitance retention ratio of over $90 \%$, and an operating potential window up to $1.4 \mathrm{~V}$ in an alkaline electrolyte of $6 \mathrm{M} \mathrm{KOH}$. The promising electrochemical performance was ascribed to the synergetic effect of (i) the pseudocapacitance that originated from phosphorusand nitrogen-containing surface groups; and (ii) the electric double layer capacitance that came from the uniform porosity developed by in situ activation.

A significant enhancement of the supercapacitive performance of graphene nanosheets due to phosphorus doping was reported [219]. With increasing phosphorus content from 0 to 1.57 at\% the specific capacitance in $6 \mathrm{M} \mathrm{KOH}$ increased from 7.6 to $244.6 \mathrm{~F} / \mathrm{g}$ at a current density of $0.1 \mathrm{~A} / \mathrm{g}$, which has been considered to be the key factor for the enhancement of the supercapacitive performance. These phosphorus-doped graphene nanosheets also exhibit a good rate capability and excellent stability (up to 10000 cycles).

$\mathrm{P}, \mathrm{N}$-doped nonporous carbon nanofibers from polyacrylonitrile and phosphoric acid showed an excellent electrochemical performance as EDLC electrode in $1 \mathrm{M} \mathrm{H}_{2} \mathrm{SO}_{4}$ [150]. Increasing the phosphorus content resulted in an increase in electrical capacitance along with content of pyrrole-like nitrogen (Fig. 52). The excellent electrochemical performance was ascribed to the synergetic effect of nitrogen groups that provide high pseudocapacitance and phosphorus groups, which enhance the surface wettability. Moreover, P,N-doped carbon nanofibers exhibit a widened electrochemical potential window up to $1.4 \mathrm{~V}$ in $1 \mathrm{M} \mathrm{H}_{2} \mathrm{SO}_{4}$ electrolyte. The widening of the potential window was ascribed to the blockage of phosphorus groups to the electrochemical 
active oxidation sites and/or to the reduction of electrochemical active oxidation sites, which are replaced by phosphorus groups.

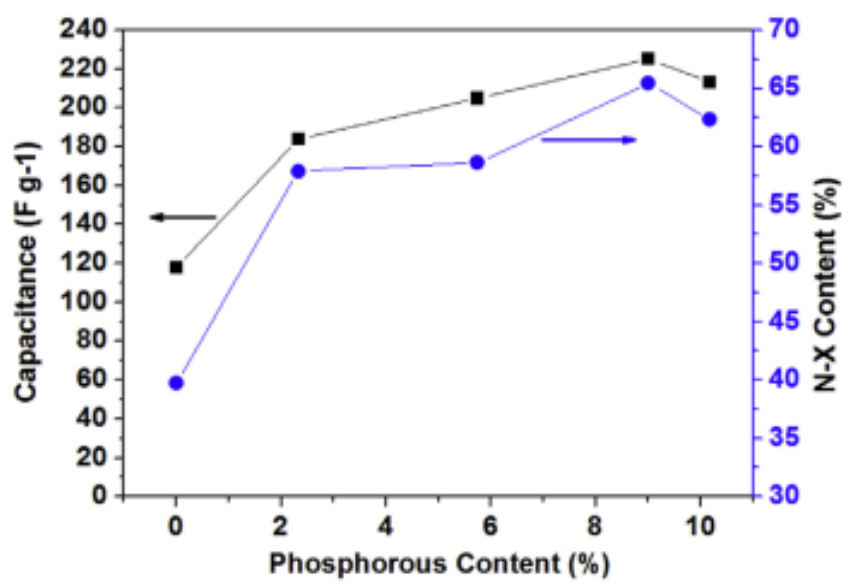

Fig. 52. Specific capacitance (left side) and $\mathrm{N}-\mathrm{X}$ (pyrrole-like nitrogen) content (right side) as a function of phosphorus content. Reprinted with permission from Ref. [150]. Copyright (2014) Elsevier.

$\mathrm{P}, \mathrm{N}$-doped carbon nanofibers (CNF) from bacterial cellulose exhibited a good supercapacitive performance [183]. With increasing phosphorus content from 3.6 to $6.6 \mathrm{wt} \%$ the electrical capacitance in $2 \mathrm{M} \mathrm{H}_{2} \mathrm{SO}_{4}$ electrolyte at a current density of $1 \mathrm{~A} / \mathrm{g}$ increased almost linearly from 129.2 to $204.9 \mathrm{~F} / \mathrm{g}$. Further increasing the phosphorus content to $7 \mathrm{wt} \%$ led to a decreased capacitance, which was ascribed to thinning of carbon fiber due to the corrosion by the highly concentrated $\mathrm{NH}_{4} \mathrm{H}_{2} \mathrm{PO}_{4}$ solution. The N,P-CNF showed a high capacity retention ratio and stable performance during 4000 cycles. The capacity decreased in the following order: N,P-CNF > $\mathrm{B}, \mathrm{P}-\mathrm{CNF}>\mathrm{P}-\mathrm{CNF}>\mathrm{CNF}$ showing that $\mathrm{P}$ and $\mathrm{N}$ dual doping is favorable for the supercapacitive performance.

Phosphorus-doped graphene (1.3 at\% of $\mathrm{P}$ ) exhibited a significant improvement in terms of specific capacitance and cycling stability, compared with an undoped graphene electrode [407]. This P-doped graphene electrode could survive at a wide voltage window of $1.7 \mathrm{~V}$ in $1 \mathrm{M} \mathrm{H}_{2} \mathrm{SO}_{4}$ with only $3 \%$ performance degradation after 5000 cycles at a current density of $5 \mathrm{~A} / \mathrm{g}$, providing a high energy density of $11.64 \mathrm{~W} \cdot \mathrm{h} / \mathrm{kg}$ and a high power density of $831 \mathrm{~W} / \mathrm{kg}$. The wide potential window in aqueous supercapacitors was attributed to the reversible electrochemical hydrogen storage in carbon materials [408].

A P,N co-doped carbon obtained by microwave carbonization of coffee grounds mixed with ammonium polyphosphate exhibited a high specific capacitance in acid and alkaline electrolytes, the highest specific capacitance value being $286 \mathrm{~F} / \mathrm{g}$ in $1 \mathrm{M} \mathrm{H}_{2} \mathrm{SO}_{4}$ [409]. This $\mathrm{P}, \mathrm{N}$ co-doped carbon was stable under acidic and alkaline conditions with continuous cycling for 2000 times. 
A ternary $\mathrm{P}, \mathrm{N}, \mathrm{O}$ co-doped carbon from shrimp shells exhibited a high specific capacitance of $206 \mathrm{~F} / \mathrm{g}$ at $0.1 \mathrm{~A} / \mathrm{g}$ in $6 \mathrm{M} \mathrm{KOH}$ solution [410]. The energy density and power density of the obtained electrodes could be substantially improved (from $2.9 \mathrm{~W} \cdot \mathrm{h} / \mathrm{kg}$ at $0.9 \mathrm{~V}$ to $5.2 \mathrm{~W} \cdot \mathrm{h} / \mathrm{kg}$ at $1.1 \mathrm{~V})$ by widening the operation voltage window with the assistance of doped $\mathrm{P}$.

An improvement of the electrochemical characteristics of a carbon xerogel by modification with $\mathrm{H}_{3} \mathrm{PO}_{4}$ at high temperature was reported [411]. Incorporation of phosphorus heteroatoms increased the capacitance by almost 5 times to $183 \mathrm{~F} / \mathrm{g}$. It was found that the presence of Pheteroatoms is a crucial factor for high electrochemical capacitance, good rate capability and excellent long-term stability.

A dramatic improvement in the capacitance, rate capability, and cyclic stability by incorporation of phosphorus into reduced graphene oxide was demonstrated [412]. Combined experimental and theoretical approaches showed a reduction in charge transfer resistance due to modification of the electronic structure of the carbon by $\mathrm{C}-\mathrm{P}=\mathrm{O}$ bonding.

Phosphorus-containing carbons from olive residues showed a higher capacitance and capacitance stability despite the lower surface area as compared to $\mathrm{KOH}$-activated carbons [413]. The superior electrochemical behavior of P-doped carbons was ascribed to the presence of phosphorus surface groups and adequate micro-mesopore network.

Widening the potential window to $1.5 \mathrm{~V}$ in $6 \mathrm{M} \mathrm{KOH}$ for $\mathrm{P}, \mathrm{N}$-doped graphene was reported [414]. This widening was ascribed to the enhanced electro-oxidation resistance of carbon electrodes with the aid of P-containing functional groups.

The enhanced electro-oxidation resistance induced by phosphorus-containing groups in olive stones-derived carbons has been demonstrated [415]. A mechanism of electro-oxidation resistance was proposed, which involves the gradual transformation of phosphorus-containing groups at high potentials from less-to more-oxidized species to slow down the introduction of oxygen groups on the carbon surface (oxidation). This hampers the generation of oxygen-carbon surface groups and hence, the corrosion of the carbon surface.

A highly flexible supercapacitor fabricated from phosphorus-containing reduced graphene oxide films achieved a specific capacitance of $149 \mathrm{~F} / \mathrm{g}$, a capacitance retention of $90.8 \%$ from 1 to $30 \mathrm{~A} / \mathrm{g}$, and a cyclic stability of $94.2 \%$ over 1000 charging/discharging cycles [416]. The capacitive performance was preserved at the bending of $120^{\circ}$ angle. The excellent electrochemical behavior was attributed to the unique hierarchical structure and the presence of electroactive $P=O$ sites. 
A flexible and binderless electrode for supercapacitors was fabricated by phosphoric acid activation of denim cloth waste [417]. This phosphorus-containing carbon showed a stable electrochemical behavior in the wide potential window $1.5 \mathrm{~V}$ in $1 \mathrm{M} \mathrm{H}_{2} \mathrm{SO}_{4}$ electrolyte with a gravimetric capacitance of $237 \mathrm{~F} / \mathrm{g}$ at $0.25 \mathrm{~A} / \mathrm{g}$ and more than $90 \%$ capacitance retention after 5000 cycles.

Phosphorus-containing carbon monoliths with high bulk density $\sim 1.1 \mathrm{~g} / \mathrm{cm}^{3}$ were prepared by phosphoric acid activation of lignin or olive stones [418]. These carbon monoliths as binderless electrodes for EDLC showed high gravimetric $(217 \mathrm{~F} / \mathrm{g})$ and volumetric $\left(205 \mathrm{~F} / \mathrm{cm}^{3}\right)$ capacitances in $1 \mathrm{M} \mathrm{H}_{2} \mathrm{SO}_{4}$ electrolyte.

Phosphorus doping improved the electrochemical characteristics of carbon in an organic electrolyte [419]. The increase of P-doped content significantly restrained the formation of unstable quinone and carboxylic groups, and then enhanced the oxidation stability of P-doped porous carbon. P-doped carbon exhibited an excellent rate capability of $75 \%$ retention at $30 \mathrm{~A} / \mathrm{g}$, an extraordinary stability of $90 \%$ capacitance retention after 20000 cycles and a low leakage current of less than $1.2 \mathrm{~mA}$ in $1 \mathrm{M} \mathrm{Et}_{4} \mathrm{NBF}_{4} / \mathrm{PC}$. Due to the blockage of active oxidation sites by phosphate groups the P-doped porous carbon could stably operate at a higher voltage of $3.0 \mathrm{~V}$ in $\mathrm{Et}_{4} \mathrm{NBF}_{4} / \mathrm{PC}$ compared to that of undoped porous carbon, so as to deliver a high energy density of $38.65 \mathrm{~W} \cdot \mathrm{h} / \mathrm{kg}$ at $1500 \mathrm{~W} / \mathrm{kg}$.

To summarize the EDLC-related findings, several phosphorus-containing carbons of different origin have been found to exhibit a very promising behavior as electrodes for EDLCS. Interestingly, among the factors that control the electrical capacitance, P content was often a factor of paramount importance. The promising electrochemical performance was generally ascribed to the synergetic effect of pseudocapacitance originated from surface groups and electric double layer capacitance that came from the uniform porosity developed by in situ activation (remember that in many cases, the studied P-containing carbons were derived from $\mathrm{H}_{3} \mathrm{PO}_{4}$ activation). Other reasons for the enhanced electrochemical performance are an increased wettability due to hydrophilic P-containing groups and an improved electrochemical stability providing long lasting charge-discharge at a wide potential window. In a number of cases, codoping of $\mathrm{P}$ with other elements such as $\mathrm{B}$ or $\mathrm{N}$ was carried out, and the resulting carbons exhibited an enhanced electrochemical behavior as electrodes for electrochemical capacitors. 


\subsubsection{Li-ion batteries}

Worldwide research is in progress to develop Li-ion rechargeable batteries using carbon as anode. Recently it was found that phosphorus-doped carbon exhibited a high reversible capacity as compared to non-doped carbon [420].

Phosphorus doping of fuel green coke increased the capacity and decreased the irreversible capacity loss (Fig. 53) [421]. The effect of phosphorus was ascribed to enhancing the intercalation of Li by expanding the layer plane spacing at the edge of the carbon structure.

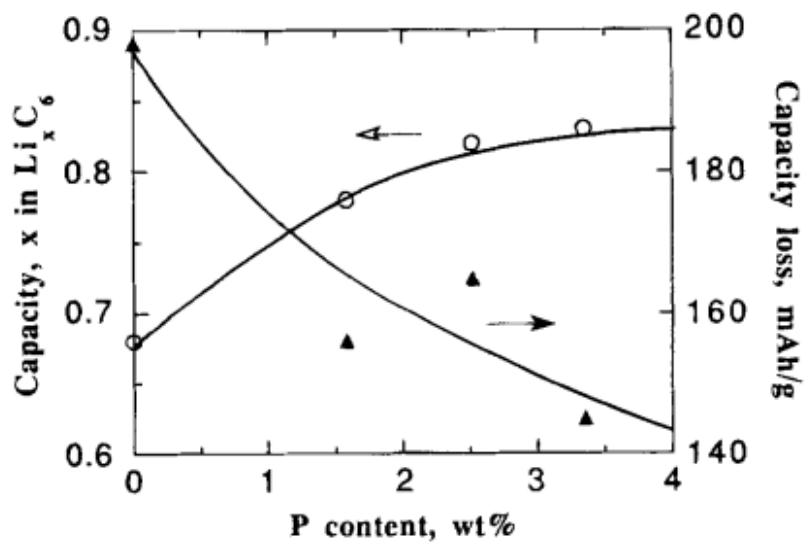

Fig. 53. Capacity and irreversible capacity loss as a function of P-doping content. Reproduced with permission from Ref [421]. Copyright 1995, The Electrochemical Society.

A plateau in the $700-1100 \mathrm{mV}$ range on the voltage curve for de-intercalation of lithium from P-doped carbons as compared to non-doped carbon was reported [148]. The reversible capacity increased almost linearly with an increase of phosphorus content (Fig. 54). It was inferred a mechanism by which lithium is bonded to phosphorus at low voltage during intercalation and debonded at a higher voltage during de-intercalation, leading to a hysteresis. Phosphorus introduction increased the overall charge/discharge coulombic efficiencies to around $80 \%$ during the first cycle (Fig. 55). At further cycles, the efficiencies stabilized around 98\%, however, the total capacities decreased. A doping level of 5-10 wt\% of phosphorus was most effective in terms of improving the capacity and efficiency. Lower dopant levels reduced these properties; higher dopant levels (13 wt\%) reached a saturation point where it became difficult to accommodate more phosphorus in the carbon structure. 


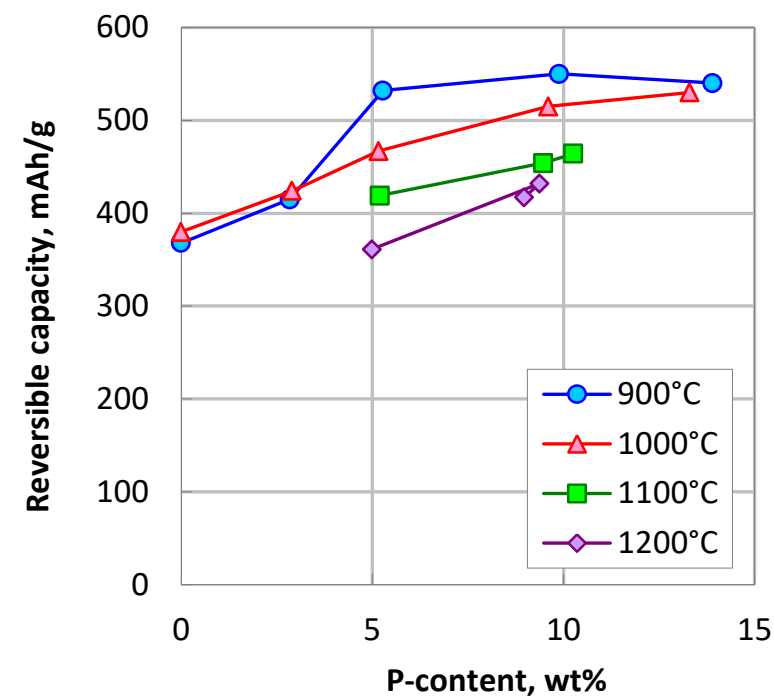

Fig. 54. The relationship between phosphorus content in carbons obtained by phosphoric acid activation of an epoxy resin at different temperatures and reversible capacity of carbon. Adapted with permission from Ref. [148]. Copyright (1997) Elsevier.

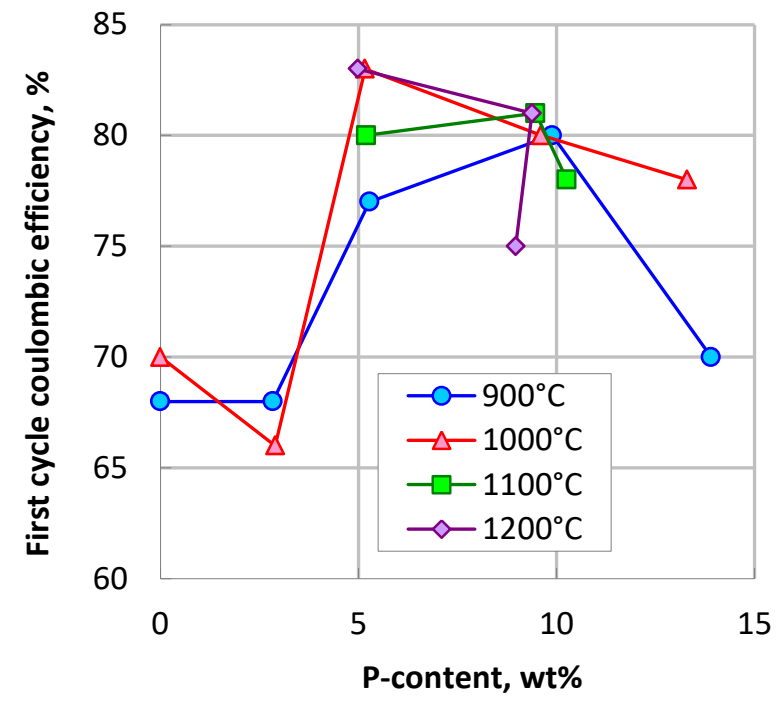

Fig. 55. Relationship between phosphorus content in carbons obtained by phosphoric acid activation of an epoxy resin at different temperatures and first cycle coulombic efficiency of carbon. Adapted with permission from Ref. [148]. Copyright (1997) Elsevier.

An increase of the reversible capacity of a carbon obtained by carbonizing a mixture of PAN and $\mathrm{H}_{3} \mathrm{PO}_{4}$ with increasing amount of added acid was reported [149]. Phosphorus doping enhanced the reversible capacity due to expansion of the layer planes of the carbon, thus facilitating the intercalation of lithium.

An almost linear increase in capacity of Li-ion rechargeable battery with increasing phosphorus content in phosphorus-doped disordered carbon was reported (Fig. 56) [188]. The phosphorus was assumed to form some cross-linking structures between neighboring crystallites or exist at the edge of the graphitic layers. The increase in capacity was attributed to additional Li species located near the phosphorus species. 


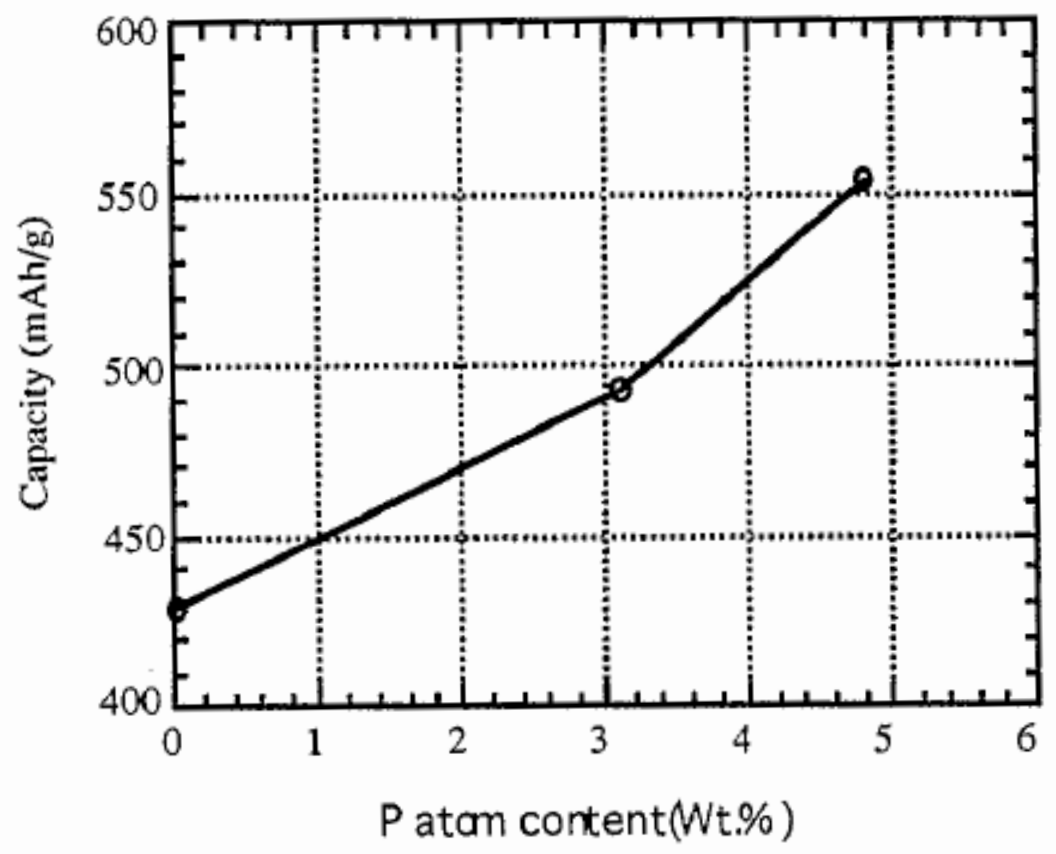

Fig. 56. Relationship between $P$ atom content and capacity of carbon. Reprinted with permission from Ref. [188]. Copyright (1999) Elsevier.

The effect of phosphorus doping on the reversible capacity depended on the carbonization temperature of phenol-formaldehyde resin with phosphoric acid [209]. The phosphoruscontaining carbon prepared by pyrolysis at $500{ }^{\circ} \mathrm{C}$ showed a similar electrochemical behavior to that of a pure carbon, indicating a small effect of phosphorus atoms. Its reversible capacity was mainly determined by the content of hydrogen atoms rather than phosphorus atoms. However, at a relatively high pyrolysis temperature, $900{ }^{\circ} \mathrm{C}$, more phosphorus atoms were bonded with carbon atoms via C-P bonds and were introduced into the microcrystallite structure of carbon. Hence, phosphorus element exerts a strike effect on the electrochemical behavior of carbon and, because of its different electronic effect from the carbon element, more lithium species were inserted into the carbon matrix.

Electrochemical measurements combined with structural analysis indicated that phosphorus incorporation in natural graphite could make the surface more stable and reinforce the solid electrolyte interphase during cyclic intercalation and de-intercalation of $\mathrm{Li}^{+}$ions [243]. It has been shown that surface modification by phosphorus incorporation is effective to improve certain electrochemical properties of natural graphite such as cyclic performance and rate capability. It was concluded that the surface of graphite modified with $\mathrm{NH}_{4} \mathrm{PF}_{6}$ could lead to the formation of a relatively stable solid electrolyte interphase by eliminating functional groups or dangling bonds on the surface of graphite and incorporating phosphorus into the graphene layers. 
A significant increase of the reversible discharge and charge capacity (from 280 to $460 \mathrm{~mA} \cdot \mathrm{h} / \mathrm{g}$ ) as a result of phosphorus doping of graphene was reported [239]. The improvement of the electrochemical performance was ascribed to the induction of a large number of topological defects onto the graphene surface during doping, which leads to the formation of a disordered carbon structure that further enhances the lithium insertion properties.

Increases in the charge and discharge capacities upon P-doping of coke were reported [223]. The increase of the reversible capacity of carbon with P-doping was ascribed to an increase in the number of sites accepting $\mathrm{Li}$ ions and an increased interlayer spacing allowing facile $\mathrm{Li}$ intercalation. In addition to this reaction mechanism, it was assumed that the P species might produce crosslinking structures between crystallites at the edge-plane of graphene layers, which would increase the capacity of carbon towards Li ions. However, the discharge capacity retention of the P-doped carbon electrodes was deteriorated at $60{ }^{\circ} \mathrm{C}$ compared to non-doped carbon due to the formation of an unstable surface film. This poor capacity retention could be improved by vinylene carbonate participating in forming a protective solid electrolyte interphase on carbon.

A significant improvement of the electrochemical stability of natural graphite by incorporation of phosphorus heteroatoms was reported [224]. Incorporation of P compounds effectively promoted the consumption of Li ions for solid electrolyte interphase formation on the surface of natural graphite during cycling, leading to the formation of a more stable solid electrolyte interphase film with better durability and thermal resistivity. As a result, the cyclic performance and rate capability of natural graphite were notably improved, even at high and low temperatures. Importantly, there was no severe increase in the interfacial impedance of natural graphite due to the incorporation of $\mathrm{P}$ or $\mathrm{B}$.

Introduction of phosphorus (1.3 at\%) in a petroleum coke-based carbon increased the reversible capacity from 337 to $391 \mathrm{~mA} \cdot \mathrm{h} / \mathrm{g}$, while the excellent rate capability and cycle performance were maintained [422]. The improved electrochemical properties were ascribed to the nanopores produced by $\mathrm{H}_{3} \mathrm{PO}_{4}$ addition, which were formed at a depth of about $1 \mathrm{~mm}$ from the surface of the soft carbon.

It should be noted that much attention is being given to red phosphorus/carbon composites for Li-ion batteries [423-430]. However, this area of investigation is out of the scope of the present review since phosphorus is not bound to the carbons in such composites.

In conclusion: it has been often reported that phosphorus doping enhances Li intercalation, probably by expanding the layer planes of the carbon. In certain cases, phosphorus was assumed to form some cross-linking structures between neighboring crystallites or exist at the edge of the 
graphitic layers; insertion of additional Li species located near the phosphorus species would explain the increase in capacity observed. Introduction of topological defects onto the graphene surface during doping has been claimed as another reason for the improvement of the electrochemical performance in P-doped carbons.

\subsubsection{Oxygen reduction reaction}

The oxygen reduction reaction (ORR) [431] occurring in aqueous solutions is a topic of tremendous interest in the development of renewable energy technologies like fuel cells, metalair batteries, microbial fuel cells etc. Theoretical calculations demonstrated that doped graphene is interesting for ORR due to the active sites generated by heteroatoms [432]. A four-electron transfer mechanism is believed to be the thermodynamically predominant pathway and the highest efficiency is obtained for P-doped graphene as compared to nitrogen and boron doping. The improvement of the electrocatalytic behavior by heteroatom doping of carbon materials was highlighted in recent reviews $[359,433,434]$.

Phosphorus doping of a nitrogen-containing carbon $\left(\mathrm{CN}_{\mathrm{x}} \mathrm{P}_{\mathrm{y}}\right)$ was reported to increase the activity in ORR determined from cyclic voltammograms in an $\mathrm{O}_{2}$ saturated half-cell of $0.5 \mathrm{M} \mathrm{H}_{2} \mathrm{SO}_{4}$ on a rotating ring disk electrode [435]. The greatest improvement in ORR activity was observed for $\mathrm{P} /$ Fe ratios lower than 3. P-doping also increased the number of electrons transferred per $\mathrm{O}_{2}$ molecule from 3.7 to 3.95. The maximum increase in the number of electrons was observed for a carbon with a P/Fe ratio of 0.33 .

Phosphorus doping significantly improved the electrocatalytic activity of carbon nanotubes for the oxygen-reduction reaction in alkaline media, and the carbon nanotubes doped with small amounts of phosphorus exhibited higher electrocatalytic activity and stability than a Pt/C catalyst [250]. Oxygen reduction currents in the potential range from about -0.25 to $-1.2 \mathrm{~V}$ increased with increasing phosphorus content from 0 to 0.13 at\% and decreased with a further increase in phosphorus content up to 1.9 at\%. From this, it was concluded that the ORR performance of the Pdoped CNTs is not only related to the P content but also to their morphologies. It was also shown that the oxygen reduction current density of P-doped CNTs was almost invariable, while Pt exhibited an obvious decrease after 10,000 cycles, suggesting that the stability of the P-doped CNTs is much superior to that of the noble metal catalyst.

A P-doped carbon containing $0.17-0.26$ at\% of phosphorus showed a high electrocatalytic activity, long-term stability (over 12000-13000 cycles), and excellent tolerance to cross-over effects of methanol in the ORR in an alkaline medium [251,252]. The oxygen reduction current densities of the P-doped carbon electrode were about four times higher than those of a 
phosphorus-free carbon electrode and much higher than for a commercial Pt/C electrode in an oxygen-saturated $0.1 \mathrm{M} \mathrm{KOH}$ solution. Furthermore, an increase in the $\mathrm{O}_{2}$ flow rate led to a clear increase in the oxygen reduction current density, which suggested a pronounced electrocatalytic activity of the P-doped carbon for oxygen reduction. The high ORR electrocatalytic activity of this P-doped carbon was ascribed to (i) the good electron-donor properties of phosphorus [396] and (ii) the strong electron affinity of phosphorus for positive charges [251,252] in substitutional position in the graphene sheets of the P-doped graphite. These properties facilitate the adsorption of $\mathrm{O}_{2}$ and significantly enhance the rate of the overall oxygen reduction process. The number of transferred electrons per oxygen molecule involved in ORR was about 3 in the potential range of 0.4 to $-0.7 \mathrm{~V}$ and increased to four at a more negative potential. This suggests that peroxide is formed first and is partially reduced to water during the ORR process.

Phosphorus-doped (about 1.4 at\%) ordered mesoporous carbons (POMCs) showed an excellent electrocatalytic activity for the oxygen reduction reaction, enhanced stability and alcohol tolerance compared to those of a platinum electrocatalyst in an alkaline medium [193]. Phosphorus doping of OMC significantly enhanced the ORR current, which was ascribed to the presence of defect-induced active sites for $\mathrm{O}_{2}$ adsorption that were generated by changes in the bond length and the bond angle of the C-P bond. Phosphorus doping changed the two-electron pathway ORR $(n=2.4)$ for undoped OMC to a four-electron pathway $(n=3.9)$ for POMC. Comparing the values of the ORR peak potential and the current density, it was concluded that the activities of the POMCs [193] are higher than that of P-doped graphite [251].

A remarkable electrocatalytic activity of phosphorus-doped (1.8 at\%) graphene towards the ORR was reported [239]. Cyclic voltammetry showed a substantial reduction process at about $0.6 \mathrm{~V}$ in an $\mathrm{O}_{2}$-saturated $0.1 \mathrm{M} \mathrm{KOH}$ solution, whereas a featureless voltammetric current was observed within the same potential range under $\mathrm{N}_{2}$, suggesting a pronounced electrocatalytic activity of $\mathrm{P}$-doped graphene. Linear sweep voltammetry in an $\mathrm{O}_{2}$-saturated $0.1 \mathrm{M} \mathrm{KOH}$ solution showed that phosphorus introduction increased the ORR current density from $-2.6 \mathrm{~mA} / \mathrm{cm}^{2}$ at $-0.2 \mathrm{~V}$ to $-3.7 \mathrm{~mA} / \mathrm{cm}^{2}$, which is close to that of a commercial Pt/C electrocatalyst. P-doped graphene showed a significantly increased ORR onset potential (0.92 V), which is much more positive than that for undoped graphene (ca. $0.82 \mathrm{~V}$ ) and close to that of commercial Pt/C electrocatalyst (ca. $0.95 \mathrm{~V}$ ). The number of electrons transferred in ORR was 3.0 to 3.8 indicating that ORR proceeds via a combination of two-electron and four-electron pathways. Moreover, Pdoped graphene showed a remarkably better tolerance to methanol crossover as compared to a commercial Pt/C catalyst. It was thus concluded that doping phosphorus atoms into the graphene structure facilitates the ORR. 
High activities for the ORR in alkaline solutions of a P-doped carbon obtained by high temperature heat treatment of a sugar-based carbon with $\mathrm{H}_{3} \mathrm{PO}_{4}$ in the presence of Co were reported [225]. The activity of this phosphorus-doped carbon, containing 1.6-1.7 at\% of phosphorus (with superior stability in alkaline solutions) was comparable to that of commercial $\mathrm{Pt} / \mathrm{C}$ catalysts. The number of electrons transferred in ORR was 3.7-3.8 for the P-doped carbon, suggesting that a four-electron reaction pathway is predominant.

An enhancement in the ORR performance in acidic media by additional P-doping (0.4 at\%) as compared to $\mathrm{N}$-doped graphene was reported [227]. Upon additional P-doping the onset potential increased from 0.84 to $0.87 \mathrm{~V}$ and the mass activity increased from $0.45 \mathrm{~mA} / \mathrm{mg}$ at $0.75 \mathrm{~V}$ to $0.8 \mathrm{~mA} / \mathrm{mg}$. Additional doping with $\mathrm{P}$ reduced the production of $\mathrm{H}_{2} \mathrm{O}_{2}$ in the ORRs, and the resulting catalyst showed a much higher stability than that of $\mathrm{Pt} / \mathrm{C}$ in acidic media. The effect of additional doping was explained by an enhanced asymmetry of the spin density or electron transfer on the basal plane of the graphene, and a decrease in the energy gap between the highest occupied molecular orbital and the lowest unoccupied molecular orbital of the graphene.

P-doped graphene showed a high electrocatalytic activity and exhibited a good resistance to methanol crossover and carbon monoxide poisoning in the ORR in an alkaline medium [244]. Phosphorus doping shifted the onset potential from -0.162 to $-0.0261 \mathrm{~V}$, a value close to that for a Pt/C electrode (-0.0026 V). The ORR current density was about $4.5-4.7 \mathrm{~mA} / \mathrm{cm}^{2}$, which is slightly higher than that for a Pt/C electrode (4.0-4.2 mA/ $\mathrm{cm}^{2}$ ) and 2-2.5 times higher than that for a Pfree graphene. The transferred electron number per oxygen molecule involved in the ORR process was 3.6 in the potential range of -0.4 to $-0.6 \mathrm{~V}$, and exceeded 3.9 at more negative potentials, indicating occurrence of the one-step four-electron pathway, which is highly desirable for fuel cells to gain a maximum energy capacity. Moreover, P-doped graphene showed a good durability - the current loss after 16000 s was only $3.6 \%$ as compared to $41.9 \%$ for a Pt/C catalyst. The enhanced electrocatalytic performance of the P-doped graphene was attributed to redistribution of the atomic charge from the carbon atom through the $\mathrm{P}$ atom as a bridge to the most electronegative oxygen atom. This creates a net positive charge on the carbon atoms adjacent to the $\mathrm{P}$ atom resulting in positively charged carbon atoms near phosphorus atoms, which are active sites for adsorption of $\mathrm{O}_{2}$, weakening the $\mathrm{O}-\mathrm{O}$ bonding, and attracting electrons from the anode to facilitate the ORR through the four-electron pathway.

Much effort has been directed to the design of carbon materials using phosphorus as a codopant, mostly in addition to nitrogen doping. The ORR activities of $\mathrm{P}, \mathrm{N}$-doped carbons in $\mathrm{O}_{2}$ saturated $1 \mathrm{M} \mathrm{HClO}_{4}$ increased with increasing phosphorus content up to $3 \mathrm{wt} \%$ and slightly 
decreased with further P-doping up to 5.8-5.9 wt\% (Table 5) [176]. The highest ORR activity was $-2.88 \mathrm{~mA} / \mathrm{mg}$ for a carbon containing $3 \mathrm{wt} \%$ of phosphorus, which is more than fourfold that of the equivalent phosphorus-free carbon. The activity of the P,N-doped carbon was about $31 \%$ of that for a commercial Pt/C catalyst. Phosphorus doping also changed the ORR pathway from a two-electron pathway producing $\mathrm{H}_{2} \mathrm{O}_{2}$ to a four-electron pathway producing $\mathrm{H}_{2} \mathrm{O}$. With increasing phosphorus content the $\mathrm{H}_{2} \mathrm{O}_{2}$ production yield decreased from $10.1-10.7 \%$ to $1.3-3.3 \%$. It was concluded that increasing P-doping concentrations could enhance the charge delocalization or asymmetric spin density, thus promoting the ORR catalytic activity of the carbon.

Table 5. Phosphorus content and ORR activity of P,N-doped carbons. Adapted from Ref. [176] with permission from The Royal Society of Chemistry

\begin{tabular}{|c|c|c|c|}
\hline $\mathrm{P}, \mathrm{wt} \%$ & ORR current, $\mathrm{mA}$ & ORR activity, $\mathrm{mA} / \mathrm{g}$ & $\mathrm{H}_{2} \mathrm{O}_{2}$ production yield, \% \\
\hline 0 & -0.034 & -0.69 & 10.1 \\
\hline 0.9 & -0.087 & -1.74 & 3.3 \\
\hline 3 & -0.144 & -2.88 & 1.3 \\
\hline 5.9 & -0.129 & -2.57 & 1.6 \\
\hline 5.8 & -0.116 & -2.32 & 0.8 \\
\hline
\end{tabular}

The effect of $P, N$ and $B$ heteroatoms on the electrocatalytic activity of carbon was also reported [177]. The ORR activities of carbons increased by $100-108 \%$ after additional doping with phosphorus, while only an 11-15\% increase was observed for additional B-doping. The tertiary $\mathrm{P}, \mathrm{N}, \mathrm{B}$-doped carbon demonstrated the highest activity among the prepared catalysts $(-6 \mathrm{~mA} / \mathrm{mg})$, along with a good stability. Additional phosphorus doping decreased the yield of $\mathrm{H}_{2} \mathrm{O}_{2}$ production thus improving the characteristics toward a four-electron pathway in ORR. The improvement in the ORR activity due to P-doping was ascribed to an enhancement of the charge delocalization of the carbon atoms and production of carbon structures with many edge sites.

Phosphorus (0.8 at\%) and nitrogen (2.9 at\%) co-doped on vertically aligned carbon nanotubes showed a high electrocatalytic activity in ORR, superior long-term durability and good tolerance to methanol and carbon monoxide [255]. These $\mathrm{P}, \mathrm{N}$-doped CNTs were more active in ORR than only P- or N-doped CNTs and even more active than a commercial Pt/C electrocatalyst in terms of the onset potential and current density. All CNT catalysts showed a much higher selectivity for the ORR with almost no methanol crossover effect than the Pt/C catalyst. The transferred electron number per oxygen molecule involved in ORR was close to four (3.7-3.9) on 
$\mathrm{P}, \mathrm{N}$-doped CTNs. The P,N-doped CNTs were insensitive to $\mathrm{CO}$ addition while the commercial Pt/C electrocatalyst was rapidly poisoned under the same condition. The superior ORR performance of $\mathrm{P}, \mathrm{N}$-doped CNTs was attributed to a synergistic effect of co-doping with $\mathrm{P}$ and $\mathrm{N}$ heteroatoms.

A P,N-functionalized nanocarbon showed a high electrocatalytic activity and exhibited good tolerance to the methanol crossover effects in the ORR in an alkaline medium [178]. The number of electrons transferred in ORR was calculated to be 3.6-4.2 over the potential range from -0.4 to $0.6 \mathrm{~V}$, indicating occurrence of the four-electron reduction process.

Improvement in the electrocatalytic ORR activity of reduced graphene oxide with phosphorus doping was reported [240]. Ternary N,S,P-doped reduced graphene oxide (phosphorus content, 0.96-1.31 at\%) was even more active in ORR, which was attributed to the synergistic interaction of $\mathrm{P}$ with $\mathrm{N}$ and/or $\mathrm{S}$ in the ternary-doped samples. This resulted in the formation of more active sites and conductive species such as $\mathrm{P}-\mathrm{N}$ bonds along with an increased $\mathrm{P}$ doping level. The electrocatalytic ORR activity of the ternary N,S,P-doped reduced graphene oxide (onset potential $-0.03 \mathrm{~V}$, current density $-6.4 \mathrm{~mA} / \mathrm{cm}^{2}$ ) was higher than that of a commercial Pt/C catalyst (onset potential $-0.06 \mathrm{~V}$, current density $-5.0 \mathrm{~mA} / \mathrm{cm}^{2}$ ). The electron number transferred per oxygen molecule in ORR was close to four indicating that the N,S,P-doped reduced graphene oxide can be a promising alternative to the costly Pt-based electrocatalyst.

The chemical state of phosphorus has a significant effect on the ORR catalytic activity of the carbon. A phosphorus-doped carbon with a pronounced P-C bonding showed a high catalytic activity in ORR via 4 electron pathway [436]. However, a P-doped carbon with predominant P-O bonding exhibited a 2-electron pathway in ORR. Dual P- and N-doped carbon showed an even better ORR performance. By contrast, an improvement in the ORR activity due to the formation of chemical C-O-P bonds and decrease in the reactivity by C-P bonds was reported [437]. The difference was attributed to a significant structural distortion arising from the large size of the phosphorus atoms. This may have weakened the stability of the key intermediates during the ORR, as indicated by a decrease in the work function.

To summarize, both theoretical calculations and experimental work have shown that doped carbon materials contain active ORR sites generated by the incorporated heteroatoms. A higher theoretical efficiency was obtained for P-doped graphene as compared with $\mathrm{N}$ - and Bdoping. The high ORR electrocatalytic activity of P-doped carbons has been ascribed to the good electron-donor properties of phosphorus and the strong electron affinity of phosphorus for positive charges. These properties facilitate $\mathrm{O}_{2}$ adsorption, thus enhancing the rate of the overall oxygen reduction process. In some cases, P-doped carbons equaled or even outperformed noble 
metal catalysts for the ORR, exhibiting high stability and durability as well as good methanol and CO tolerance. In a number of cases, occurrence of the one-step four-electron pathway was detected, which is highly desirable to gain a maximum energy capacity in fuel cells. Much effort has been directed to studying the effects of co-doping carbon materials with several heteroatoms, using phosphorus as a co-dopant, mostly in addition to nitrogen as well as boron and sulfur doping.

\subsubsection{Nitrogen reduction reaction}

Recently it was demonstrated that an N,P co-doped hierarchical porous carbon can serve as an electrocatalyst for the nitrogen reduction reaction (NRR) in an acid aqueous solution under ambient conditions [438]. Electrochemical in situ-FTIR experiments revealed that the NRR process on the N,P co-doped carbon follows an associative pathway (Fig. 57). Molecular $\mathrm{N}_{2}$ is firstly adsorbed on the surface of the heterogeneous catalyst, and then protons get attached to $\mathrm{N}_{2}$ to form a $-\mathrm{N} \equiv \mathrm{N}-\mathrm{H}$ bond, which could weaken the stable $\mathrm{N} \equiv \mathrm{N}$ bond. In the second step, another proton further hydrogenates the weakened $-\mathrm{N} \equiv \mathrm{N}-\mathrm{H}$ bond and forms a $-\mathrm{H}-\mathrm{N}=\mathrm{N}-\mathrm{H}$ bond; thereafter, the continuous electron transfer and hydrogenation of $-\mathrm{H}-\mathrm{N}=\mathrm{N}-\mathrm{H}$ intermediates occurs to form $-\mathrm{H}-\mathrm{N}-\mathrm{NH}_{2}$, and eventually $\mathrm{NH}_{3}$ is formed on the surface of $\mathrm{N}, \mathrm{P}$ co-doped carbon and the NRR is achieved under ambient conditions in a $0.1 \mathrm{M} \mathrm{HCl}$ solution.

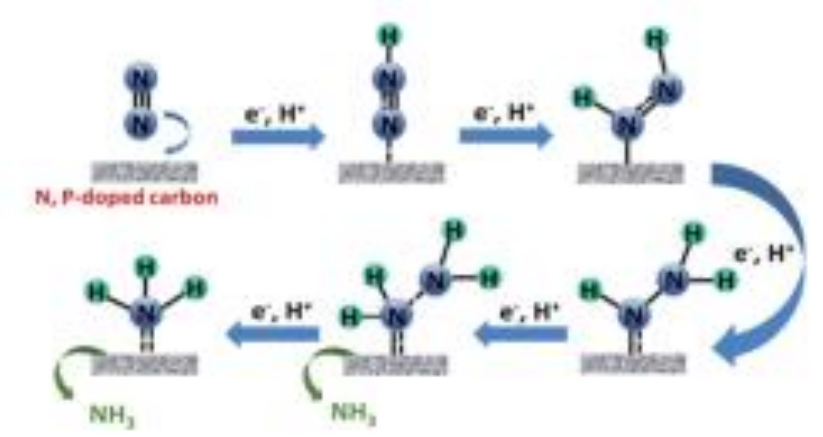

Fig. 57. Associative mechanism of the NRR process on NPC. Reproduced from Ref. [438] with permission from The Royal Society of Chemistry.

\subsubsection{Fuel cells}

Phosphorus-doped multiwalled carbon nanotubes (P-MCNTs) were used as support for a platinum catalyst for direct methanol fuel cells [253,254]. These Pt/P-MCNTs exhibited a much higher electrocatalytic activity and longer-term stability for methanol oxidation than Pt/MCNTs in an acidic medium, due to (i) the higher Pt utilization ratio and Pt area-specific activity, (ii) the better electronic conductivity of P-MCNT support and (iii) the faster rate of charge transfer at the 
P-MCNTs/electrolyte interface. This indicates a high potential for application of Pt/P-MCNTs as anode catalyst for methanol oxidation in alkaline methanol fuel cells.

Phosphorus-containing Pt-loaded carbon nanofibers from lignin were tested as electrodes for electrooxidation of methanol and ethanol [439]. It has been shown that the presence of phosphorus improved the resistance to poisoning of Pt-loaded carbon microfibers as anodes for the electro-oxidation of methanol, though unfortunately, the presence of phosphorus decreased the catalytic activity.

A phosphorus-doped carbon was prepared via direct pyrolysis of cellulose phosphate to be used as an efficient oxygen reduction catalyst in the air-cathode of microbial fuel cells [440]. A maximum power density of $1312 \pm 82 \mathrm{~mW} / \mathrm{m}^{2}$ was produced by the air-cathode with the P-doped carbon catalyst prepared at $1000^{\circ} \mathrm{C}$. This value was higher than for the air-cathode with a Pt/C catalyst and three times larger than that for a P-free carbon catalyst derived from pure cellulose.

Phosphorus and nitrogen dual-doped carbons were prepared by pyrolysis of cellulose with ammonium phosphate as doping source and used as oxygen reduction reaction catalyst in the aircathode of a microbial fuel cell [186]. A maximum power density of $2293 \pm 50 \mathrm{~mW} / \mathrm{m}^{2}$ was generated by the air-cathode using the dual-doped carbon catalyst, which was higher than using a $\mathrm{Pt} / \mathrm{C}$ catalyst with a Pt load of $0.5 \mathrm{mg} / \mathrm{cm}^{2}\left(1680 \pm 32 \mathrm{~mW} / \mathrm{m}^{2}\right)$.

Introduction of phosphorus substantially improved the performance of an activated carbon air cathode in a microbial fuel cell [441]. The microbial fuel cell with a P-doped carbon air cathode showed a $75 \%$ higher maximum power density $\left(1278 \mathrm{~mW} / \mathrm{m}^{2}\right)$ than those obtained with a P-free carbon air cathode.

\subsubsection{Indicator electrodes}

It has been shown that P-doping of glassy carbon electrodes substantially increased the overpotential for $\mathrm{H}^{+}$reduction in $\mathrm{H}_{2} \mathrm{SO}_{4}$ by about $200 \mathrm{mV}$, thus expanding the electrochemical window of the material [442]. In the argentometric titration of halides, a P-doped glassy carbon showed a $100 \mathrm{mV}$ higher potential jump around the equivalence point as compared to non-doped and boron-doped electrodes, and by $300 \mathrm{mV}$ higher than a silver electrode.

Phosphorus-doped glassy carbon was also applied as a potentiometric indicator electrode in the titrimetric determination of active components with bromide or chloride in their molecules in different pharmaceutical preparations [443]. It was reported that phosphorus-doped glassy carbon is comparable to a standard non-doped glassy carbon in respect to accuracy and has an 
advantage in respect of precision. The method was advantageous over the official methods because it requires 75 times less amount of sample.

\section{Conclusions and Prospects}

Phosphorus-containing carbons represent a separate class of carbon materials with unique properties due to the contained phosphorus species. The most commonly found structure is pentavalent tetra-coordinated phosphorus as in phosphates, however, some P-O bonds may be replaced with $\mathrm{P}-\mathrm{C}$ bonds. The introduction of phosphorus atoms in a trigonal substitutional position in the $\mathrm{sp}^{2}$ carbon framework is challenging because the larger size of the phosphorus atom results in a stressed corrugated graphene lattice. Moreover, the phosphorus atoms in a substitutional position readily chemisorb oxygen, which leads to transformation of trigonal to tetra-coordinated phosphorus species.

The final heat treatment temperature has a greater impact on the structure of phosphoruscontaining species in the carbon in comparison with the source of phosphorus. Phosphorus species are stable up to $800-830^{\circ} \mathrm{C}$ and are eliminated at higher temperatures. Increasing the heat treatment temperature causes a gradual reduction of pentavalent phosphorus to trivalent and even elemental zero valent forms. The reduced phosphorus species could be reoxidized by aerial oxygen at low temperatures, which is a reason for the more abundant occurrence of pentavalent tetra-coordinated phosphorus.

There is a controversy between two different schemes of interpretation of the XPS spectra of P-containing carbons heat-treated at increasing temperatures. One involves a gradual dehydration of phosphates (phosphates --> polyphosphates --> metaphosphates --> $\mathrm{P}_{2} \mathrm{O}_{5}-->P$ elemental) with increasing temperature. Another scheme involves the gradual reduction of phosphates (gradual replacement of O-P bonds by C-P bonds and finally formation of $\mathrm{C}_{3} \mathrm{P}$, where $\mathrm{P}$ is 3-valent) with increasing temperature. More research is needed with the use of standard substances and confirmation by other methods like solid-state ${ }^{31} \mathrm{P}-\mathrm{NMR}$.

Phosphorus species bind to the active sites of carbon rendering stability to phosphoruscontaining carbons. This defines the properties of P-containing carbons: hydrophilic acid surface and chemical stability. Phosphorus-containing carbons show a high adsorption capacity for metal ions and organic molecules with basic nature. Phosphorus-containing species of acidic nature impart carbon a catalytic activity in diverse reactions useful in the production of commodity chemicals and biomass transformation. Phosphorus-containing species alter the optical properties of carbons suitable in energy generation, protection of the environment or bioimaging. Finally, 
phosphorus-containing species make the corresponding carbons very promising in electrochemical applications like energy storage (EDLC, Li-ion batteries) or in fuel cells.

Based on the current tendencies in publication of works on heteroatom-containing carbons (and on carbons in general), one can predict much future research on applications (even on different applications not connected with each other, but reported in the same paper). Such a research where novelty is limited to ascertaining the effects of changes in carbon composition or in operation conditions is not much desirable, and we do not consider this as a research need per se. Rather, future research on the applications of P-containing carbons should be focused on uses where these carbons can be unique, or at least advantageous over carbons that do not contain phosphorus. In this regard, further applied research on P-containing carbons could be focused on the applications where they are most successful, i.e., energy related like EDLC, Li-ion batteries or ORR. Definitely, the chemical and electrochemical stability of P-carbons is important for these processes. The possible red-ox behavior of $\mathrm{P}$-species also deserves attention as this is important for pseudocapacitance in supercapacitors.

Another area in which phosphorus-containing carbons may deserve interesting applications is metal ion adsorption. Once the high adsorption capacity for metal ions and organic molecules with basic nature has been demonstrated, this property should be exploited to further steps such as making this adsorption selective for species with industrial or environmental impact such as rare earth elements or uranium from aqueous solutions.

The catalytic properties of phosphorus-containing carbons also deserve further investigation. Phosphorus-containing carbons have proven to be an active catalyst in various industrially important reactions including oxidation, dehydrogenation, dehydration, hydrolysis and etherification or esterification, cycloaddition and biomass transformation.

Finally, a field in which a great deal of research is to be expected is the combination of different heteroatoms in carbons. Although the number of elements that can be incorporated into carbons is relatively limited, their combinations can plague the literature with many papers on different (ternary, quaternary, and so on) combinations of $P$ and other heteroelements, in different proportions, in carbons. Like the aforementioned work on applications, future research in this field should be guided by judicious selection rather than by a trial and error approach, being focused on those element combinations expected to bring novel behaviors. In this regard, basic research, including theoretical work (supplemented, whenever possible, with experiments), can provide a useful guide to select the most promising heteroelement combinations to be investigated. 


\section{Acknowledgements}

One of us (J.M.D.T.) acknowledges partial funding from Gobierno del Principado de Asturias and FEDER (grant IDI/2018/000233).

\section{References}

[1] H.-P. Boehm, E. Diehl, W. Heck, R. Sappok, Surface Oxides of Carbon, Angew. Chem. Int. Ed. 3 (1964) 669-677. doi:10.1002/anie.196406691.

[2] B.R. Puri, Surface complexes on carbons, in: P.L. Walker Jr. (Ed.), Chemistry and Physics of Carbon, Marcel Dekker, Inc., New York, 1970: pp. 191-282.

[3] H.P. Boehm, Some aspects of the surface chemistry of carbon blacks and other carbons, Carbon 32 (1994) 759-769. doi:10.1016/0008-6223(94)90031-0.

[4] C. Moreno-Castilla, M.V. López-Ramón, F. Carrasco-Marín, Changes in surface chemistry of activated carbons by wet oxidation, Carbon 38 (2000) 1995-2001. doi:10.1016/S0008-6223(00)00048-8.

[5] J. Choma, W. Burakiewicz-Mortka, M. Jaroniec, Z. Li, J. Klinik, Monitoring changes in surface and structural properties of porous carbons modified by different oxidizing agents, J. Colloid Interface Sci. 214 (1999) 438-446. doi:10.1006/jcis.1999.6246.

[6] J. Rivera-Utrilla, M.A. Ferro-García, Effect of carbon-oxygen and carbon-nitrogen surface complexes on the adsorption of cations by activated carbons, Adsorpt. Sci. Technol. 3 (1986) 293-302.

[7] J. Rivera-Utrilla, M. Sánchez-Polo, V. Gómez-Serrano, P.M. Alvarez, M.C.M. Alvim-Ferraz, J.M. Dias, Activated carbon modifications to enhance its water treatment applications. An overview., J. Hazard. Mater. 187 (2011) 1-23. doi:10.1016/j.jhazmat.2011.01.033.

[8] F. Rodriguez-Reinoso, M. Molina-Sabio, M.A. Muñecas, Effect of microporosity and oxygen surface groups of activated carbon in the adsorption of molecules of different polarity, J. Phys. Chem. 96 (1992) 2707-2713. doi:10.1021/j100185a056.

[9] A.R. Ferens, R.D. Weinstein, R. Giuliano, J.A. Hull, Selective decomposition of isopropanol using as prepared and oxidized graphite nanofibers, Carbon 50 (2012) 192-200. doi:10.1016/j.carbon.2011.08.020.

[10] T. Budinova, M. Razvigorova, N. Petrov, V. Minkova, R. Taranjiska, Catalytic hydrolysis of soya oil with carbon adsorbents, Carbon 36 (1998) 899-901. doi:10.1016/S0008-6223(97)00201-7.

[11] J. Lahaye, G. Nansé, A. Bagreev, V.V. Strelko, Porous structure and surface chemistry of nitrogen containing carbons from polymers, Carbon 37 (1999) 585-590. doi:10.1016/S0008-6223(98)002255 .

[12] F. Kapteijn, J.A. Moulijn, S. Matzner, H.-P. Boehm, The development of nitrogen functionality in model chars during gasification in $\mathrm{CO}_{2}$ and $\mathrm{O}_{2}$, Carbon 37 (1999) 1143-1150. doi:10.1016/S00086223(98)00312-1.

[13] J.F. Keegel, W.A. Suruda, C. Schwob, The catalytic properties of charcoal. III. A comparison of the oxidative properties of various charcoals. The effect of charcoal hydrosols on hydrogen peroxide and oxygen, J. Am. Chem. Soc. 60 (1938) 2483-2486. doi:10.1021/ja01277a056.

[14] B. Stöhr, H.P. Boehm, R. Schlögl, Enhancement of the catalytic activity of activated carbons in oxidation reactions by thermal treatment with ammonia or hydrogen cyanide and observation of a superoxide species as a possible intermediate, Carbon 29 (1991) 707-720. doi:10.1016/00086223(91)90006-5.

[15] H.-P. Boehm, Catalytic Properties of Nitrogen-Containing Carbons, in: P. Serp, J.L. Figueiredo (Eds.), Carbon Materials for Catalysis, John Wiley \& Sons, Inc., Hoboken, NJ, USA, 2008: pp. 219-265. 
doi:10.1002/9780470403709.ch7.

[16] M. Inagaki, M. Toyoda, Y. Soneda, T. Morishita, Nitrogen-doped carbon materials, Carbon 132 (2018) 104-140. doi:10.1016/j.carbon.2018.02.024.

[17] S. Marinkovic, Substitutional solid solubility in carbon and graphite, in: P.A. Thrower (Ed.), Chemistry and Physics of Carbon, Marcel Dekker, Inc., New York, Basel, 1984: pp. 1-64.

[18] Y.-J. Lee, Y. Uchiyama, L.R. Radovic, Effects of boron doping in low- and high-surface-area carbon powders, Carbon 42 (2004) 2233-2244. doi:10.1016/j.carbon.2004.04.030.

[19] L.R. Radovic, M. Karra, K. Skokova, P.A. Thrower, The role of substitutional boron in carbon oxidation, Carbon 36 (1998) 1841-1854. doi:10.1016/S0008-6223(98)00156-0.

[20] Y.-J. Lee, L.R. Radovic, Oxidation inhibition effects of phosphorus and boron in different carbon fabrics, Carbon 41 (2003) 1987-1997. doi:10.1016/S0008-6223(03)00199-4.

[21] D. Lozano-Castelló, R. Kamalakaran, K. van Benthem, Y.J. Phillipp, N. Grobert, M. Rühle, Preparation and characterisation of novel "sea-cucumber"-like structures containing carbon and boron, Carbon 42 (2004) 2223-2231. doi:10.1016/j.carbon.2004.04.029.

[22] Y.-J. Lee, H.-H. Kim, H. Hatori, Effects of substitutional B on oxidation of carbon nanotubes in air and oxygen plasma, Carbon 42 (2004) 1053-1056. doi:10.1016/j.carbon.2003.12.002.

[23] A. Vinu, M. Terrones, D. Golberg, S. Hishita, K. Ariga, T. Mori, Synthesis of mesoporous BN and BCN exhibiting large surface areas via templating methods, Chem. Mater. 17 (2005) 5887-5890. doi:10.1021/cm051780j.

[24] D.-W. Wang, F. Li, Z.-G. Chen, G.Q. Lu, H.-M. Cheng, Synthesis and electrochemical property of boron-doped mesoporous carbon in supercapacitor, Chem. Mater. 20 (2008) 7195-7200. doi:10.1021/cm801729y.

[25] X. Zhao, A. Wang, J. Yan, G. Sun, L. Sun, T. Zhang, Synthesis and electrochemical performance of heteroatom-incorporated ordered mesoporous carbons, Chem. Mater. 22 (2010) 5463-5473. doi:10.1021/cm101072z.

[26] M. Enterría, M.F.R. Pereira, J.I. Martins, J.L. Figueiredo, Hydrothermal functionalization of ordered mesoporous carbons: The effect of boron on supercapacitor performance, Carbon 95 (2015) 72-83. doi:10.1016/j.carbon.2015.08.009.

[27] H. Itoi, H. Nishihara, T. Kyotani, Effect of heteroatoms in ordered microporous carbons on their electrochemical capacitance, Langmuir 32 (2016) 11997-12004. doi:10.1021/acs.langmuir.6b02667.

[28] H. Fujimoto, A. Mabuchi, C. Natarajan, T. Kasuh, Properties of graphite prepared from boron-doped pitch as an anode for a rechargeable Li ion battery, Carbon 40 (2002) 567-574. doi:10.1016/S00086223(01)00152-X.

[29] G. Yin, Y. Gao, P. Shi, X. Cheng, A. Aramata, The effect of boron doping on lithium intercalation performance of boron-doped carbon materials, Mater. Chem. Phys. 80 (2003) 94-101. doi:10.1016/S0254-0584(02)00337-1.

[30] T.C. King, P.D. Matthews, H. Glass, J.A. Cormack, J.P. Holgado, M. Leskes, J.M. Griffin, O.A. Scherman, P.D. Barker, C.P. Grey, S.E. Dutton, R.M. Lambert, G. Tustin, A. Alavi, D.S. Wright, Theory and practice: bulk synthesis of $\mathrm{C}_{3} \mathrm{~B}$ and its $\mathrm{H}_{2}$ - and Li-storage capacity, Angew. Chem. Int. Ed. 54 (2015) 5919-5923. doi:10.1002/anie.201412200.

[31] J.P. Paraknowitsch, A. Thomas, Doping carbons beyond nitrogen: an overview of advanced heteroatom doped carbons with boron, sulphur and phosphorus for energy applications, Energy Environ. Sci. 6 (2013) 2839-2855. doi:10.1039/c3ee41444b.

[32] W. Kiciński, M. Szala, M. Bystrzejewski, Sulfur-doped porous carbons: Synthesis and applications, Carbon 68 (2014) 1-32. doi:10.1016/j.carbon.2013.11.004. 
[33] T.J. Bandosz, T. Ren, Porous carbon modified with sulfur in energy related applications, Carbon 118 (2017) 561-577. doi:10.1016/j.carbon.2017.03.095.

[34] T.J. Bandosz, M. Seredych, On the photoactivity of S-doped nanoporous carbons: Importance of surface chemistry and porosity, Chinese J. Catal. 35 (2014) 807-814. doi:10.1016/S18722067(14)60100-5.

[35] T.J. Bandosz, A. Policicchio, M. Florent, W. Li, P.S. Poon, J. Matos, Solar light-driven photocatalytic degradation of phenol on S-doped nanoporous carbons: The role of functional groups in governing activity and selectivity, Carbon (2019). doi:10.1016/j.carbon.2019.09.037.

[36] K. Nakajima, M. Hara, Amorphous Carbon with $\mathrm{SO}_{3} \mathrm{H}$ Groups as a Solid Brønsted Acid Catalyst, ACS Catal. 2 (2012) 1296-1304. doi:10.1021/cs300103k.

[37] M.J.B. Evans, E. Halliop, S. Liang, J.A.F. MacDonald, The effect of chlorination on surface properties of activated carbon, Carbon 36 (1998) 1677-1682. doi:10.1016/S0008-6223(98)00165-1.

[38] A.F. Pérez-Cadenas, F.J. Maldonado-Hódar, C. Moreno-Castilla, On the nature of surface acid sites of chlorinated activated carbons, Carbon 41 (2003) 473-478. doi:10.1016/S0008-6223(02)00353-6.

[39] E. Sasmaz, A. Kirchofer, A.D. Jew, A. Saha, D. Abram, T.F. Jaramillo, J. Wilcox, Mercury chemistry on brominated activated carbon, Fuel 99 (2012) 188-196. doi:10.1016/j.fuel.2012.04.036.

[40] E.C. Rupp, J. Wilcox, Mercury chemistry of brominated activated carbons - Packed-bed breakthrough experiments, Fuel 117 (2014) 351-353. doi:10.1016/j.fuel.2013.09.017.

[41] G. Li, K. Kaneko, S. Ozeki, F. Okino, H. Touhara, Water rejective nature of fluorinated microporous carbon fibers, Langmuir 11 (1995) 716-717. doi:10.1021/la00003a008.

[42] Y.-S. Lee, Syntheses and properties of fluorinated carbon materials, J. Fluor. Chem. 128 (2007) 392403. doi:10.1016/j.jfluchem.2006.11.014.

[43] Y.-S. Lee, Surface-Fluorinated Carbon Materials for Supercapacitor, in: Advanced Fluoride-Based Materials for Energy Conversion, Elsevier, 2015: pp. 375-386. doi:10.1016/B978-0-12-8006795.00015-4.

[44] P. Barpanda, G. Fanchini, G.G. Amatucci, Structure, surface morphology and electrochemical properties of brominated activated carbons, Carbon 49 (2011) 2538-2548. doi:10.1016/j.carbon.2011.02.028.

[45] Y. Ahmad, K. Guérin, M. Dubois, W. Zhang, A. Hamwi, Enhanced performances in primary lithium batteries of fluorinated carbon nanofibers through static fluorination, Electrochim. Acta 114 (2013) 142-151. doi:10.1016/j.electacta.2013.09.140.

[46] Y. Ahmad, E. Disa, K. Guérin, M. Dubois, E. Petit, A. Hamwi, P. Thomas, J.-L. Mansot, Structure control at the nanoscale in fluorinated graphitized carbon blacks through the fluorination route, $\mathrm{J}$. Fluor. Chem. 168 (2014) 163-172. doi:10.1016/j.jfluchem.2014.09.021.

[47] T. Nakajima, Surface Modification of Carbon Anodes for Lithium Ion Batteries by Fluorine and Chlorine, in: Advanced Fluoride-Based Materials for Energy Conversion, Elsevier, 2015: pp. 203-223. doi:10.1016/B978-0-12-800679-5.00009-9.

[48] R. Schlögl, Surface Composition and Structure of Active Carbons, in: F. Schüth, K.S.W. Sing, J. Weitkamp (Eds.), Handbook of Porous Solids, Wiley-VCH Verlag GmbH, Weinheim, Germany, 2002: pp. 1863-1900. doi:10.1002/9783527618286.ch24c.

[49] T.J. Bandosz, C.O. Ania, Surface chemistry of activated carbons and its characterization, in: T.J. Bandosz (Ed.), Activated Carbon Surfaces in Environmental Remediation, Academic Press, Amsterdam, 2006: pp. 159-229.

[50] F. Rodríguez-Reinoso, M. Molina-Sabio, Textural and chemical characterization of microporous carbons, Adv. Colloid Interface Sci. 76-77 (1998) 271-294. doi:10.1016/S0001-8686(98)00049-9. 
[51] J. Lahaye, The chemistry of carbon surfaces, Fuel 77 (1998) 543-547. doi:10.1016/S00162361(97)00099-9.

[52] W.M.A.W. Daud, A.H. Houshamnd, Textural characteristics, surface chemistry and oxidation of activated carbon, J. Nat. Gas Chem. 19 (2010) 267-279. doi:10.1016/S1003-9953(09)60066-9.

[53] T.J. Bandosz, Surface Chemistry of Carbon Materials, in: P. Serp, J.L. Figueiredo (Eds.), Carbon Materials for Catalysis, John Wiley \& Sons, Inc., Hoboken, New Jersey, 2009: pp. 45-92.

[54] C.A. Leon y Leon, L.R. Radovic, Interfacial Chemistry and Electrochemistry of Carbon Surfaces, in: P.A. Thrower (Ed.), Chemistry and Physics of Carbon, Marcel Dekker, New York, 1994: pp. 213-310.

[55] L.R. Radovic, C. Moreno-Castilla, J. Rivera-Utrilla, Carbon materials as adsorbents in aqueous solutions, in: L.R. Radovic (Ed.), Chemistry and Physics of Carbon, Marcel Dekker, Inc., New York, 2001: pp. 227-405.

[56] M. Seredych, D. Hulicova-Jurcakova, G.Q. Lu, T.J. Bandosz, Surface functional groups of carbons and the effects of their chemical character, density and accessibility to ions on electrochemical performance, Carbon 46 (2008) 1475-1488. doi:10.1016/j.carbon.2008.06.027.

[57] M.G. Plaza, F. Rubiera, J.J. Pis, C. Pevida, Ammoxidation of carbon materials for $\mathrm{CO}_{2}$ capture, Appl. Surf. Sci. 256 (2010) 6843-6849. doi:10.1016/j.apsusc.2010.04.099.

[58] S. Giraudet, Z. Zhu, X. Yao, G. Lu, Ordered mesoporous carbons enriched with nitrogen: application to hydrogen storage, J. Phys. Chem. C 114 (2010) 8639-8645. doi:10.1021/jp101119r.

[59] M. Seredych, D. Hulicova-Jurcakova, T.J. Bandosz, Effect of the incorporation of nitrogen to a carbon matrix on the selectivity and capacity for adsorption of dibenzothiophenes from model diesel fuel, Langmuir 26 (2010) 227-33. doi:10.1021/la902059y.

[60] W. Shen, W. Fan, Nitrogen-containing porous carbons: synthesis and application, J. Mater. Chem. A 1 (2013) 999-1013. doi:10.1039/C2TA00028H.

[61] R.J.J. Jansen, H. van Bekkum, Amination and ammoxidation of activated carbons, Carbon 32 (1994) 1507-1516. doi:10.1016/0008-6223(94)90146-5.

[62] J.R. Pels, F. Kapteijn, J.A. Moulijn, Q. Zhu, K.M. Thomas, Evolution of nitrogen functionalities in carbonaceous materials during pyrolysis, Carbon 33 (1995) 1641-1653. doi:10.1016/00086223(95)00154-6.

[63] S. Matzner, H.P. Boehm, Influence of nitrogen doping on the adsorption and reduction of nitric oxide by activated carbons, Carbon 36 (1998) 1697-1703. doi:10.1016/S0008-6223(98)90047-1.

[64] K. Jurewicz, K. Babeł, A. Ziółkowski, H. Wachowska, Capacitance behaviour of the ammoxidised coal, J. Phys. Chem. Solids 65 (2004) 269-273. doi:10.1016/j.jpcs.2003.10.023.

[65] D. Hulicova-Jurcakova, M. Kodama, H. Hatori, Electrochemical performance of nitrogen-enriched carbons in aqueous and non-aqueous supercapacitors, Chem. Mater. 18 (2006) 2318-2326. doi:10.1021/cm060146i.

[66] C.O. Ania, V. Khomenko, E. Raymundo-Piñero, J.B. Parra, F. Béguin, The large electrochemical capacitance of microporous doped carbon obtained by using a zeolite template, Adv. Funct. Mater. 17 (2007) 1828-1836. doi:10.1002/adfm.200600961.

[67] F.G.R. Gimblett, J.J. Freeman, K.S.W. Sing, Element-containing carbon fibres: recent USSR/Eastern European research in fibre technology, J. Mater. Sci. 24 (1989) 3799-3812. doi:10.1007/BF01168939.

[68] D.W. McKee, Oxidation protection of carbon materials, in: P.A. Thrower (Ed.), Chemistry and Physics of Carbon, Marcel Dekker, Inc., New York, 1991: pp. 173-232.

[69] C.O. Ania, Chapter 1: Surface Chemistry of Green Carbons, in: J. Zhu, D. Hulicova-Jurcakova, T.E. Rufford (Eds.), Green Carbon Materials - Advances and Applications, Pan Stanford Publishing, Boca 
Raton, FL, 2014: pp. 1-33. doi:10.4032/9789814411141.

[70] E. García-Bordejé, M.F.R. Pereira, M. Rönning, D. Chen, Novel carbon materials modified with heteroatoms as metal-free catalyst and metal catalyst support, in: J. Spivey, Y.-F. Han, K. Dooley (Eds.), Catalysis, Royal Society of Chemistry, Cambridge, 2014: pp. 72-108. doi:10.1039/9781782620037-00072.

[71] M.R. Benzigar, S.N. Talapaneni, S. Joseph, K. Ramadass, G. Singh, J. Scaranto, U. Ravon, K. Al-Bahily, A. Vinu, Recent advances in functionalized micro and mesoporous carbon materials: synthesis and applications, Chem. Soc. Rev. 47 (2018) 2680-2721. doi:10.1039/C7CS00787F.

[72] A.M. Puzii, Methods of production, structure, and physicochemical characteristics of phosphorylated carbon adsorbents, Theor. Exp. Chem. 47 (2011) 277-291. doi:10.1007/s11237-011-9216-8.

[73] A.M. Puziy, J.M.D. Tascón, Adsorption by phosphorus-containing carbons, in: J.M.D. Tascón (Ed.), Novel Carbon Adsorbents, Elsevier, Amsterdam, 2012: pp. 245-267. doi:10.1016/B978-0-08-0977447.00008-9.

[74] G. Camino, N. Grassie, I.C. McNeill, Influence of the fire retardant, ammonium polyphosphate, on the thermal degradation of poly(methyl methacrylate), J. Polym. Sci. Polym. Chem. Ed. 16 (1978) 95106. doi:10.1002/pol.1978.170160110.

[75] S. Bourbigot, M. Le Bras, R. Delobel, Carbonization mechanisms resulting from intumescence association with the ammonium polyphosphate-pentaerythritol fire retardant system, Carbon 31 (1993) 1219-1230. doi:10.1016/0008-6223(93)90079-P.

[76] S. Bourbigot, M. Le Bras, R. Delobel, P. Bréant, J.-M. Trémillon, Carbonization mechanisms resulting from intumescence-part II. Association with an ethylene terpolymer and the ammonium polyphosphate-pentaerythritol fire retardant system, Carbon 33 (1995) 283-294. doi:10.1016/00086223(94)00131-I.

[77] S. Bourbigot, X. Flambard, Heat resistance and flammability of high performance fibres: A review, Fire Mater. 26 (2002) 155-168. doi:10.1002/fam.799.

[78] A. Gentilhomme, M. Cochez, M. Ferriol, N. Oget, J.L. Mieloszynski, Thermal degradation of methyl methacrylate polymers functionalized by phosphorus-containing molecules. III: Cone calorimeter experiments and investigation of residues, Polym. Degrad. Stab. 88 (2005) 92-97. doi:10.1016/j.polymdegradstab.2004.04.029.

[79] A.I. Balabanovich, D. Pospiech, A. Korwitz, L. Häußler, C. Harnisch, Pyrolysis study of a phosphoruscontaining aliphatic-aromatic polyester and its nanocomposites with layered silicates, Polym. Degrad. Stab. 94 (2009) 355-364. doi:10.1016/j.polymdegradstab.2008.12.004.

[80] S. Gaan, G. Sun, Effect of phosphorus flame retardants on thermo-oxidative decomposition of cotton, Polym. Degrad. Stab. 92 (2007) 968-974. doi:10.1016/j.polymdegradstab.2007.03.009.

[81] L. Chen, Y.-Z. Wang, Aryl polyphosphonates: useful halogen-free flame retardants for polymers, Materials (Basel). 3 (2010) 4746-4760. doi:10.3390/ma3104746.

[82] H. Marsh, F. Rodríguez-Reinoso, Activated Carbon, Elsevier Ltd., Oxford, 2006. http://www.sciencedirect.com/science/book/9780080444635.

[83] F. Rodríguez-Reinoso, Production and Applications of Activated Carbons, in: F. Schüth, K.S.W. Sing, J. Weitkamp (Eds.), Handbook of Porous Solids, Wiley, Weinheim, Germany, 2002: pp. 1766-1827. doi:10.1002/9783527618286.ch24a.

[84] M. Enterría, J.L. Figueiredo, Nanostructured mesoporous carbons: Tuning texture and surface chemistry, Carbon 108 (2016) 79-102. doi:10.1016/j.carbon.2016.06.108.

[85] H. Benaddi, D. Legras, J.-N. Rouzaud, F. Béguin, Influence of the atmosphere in the chemical activation of wood by phosphoric acid, Carbon 36 (1998) 306-309. doi:10.1016/S00086223(98)80123-1. 
[86] M.S. Solum, R.J. Pugmire, M. Jagtoyen, F. Derbyshire, Evolution of carbon structure in chemically activated wood, Carbon 33 (1995) 1247-1254. doi:10.1016/0008-6223(95)00067-N.

[87] M. Jagtoyen, F. Derbyshire, Activated carbons from yellow poplar and white oak by $\mathrm{H}_{3} \mathrm{PO}_{4}$ activation, Carbon 36 (1998) 1085-1097. doi:10.1016/S0008-6223(98)00082-7.

[88] M. Ruiz-Fernández, M. Alexandre-Franco, C. Fernández-González, V. Gómez-Serrano, Development of activated carbon from vine shoots by physical and chemical activation methods. Some insight into activation mechanisms, Adsorption 17 (2011) 621-629. doi:10.1007/s10450-011-9347-1.

[89] M. Molina-Sabio, F. Rodríguez-Reinoso, F. Caturla, M.J. Sellés, Porosity in granular carbons activated with phosphoric acid, Carbon 33 (1995) 1105-1113. doi:10.1016/0008-6223(95)00059-M.

[90] J.M. Stencel, J. Yang, J.K. Neathery, Desulfurization of bituminous coals: fluidized bed gasification of coal/phosphoric acid mixtures, Fuel Process. Technol. 41 (1995) 135-146. doi:10.1016/03783820(94)00081-4.

[91] M. Jagtoyen, M. Thwaites, J.M. Stencel, B. McEnaney, F. Derbyshire, Adsorbent carbon synthesis from coals by phosphoric acid activation, Carbon 30 (1992) 1089-1096. doi:10.1016/00086223(92)90140-R.

[92] M. Jagtoyen, J. Groppo, F. Derbyshire, Activated carbons from bituminous coals by reaction with $\mathrm{H}_{3} \mathrm{PO}_{4}$ : The influence of coal cleaning, Fuel Process. Technol. 34 (1993) 85-96. doi:10.1016/03783820(93)90093-J.

[93] H. Benaddi, T.J. Bandosz, J. Jagiello, J.A. Schwarz, J.-N. Rouzaud, D. Legras, F. Béguin, Surface functionality and porosity of activated carbons obtained from chemical activation of wood, Carbon 38 (2000) 669-674. doi:10.1016/S0008-6223(99)00134-7.

[94] T. Budinova, E. Ekinci, F. Yardim, A. Grimm, E. Björnbom, V. Minkova, M. Goranova, Characterization and application of activated carbon produced by $\mathrm{H}_{3} \mathrm{PO}_{4}$ and water vapor activation, Fuel Process. Technol. 87 (2006) 899-905. doi:10.1016/j.fuproc.2006.06.005.

[95] J. Bedia, J.M. Rosas, J. Márquez, J. Rodríguez-Mirasol, T. Cordero, Preparation and characterization of carbon based acid catalysts for the dehydration of 2-propanol, Carbon 47 (2009) 286-294. doi:10.1016/j.carbon.2008.10.008.

[96] S. Zuo, J. Yang, J. Liu, X. Cai, Significance of the carbonization of volatile pyrolytic products on the properties of activated carbons from phosphoric acid activation of lignocellulosic material, Fuel Process. Technol. 90 (2009) 994-1001. doi:10.1016/j.fuproc.2009.04.003.

[97] M. Danish, R. Hashim, M.N.M. Ibrahim, O. Sulaiman, Effect of acidic activating agents on surface area and surface functional groups of activated carbons produced from Acacia mangium wood, J. Anal. Appl. Pyrolysis 104 (2013) 418-425. doi:10.1016/j.jaap.2013.06.003.

[98] W.H. Lee, P.J. Reucroft, Vapor adsorption on coal- and wood-based chemically activated carbons - (I) - Surface oxidation states and adsorption of $\mathrm{H}_{2} \mathrm{O}$, Carbon 37 (1999) 7-14. doi:10.1016/S00086223(98)00181-X.

[99] Q.-S. Liu, T. Zheng, P. Wang, L. Guo, Preparation and characterization of activated carbon from bamboo by microwave-induced phosphoric acid activation, Ind. Crops Prod. 31 (2010) 233-238. doi:10.1016/j.indcrop.2009.10.011.

[100] J. Laine, A. Calafat, M. Labady, Preparation and characterization of activated carbons from coconut shell impregnated with phosphoric acid, Carbon 27 (1989) 191-195. doi:10.1016/00086223(89)90123-1.

[101] J. Bedia, R. Ruiz-Rosas, J. Rodríguez-Mirasol, T. Cordero, Kinetic study of the decomposition of 2butanol on carbon-based acid catalyst, AIChE J. 56 (2010) 1557-1568. doi:10.1002/aic.12056.

[102] J. Bedia, R. Barrionuevo, J. Rodríguez-Mirasol, T. Cordero, Ethanol dehydration to ethylene on acid carbon catalysts, Appl. Catal. B Environ. 103 (2011) 302-310. doi:10.1016/j.apcatb.2011.01.032. 
[103] M.O. Guerrero-Pérez, M.J. Valero-Romero, S. Hernández, J.M.L. Nieto, J. Rodríguez-Mirasol, T. Cordero, Lignocellulosic-derived mesoporous materials: An answer to manufacturing non-expensive catalysts useful for the biorefinery processes, Catal. Today 195 (2012) 155-161. doi:10.1016/j.cattod.2012.03.068.

[104] A.M. Puziy, O.I. Poddubnaya, A. Martínez-Alonso, F. Suárez-García, J.M.D. Tascón, Surface chemistry of phosphorus-containing carbons of lignocellulosic origin, Carbon 43 (2005) 2857-2868. doi:10.1016/j.carbon.2005.06.014.

[105] A.M. Puziy, O.I. Poddubnaya, A. Martínez-Alonso, A. Castro-Muñiz, F. Suárez-García, J.M.D. Tascón, Oxygen and phosphorus enriched carbons from lignocellulosic material, Carbon 45 (2007) 19411950. doi:10.1016/j.carbon.2007.06.014.

[106] A.-N.A. El-Hendawy, Variation in the FTIR spectra of a biomass under impregnation, carbonization and oxidation conditions, J. Anal. Appl. Pyrolysis 75 (2006) 159-166. doi:10.1016/j.jaap.2005.05.004.

[107] J.A.F. MacDonald, D.F. Quinn, Adsorbents for methane storage made by phosphoric acid activation of peach pits, Carbon 34 (1996) 1103-1108. doi:10.1016/0008-6223(96)00062-0.

[108] C.A. Toles, W.E. Marshall, M.M. Johns, Granular activated carbons from nutshells for the uptake of metals and organic compounds, Carbon 35 (1997) 1407-1414. doi:10.1016/S0008-6223(97)00073-0.

[109] S.A. Dastgheib, D.A. Rockstraw, Pecan shell activated carbon: synthesis, characterization, and application for the removal of copper from aqueous solution, Carbon 39 (2001) 1849-1855. doi:10.1016/S0008-6223(00)00315-8.

[110] Y. Guo, D.A. Rockstraw, Physicochemical properties of carbons prepared from pecan shell by phosphoric acid activation, Bioresour. Technol. 98 (2007) 1513-21. doi:10.1016/j.biortech.2006.06.027.

[111] H.N. Cheng, L.H. Wartelle, K.T. Klasson, J.C. Edwards, Solid-state NMR and ESR studies of activated carbons produced from pecan shells, Carbon 48 (2010) 2455-2469. doi:10.1016/j.carbon.2010.03.016.

[112] T. Xu, X. Liu, Peanut Shell Activated Carbon: Characterization, Surface Modification and Adsorption of $\mathrm{Pb}^{2+}$ from Aqueous Solution, Chinese J. Chem. Eng. 16 (2008) 401-406. doi:10.1016/S10049541(08)60096-8.

[113] D. Li, Y. Tian, Y. Qiao, Forming Active Carbon Monoliths from H3PO4-Loaded Sawdust with Addition of Peanut Shell Char, Bio Resour. 9 (2014) 4981-4992.

http://www.ncsu.edu/bioresources/BioRes_09/BioRes_09_3_4981_Li_TQ_Conversion_Powder_Biochar_Highly_Porous_ACM_5657.pdf.

[114] N.V. Sych, S.I. Trofymenko, O.I. Poddubnaya, M.M. Tsyba, V.I. Sapsay, D.O. Klymchuk, A.M. Puziy, Porous structure and surface chemistry of phosphoric acid activated carbon from corncob, Appl. Surf. Sci. 261 (2012) 75-82. doi:10.1016/j.apsusc.2012.07.084.

[115] R. Beltrán-Suito, A. Pinedo-Flores, F. Bravo-Hualpa, J. Ramos-Muñoz, G. Picasso-Escobar, M. del R. Sun-Kou, Synthesis of activated carbon from aguaje seeds (Mauritia flexuosa) for the adsorption of the $N, N$-dimethylamine, Adsorption 21 (2015) 577-587. doi:10.1007/s10450-015-9705-5.

[116] F. Suárez-García, A. Martínez-Alonso, J.M.D. Tascón, Porous texture of activated carbons prepared by phosphoric acid activation of apple pulp, Carbon 39 (2001) 1111-1115. doi:10.1016/S00086223(01)00053-7.

[117] F. Suárez-García, A. Martínez-Alonso, J.M.D. Tascón, A comparative study of the thermal decomposition of apple pulp in the absence and presence of phosphoric acid, Polym. Degrad. Stab. 75 (2002) 375-383. doi:10.1016/S0141-3910(01)00243-9.

[118] T. Vernersson, P.R. Bonelli, E.G. Cerrella, A.L. Cukierman, Arundo donax cane as a precursor for activated carbons preparation by phosphoric acid activation, Bioresour. Technol. 83 (2002) 95-104. doi:10.1016/S0960-8524(01)00205-X. 
[119] A.-N.A. El-Hendawy, A.J. Alexander, R.J. Andrews, G. Forrest, Effects of activation schemes on porous, surface and thermal properties of activated carbons prepared from cotton stalks, J. Anal. Appl. Pyrolysis 82 (2008) 272-278. doi:10.1016/j.jaap.2008.04.006.

[120] M.A. Nahil, P.T. Williams, Pore characteristics of activated carbons from the phosphoric acid chemical activation of cotton stalks, Biomass and Bioenergy 37 (2012) 142-149. doi:10.1016/j.biombioe.2011.12.019.

[121] J.M. Rosas, J. Bedia, J. Rodríguez-Mirasol, T. Cordero, Preparation of hemp-derived activated carbon monoliths. Adsorption of water vapor, Ind. Eng. Chem. Res. 47 (2008) 1288-1296. doi:10.1021/ie070924w.

[122] J.M. Rosas, J. Bedia, J. Rodríguez-Mirasol, T. Cordero, Hemp-derived activated carbon fibers by chemical activation with phosphoric acid, Fuel 88 (2009) 19-26. doi:10.1016/j.fuel.2008.08.004.

[123] R. Yang, G. Liu, X. Xu, M. Li, J. Zhang, X. Hao, Surface texture, chemistry and adsorption properties of acid blue 9 of hemp (Cannabis sativa L.) bast-based activated carbon fibers prepared by phosphoric acid activation, Biomass and Bioenergy 35 (2011) 437-445. doi:10.1016/j.biombioe.2010.08.061.

[124] L. John Kennedy, J.J. Vijaya, G. Sekaran, Effect of two-stage process on the preparation and characterization of porous carbon composite from rice husk by phosphoric acid activation, Ind. Eng. Chem. Res. 43 (2004) 1832-1838. doi:10.1021/ie034093f.

[125] L. John Kennedy, K. Mohan das, G. Sekaran, Integrated biological and catalytic oxidation of organics/inorganics in tannery wastewater by rice husk based mesoporous activated carbonBacillus sp., Carbon 42 (2004) 2399-2407. doi:10.1016/j.carbon.2004.04.002.

[126] Y. Guo, D.A. Rockstraw, Activated carbons prepared from rice hull by one-step phosphoric acid activation, Micropor. Mesopor. Mater. 100 (2007) 12-19. doi:10.1016/j.micromeso.2006.10.006.

[127] Y. Chen, S.-R. Zhai, N. Liu, Y. Song, Q.-D. An, X.-W. Song, Dye removal of activated carbons prepared from $\mathrm{NaOH}$-pretreated rice husks by low-temperature solution-processed carbonization and $\mathrm{H}_{3} \mathrm{PO}_{4}$ activation, Bioresour. Technol. 144 (2013) 401-409. doi:10.1016/j.biortech.2013.07.002.

[128] D. Prahas, Y. Kartika, N. Indraswati, S. Ismadji, Activated carbon from jackfruit peel waste by $\mathrm{H}_{3} \mathrm{PO}_{4}$ chemical activation: Pore structure and surface chemistry characterization, Chem. Eng. J. 140 (2008) 32-42. doi:10.1016/j.cej.2007.08.032.

[129] B. Corcho-Corral, M. Olivares-Marín, E. Valdes-Sánchez, C. Fernández-González, A. Macías-García, V. Gómez-Serrano, Development of activated carbon using vine shoots (Vitis vinifera) and its use for wine treatment, J. Agric. Food Chem. 53 (2005) 644-50. doi:10.1021/jf048824d.

[130] B. Corcho-Corral, M. Olivares-Marín, C. Fernández-González, V. Gómez-Serrano, A. Macías-García, Preparation and textural characterisation of activated carbon from vine shoots (Vitis vinifera) by $\mathrm{H}_{3} \mathrm{PO}_{4}$-Chemical activation, Appl. Surf. Sci. 252 (2006) 5961-5966. doi:10.1016/j.apsusc.2005.11.007.

[131] R. Fu, L. Liu, W. Huang, P. Sun, Studies on the structure of activated carbon fibers activated by phosphoric acid, J. Appl. Polym. Sci. 87 (2003) 2253-2261. doi:10.1002/app.11607.

[132] A. Reffas, V. Bernardet, B. David, L. Reinert, M.B. Lehocine, M. Dubois, N. Batisse, L. Duclaux, Carbons prepared from coffee grounds by $\mathrm{H} 3 \mathrm{PO} 4$ activation: characterization and adsorption of methylene blue and Nylosan Red N-2RBL, J. Hazard. Mater. 175 (2010) 779-788. doi:10.1016/j.jhazmat.2009.10.076.

[133] C. Huang, T. Sun, D. Hulicova-Jurcakova, Wide Electrochemical Window of Supercapacitors from Coffee Bean-Derived Phosphorus-Rich Carbons, ChemSusChem 6 (2013) 2330-2339. doi:10.1002/cssc.201300457.

[134] Z. Wang, E. Nie, J. Li, Y. Zhao, X. Luo, Z. Zheng, Carbons prepared from Spartina alterniflora and its anaerobically digested residue by $\mathrm{H}_{3} \mathrm{PO}_{4}$ activation: characterization and adsorption of cadmium from aqueous solutions., J. Hazard. Mater. 188 (2011) 29-36. doi:10.1016/j.jhazmat.2011.01.041. 
[135] C. Nieto-Delgado, J.R. Rangel-Mendez, Production of activated carbon from organic by-products from the alcoholic beverage industry: Surface area and hardness optimization by using the response surface methodology, Ind. Crops Prod. 34 (2011) 1528-1537. doi:10.1016/j.indcrop.2011.05.014.

[136] M. Benadjemia, L. Millière, L. Reinert, N. Benderdouche, L. Duclaux, Preparation, characterization and Methylene Blue adsorption of phosphoric acid activated carbons from globe artichoke leaves, Fuel Process. Technol. 92 (2011) 1203-1212. doi:10.1016/j.fuproc.2011.01.014.

[137] J. Xu, L. Chen, H. Qu, Y. Jiao, J. Xie, G. Xing, Preparation and characterization of activated carbon from reedy grass leaves by chemical activation with $\mathrm{H}_{3} \mathrm{PO}_{4}$, Appl. Surf. Sci. 320 (2014) 674-680. doi:10.1016/j.apsusc.2014.08.178.

[138] H. Liu, J. Zhang, N. Bao, C. Cheng, L. Ren, C. Zhang, Textural properties and surface chemistry of lotus stalk-derived activated carbons prepared using different phosphorus oxyacids: Adsorption of trimethoprim, J. Hazard. Mater. 235-236 (2012) 367-375. doi:10.1016/j.jhazmat.2012.08.015.

[139] Y. Huang, S. Li, J. Chen, X. Zhang, Y. Chen, Adsorption of Pb(II) on mesoporous activated carbons fabricated from water hyacinth using $\mathrm{H} 3 \mathrm{PO} 4$ activation: Adsorption capacity, kinetic and isotherm studies, Appl. Surf. Sci. 293 (2014) 160-168. doi:10.1016/j.apsusc.2013.12.123.

[140] J. Kazmierczak-Razna, P. Nowicki, M. Wiśniewska, A. Nosal-Wiercińska, R. Pietrzak, Thermal and physicochemical properties of phosphorus-containing activated carbons obtained from biomass, $\mathrm{J}$. Taiwan Inst. Chem. Eng. 80 (2017) 1006-1013. doi:10.1016/j.jtice.2017.09.015.

[141] Y. Guo, D.A. Rockstraw, Physical and chemical properties of carbons synthesized from xylan, cellulose, and Kraft lignin by $\mathrm{H}_{3} \mathrm{PO}_{4}$ activation, Carbon 44 (2006) 1464-1475. doi:10.1016/j.carbon.2005.12.002.

[142] Z. Long, L. Sun, W. Zhu, G. Chen, X. Wang, W. Sun, P-Doped carbons derived from cellulose as highly efficient metal-free catalysts for aerobic oxidation of benzyl alcohol in water under an air atmosphere, Chem. Commun. 54 (2018) 8991-8994. doi:10.1039/C8CC03711F.

[143] V. Fierro, V. Torné-Fernández, A. Celzard, Kraft lignin as a precursor for microporous activated carbons prepared by impregnation with ortho-phosphoric acid: Synthesis and textural characterisation, Micropor. Mesopor. Mater. 92 (2006) 243-250. doi:10.1016/j.micromeso.2006.01.013.

[144] J.M. Rosas, R. Ruiz-Rosas, J. Rodríguez-Mirasol, T. Cordero, Kinetic study of the oxidation resistance of phosphorus-containing activated carbons, Carbon 50 (2012) 1523-1537. doi:10.1016/j.carbon.2011.11.030.

[145] M. Myglovets, O.I. Poddubnaya, O. Sevastyanova, M.E. Lindström, B. Gawdzik, M. Sobiesiak, M.M. Tsyba, V.I. Sapsay, D.O. Klymchuk, A.M. Puziy, Preparation of carbon adsorbents from lignosulfonate by phosphoric acid activation for the adsorption of metal ions, Carbon 80 (2014) 771-783. doi:10.1016/j.carbon.2014.09.032.

[146] F.J. García-Mateos, R. Berenguer, M.J. Valero-Romero, J. Rodríguez-Mirasol, T. Cordero, Phosphorus functionalization for the rapid preparation of highly nanoporous submicron-diameter carbon fibers by electrospinning of lignin solutions, J. Mater. Chem. A 6 (2018) 1219-1233. doi:10.1039/C7TA08788H.

[147] A. Kriaa, N. Hamdi, E. Srasra, Removal of Cu (II) from water pollutant with Tunisian activated lignin prepared by phosphoric acid activation, Desalination 250 (2010) 179-187. doi:10.1016/j.desal.2008.12.056.

[148] H.H. Schönfelder, K. Kitoh, H. Nemoto, Nanostructure criteria for lithium intercalation in non-doped and phosphorus-doped hard carbons, J. Power Sources 68 (1997) 258-262. doi:10.1016/S03787753(96)02559-1.

[149] Y. Wu, S. Fang, Y. Jiang, Carbon anodes for a lithium secondary battery based on polyacrylonitrile, J. Power Sources 75 (1998) 201-206. doi:10.1016/S0378-7753(98)00097-4. 
[150] X. Yan, Y. Liu, X. Fan, X. Jia, Y. Yu, X. Yang, Nitrogen/phosphorus co-doped nonporous carbon nanofibers for high-performance supercapacitors, J. Power Sources 248 (2014) 745-751. doi:10.1016/j.jpowsour.2013.09.129.

[151] A.M. Puziy, O.I. Poddubnaya, A. Martínez-Alonso, F. Suárez-García, J.M.D. Tascón, Synthetic carbons activated with phosphoric acid. I. Surface chemistry and ion binding properties, Carbon 40 (2002) 1493-1505. doi:10.1016/S0008-6223(01)00317-7.

[152] A.M. Puziy, O.I. Poddubnaya, A. Martínez-Alonso, F. Suárez-García, J.M.D. Tascón, Synthetic carbons activated with phosphoric acid III. Carbons prepared in air, Carbon 41 (2003) 1181-1191. doi:10.1016/S0008-6223(03)00031-9.

[153] A.M. Puziy, O.I. Poddubnaya, M. Sobiesiak, B. Gawdzik, Structural and surface heterogeneity of phosphorus-containing polyimide-derived carbons: effect of heat treatment temperature, Adsorption 19 (2013) 717-722. doi:10.1007/s10450-013-9497-4.

[154] F. Suárez-García, A. Martínez-Alonso, J.M.D. Tascón, Beneficial effects of phosphoric acid as an additive in the preparation of activated carbon fibers from Nomex aramid fibers by physical activation, Fuel Process. Technol. 77-78 (2002) 237-244. doi:10.1016/S0378-3820(02)00052-8.

[155] F. Suárez-García, A. Martínez-Alonso, J.M.D. Tascón, Activated carbon fibers from Nomex by chemical activation with phosphoric acid, Carbon 42 (2004) 1419-1426. doi:10.1016/j.carbon.2003.11.011.

[156] F. Suárez-García, S. Villar-Rodil, C.G. Blanco, A. Martínez-Alonso, J.M.D. Tascón, Effect of phosphoric acid on chemical transformations during Nomex pyrolysis, Chem. Mater. 16 (2004) 2639-2647. doi:10.1021/cm0349654.

[157] J.P. Boudou, P. Parent, F. Suárez-García, S. Villar-Rodil, A. Martínez-Alonso, J.M.D. Tascón, Nitrogen in aramid-based activated carbon fibers by TPD, XPS and XANES, Carbon 44 (2006) 2452-2462. doi:10.1016/j.carbon.2006.04.036.

[158] F. Suárez-García, A. Martínez-Alonso, J.M.D. Tascón, Nomex polyaramid as a precursor for activated carbon fibres by phosphoric acid activation. Temperature and time effects, Micropor. Mesopor. Mater. 75 (2004) 73-80. doi:10.1016/j.micromeso.2004.07.004.

[159] A. Castro-Muñiz, F. Suárez-García, A. Martínez-Alonso, J.M.D. Tascón, Activated carbon fibers with a high content of surface functional groups by phosphoric acid activation of PPTA, J. Colloid Interface Sci. 361 (2011) 307-315. doi:10.1016/j.jcis.2011.05.064.

[160] M.B. Vázquez-Santos, A. Martínez-Alonso, J.M.D. Tascón, Effects of phosphoric acid as additive in the preparation of activated carbon fibers from poly( $p$-phenylene benzobisoxazole) by carbon dioxide activation, J. Anal. Appl. Pyrolysis 95 (2012) 68-74. doi:10.1016/j.jaap.2012.01.007.

[161] M.B. Vázquez-Santos, F. Suárez-García, A. Martínez-Alonso, J.M.D. Tascón, Activated carbon fibers with a high heteroatom content by chemical activation of PBO with phosphoric acid, Langmuir 28 (2012) 5850-5860. doi:10.1021/la300189v.

[162] Z. Yue, J. Economy, C.L. Mangun, Preparation of fibrous porous materials by chemical activation 2. $\mathrm{H}_{3} \mathrm{PO}_{4}$ activation of polymer coated fibers, Carbon 41 (2003) 1809-1817. doi:10.1016/S00086223(03)00151-9.

[163] Z. Yue, C.L. Mangun, J. Economy, Characterization of surface chemistry and pore structure of $\mathrm{H}_{3} \mathrm{PO}_{4}$ activated poly(vinyl alcohol) coated fiberglass, Carbon 42 (2004) 1973-1982. doi:10.1016/j.carbon.2004.03.030.

[164] P.F. Fulvio, R.T. Mayes, J.C. Bauer, X. Wang, S.M. Mahurin, G.M. Veith, S. Dai, "One-pot" synthesis of phosphorylated mesoporous carbon heterogeneous catalysts with tailored surface acidity, Catal. Today 186 (2012) 12-19. doi:10.1016/j.cattod.2011.08.004.

[165] A. Villa, M. Schiavoni, P.F. Fulvio, S.M. Mahurin, S. Dai, R.T. Mayes, G.M. Veith, L. Prati, Phosphorylated mesoporous carbon as effective catalyst for the selective fructose dehydration to 
HMF, J. Energy Chem. 22 (2013) 305-311. doi:10.1016/S2095-4956(13)60037-6.

[166] X. Zhao, Q. Zhang, B. Zhang, C.-M. Chen, A. Wang, T. Zhang, D.S. Su, Dual-heteroatom-modified ordered mesoporous carbon: Hydrothermal functionalization, structure, and its electrochemical performance, J. Mater. Chem. 22 (2012) 4963-4969. doi:10.1039/c2jm15820e.

[167] H. Xue, T. Wang, J. Zhao, H. Gong, J. Tang, H. Guo, X. Fan, J. He, Constructing a multicomponent ordered mesoporous carbon for improved electrochemical performance induced by in-situ doping phosphorus, Carbon 104 (2016) 10-19. doi:10.1016/j.carbon.2016.03.026.

[168] N.A. Fathy, M.A. Shouman, R.M.M. Aboelenin, Nitrogen and phosphorous-doped porous carbon xerogels as metal-free catalysts for environmental catalytic peroxide oxidation of 4-nitrophenol, Asia-Pacific J. Chem. Eng. 11 (2016) 836-845. doi:10.1002/apj.2017.

[169] V.G. Bairi, S.E. Bourdo, U.B. Nasini, S.K. Ramasahayam, F. Watanabe, B.C. Berry, T. Viswanathan, Microwave-assisted synthesis of nitrogen and phosphorus co-doped mesoporous carbon and their potential application in alkaline fuel cells, Sci. Adv. Mater. 5 (2013) 1275-1281. doi:10.1166/sam.2013.1583.

[170] V.M. Gun'ko, O. Seledets, J. Skubiszewska-Zięba, V.I. Zarko, R. Leboda, W. Janusz, S. Chibowski, Phosphorus-containing carbon deposits on silica gel Si-100, Micropor. Mesopor. Mater. 87 (2005) 133-145. doi:10.1016/j.micromeso.2005.06.044.

[171] H. Ye, Y.-X. Yin, Y.-G. Guo, Insight into the loading temperature of sulfur on sulfur/carbon cathode in lithium-sulfur batteries, Electrochim. Acta 185 (2015) 62-68. doi:10.1016/j.electacta.2015.10.102.

[172] M. Wiśniewski, A. Pacholczyk, A.P. Terzyk, G. Rychlicki, New phosphorus-containing spherical carbon adsorbents as promising materials in drug adsorption and release, J. Colloid Interface Sci. 354 (2011) 891-894. doi:10.1016/j.jcis.2010.11.072.

[173] N.D. Lysenko, P.S. Yaremov, M. V. Ovcharova, V.G. Ilyin, Highly acidic phosphorus-containing porous carbons: synthesis and physicochemical properties, J. Mater. Sci. 47 (2012) 3089-3095. doi:10.1007/s10853-011-6142-z.

[174] A.M. Puziy, O.I. Poddubnaya, C.A. Reinish, M.M. Tsyba, L.I. Mikhalovska, S. V. Mikhalovsky, One-pot preparation of functionalized nanostructured carbons, Carbon 49 (2011) 599-604. doi:10.1016/j.carbon.2010.10.002.

[175] C. Wang, L. Sun, Y. Zhou, P. Wan, X. Zhang, J. Qiu, P/N co-doped microporous carbons from $\mathrm{H}_{3} \mathrm{PO}_{4^{-}}$ doped polyaniline by in situ activation for supercapacitors, Carbon 59 (2013) 537-546. doi:10.1016/j.carbon.2013.03.052.

[176] C.H. Choi, S.H. Park, S.I. Woo, Phosphorus-nitrogen dual doped carbon as an effective catalyst for oxygen reduction reaction in acidic media: effects of the amount of P-doping on the physical and electrochemical properties of carbon, J. Mater. Chem. 22 (2012) 12107. doi:10.1039/c2jm31079a.

[177] C.H. Choi, S.H. Park, S.I. Woo, Binary and ternary doping of nitrogen, boron, and phosphorus into carbon for enhancing electrochemical oxygen reduction activity, ACS Nano 6 (2012) 7084-7091. doi:10.1021/nn3021234.

[178] K.S. Prasad, R. Pallela, D.-M. Kim, Y.-B. Shim, Microwave-Assisted One-Pot Synthesis of Metal-Free Nitrogen and Phosphorus Dual-Doped Nanocarbon for Electrocatalysis and Cell Imaging, Part. Part. Syst. Charact. 30 (2013) 557-564. doi:10.1002/ppsc.201300020.

[179] C. Cheng, J. Zhang, Y. Mu, J. Gao, Y. Feng, H. Liu, Z. Guo, C. Zhang, Preparation and evaluation of activated carbon with different polycondensed phosphorus oxyacids (H3PO4, H4P2O7, H6P4O13 and $\mathrm{C} 6 \mathrm{H} 18 \mathrm{O} 24 \mathrm{P} 6)$ activation employing mushroom roots as precursor, J. Anal. Appl. Pyrolysis 108 (2014) 41-46. doi:10.1016/j.jaap.2014.05.019.

[180] Y. Gao, Q. Yue, B. Gao, Y. Sun, W. Wang, Q. Li, Y. Wang, Comparisons of porous, surface chemistry and adsorption properties of carbon derived from Enteromorpha prolifera activated by $\mathrm{H}_{4} \mathrm{P}_{2} \mathrm{O}_{7}$ and KOH, Chem. Eng. J. 232 (2013) 582-590. doi:10.1016/j.cej.2013.08.011. 
[181] J. Kong, Q. Yue, L. Huang, Y. Gao, Y. Sun, B. Gao, Q. Li, Y. Wang, Preparation, characterization and evaluation of adsorptive properties of leather waste based activated carbon via physical and chemical activation, Chem. Eng. J. 221 (2013) 62-71. doi:10.1016/j.cej.2013.02.021.

[182] M. Latorre-Sánchez, A. Primo, H. García, P-doped graphene obtained by pyrolysis of modified alginate as a photocatalyst for hydrogen generation from water-methanol mixtures, Angew. Chem. Int. Ed. 52 (2013) 11813-11816. doi:10.1002/anie.201304505.

[183] L.-F. Chen, Z.-H. Huang, H.-W. Liang, H.-L. Gao, S.-H. Yu, Three-dimensional heteroatom-doped carbon nanofiber networks derived from bacterial cellulose for supercapacitors, Adv. Funct. Mater. 24 (2014) 5104-5111. doi:10.1002/adfm.201400590.

[184] M. Nahata, C.Y. Seo, P. Krishnakumar, J. Schwank, New approaches to water purification for resource-constrained settings: Production of activated biochar by chemical activation with diammonium hydrogenphosphate, Front. Chem. Sci. Eng. 12 (2018) 194-208. doi:10.1007/s11705017-1647-x.

[185] C. Wang, Y. Zhou, L. Sun, P. Wan, X. Zhang, J. Qiu, Sustainable synthesis of phosphorus- and nitrogen-co-doped porous carbons with tunable surface properties for supercapacitors, J. Power Sources 239 (2013) 81-88. doi:10.1016/j.jpowsour.2013.03.126.

[186] Q. Liu, Y. Zhou, S. Chen, Z. Wang, H. Hou, F. Zhao, Cellulose-derived nitrogen and phosphorus dualdoped carbon as high performance oxygen reduction catalyst in microbial fuel cell, J. Power Sources 273 (2015) 1189-1193. doi:10.1016/j.jpowsour.2014.09.102.

[187] T. Đurkić, A. Perić, M. Laušević, A. Dekanski, O. Nešković, M. Veljković, Z. Laušević, Boron and phosphorus doped glassy carbon: I. Surface properties, Carbon 35 (1997) 1567-1572. doi:10.1016/S0008-6223(97)00113-9.

[188] S. Wang, H. Matsui, Y. Matsumura, ${ }^{7}$ Li-NMR study of lithium charged phosphorus-doped disordered carbon, Synth. Met. 103 (1999) 2521-2522. doi:10.1016/S0379-6779(98)01088-1.

[189] Z. Jin, Z. Sun, L.J. Simpson, K.J. O’Neill, P.A. Parilla, Y. Li, N.P. Stadie, C.C. Ahn, C. Kittrell, J.M. Tour, Solution-phase synthesis of heteroatom-substituted carbon scaffolds for hydrogen storage, J. Am. Chem. Soc. 132 (2010) 15246-15251. doi:10.1021/ja105428d.

[190] H. Liu, P. Dai, J. Zhang, C. Zhang, N. Bao, C. Cheng, L. Ren, Preparation and evaluation of activated carbons from lotus stalk with trimethyl phosphate and tributyl phosphate activation for lead removal, Chem. Eng. J. 228 (2013) 425-434. doi:10.1016/j.cej.2013.04.117.

[191] T. Tsubota, Y. Miyauchi, N. Murakami, T. Ohno, Improvement of capacitance value as the electrode of an electrochemical capacitor by mixing starch with guanidine phosphate, J. Power Sources 196 (2011) 5769-5773. doi:10.1016/j.jpowsour.2011.02.043.

[192] T. Tsubota, M. Morita, S. Kamimura, T. Ohno, New approach for synthesis of activated carbon from bamboo, J. Porous Mater. 23 (2016) 349-355. doi:10.1007/s10934-015-0087-6.

[193] D.-S. Yang, D. Bhattacharjya, S. Inamdar, J. Park, J.-S. Yu, Phosphorus-doped ordered mesoporous carbons with different lengths as efficient metal-free electrocatalysts for oxygen reduction reaction in alkaline media, J. Am. Chem. Soc. 134 (2012) 16127-16130. doi:10.1021/ja306376s.

[194] X. Qing, Y. Cao, J. Wang, J. Chen, Y. Lu, P/N/O co-doped carbonaceous material based supercapacitor with voltage up to $1.9 \mathrm{~V}$ in aqueous electrolyte, RSC Adv. 4 (2014) 55971-55979. doi:10.1039/C4RA06336H.

[195] J. Zhang, Z. Zhao, Z. Xia, L. Dai, A metal-free bifunctional electrocatalyst for oxygen reduction and oxygen evolution reactions, Nat. Nanotechnol. 10 (2015) 444-452. doi:10.1038/nnano.2015.48.

[196] T. Panja, D. Bhattacharjya, J.-S. Yu, Nitrogen and phosphorus co-doped cubic ordered mesoporous carbon as a supercapacitor electrode material with extraordinary cyclic stability, J. Mater. Chem. A 3 (2015) 18001-18009. doi:10.1039/C5TA04169D. 
[197] M.A. Patel, F. Luo, M.R. Khoshi, E. Rabie, Q. Zhang, C.R. Flach, R. Mendelsohn, E. Garfunkel, M. Szostak, H. He, P-doped porous carbon as metal free catalysts for selective aerobic oxidation with an unexpected mechanism, ACS Nano 10 (2016) 2305-2315. doi:10.1021/acsnano.5b07054.

[198] S.K. Park, S.H. Kwon, S.G. Lee, M.S. Choi, D.H. Suh, P. Nakhanivej, H. Lee, H.S. Park, $10^{5}$ cyclable pseudocapacitive $\mathrm{Na}$-ion storage of hierarchically structured phosphorus-incorporating nanoporous carbons in organic electrolytes, ACS Energy Lett. 3 (2018) 724-732.

doi:10.1021/acsenergylett.8b00068.

[199] G. Liu, Z. Liu, J. Li, M. Zeng, Z. Li, L. He, F. Li, Chitosan/phytic acid hydrogel as a platform for facile synthesis of heteroatom-doped porous carbon frameworks for electrocatalytic oxygen reduction, Carbon 137 (2018) 68-77. doi:10.1016/j.carbon.2018.05.027.

[200] T. Najam, S.S.A. Shah, W. Ding, J. Jiang, L. Jia, W. Yao, L. Li, Z. Wei, An efficient anti-poisoning catalyst against $\mathrm{SO}_{\mathrm{x}}, \mathrm{NO}_{\mathrm{x}}$, and $\mathrm{PO}_{\mathrm{x}}: \mathrm{P}, \mathrm{N}$-doped carbon for oxygen reduction in acidic media, Angew. Chem. Int. Ed. 57 (2018) 15101-15106. doi:10.1002/anie.201808383.

[201] Y. Zhang, T. Mori, J. Ye, M. Antonietti, Phosphorus-doped carbon nitride solid: enhanced electrical conductivity and photocurrent generation, J. Am. Chem. Soc. 132 (2010) 6294-6295. doi:10.1021/ja101749y.

[202] L. Zhang, X. Chen, J. Guan, Y. Jiang, T. Hou, X. Mu, Facile synthesis of phosphorus doped graphitic carbon nitride polymers with enhanced visible-light photocatalytic activity, Mater. Res. Bull. 48 (2013) 3485-3491. doi:10.1016/j.materresbull.2013.05.040.

[203] J.P. Paraknowitsch, Y. Zhang, B. Wienert, A. Thomas, Nitrogen- and phosphorus-co-doped carbons with tunable enhanced surface areas promoted by the doping additives, Chem. Commun. 49 (2013) 1208. doi:10.1039/c2cc37398j.

[204] D. Carriazo, M.C. Gutiérrez, F. Picó, J.M. Rojo, J.L.G. Fierro, M.L. Ferrer, F. del Monte, Phosphatefunctionalized carbon monoliths from deep eutectic solvents and their use as monolithic electrodes in supercapacitors, ChemSusChem 5 (2012) 1405-1409. doi:10.1002/cssc.201200136.

[205] R. Imamura, K. Matsui, J. Ozaki, A. Oya, Steam activation of a phosphorus-containing phenolic resinbased carbon fiber, Carbon 36 (1998) 1243-1245.

[206] R. Imamura, K. Matsui, S. Takeda, J. Ozaki, A. Oya, A new role for phosphorus in graphitization of phenolic resin, Carbon 37 (1999) 261-267. doi:10.1016/S0008-6223(98)00172-9.

[207] I.N. Ermolenko, L.H. Kliuchnikova, Preparation of carbon fibrous materials by pyrolysis of cellulose phospahte, Vestsi Akad. Navuk Belarus. SSR, Seryia Khimichnyh Navuk (1968) 84-87.

[208] I.N. Ermolenko, I.I. Vygovskiy, I.P. Lubliner, Investigation of structure and properties of carbon fibers containing phosphorus and metal, Vestsi Akad. Navuk Belarus. SSR, Seryia Khimichnyh Navuk (1974) 78-81.

[209] H.-Q. Xiang, S.-B. Fang, Y.-Y. Jiang, Lithium insertion in carbons prepared from phosphoruscontaining polymers, J. Power Sources 94 (2001) 85-91. doi:10.1016/S0378-7753(00)00628-5.

[210] I.S. Skorynina, S.S. Gusev, N.K. Vorobyova, I.N. Ermolenko, Study of pyrolysis of cellulose modified with condensed phosphates, Vestsi Akad. Navuk Belarus. SSR (1970) 29-34.

[211] S. Ronka, Properties of novel spherical carbon adsorbents synthesized from phosphorylated polymeric precursors, J. Anal. Appl. Pyrolysis 110 (2014) 390-400. doi:10.1016/j.jaap.2014.10.012.

[212] S. Ronka, A.W. Trochimczuk, Carbon sorbents produced from phosphorylated gel-type styrene/divinylbenzene copolymers, Carbon 46 (2008) 1098-1100. doi:10.1016/j.carbon.2008.02.026.

[213] V. Strelko, Jr., M. Streat, O.P. Kozynchenko, Preparation, characterisation and sorptive properties of polymer based phosphorus-containing carbon, React. Funct. Polym. 41 (1999) 245-253. doi:10.1016/S1381-5148(99)00061-9. 
[214] D.J. Malik, V. Strelko, Jr., M. Streat, A.M. Puziy, Characterisation of novel modified active carbons and marine algal biomass for the selective adsorption of lead, Water Res. 36 (2002) 1527-1538. doi:10.1016/S0043-1354(01)00348-7.

[215] A.M. Puziy, O.I. Poddubnaya, The properties of synthetic carbon derived from nitrogen- and phosphorus-containing polymer, Carbon 36 (1998) 45-50. doi:10.1016/S0008-6223(97)00149-8.

[216] A.M. Puziy, O.I. Poddubnaya, Microbalance techniques in design and control of synthetic carbons, J. Therm. Anal. Calorim. 62 (2000) 491-497. doi:10.1023/A:1010123121735.

[217] A.N. Amelin, Y.V. Kariakin, Investigation metal ion exchange constants on carbons activated with phosphoric acid, Zh. Fiz. Khim. 45 (1971) 2357-2359.

[218] S. Labruquère, R. Pailler, R. Naslain, B. Desbat, Oxidation inhibition of carbon fibre preforms and C/C composites by $\mathrm{H}_{3} \mathrm{PO}_{4}$, J. Eur. Ceram. Soc. 18 (1998) 1953-1960. doi:10.1016/S0955-2219(98)001356.

[219] P. Wang, H. He, X. Xu, Y. Jin, Significantly enhancing supercapacitive performance of nitrogen-doped graphene nanosheet electrodes by phosphoric acid activation, ACS Appl. Mater. Interfaces 6 (2014) 1563-1568. doi:10.1021/am404277j.

[220] A. Ariharan, B. Viswanathan, V. Nandhakumar, Heteroatom doped multi-layered graphene material for hydrogen storage application, Graphene 5 (2016) 39-50. doi:10.4236/graphene.2016.52005.

[221] A.M. Puzii, S.S. Stavitskaya, O.I. Poddubnaya, V.M. Vikarchuk, N.N. Tsyba, Structural and adsorption properties of active carbon from coconut shells modified with phosphorus heteroatoms, Theor. Exp. Chem. 48 (2012) 272-277. doi:10.1007/s11237-012-9272-8.

[222] M. Seredych, C.T. Wu, P. Brender, C.O. Ania, C. Vix-Guterl, T.J. Bandosz, Role of phosphorus in carbon matrix in desulfurization of diesel fuel using adsorption process, Fuel 92 (2012) 318-326. doi:10.1016/j.fuel.2011.08.007.

[223] M.-J. Kim, J.-T. Yeon, K. Hong, S.-I. Lee, N.-S. Choi, S.-S. Kim, Effects of phosphorous-doping on electrochemical performance and surface chemistry of soft carbon electrodes, Bull. Korean Chem. Soc. 34 (2013) 2029-2035. doi:10.5012/bkcs.2013.34.7.2029.

[224] M.-S. Park, J. Lee, J.-W. Lee, K.J. Kim, Y.-N. Jo, S.-G. Woo, Y.-J. Kim, Tuning the surface chemistry of natural graphite anode by $\mathrm{H}_{3} \mathrm{PO}_{4}$ and $\mathrm{H}_{3} \mathrm{BO}_{3}$ treatments for improving electrochemical and thermal properties, Carbon 62 (2013) 278-287. doi:10.1016/j.carbon.2013.05.065.

[225] J. Wu, Z. Yang, X. Li, Q. Sun, C. Jin, P. Strasser, R. Yang, Phosphorus-doped porous carbons as efficient electrocatalysts for oxygen reduction, J. Mater. Chem. A 1 (2013) 9889-9896. doi:10.1039/C3TA11849E.

[226] P. Karthika, N. Rajalakshmi, K.S. Dhathathreyan, Phosphorus-doped exfoliated graphene for supercapacitor electrodes, J. Nanosci. Nanotechnol. 13 (2013) 1746-1751. doi:10.1166/jnn.2013.7112.

[227] C.H. Choi, M.W. Chung, H.C. Kwon, S.H. Park, S.I. Woo, B, N- and P, N-doped graphene as highly active catalysts for oxygen reduction reactions in acidic media, J. Mater. Chem. A 1 (2013) 3694. doi:10.1039/c3ta01648j.

[228] C.H. Choi, M.W. Chung, S.H. Park, S.I. Woo, Additional doping of phosphorus and/or sulfur into nitrogen-doped carbon for efficient oxygen reduction reaction in acidic media, Phys. Chem. Chem. Phys. 15 (2013) 1802-1805. doi:10.1039/C2CP44147K.

[229] R.T. Mayes, P.F. Fulvio, Z. Ma, S. Dai, Phosphorylated mesoporous carbon as a solid acid catalyst, Phys. Chem. Chem. Phys. 13 (2011) 2492-2494. doi:10.1039/C0CP01861A.

[230] X. Zhao, H. Li, M. Chen, K. Li, B. Wang, Z. Xu, S. Cao, L. Zhang, H. Deng, J. Lu, Strong-bonding calcium phosphate coatings on carbon/carbon composites by ultrasound-assisted anodic oxidation treatment and electrochemical deposition, Appl. Surf. Sci. 258 (2012) 5117-5125. 
doi:10.1016/j.apsusc.2012.01.144.

[231] D.W. McKee, C.L. Spiro, E.J. Lamby, The inhibition of graphite oxidation by phosphorus additives, Carbon 22 (1984) 285-290. doi:10.1016/0008-6223(84)90172-6.

[232] S.G. Oh, N.M. Rodriguez, In situ electron microscopy studies of the inhibition of graphite oxidation by phosphorus, J. Mater. Res. 8 (1993) 2879-2888. doi:10.1557/JMR.1993.2879.

[233] X. Wu, L.R. Radovic, Inhibition of catalytic oxidation of carbon/carbon composites by phosphorus, Carbon 44 (2006) 141-151. doi:10.1016/j.carbon.2005.06.038.

[234] I.A. Kuzin, L.A. Koemets, Preparation of phosphorylated active carbon, Zh. Prikl. Khim. 43 (1970) 695-698.

[235] I.A. Kuzin, A.I. Loskutov, V.F. Palfitov, L.A. Koemets, Investigation of the effect of active carbon surface chemistry on adsorption of water, carbon dioxide and ammonia, Zh. Prikl. Khim. 45 (1972) 760-765.

[236] I.P. Lubliner, I.N. Ermolenko, A.E. Kofman, D.K. Kuk, Investigation of phosphorylation of carbon fibers, Vestsi Akad. Navuk Belarus. SSR (1973) 80-85.

[237] J. Siedlewski, W. Śmigel, A. Arcimowicz, Badanie własności węgli aktywowanych modyfikowanych trójchlorkiem fosforu, Koks, Smola, Gaz (1975) 300-302.

[238] D.W. McKee, Effect of adsorbed phosphorus oxychloride on the oxidation behavior of graphite, Carbon 10 (1972) 491-497. doi:10.1016/0008-6223(72)90069-3.

[239] C. Zhang, N. Mahmood, H. Yin, F. Liu, Y. Hou, Synthesis of phosphorus-doped graphene and its multifunctional applications for oxygen reduction reaction and lithium ion batteries., Adv. Mater. 25 (2013) 4932-4937. doi:10.1002/adma.201301870.

[240] F. Razmjooei, K.P. Singh, M.Y. Song, J.-S. Yu, Enhanced electrocatalytic activity due to additional phosphorous doping in nitrogen and sulfur-doped graphene: A comprehensive study, Carbon 78 (2014) 257-267. doi:10.1016/j.carbon.2014.07.002.

[241] D. Saha, S.D. Akkoyunlu, R. Thorpe, D.K. Hensley, J. Chen, Adsorptive recovery of neodymium and dysprosium in phosphorous functionalized nanoporous carbon, J. Environ. Chem. Eng. 5 (2017) 4684-4692. doi:10.1016/j.jece.2017.09.009.

[242] F. Razmjooei, K.P. Singh, E.J. Bae, J.-S. Yu, A new class of electroactive Fe- and P-functionalized graphene for oxygen reduction, J. Mater. Chem. A 3 (2015) 11031-11039. doi:10.1039/C5TA00970G.

[243] M.-S. Park, J.-H. Kim, Y.-N. Jo, S.-H. Oh, H. Kim, Y.-J. Kim, Incorporation of phosphorus into the surface of natural graphite anode for lithium ion batteries, J. Mater. Chem. 21 (2011) 17960. doi:10.1039/c1jm13158c.

[244] R. Li, Z. Wei, X. Gou, W. Xu, Phosphorus-doped graphene nanosheets as efficient metal-free oxygen reduction electrocatalysts, RSC Adv. 3 (2013) 9978-9984. doi:10.1039/c3ra41079j.

[245] N. Feldtner, W. Brockner, P. Scharff, M.M. Dadras, Novel carbon materials obtained by reactions of $\mathrm{C}_{60}$ fullerene with phosphorus at high temperature, J. Non-Cryst. Solids 333 (2004) 301-306. doi:10.1016/j.jnoncrysol.2003.12.056.

[246] G. Hasegawa, T. Deguchi, K. Kanamori, Y. Kobayashi, H. Kageyama, T. Abe, K. Nakanishi, High-level doping of nitrogen, phosphorus, and sulfur into activated carbon monoliths and their electrochemical capacitances, Chem. Mater. 27 (2015) 4703-4712. doi:10.1021/acs.chemmater.5b01349.

[247] H.L. Poh, Z. Sofer, M. Nováček, M. Pumera, Concurrent phosphorus doping and reduction of graphene oxide., Chem. Eur. J. 20 (2014) 4284-91. doi:10.1002/chem.201304217.

[248] S. Marinkovic, C. Suznjevic, A. Tukovic, I. Dezarov, D. Cerovic, Preparation and properties of phosphorus-containing pyrocarbon $-\mathrm{I}$. Chemical-vapour-codeposition of carbon and phosphorus, 
Carbon 11 (1973) 217-220. doi:10.1016/0008-6223(73)90023-7.

[249] S. Marinkovic, C. Suznejevic, A. Tukovic, I. Dezarov, D. Cerovic, Preparation and properties of phosphorus-containing pyrocarbon - part II. Effect of heat-treatment on phosphorus-containing pyrocarbon, Carbon 12 (1974) 57-62. doi:10.1016/0008-6223(74)90041-4.

[250] Z. Liu, F. Peng, H. Wang, H. Yu, J. Tan, L. Zhu, Novel phosphorus-doped multiwalled nanotubes with high electrocatalytic activity for $\mathrm{O}_{2}$ reduction in alkaline medium, Catal. Commun. 16 (2011) 35-38. doi:10.1016/j.catcom.2011.08.038.

[251] Z.-W. Liu, F. Peng, H.-J. Wang, H. Yu, W.-X. Zheng, J. Yang, Phosphorus-doped graphite layers with high electrocatalytic activity for the $\mathrm{O}_{2}$ reduction in an alkaline medium, Angew. Chem. Int. Ed. 50 (2011) 3257-3261. doi:10.1002/anie.201006768.

[252] Z. Liu, F. Peng, H. Wang, H. Yu, W. Zheng, X. Wei, Preparation of phosphorus-doped carbon nanospheres and their electrocatalytic performance for $\mathrm{O}_{2}$ reduction, J. Nat. Gas Chem. 21 (2012) 257-264. doi:10.1016/S1003-9953(11)60362-9.

[253] Z. Liu, Q. Shi, F. Peng, H. Wang, H. Yu, J. Li, X. Wei, Enhanced methanol oxidation activity of Pt catalyst supported on the phosphorus-doped multiwalled carbon nanotubes in alkaline medium, Catal. Commun. 22 (2012) 34-38. doi:10.1016/j.catcom.2012.02.013.

[254] Z. Liu, Q. Shi, F. Peng, H. Wang, R. Zhang, H. Yu, Pt supported on phosphorus-doped carbon nanotube as an anode catalyst for direct methanol fuel cells, Electrochem. Commun. 16 (2012) 7376. doi:10.1016/j.elecom.2011.11.033.

[255] D. Yu, Y. Xue, L. Dai, Vertically aligned carbon nanotube arrays co-doped with phosphorus and nitrogen as efficient metal-free electrocatalysts for oxygen reduction, J. Phys. Chem. Lett. 3 (2012) 2863-2870. doi:10.1021/jz3011833.

[256] Y. Xue, B. Wu, H. Liu, J. Tan, W. Hu, Y. Liu, Direct synthesis of phosphorus and nitrogen co-doped monolayer graphene with air-stable n-type characteristics, Phys. Chem. Chem. Phys. 16 (2014) 20392-20397. doi:10.1039/C4CP02935F.

[257] M.-T. Kuo, P.W. May, A. Gunn, M.N.R. Ashfold, R.K. Wild, Studies of phosphorus doped diamond-like carbon films, Diam. Relat. Mater. 9 (2000) 1222-1227. doi:10.1016/S0925-9635(99)00305-2.

[258] S.R.J. Pearce, P.W. May, R.K. Wild, K.R. Hallam, P.J. Heard, Deposition and properties of amorphous carbon phosphide films, Diam. Relat. Mater. 11 (2002) 1041-1046. doi:10.1016/S09259635(01)00611-2.

[259] S.R.J. Pearce, J. Filik, P.W. May, R.K. Wild, K.R. Hallam, P.J. Heard, The effect of ion energy on the deposition of amorphous carbon phosphide films, Diam. Relat. Mater. 12 (2003) 979-982. doi:10.1016/S0925-9635(02)00371-0.

[260] M. Rusop, T. Soga, T. Jimbo, Structural, bonding and physical characteristics of phosphorus-doped hydrogenated amorphous carbon films grown by plasma-enhanced chemical vapor deposition, Thin Solid Films 482 (2005) 280-286. doi:10.1016/j.tsf.2004.11.138.

[261] M. Rusop, T. Soga, T. Jimbo, Photovoltaic characteristics of phosphorus-doped amorphous carbon films grown by r.f. plasma-enhanced CVD, Sol. Energy Mater. Sol. Cells 90 (2006) 3214-3222. doi:10.1016/j.solmat.2006.06.017.

[262] S.M. Mominuzzaman, H. Ebisu, T. Soga, T. Jimbo, M. Umeno, Phosphorus doping and defect studies of diamond-like carbon films by pulsed laser deposition using camphoric carbon target, Diam. Relat. Mater. 10 (2001) 984-988. doi:10.1016/S0925-9635(00)00542-2.

[263] S.M. Mominuzzaman, M. Alam, T. Soga, T. Jimbo, Rearrangements of $\mathrm{sp}^{2} / \mathrm{sp}^{3}$ hybridized bonding with phosphorus incorporation in pulsed laser deposited semiconducting carbon films by X-ray photoelectron spectroscopic analysis, Diam. Relat. Mater. 15 (2006) 1795-1798. doi:10.1016/j.diamond.2006.08.003. 
[264] M. Rusop, T. Soga, T. Jimbo, Defect studies and photoelectrical properties of phosphorus doped amorphous carbon films, Diam. Relat. Mater. 13 (2004) 2197-2202.

doi:10.1016/j.diamond.2004.06.007.

[265] M. Rusop, S.M. Mominuzzaman, T. Soga, T. Jimbo, M. Umeno, Characterization of PhosphorusDoped Amorphous Carbon and Construction of n-Carbon/p-Silicon Heterojunction Solar Cells, Jpn. J. Appl. Phys. 42 (2003) 2339-2344. doi:10.1143/JJAP.42.2339.

[266] G.M. Fuge, P.W. May, K.N. Rosser, S.R.J. Pearce, M.N.R. Ashfold, Laser Raman and X-ray photoelectron spectroscopy of phosphorus containing diamond-like carbon films grown by pulsed laser ablation methods, Diam. Relat. Mater. 13 (2004) 1442-1448. doi:10.1016/j.diamond.2003.11.069.

[267] F. Claeyssens, G.M. Fuge, N.L. Allan, P.W. May, M.N.R. Ashfold, Phosphorus carbides: theory and experiment, Dalton Trans. (2004) 3085-3092. doi:10.1039/b402740j.

[268] F. Claeyssens, G.M. Fuge, N.L. Allan, P.W. May, S.R.J. Pearce, M.N.R. Ashfold, Phosphorus carbide thin films: experiment and theory, Appl. Phys. A Mater. Sci. Process. 79 (2004) 1237-1241. doi:10.1007/s00339-004-2726-7.

[269] J.N. Hart, P.W. May, N.L. Allan, K.R. Hallam, F. Claeyssens, G.M. Fuge, M. Ruda, P.J. Heard, Towards new binary compounds: Synthesis of amorphous phosphorus carbide by pulsed laser deposition, J. Solid State Chem. 198 (2013) 466-474. doi:10.1016/j.jssc.2012.11.008.

[270] G. Peters, M. Jansen, A new fullerene synthesis, Angew. Chem. Int. Ed. 31 (1992) 223-224. doi:10.1002/anie.199202231.

[271] C. Möschel, M. Jansen, Darstellung stabiler Phosphor-Heterofullerene im Hochfrequenzofen, Z. Anorg. Allg. Chem. 625 (1999) 175-177. doi:10.1002/(SICI)1521-3749(199902)625:2<175::AIDZAAC175>3.0.CO;2-2.

[272] G.A.J. Amaratunga, V.S. Veerasamy, C.A. Davis, W. Milne, D.R. McKenzie, J. Yuan, M. Weiler, Doping of highly tetrahedral amorphous carbon, J. Non-Cryst. Solids 164-166 (1993) 1119-1122. doi:10.1016/0022-3093(93)91195-9.

[273] V.S. Veerasamy, G.A.J. Amaratunga, C.A. Davis, A.E. Timbs, W.I. Milne, D.R. McKenzie, n-type doping of highly tetrahedral diamond-like amorphous carbon, J. Phys. Condens. Matter 5 (1993) L169-L174. doi:10.1088/0953-8984/5/13/004.

[274] A. Liu, J. Zhu, J. Han, H. Wu, W. Gao, Influence of phosphorus doping level and acid pretreatment on the voltammetric behavior of phosphorus incorporated tetrahedral amorphous carbon film electrodes, Electroanalysis 19 (2007) 1773-1778. doi:10.1002/elan.200703931.

[275] A. Liu, J. Zhu, J. Han, H. Wu, Z. Jia, Correlation between substrate bias, growth process and structural properties of phosphorus incorporated tetrahedral amorphous carbon films, Appl. Surf. Sci. 253 (2007) 9124-9129. doi:10.1016/j.apsusc.2007.05.040.

[276] A. Liu, J. Zhu, M. Tan, X. Han, W. Chen, J. Han, Structural characteristics and electrode activities of phosphorus incorporated tetrahedral amorphous carbon films, Phosphorus Sulfur Silicon Relat. Elem. 183 (2008) 657-664. doi:10.1080/10426500701796108.

[277] J.C. Han, A.P. Liu, J.Q. Zhu, M.L. Tan, H.P. Wu, Effect of phosphorus content on structural properties of phosphorus incorporated tetrahedral amorphous carbon films, Appl. Phys. A Mater. Sci. Process. 88 (2007) 341-345. doi:10.1007/s00339-007-3938-4.

[278] A.M. Puziy, O.I. Poddubnaya, M. Sobiesiak, B. Gawdzik, Assessment of the structural evolution of polyimide-derived carbons obtained by phosphoric acid activation using Fourier transform infrared and Raman spectroscopy, Adsorpt. Sci. Technol. 35 (2017) 403-412. doi:10.1177/0263617417693627.

[279] A.M. Puziy, O.I. Poddubnaya, R.P. Socha, J. Gurgul, M. Wiśniewski, XPS and NMR studies of phosphoric acid activated carbons, Carbon 46 (2008) 2113-2123. doi:10.1016/j.carbon.2008.09.010. 
[280] N.N. Greenwood, A. Earnshaw, Chemistry of the Elements, 2nd ed., Butterworth-Heinemann, Oxford, 1998.

[281] S.S. Stavitskaya, V.M. Vikarchuk, M.F. Kovtun, O.I. Poddubnaya, A.M. Puziy, Adsorption of copper ions by carbon adsorbents modified by phosphoric acid at different temperatures, J. Water Chem. Technol. 36 (2014) 110-114. doi:10.3103/S1063455X14030023.

[282] Y. Wang, S. Zuo, Y. Zhu, Q. Shao, Y. Ni, Role of oxidant during phosphoric acid activation of lignocellulosic material, Carbon 66 (2014) 734-737. doi:10.1016/j.carbon.2013.09.048.

[283] S. Campisi, F. Sanchez Trujillo, D. Motta, T. Davies, N. Dimitratos, A. Villa, Controlling the incorporation of phosphorus functionalities on carbon nanofibers: effects on the catalytic performance of fructose dehydration, C 4 (2018) 9. doi:10.3390/c4010009.

[284] L. Wang, X. Dong, H. Jiang, G. Li, M. Zhang, Phosphorylated ordered mesoporous carbon as a novel solid acid catalyst for the esterification of oleic acid, Catal. Commun. 56 (2014) 164-167. doi:10.1016/j.catcom.2014.07.008.

[285] M. Olivares-Marín, C. Fernández-González, A. Macías-García, V. Gómez-Serrano, Thermal behaviour of lignocellulosic material in the presence of phosphoric acid. Influence of the acid content in the initial solution, Carbon 44 (2006) 2347-2350. doi:10.1016/j.carbon.2006.04.004.

[286] M.J. Valero-Romero, F.J. García-Mateos, J. Rodríguez-Mirasol, T. Cordero, Role of surface phosphorus complexes on the oxidation of porous carbons, Fuel Process. Technol. 157 (2017) 116126. doi:10.1016/j.fuproc.2016.11.014.

[287] L.J. Bellamy, The Infra-Red Spectra of Complex Molecules, Wiley, New York, 1954.

[288] D.E.C. Corbridge, Infra-red analysis of phosphorus compounds, J. Appl. Chem. 6 (1956) 456-465. doi:10.1002/jctb.5010061007.

[289] G. Socrates, Infrared and Raman Characteristic Group Frequencies: Tables and Charts, 3rd ed., John Wiley \& Sons, Chichester, 2001.

[290] S. Thomas, Spectroscopic Tools, (n.d.). http://www.science-and-fun.de/tools/ (accessed September 24, 2019).

[291] R. Xie, B. Qu, K. Hu, Dynamic FTIR studies of thermo-oxidation of expandable graphite-based halogen-free flame retardant LLDPE blends, Polym. Degrad. Stab. 72 (2001) 313-321. doi:10.1016/S0141-3910(01)00026-X.

[292] J.F. Moulder, W.F. Stickle, P.E. Sobol, K.D. Bomben, Handbook of X-ray Photoelectron Spectroscopy, 2nd ed., Perkin-Elmer, Eden Prarie, MN, 1992.

[293] A. V. Naumkin, A. Kraut-Vass, S.W. Gaarenstroom, C.J. Powell, NIST Standard Reference Database 20, Version 4.1 (Web Version), (2012). doi:10.18434/T4T88K.

[294] J. Dai, J. Yuan, Modulating the electronic and magnetic structures of P-doped graphene by molecule doping, J. Phys. Condens. Matter 22 (2010) 225501. doi:10.1088/0953-8984/22/22/225501.

[295] H. Zhang, X. Li, D. Zhang, L. Zhang, M. Kapilashrami, T. Sun, P.-A. Glans, J. Zhu, J. Zhong, Z. Hu, J. Guo, $X$. Sun, Comprehensive electronic structure characterization of pristine and nitrogen/phosphorus doped carbon nanocages, Carbon 103 (2016) 480-487. doi:10.1016/j.carbon.2016.03.042.

[296] A.M. Puziy, O.I. Poddubnaya, A.M. Ziatdinov, On the chemical structure of phosphorus compounds in phosphoric acid-activated carbon, Appl. Surf. Sci. 252 (2006) 8036-8038. doi:10.1016/j.apsusc.2005.10.044.

[297] C. Huang, A.M. Puziy, T. Sun, O.I. Poddubnaya, F. Suárez-García, J.M.D. Tascón, D. HulicovaJurcakova, Capacitive Behaviours of Phosphorus-Rich Carbons Derived from Lignocelluloses, Electrochim. Acta 137 (2014) 219-227. doi:10.1016/j.electacta.2014.05.101.

[298] C. Huang, A.M. Puziy, O.I. Poddubnaya, D. Hulicova-Jurcakova, M. Sobiesiak, B. Gawdzik, 
Phosphorus, nitrogen and oxygen co-doped polymer-based core-shell carbon sphere for highperformance hybrid supercapacitors, Electrochim. Acta 270 (2018) 339-351.

doi:10.1016/j.electacta.2018.02.115.

[299] J. Bedia, R. Ruiz-Rosas, J. Rodríguez-Mirasol, T. Cordero, A kinetic study of 2-propanol dehydration on carbon acid catalysts, J. Catal. 271 (2010) 33-42. doi:10.1016/j.jcat.2010.01.023.

[300] Y. Wang, S. Zuo, J. Yang, S.-H. Yoon, Evolution of phosphorus-containing groups on activated carbons during heat treatment, Langmuir 33 (2017) 3112-3122. doi:10.1021/acs.langmuir.7b00095.

[301] D.E.C. Corbridge, Phosphorus: Chemistry, Biochemistry and Technology, 6th ed., CRC Press, Boca Raton, FL, 2013.

[302] J.R. Van Wazer, Phosphorus and Its Compounds. Chemistry, Interscience, New York, 1958.

[303] M. Hupfer, R. Gachter, Polyphosphate in lake sediments: ${ }^{31} \mathrm{P}$ NMR spectroscopy as a tool for its identification, Limnol. Oceanogr. 40 (1995) 610-617. doi:10.4319/lo.1995.40.3.0610.

[304] B.L. Turner, N. Mahieu, L.M. Condron, Phosphorus-31 nuclear magnetic resonance spectral assignments of phosphorus compounds in soil NaOH-EDTA extracts, Soil Sci. Soc. Am. J. 67 (2003) 497-510. doi:10.2136/sssaj2003.4970.

[305] A.M. Puziy, O.I. Poddubnaya, T.Y. Gromovoy, Laser desorption/ionization time of flight mass spectrometry of phosphorus-containing carbons, Carbon 53 (2013) 405-408. doi:10.1016/j.carbon.2012.10.064.

[306] J. Siedlewski, W. Śmigel, A. Arcimowicz, Badanie własności sorpcyjnych i katalitycznych węgli aktywowanych modyfikowanych trójchlorkiem fosforowym, Przem. Chem. 58 (1979) 677-678.

[307] A.M. Puziy, O.I. Poddubnaya, Y.N. Kochkin, N. V. Vlasenko, M.M. Tsyba, Acid properties of phosphoric acid activated carbons and their catalytic behavior in ethyl-tert-butyl ether synthesis, Carbon 48 (2010) 706-713. doi:10.1016/j.carbon.2009.10.015.

[308] N. V. Vlasenko, Y.N. Kochkin, A.M. Puziy, Liquid phase synthesis of ethyl-tert-butyl ether: The relationship between acid, adsorption and catalytic properties of zeolite catalysts, J. Mol. Catal. A Chem. 253 (2006) 192-197. doi:10.1016/j.molcata.2006.03.041.

[309] H.P. Boehm, Chemical identification of surface groups, in: D.D. Eley, H. Pines, P.B. Weisz (Eds.), Advances in Catalysis, Academic Press, 1966: pp. 179-274. doi:10.1016/S0360-0564(08)60354-5.

[310] J. Lyklema, Points of zero charge in the presence of specific adsorption, J. Colloid Interface Sci. 99 (1984) 109-117. doi:10.1016/0021-9797(84)90090-0.

[311] J.S. Noh, J.A. Schwarz, Effect of $\mathrm{HNO}_{3}$ treatment on the surface acidity of activated carbons, Carbon 28 (1990) 675-682. doi:10.1016/0008-6223(90)90069-B.

[312] J.A. Menéndez, J. Phillips, B. Xia, L.R. Radovic, On the modification and characterization of chemical surface properties of activated carbon: in the search of carbons with stable basic properties, Langmuir 12 (1996) 4404-4410. doi:10.1021/la9602022.

[313] A.M. Puzii, O.I. Poddubnaya, S.S. Stavitskaya, Acid-base characteristics of carbon adsorbents, determined by potentiometric titration, Russ. J. Appl. Chem. 77 (2004) 1263-1267. doi:10.1007/s11167-005-0011-y.

[314] G. Newcombe, R. Hayes, M. Drikas, Granular activated carbon: Importance of surface properties in the adsorption of naturally occurring organics, Colloid Surf. A 78 (1993) 65-71. doi:10.1016/09277757(93)80311-2.

[315] M.V. Lopez-Ramon, F. Stoeckli, C. Moreno-Castilla, F. Carrasco-Marín, On the characterization of acidic and basic surface sites on carbons by various techniques, Carbon 37 (1999) 1215-1221. doi:10.1016/S0008-6223(98)00317-0.

[316] A.M. Puziy, O.I. Poddubnaya, Characterization of surface heterogeneity of carbon-composite 
adsorbents, Mater. Sci. Forum 308-311 (1999) 908-916. doi:10.4028/www.scientific.net/MSF.308311.908.

[317] A.M. Puziy, O.I. Poddubnaya, J.A. Ritter, A.D. Ebner, C.E. Holland, Elucidation of the ion binding mechanism in heterogeneous carbon-composite adsorbents, Carbon 39 (2001) 2313-2324. doi:10.1016/S0008-6223(01)00048-3.

[318] S. Chen, H. Zeng, Improvement of the reduction capacity of activated carbon fiber, Carbon 41 (2003) 1265-1271. doi:10.1016/S0008-6223(03)00077-0.

[319] S. Chen, J. Liu, H. Zeng, Structure and antibacterial activity of silver-supporting activated carbon fibers, J. Mater. Sci. 40 (2005) 6223-6231. doi:10.1007/s10853-005-3149-3.

[320] D. Yu, E. Nagelli, F. Du, L. Dai, Metal-free carbon nanomaterials become more active than metal catalysts and last longer, J. Phys. Chem. Lett. 1 (2010) 2165-2173. doi:10.1021/jz100533t.

[321] R.W. Coughlin, F.S. Ezra, Role of surface acidity in the adsorption of organic pollutants on the surface of carbon, Environ. Sci. Technol. 2 (1968) 291-297. doi:10.1021/es60016a002.

[322] J.A. Mattson, H.B. Mark, M.D. Malbin, W.J. Weber, J.C. Crittenden, Surface chemistry of active carbon: Specific adsorption of phenols, J. Colloid Interface Sci. 31 (1969) 116-130. doi:10.1016/0021-9797(69)90089-7.

[323] A.P. Terzyk, Further insights into the role of carbon surface functionalities in the mechanism of phenol adsorption, J. Colloid Interface Sci. 268 (2003) 301-329. doi:10.1016/S0021-9797(03)006908.

[324] A.A.M. Daifullah, B.S. Girgis, Impact of surface characteristics of activated carbon on adsorption of BTEX, Colloid Surf. A 214 (2003) 181-193. doi:10.1016/S0927-7757(02)00392-8.

[325] G.X. Yu, J. Sun, X.M. Hou, X.L. Zhou, C.L. Li, L.F. Chen, J.A. Wang, Adsorptive removal of dibenzothiophene in diesel fuel on an adsorbent from rice hull activated by phosphoric acid, Adv. Mater. Res. 132 (2010) 133-140. doi:10.4028/www.scientific.net/AMR.132.133.

[326] Permutit, Verfahren zum Entfernen von Kationen aus Wasser oder wässerigen Lösungen, DE733410, 1943.

http://worldwide.espacenet.com/publicationDetails/biblio?FT=D\&date=19430326\&DB=EPODOC\&lo cale $=e n \_E P \& C C=D E \& N R=733410 C \& K C=C \& N D=4$.

[327] S.A. Dastgheib, D.A. Rockstraw, A systematic study and proposed model of the adsorption of binary metal ion solutes in aqueous solution onto activated carbon produced from pecan shells, Carbon 40 (2002) 1853-1861. doi:10.1016/S0008-6223(02)00036-2.

[328] S.A. Dastgheib, D.A. Rockstraw, A model for the adsorption of single metal ion solutes in aqueous solution onto activated carbon produced from pecan shells, Carbon 40 (2002) 1843-1851. doi:10.1016/S0008-6223(02)00037-4.

[329] R.A. Shawabkeh, D.A. Rockstraw, R.K. Bhada, Copper and strontium adsorption by a novel carbon material manufactured from pecan shells, Carbon 40 (2002) 781-786. doi:10.1016/S00086223(01)00198-1.

[330] A.M. Puziy, O.I. Poddubnaya, B. Gawdzik, M. Sobiesiak, M.M. Tsyba, Phosphoric acid activation functionalization and porosity modification, Appl. Surf. Sci. 253 (2007) 5736-5740. doi:10.1016/j.apsusc.2006.12.034.

[331] A.M. Puziy, O.I. Poddubnaya, B. Gawdzik, M. Sobiesiak, M.M. Tsyba, Functionalization of Carbon and Silica Gel by Phosphoric Acid, Adsorpt. Sci. Technol. 25 (2007) 531-542. doi:10.1260/02636174.25.8.531.

[332] A.M. Puziy, O.I. Poddubnaya, V.N. Zaitsev, O.P. Konoplitska, Modeling of heavy metal ion binding by phosphoric acid activated carbon, Appl. Surf. Sci. 221 (2004) 421-429. doi:10.1016/S01694332(03)00956-5. 
[333] K.F. Hayes, G. Redden, W. Ela, J.O. Leckie, Surface complexation models: An evaluation of model parameter estimation using FITEQL and oxide mineral titration data, J. Colloid Interface Sci. 142 (1991) 448-469. doi:10.1016/0021-9797(91)90075-J.

[334] J. Westall, H. Hohl, A comparison of electrostatic models for the oxide/solution interface, Adv. Colloid Interface Sci. 12 (1980) 265-294. doi:10.1016/0001-8686(80)80012-1.

[335] J. Rivera-Utrilla, M. Sánchez-Polo, Adsorption of $\mathrm{Cr}$ (III) on ozonised activated carbon. Importance of Cr-cation interactions, Water Res. 37 (2003) 3335-3340. doi:10.1016/S0043-1354(03)00177-5.

[336] M. Sánchez-Polo, J. Rivera-Utrilla, Adsorbent-adsorbate interactions in the adsorption of Cd(II) and $\mathrm{Hg}$ (II) on ozonized activated carbons, Environ. Sci. Technol. 36 (2002) 3850-3854.

doi:10.1021/es0255610.

[337] H. Peng, P. Gao, G. Chu, B. Pan, J. Peng, B. Xing, Enhanced adsorption of Cu(II) and Cd(II) by phosphoric acid-modified biochars, Environ. Pollut. 229 (2017) 846-853. doi:10.1016/j.envpol.2017.07.004.

[338] Rajeshwarisivaraj, S. Sivakumar, P. Senthilkumar, V. Subburam, Carbon from Cassava peel, an agricultural waste, as an adsorbent in the removal of dyes and metal ions from aqueous solution, Bioresour. Technol. 80 (2001) 233-5. http://www.ncbi.nlm.nih.gov/pubmed/11601548.

[339] Z. Zhang, Z. Zhou, X. Cao, Y. Liu, G. Xiong, P. Liang, Removal of uranium(VI) from aqueous solutions by new phosphorus-containing carbon spheres synthesized via one-step hydrothermal carbonization of glucose in the presence of phosphoric acid, J. Radioanal. Nucl. Chem. 299 (2014) 1479-1487. doi:10.1007/s10967-013-2830-2.

[340] A. Mohammadhosseini, P. Boulet, B. Kuchta, Grand canonical monte carlo modeling of hydrogen adsorption on phosphorus-doped open carbon framework, Adsorption 19 (2013) 869-877. doi:10.1007/s10450-013-9541-4.

[341] M. Sankaran, B. Viswanathan, The role of heteroatoms in carbon nanotubes for hydrogen storage, Carbon 44 (2006) 2816-2821. doi:10.1016/j.carbon.2006.03.025.

[342] A. Ariharan, B. Viswanathan, V. Nandhakumar, Phosphorous-doped porous carbon derived from paste of newly growing Ficus benghalensis as hydrogen storage material, Indian J. Chem. A 55 (2016) 649-656. http://nopr.niscair.res.in/bitstream/123456789/34356/1/IJCA 55A\%286\%29 649-656.pdf.

[343] E.J. Hippo, N. Murdie, W. Kowbel, The effect of acid treatments on subsequent reactivity of carboncarbon composites, Carbon 27 (1989) 331-336. doi:10.1016/0008-6223(89)90064-X.

[344] E.J. Hippo, N. Murdie, A. Hyjazie, The role of active sites in the inhibition of gas-carbon reactions, Carbon 27 (1989) 689-695. doi:10.1016/0008-6223(89)90202-9.

[345] W. Lu, D.D.L. Chung, Oxidation protection of carbon materials by acid phosphate impregnation, Carbon 40 (2002) 1249-1254. doi:10.1016/S0008-6223(01)00297-4.

[346] A.P. Wieber, J.E. Guzman, E.E. Wolf, An STM study of phosphoric acid inhibition of the oxidation of HOPG and carbon catalyzed by alkali salts, Carbon 44 (2006) 2069-2079. doi:10.1016/j.carbon.2005.12.028.

[347] S. Stegenga, M. Van Waveren, F. Kapteijn, J.A. Moulijn, Stability of carbon-supported catalysts in an oxidizing environment, Carbon 30 (1992) 577-585. doi:10.1016/0008-6223(92)90175-V.

[348] J.J. Ternero-Hidalgo, J.M. Rosas, J. Palomo, M.J. Valero-Romero, J. Rodríguez-Mirasol, T. Cordero, Functionalization of activated carbons by $\mathrm{HNO}_{3}$ treatment: Influence of phosphorus surface groups, Carbon 101 (2016) 409-419. doi:10.1016/j.carbon.2016.02.015.

[349] J. Palomo, J.J. Ternero-Hidalgo, J.M. Rosas, J. Rodríguez-Mirasol, T. Cordero, Selective nitrogen functionalization of phosphorus-containing activated carbons, Fuel Process. Technol. 156 (2017) 438-445. doi:10.1016/j.fuproc.2016.10.006.

[350] Y. Cao, H. Yu, J. Tan, F. Peng, H. Wang, J. Li, W. Zheng, N.-B. Wong, Nitrogen-, phosphorous- and 
boron-doped carbon nanotubes as catalysts for the aerobic oxidation of cyclohexane, Carbon 57 (2013) 433-442. doi:10.1016/j.carbon.2013.02.016.

[351] M. Besson, F. Gauthard, B. Horvath, P. Gallezot, Catalytic oxidation with air of cyclohexanone to dicarboxylic acids on synthetic carbons. Effect of supported metals and solvents, J. Phys. Chem. B 109 (2005) 2461-2467. doi:10.1021/jp0459662.

[352] M. Patel, K. Savaram, Q. Li, J. Buchspies, N. Ma, M. Szostak, H. He, Carbon-based, metal-free catalysts for chemical catalysis, in: Carbon-Based Metal-Free Catalysts, Wiley-VCH Verlag GmbH \& Co. KGaA, Weinheim, Germany, 2018: pp. 597-657. doi:10.1002/9783527811458.vol2-ch9.

[353] M.A. Patel, F. Luo, K. Savaram, P. Kucheryavy, Q. Xie, C. Flach, R. Mendelsohn, E. Garfunkel, J. V. Lockard, H. He, P and S dual-doped graphitic porous carbon for aerobic oxidation reactions: Enhanced catalytic activity and catalytic sites, Carbon 114 (2017) 383-392. doi:10.1016/j.carbon.2016.11.064.

[354] S. Yang, L. Peng, P. Huang, X. Wang, Y. Sun, C. Cao, W. Song, Nitrogen, phosphorus, and sulfur codoped hollow carbon shell as superior metal-free catalyst for selective oxidation of aromatic alkanes, Angew. Chem. Int. Ed. 55 (2016) 4016-4020. doi:10.1002/anie.201600455.

[355] L. Li, W. Zhu, Y. Liu, L. Shi, H. Liu, Y. Ni, S. Liu, H. Zhou, Z. Liu, Phosphorous-modified ordered mesoporous carbon for catalytic dehydrogenation of propane to propylene, RSC Adv. 5 (2015) 56304-56310. doi:10.1039/C5RA06619K.

[356] Y. Song, G. Liu, Z.-Y. Yuan, N-, P- and B-doped mesoporous carbons for direct dehydrogenation of propane, RSC Adv. 6 (2016) 94636-94642. doi:10.1039/C6RA20726J.

[357] D. Chen, A. Holmen, Z. Sui, X. Zhou, Carbon mediated catalysis: A review on oxidative dehydrogenation, Chinese J. Catal. 35 (2014) 824-841. doi:10.1016/S1872-2067(14)60120-0.

[358] W. Qi, D. Su, Metal-free carbon catalysts for oxidative dehydrogenation reactions, ACS Catal. 4 (2014) 3212-3218. doi:10.1021/cs500723v.

[359] P. Serp, B. Machado, Nanostructured Carbon Materials for Catalysis, Royal Society of Chemistry, Cambridge, 2015. doi:10.1039/9781782622567.

[360] Z. Sui, J. Zhou, Y. Dai, W. Yuan, Oxidative dehydrogenation of propane over catalysts based on carbon nanofibers, Catal. Today 106 (2005) 90-94. doi:http://dx.doi.org/10.1016/j.cattod.2005.07.141.

[361] B. Frank, J. Zhang, R. Blume, R. Schlögl, D.S. Su, Heteroatoms increase the selectivity in oxidative dehydrogenation reactions on nanocarbons, Angew. Chem. Int. Ed. 48 (2009) 6913-6917. doi:10.1002/anie.200901826.

[362] J. Zhang, X. Liu, R. Blume, A. Zhang, R. Schlögl, D.S. Su, Surface-modified carbon nanotubes catalyze oxidative dehydrogenation of n-butane, Science 322 (2008) 73-77. doi:10.1126/science.1161916.

[363] B. Frank, M. Morassutto, R. Schomäcker, R. Schlögl, D.S. Su, Oxidative dehydrogenation of ethane over multiwalled carbon nanotubes, ChemCatChem 2 (2010) 644-648. doi:10.1002/cctc.201000035.

[364] X. Sun, Y. Ding, B. Zhang, R. Huang, D. Chen, D.S. Su, Insight into the enhanced selectivity of phosphate-modified annealed nanodiamond for oxidative dehydrogenation reactions, ACS Catal. 5 (2015) 2436-2444. doi:10.1021/acscatal.5b00042.

[365] V. Schwartz, H. Xie, H.M. Meyer III, S.H. Overbury, C. Liang, Oxidative dehydrogenation of isobutane on phosphorous-modified graphitic mesoporous carbon, Carbon 49 (2011) 659-668. doi:10.1016/j.carbon.2010.10.015.

[366] S.S. Stavitskaya, O.I. Poddubnaya, N.N. Tsyba, A.M. Puziy, Catalytic properties of phosphoruscontaining charcoals in ethyl acetate hydrolysis, Theor. Exp. Chem. 50 (2014) 187-190. doi:10.1007/s11237-014-9364-8.

[367] M.J. Valero-Romero, E.M. Calvo-Muñoz, R. Ruiz-Rosas, J. Rodríguez-Mirasol, T. Cordero, Phosphorus- 
containing mesoporous carbon acid catalyst for methanol dehydration to dimethyl ether, Ind. Eng. Chem. Res. 58 (2019) 4042-4053. doi:10.1021/acs.iecr.8b05897.

[368] J. Bedia, J.M. Rosas, D. Vera, J. Rodríguez-Mirasol, T. Cordero, Isopropanol decomposition on carbon based acid and basic catalysts, Catal. Today 158 (2010) 89-96. doi:10.1016/j.cattod.2010.04.043.

[369] J. Soto, J.M. Rosas, J.C. Otero, J. Rodríguez-Mirasol, T. Cordero, Reaction mechanisms of 2-butanol dehydration over a phosphorus-containing activated carbon acid catalyst, J. Phys. Chem. C 122 (2018) 16772-16778. doi:10.1021/acs.jpcc.8b03700.

[370] F. Yang, X. Tong, F. Xia, C. Zheng, L. Qin, X. Jiang, Efficient hydroxymethylfurfural production over phosphoric carbon solid acids, Catal. Lett. 148 (2018) 1848-1855. doi:10.1007/s10562-018-2396-2.

[371] A.M. Puziy, Y.N. Kochkin, O.I. Poddubnaya, M.M. Tsyba, Ethyl tert-butyl ether synthesis using carbon catalysts from lignocellulose, Adsorpt. Sci. Technol. 35 (2017) 473-481. doi:10.1177/0263617417696091.

[372] A.M. Puziy, O.I. Poddubnaya, O. Sevastyanova, Carbon materials from technical lignins: recent advances, Top. Curr. Chem. 376 (2018) 33. doi:10.1007/s41061-018-0210-7.

[373] P. Rechnia, A. Malaika, M. Kozłowski, Synthesis of tert-amyl methyl ether (TAME) over modified activated carbon catalysts, Fuel 154 (2015) 338-345. doi:10.1016/j.fuel.2015.03.086.

[374] I. Matos, M.F. Silva, R. Ruiz-Rosas, J. Vital, J. Rodríguez-Mirasol, T. Cordero, J.E. Castanheiro, I.M. Fonseca, Methoxylation of $\alpha$-pinene over mesoporous carbons and microporous carbons: $A$ comparative study, Micropor. Mesopor. Mater. 199 (2014) 66-73. doi:10.1016/j.micromeso.2014.08.006.

[375] D.-H. Lan, H.-T. Wang, L. Chen, C.-T. Au, S.-F. Yin, Phosphorous-modified bulk graphitic carbon nitride: Facile preparation and application as an acid-base bifunctional and efficient catalyst for $\mathrm{CO}_{2}$ cycloaddition with epoxides, Carbon 100 (2016) 81-89. doi:10.1016/j.carbon.2015.12.098.

[376] X.N. Ye, Q. Lu, X. Wang, H.Q. Guo, M.S. Cui, C.Q. Dong, Y.P. Yang, Catalytic fast pyrolysis of cellulose and biomass to selectively produce levoglucosenone using activated carbon catalyst, ACS Sustain. Chem. Eng. 5 (2017) 10815-10825. doi:10.1021/acssuschemeng.7b02762.

[377] K.M. Eblagon, A. Malaika, M.F.R. Pereira, J.L. Figueiredo, Cutting the green waste. Structureperformance relationship in functionalized carbon xerogels for hydrolysis of cellobiose, ChemCatChem 10 (2018) 4948-4960. doi:10.1002/cctc.201800649.

[378] E. Guillén, R. Rico, J.M. López-Romero, J. Bedia, J.M. Rosas, J. Rodríguez-Mirasol, T. Cordero, Pdactivated carbon catalysts for hydrogenation and Suzuki reactions, Appl. Catal. A Gen. 368 (2009) 113-120. doi:10.1016/j.apcata.2009.08.016.

[379] J. Bedia, J.M. Rosas, J. Rodríguez-Mirasol, T. Cordero, Pd supported on mesoporous activated carbons with high oxidation resistance as catalysts for toluene oxidation, Appl. Catal. B Environ. 94 (2010) 8-18. doi:10.1016/j.apcatb.2009.10.015.

[380] I. Hita, T. Cordero-Lanzac, A. Gallardo, J.M. Arandes, J. Rodríguez-Mirasol, J. Bilbao, T. Cordero, P. Castaño, Phosphorus-containing activated carbon as acid support in a bifunctional Pt-Pd catalyst for tire oil hydrocracking, Catal. Commun. 78 (2016) 48-51. doi:10.1016/j.catcom.2016.01.035.

[381] T. Cordero-Lanzac, I. Hita, A. Veloso, J.M. Arandes, J. Rodríguez-Mirasol, J. Bilbao, T. Cordero, P. Castaño, Characterization and controlled combustion of carbonaceous deactivating species deposited on an activated carbon-based catalyst, Chem. Eng. J. 327 (2017) 454-464. doi:10.1016/j.cej.2017.06.077.

[382] T. Cordero-Lanzac, R. Palos, J.M. Arandes, P. Castaño, J. Rodríguez-Mirasol, T. Cordero, J. Bilbao, Stability of an acid activated carbon based bifunctional catalyst for the raw bio-oil hydrodeoxygenation, Appl. Catal. B Environ. 203 (2017) 389-399. doi:10.1016/j.apcatb.2016.10.018.

[383] T. Cordero-Lanzac, R. Palos, I. Hita, J.M. Arandes, J. Rodríguez-Mirasol, T. Cordero, J. Bilbao, P. 
Castaño, Revealing the pathways of catalyst deactivation by coke during the hydrodeoxygenation of raw bio-oil, Appl. Catal. B Environ. 239 (2018) 513-524. doi:10.1016/j.apcatb.2018.07.073.

[384] M.O. Guerrero-Pérez, J.M. Rosas, R. López-Medina, M.A. Bañares, J. Rodríguez-Mirasol, T. Cordero, Lignocellulosic-derived catalysts for the selective oxidation of propane, Catal. Commun. 12 (2011) 989-992. doi:10.1016/j.catcom.2011.03.010.

[385] L. Yu, D. Tatsumi, S. Zuo, M. Morita, Promotion of crystal growth on biomass-based carbon using phosphoric acid treatments, BioResources 10 (2015) 2406-2417.

http://ojs.cnr.ncsu.edu/index.php/BioRes/article/view/BioRes_10_2_2406_Yu_Crystal_Growth_Bio mass_Carbon/3408.

[386] S.M. Mominuzzaman, K.M. Krishna, T. Soga, T. Jimbo, M. Umeno, Optical absorption and electrical conductivity of amorphous carbon thin films from camphor: a natural source, Jpn. J. Appl. Phys. 38 (1999) 658-663. doi:10.1143/JJAP.38.658.

[387] M. Rusop, X.M. Tian, S.M. Mominuzzaman, T. Soga, T. Jimbo, M. Umeno, Photoelectrical properties of pulsed laser deposited boron doped $\mathrm{p}$-carbon/n-silicon and phosphorus doped $\mathrm{n}$-carbon/p-silicon heterojunction solar cells, Sol. Energy 78 (2005) 406-415. doi:10.1016/j.solener.2004.08.005.

[388] S. Some, J. Kim, K. Lee, A. Kulkarni, Y. Yoon, S. Lee, T. Kim, H. Lee, Highly air-stable phosphorusdoped n-type graphene field-effect transistors, Adv. Mater. 24 (2012) 5481-5486. doi:10.1002/adma.201202255.

[389] T.J. Bandosz, C.O. Ania, Origin and Perspectives of the Photochemical Activity of Nanoporous Carbons, Adv. Sci. 5 (2018) 1800293. doi:10.1002/advs.201800293.

[390] J. Tauc, R. Grigorovici, A. Vancu, Optical Properties and Electronic Structure of Amorphous Germanium, Phys. Status Solidi 15 (1966) 627-637. doi:10.1002/pssb.19660150224.

[391] M. Rusop, S.M. Mominuzzaman, X.M. Tian, T. Soga, T. Jimbo, M. Umeno, Nitrogen doping and structural properties of amorphous carbon films deposited by pulsed laser ablation, Appl. Surf. Sci. 197-198 (2002) 542-546. doi:10.1016/S0169-4332(02)00332-X.

[392] M. Seredych, T.J. Bandosz, Visible light photoactivity of sulfur and phosphorus doped nanoporous carbons in oxidation of dibenzothiophenes, Fuel 108 (2013) 846-849. doi:10.1016/j.fuel.2012.12.064.

[393] B. Chai, J. Yan, C. Wang, Z. Ren, Y. Zhu, Enhanced visible light photocatalytic degradation of Rhodamine B over phosphorus doped graphitic carbon nitride, Appl. Surf. Sci. 391 (2017) 376-383. doi:10.1016/j.apsusc.2016.06.180.

[394] Y.-P. Zhu, T.-Z. Ren, Z.-Y. Yuan, Mesoporous phosphorus-doped g- $\mathrm{C}_{3} \mathrm{~N}_{4}$ nanostructured flowers with superior photocatalytic hydrogen evolution performance, ACS Appl. Mater. Interfaces 7 (2015) 16850-16856. doi:10.1021/acsami.5b04947.

[395] H. Wang, H. Wang, Y. Chen, Y. Liu, J. Zhao, Q. Cai, X. Wang, Phosphorus-doped graphene and (8, 0) carbon nanotube: Structural, electronic, magnetic properties, and chemical reactivity, Appl. Surf. Sci. 273 (2013) 302-309. doi:10.1016/j.apsusc.2013.02.035.

[396] V.V. Strelko, V.S. Kuts, P.A. Thrower, On the mechanism of possible influence of heteroatoms of nitrogen, boron and phosphorus in a carbon matrix on the catalytic activity of carbons in electron transfer reactions, Carbon 38 (2000) 1499-1503. doi:10.1016/S0008-6223(00)00121-4.

[397] N. Kurita, M. Endo, Molecular orbital calculations on electronic and Li-adsorption properties of sulfur-, phosphorus- and silicon-substituted disordered carbons, Carbon 40 (2002) 253-260. doi:10.1016/S0008-6223(01)00089-6.

[398] A.G. Garcia, S.E. Baltazar, A.H.R. Castro, J.F.P. Robles, A. Rubio, Influence of S and P doping in a graphene sheet, J. Comput. Theor. Nanosci. 5 (2008) 2221-2229. doi:10.1166/jctn.2008.1123.

[399] D. Hulicova-Jurcakova, A.M. Puziy, O.I. Poddubnaya, F. Suárez-García, J.M.D. Tascón, G.Q. Lu, Highly 
stable performance of supercapacitors from phosphorus-enriched carbons, J. Am. Chem. Soc. 131 (2009) 5026-5027. doi:10.1021/ja809265m.

[400] C.J.T. de Grotthuss, Sur la décomposition de l'eau et des corps qu'elle tient en dissolution à l'aide de l'électricité galvanique, Ann. Chim. 58 (1806) 54-73.

[401] S. Cukierman, Et tu, Grotthuss! and other unfinished stories, Biochim. Biophys. Acta - Bioenerg. 1757 (2006) 876-885. doi:10.1016/j.bbabio.2005.12.001.

[402] N.N. Greenwood, A. Thompson, Anomalous conduction in phosphoric acid hemihydrate, $2 \mathrm{H}_{3} \mathrm{PO}_{4} \cdot \mathrm{H}_{2} \mathrm{O}$, J. Chem. Soc. (1959) 3864-3867. doi:10.1039/jr9590003864.

[403] D.-T. Chin, H.H. Chang, On the conductivity of phosphoric acid electrolyte, J. Appl. Electrochem. 19 (1989) 95-99. doi:10.1007/BF01039396.

[404] R.P. Hamlen, lonic conductivity of zirconium phosphate, J. Electrochem. Soc. 109 (1962) 746. doi:10.1149/1.2425546.

[405] B.E. Conway, Electrochemical Supercapacitors: Scientific Fundamentals and Technological Applications, Springer US, Boston, MA, 1999. doi:10.1007/978-1-4757-3058-6.

[406] D. Hulicova-Jurcakova, M. Seredych, G.Q. Lu, N.K.A.C. Kodiweera, P.E. Stallworth, S. Greenbaum, T.J. Bandosz, Effect of surface phosphorus functionalities of activated carbons containing oxygen and nitrogen on electrochemical capacitance, Carbon 47 (2009) 1576-1584. doi:10.1016/j.carbon.2009.02.006.

[407] Y. Wen, B. Wang, C. Huang, L. Wang, D. Hulicova-Jurcakova, Synthesis of phosphorus-doped graphene and its wide potential window in aqueous supercapacitors, Chem. Eur. J. 21 (2015) 80-85. doi:10.1002/chem.201404779.

[408] Q. Gao, L. Demarconnay, E. Raymundo-Piñero, F. Béguin, Exploring the large voltage range of carbon/carbon supercapacitors in aqueous lithium sulfate electrolyte, Energy Environ. Sci. 5 (2012) 9611-9617. doi:10.1039/c2ee22284a.

[409] S.K. Ramasahayam, A.L. Clark, Z. Hicks, T. Viswanathan, Spent coffee grounds derived P, N co-doped C as electrocatalyst for supercapacitor applications, Electrochim. Acta 168 (2015) 414-422. doi:10.1016/j.electacta.2015.03.193.

[410] J. Qu, C. Geng, S. Lv, G. Shao, S. Ma, M. Wu, Nitrogen, oxygen and phosphorus decorated porous carbons derived from shrimp shells for supercapacitors, Electrochim. Acta 176 (2015) 982-988. doi:10.1016/j.electacta.2015.07.094.

[411] K.P. Annamalai, N.A. Fathy, Y. Tao, Synthesis and capacitance performance of phosphorous-enriched carbon xerogel, J. Sol-Gel Sci. Technol. (2017) 1-7. doi:10.1007/s10971-017-4452-6.

[412] X. Yu, H.J. Kim, J.-Y. Hong, Y.M. Jung, K.D. Kwon, J. Kong, H.S. Park, Elucidating surface redox charge storage of phosphorus-incorporated graphenes with hierarchical architectures, Nano Energy 15 (2015) 576-586. doi:10.1016/j.nanoen.2015.05.010.

[413] A. Elmouwahidi, E. Bailón-García, A.F. Pérez-Cadenas, F.J. Maldonado-Hódar, F. Carrasco-Marín, Activated carbons from $\mathrm{KOH}$ and $\mathrm{H}_{3} \mathrm{PO}_{4}$-activation of olive residues and its application as supercapacitor electrodes, Electrochim. Acta 229 (2017) 219-228. doi:10.1016/j.electacta.2017.01.152.

[414] K. Xia, Z. Huang, L. Zheng, B. Han, Q. Gao, C. Zhou, H. Wang, J. Wu, Facile and controllable synthesis of N/P co-doped graphene for high-performance supercapacitors, J. Power Sources 365 (2017) 380388. doi:10.1016/j.jpowsour.2017.09.008.

[415] R. Berenguer, R. Ruiz-Rosas, A. Gallardo, D. Cazorla-Amorós, E. Morallón, H. Nishihara, T. Kyotani, J. Rodríguez-Mirasol, T. Cordero, Enhanced electro-oxidation resistance of carbon electrodes induced by phosphorus surface groups, Carbon 95 (2015) 681-689. doi:10.1016/j.carbon.2015.08.101.

[416] X. Yu, L. Feng, H.S. Park, Highly flexible pseudocapacitors of phosphorus-incorporated porous 
reduced graphene oxide films, J. Power Sources 390 (2018) 93-99.

doi:10.1016/j.jpowsour.2018.04.032.

[417] T. Cordero-Lanzac, F.J. García-Mateos, J.M. Rosas, J. Rodríguez-Mirasol, T. Cordero, Flexible binderless capacitors based on $\mathrm{P}$ - and $\mathrm{N}$-containing fibrous activated carbons from denim cloth waste, Carbon 139 (2018) 599-608. doi:10.1016/j.carbon.2018.06.060.

[418] P.O. Ibeh, F.J. García-Mateos, J.M. Rosas, J. Rodríguez-Mirasol, T. Cordero, Activated carbon monoliths from lignocellulosic biomass waste for electrochemical applications, J. Taiwan Inst. Chem. Eng. 97 (2019) 480-488. doi:10.1016/j.jtice.2019.02.019.

[419] W. Ma, L. Xie, L. Dai, G. Sun, J. Chen, F. Su, Y. Cao, H. Lei, Q. Kong, C.-M. Chen, Influence of phosphorus doping on surface chemistry and capacitive behaviors of porous carbon electrode, Electrochim. Acta 266 (2018) 420-430. doi:10.1016/j.electacta.2018.02.031.

[420] K. Tokuo, A. Hideto, N. Mio, Negative electrode material and manufacture thereof, and nonaqueous electrolyte battery using it, JP5074457, 1993.

http://worldwide.espacenet.com/publicationDetails/biblio?FT=D\&date=19930326\&DB=EPODOC\&lo cale $=$ en_EP\&CC $=J P \& N R=5074457 A \& K C=A \& N D=4$.

[421] T.D. Tran, J.H. Feikert, X. Song, K. Kinoshita, Commercial carbonaceous materials as lithium intercalation anodes, J. Electrochem. Soc. 142 (1995) 3297-3302. doi:10.1149/1.2049977.

[422] Y.-N. Jo, M.-S. Park, E.-Y. Lee, J.-G. Kim, K.-J. Hong, S.-I. Lee, H.Y. Jeong, G.H. Ryu, Z. Lee, Y.-J. Kim, Increasing reversible capacity of soft carbon anode by phosphoric acid treatment, Electrochim. Acta 146 (2014) 630-637. doi:10.1016/j.electacta.2014.09.088.

[423] L. Wang, X. He, J. Li, W. Sun, J. Gao, J. Guo, C. Jiang, Nano-structured phosphorus composite as highcapacity anode materials for lithium batteries, Angew. Chem. Int. Ed. 51 (2012) 9034-9037. doi:10.1002/anie.201204591.

[424] W. Li, Z. Yang, Y. Jiang, Z. Yu, L. Gu, Y. Yu, Crystalline red phosphorus incorporated with porous carbon nanofibers as flexible electrode for high performance lithium-ion batteries, Carbon 78 (2014) 455-462. doi:10.1016/j.carbon.2014.07.026.

[425] J. Li, L. Wang, Y. Ren, Y. Zhang, Y. Wang, A. Hu, X. He, Distinctive slit-shaped porous carbon encapsulating phosphorus as a promising anode material for lithium batteries, lonics (Kiel). 22 (2016) 167-172. doi:10.1007/s11581-015-1550-8.

[426] Q. Wang, P. Lian, B. Wang, Y. Tang, H. Liu, Y. Mei, Red phosphorus encapsulated in porous carbon derived from cigarette filter solid waste as a promising anode material for lithium-ion batteries, Ionics (Kiel). 24 (2018) 3393-3403. doi:10.1007/s11581-018-2487-5.

[427] T. Xu, D. Li, S. Chen, Y. Sun, H. Zhang, Y. Xia, D. Yang, Nanoconfinement of red phosphorus nanoparticles in seaweed-derived hierarchical porous carbonaceous fibers for enhanced lithium ion storage, Chem. Eng. J. 345 (2018) 604-610. doi:10.1016/j.cej.2018.01.099.

[428] T. Tojo, S. Yamaguchi, Y. Furukawa, K. Aoyanagi, K. Umezaki, R. Inada, Y. Sakurai, Electrochemical performance of lithium ion battery anode using phosphorus encapsulated into nanoporous carbon nanotubes, J. Electrochem. Soc. 165 (2018) A1231-A1237. doi:10.1149/2.0351807jes.

[429] Z. Yue, T. Gupta, F. Wang, C. Li, R. Kumar, Z. Yang, N. Koratkar, Utilizing a graphene matrix to overcome the intrinsic limitations of red phosphorus as an anode material in lithium-ion batteries, Carbon 127 (2018) 588-595. doi:10.1016/j.carbon.2017.11.043.

[430] X. Li, G. Chen, Z. Le, X. Li, P. Nie, X. Liu, P. Xu, H. Bin Wu, Z. Liu, Y. Lu, Well-dispersed phosphorus nanocrystals within carbon via high-energy mechanical milling for high performance lithium storage, Nano Energy 59 (2019) 464-471. doi:10.1016/j.nanoen.2019.02.061.

[431] E. Yeager, Dioxygen electrocatalysis: mechanisms in relation to catalyst structure, J. Mol. Catal. 38 (1986) 5-25. doi:10.1016/0304-5102(86)87045-6. 
[432] M. del Cueto, P. Ocón, J.M.L. Poyato, Comparative study of oxygen reduction reaction mechanism on nitrogen-, phosphorus-, and boron-doped graphene surfaces for fuel cell applications, J. Phys. Chem. C 119 (2015) 2004-2009. doi:10.1021/jp512588r.

[433] D.-W. Wang, D. Su, Heterogeneous nanocarbon materials for oxygen reduction reaction, Energy Environ. Sci. 7 (2014) 576. doi:10.1039/c3ee43463j.

[434] L. Dai, Y. Xue, L. Qu, H.-J. Choi, J.-B. Baek, Metal-free catalysts for oxygen reduction reaction, Chem. Rev. 115 (2015) 4823-4892. doi:10.1021/cr5003563.

[435] D. von Deak, E.J. Biddinger, K.A. Luthman, U.S. Ozkan, The effect of phosphorus in nitrogencontaining carbon nanostructures on oxygen reduction in PEM fuel cells, Carbon 48 (2010) 36373639. doi:10.1016/j.carbon.2010.05.022.

[436] M. Patel, K. Savaram, K. Keating, H. He, Rapid Transformation of Biomass Compounds to Metal Free Catalysts via Short Microwave Irradiation, J. Nat. Prod. Res. Updat. 1 (2015) 18-28. https://www.jpmpress.com/wp-content/uploads/2018/04/jpnruV1A3.pdf.

[437] X. Sun, J. Xu, Y. Ding, B. Zhang, Z. Feng, D.S. Su, The effect of different phosphorus chemical states on an onion-like carbon surface for the oxygen reduction reaction, ChemSusChem 8 (2015) 28722876. doi:10.1002/cssc.201500154.

[438] P. Song, H. Wang, L. Kang, B. Ran, H. Song, R. Wang, Electrochemical nitrogen reduction to ammonia at ambient conditions on nitrogen and phosphorus co-doped porous carbon, Chem. Commun. 55 (2019) 687-690. doi:10.1039/C8CC09256G.

[439] F.J. García-Mateos, T. Cordero-Lanzac, R. Berenguer, E. Morallón, D. Cazorla-Amorós, J. RodríguezMirasol, T. Cordero, Lignin-derived Pt supported carbon (submicron)fiber electrocatalysts for alcohol electro-oxidation, Appl. Catal. B Environ. 211 (2017) 18-30. doi:10.1016/j.apcatb.2017.04.008.

[440] Q. Liu, S. Chen, Y. Zhou, S. Zheng, H. Hou, F. Zhao, Phosphorus-doped carbon derived from cellulose phosphate as efficient catalyst for air-cathode in microbial fuel cells, J. Power Sources 261 (2014) 245-248. doi:10.1016/j.jpowsour.2014.03.060.

[441] Y. Liu, K. Li, Y. Liu, L. Pu, Z. Chen, S. Deng, The high-performance and mechanism of P-doped activated carbon as a catalyst for air-cathode microbial fuel cells, J. Mater. Chem. A 3 (2015) 2114921158. doi:10.1039/C5TA04595A.

[442] B.F. Abramović, L.J. Bjelica, F.F. Gaál, V.J. Guzsvány, L.S. Jovanovic, Some electrochemical characteristics of boron- and phosphorus-doped glassy carbon electrodes, Electroanalysis 15 (2003) 878-884. doi:10.1002/elan.200390109.

[443] B.F. Abramović, V.J. Guzsvány, F.F. Gaál, Phosphorus-doped and undoped glassy carbon indicator electrodes in controlled-current potentiometric titrations of bromide- or chloride-containing active ingredients in some pharmaceutical preparations, J. Pharm. Biomed. Anal. 37 (2005) 265-271. doi:10.1016/j.jpba.2004.10.033. 